UNIVERSIDADE DE BRASÍLIA

FACULDADE DE TECNOLOGIA

DEPARTAMENTO DE ENGENHARIA CIVIL E AMBIENTAL

MICROSTRUCTURAL-BASED APPROACH TO THE INTERPRETATION OF CLAYS AND TRANSITIONAL SOILS BEHAVIOUR

BRUNA DE CARVALHO FARIA LIMA LOPES

ORIENTADOR: MANOEL PORFÍRIO CORDÃO NETO, DSC. CO-ORIENTADOR: ALESSANDRO TARANTINO, PhD.

TESE DE DOUTORADO EM GEOTECNIA

BRASÍLIA/DF: 29 DE MARÇO DE 2016 
UNIVERSIDADE DE BRASÍLIA

FACULDADE DE TECNOLOGIA

DEPARTAMENTO DE ENGENHARIA CIVIL E AMBIENTAL

\section{MICROSTRUCTURAL-BASED APPROACH TO THE MODELLING OF CLAYS AND TRANSITIONAL SOILS}

BRUNA DE CARVALHO FARIA LIMA LOPES

TESE DE DOUTORADO SUBMETIDA AO DEPARTAMENTO DE ENGENHARIA CIVIL E AMBIENTAL DA UNIVERSIDAdE DE BRASíliA COMO PARTE DOS REQUISITOS NECESSÁRIOS PARA A OBTENÇÃO DO GRAU DE DOUTOR.

APROVADA POR:

MANOEL PORFÍRIO CORDÃO NETO, DSc. (UnB) ORIENTADOR

Alessoudroporanotino

ALESSANDRO TARANTINO, PhD (University of Strathclyde). CO-ORIENTADOR

JOSÉ CAMAPUM DE CARVALHO, DSc. (UnB)

(EXAMINADOR INTERNO)

MÁRCIO MUNIZ DE FARIAS, PhD (UnB).

(EXAMINADOR INTERNO)

FERNANDO ANTÔNIO MEDEIROS MARINHO, PhD (USP).

(EXAMINADOR EXTERNO)

MARCIA MARIA DOS ANJOS MASCARENHA, DSc. (UFG). (EXAMINADOR EXTERNO)

DATA: BRASÍLIA/DF, 29 de MARÇO de 2016. 


\section{FICHA CATALOGRÁFICA}

\section{LOPES, BRUNA DE CARVALHO FARIA LIMA}

Microstructural based approach to the modelling of clays and transitional soils behaviour, Distrito Federal, 2016. xxix, 133p., 297 mm (ENC/FT/UnB, Doutor, Geotecnia, 2016)

Tese de Doutorado - Universidade de Brasília. Faculdade de Tecnologia. Departamento de Engenharia Civil e Ambiental
1. Solos saturados
2. Comportamento mecânico
3. Estrutura
4. Distribuição do tamanho dos poros
II. Título (série)

I. ENC/FT/UnB

\section{REFERÊNCIA BIBLIOGRÁFICA}

LOPES, B. C. F. L. (2016). Microstructural based approach to the modelling of clays and transitional soils behaviour, Distrito Federal, 2016. Tese de Doutorado, Publicação G.TD-115/16, Departamento de Engenharia Civil e Ambiental, Universidade de Brasília, Brasília-DF, 133p.

\section{CESSÃO DE DIREITOS}

NOME DO AUTOR: Bruna de Carvalho Faria Lima Lopes

TÍTULO DA TESE DE DOUTORADO: Microstructural based approach to the modelling of clays and transitional soils behaviour

GRAU: Doutor ANO: 2016

É concedida à Universidade de Brasília a permissão para reproduzir cópias desta tese de doutorado e para emprestar ou vender tais cópias somente para propósitos acadêmicos e científicos. O autor reserva outros direitos de publicação e nenhuma parte desta tese de doutorado pode ser reproduzida sem a autorização por escrito do autor.

\footnotetext{
Bruna de Carvalho Faria Lima Lopes

RUA JOSÉ FRANCISCO ZULIANI, 104 - GURIRI NORTE

CEP: 29946-630

São Mateus/ES - Brasil

bfarialima@gmail.com
} 


\section{ACKNOWLEDGMENTS}

Agradeço aos meus pais, Mônica e Reis, a minha irmã, Laís, e ao meu noivo, Renan, pelo apoio, carinho, paciência, amor e compreensão em todos os momentos. Obrigada a todos vocês que souberam compreender minha ausência em momentos importantes e que mesmo assim nunca deixaram de apoiar e acreditar em mim. Agradeço também a todos os meus familiares: avós, tios, tias, primos e primas pelo incentivo, atenção, alegria e animação em todos os nossos poucos encontros anuais, especial obrigada à minha madrinha, Tia Técia, que está sempre presente, incentivando e puxando a orelha quando a ocasião determina além das minhas tias superpoderosas: Tia Nita, Tia Deli, Tia Catarina, Tia Bé e Tia Técia (de novo!) que são exemplos de coragem e determinação.

Ao professor e supervisor Manoel Porfírio Cordão Neto pela orientação, paciência, pelo incentivo nos momentos de dificuldade e pela confiança depositada em mim. Obrigada por sua dedicação, por toda compreensão diante minhas difíceis demandas e por todo conhecimento que me foi transmitido ao longo da pesquisa.

Às minhas amigas de Brasília: Rosely e Camilla, por todas as caronas, risadas, dificuldades e por fazerem minha estada em Brasília mais leve e menos difícil. Obrigada aos colegas da geotecnia da UnB pelas conversas, parcerias e momentos únicos compartilhados. A todos os professores, pelos ensinamentos e companheirismo durante esta jornada.

Obrigada também às minhas amigas de toda uma vida, Débora, Garrafinha, Pollyanna, Karlinha e Fernanda Pisa, por simplesmente continuarem fazendo parte da minha vida.

I would like to express my immense gratitude to my supervisor Prof. Alessandro Tarantino for his dedication, guidance and patience. I am thankful for all opportunities you created for me and for sharing with me part of your knowledge in meetings with no time to end that are responsible for my professional and personal improvements.

Matteo Pedrotti for the help with the freeze-drying and MIP tests besides all the contributions discussing techniques and analysis of the data; Camilla Borges and Kannan Iyer for the discussions regarding microstructure of soils in general; Anastasia Capotosto for sharing her knowledge of mixtures of lime and kaolin and changes in $\mathrm{pH}$; Riccardo Maddalena for sharing his knowledge of metakaolin properties and preparation procedures; Ian Murray for the help with the tensiometers; The technicians from the Civil Engineering lab at University 
of Strathclyde, Mara Knapp, Derek McNee, John Carlin, Chris Bonner and Gavin Gibson for their everyday help; The technicians from the Mechanical Engineering lab at University of Strathclyde, Fiona Sillars and Gerry Johnson, for their support and assistance on the use of the MIP. My special thanks for all lectures, professors and staff in general of the Civil and Environmental Engineering Department of University of Strathclyde for welcoming me into the group.

I would also like to acknowledge the support of the European Commission via the Marie Curie IRSES project GREAT - Geotechnical and geological Responses to climate change: Exchanging Approaches and Technologies on a world-wide scale (FP7-PEOPLE-2013IRSES-612665), GEO-EXCEL (PIRSES-GA-2008-230860) and CAPES/MEC for the funding support. 


\section{RESUMO}

O futuro da prática da engenharia é a incorporação de aspectos da microestrutura nas características macroestruturais dos solos de modo a simplificar e tornar mais realistas as análises geotécnicas. Consequentemente, é de fundamental importância que se entenda a estrutura dos solos em diferentes estados (inderformado, reconstitutído, remouldado, compactado, etc.) e se correlacionem os mesmos, já que se sabe que o estado inicial do solo dita o seu comportamento. Neste sentido, esta pesquisa está focada no desenvolvimento do entendimento das mudanças na estrutura do solo através dos tamanhos dos seus poros e sua distribuição quando submetido a carregamentos mecânicos assim como a determinação do estado mais apropriado para descrever um estado de referência do comportamento do solo. Os solos testados foram duas argilas: Caulinita e Ball; e um solo tropical transicional: Solo de Brasília. A partir dos solos estudados foram produzidas amostras com $\mathrm{pH}$ 9, reconstituídas, remoldadas e indeformadas, esta última somente para o solo de Brasília. Cada uma destas amostras foi submetida à compressão unidimensional combinada no oedometro e aparelho de taxa constante de deformação a diferentes tensões: 2, 90, 360, 2.000, 5.000 e 11.000kPa. Em seguida as amostras foram congeladas e secas pelo processo de liofilização e por último foram submetidas ao ensaio de porosimetria por intrusão de mercúrio. Adicionalmente, mediu-se a sucção inicial de algumas das amostras dos três solos estudados. A partir dos resultados dos ensaios realizados foram propostos dois modelos conceituais um para as argilas e outro para o solo transicional. Os resultados do ensaio de adensamento foram modelados usando uma adaptação do modelo constitutivo SCLAY-1S (Koskinen et al., 2002) na qual a variável x descreve os efeitos da estrutura ao invés de cimentação como proposto originalmente. Além disto, a amostra pH 9 foi considerada a amostra de referência, assim para este estado $\mathrm{x}=0$ e todas as outras amostras tem estrutura, de acordo com a metodologia aqui proposta. Os resultados mostraram que a metodologia proposta para obtenção das amostras é adequada. A sucção inicial foi satisfatoriamente correlacionada à tensão de preadensamento. Resultados das análises de porosimetria confirmam que o estado da estrutura das amostras com pH 9 é mais adequado para representar um estado de referência que o estado das amostras reconstituídas. As amostras com pH 9 apresentam uma estrutura dispersa já que as laterais da partícula de caulinita são carregadas negativamente assim como as faces. Dessa forma com o aumento do carregamento não há muitas configurações possíveis, a estrutura da amostra irá ficar cada vez mais orientada e alinhada paralelamente. O 
mesmo acontece com as amostras em outros estados. A amostra indeformada apresenta inicialmente a estrutura mais aberta, seguida da reconstituída e remouldada. À medida que o carregamento aumenta a estrutura destas outras amostras tende para uma configuração dispersa com as partículas de caulinita orientadas e alinhadas paralelamente. A modelagem constitutiva se mostrou apropriada, embora ainda haja necessidade de aprimoramento nos estudos para que o parâmetro $\mathrm{a}_{\mathrm{x}}$ possa ser correlacionado com a variável x.

Palavras-chave: Argilas, Solo transicional, Porosimetria por intrusão de mercúrio, Microestrutura, S-CLAY1S. 


\begin{abstract}
The future of engineering practice is to incorporate aspects of the microstructure into the macroscopic characteristics of soils in order to simplify and make the geotechnical analysis more realistic. Therefore, it is fundamentally important to understand the structure of soils in various states (undisturbed, reconstituted, remoulded, compacted, etc.) and correlate them, as it is already known that the initial state of the soil dictates its behaviour. Hence, this research focuses on developing an understanding of the changes in the soil structure through its pore sizes and distribution under mechanical loading, as well as determining which state is appropriate to describe a reference state of the soil behaviour. The soils tested were the two clays: Kaolin and Ball; and the tropical transitional soil: Brasilia Soil. From the studied soils, samples with pH9, reconstituted, remoulded and undisturbed (for the Brasilia Soil only), were produced. Each of these samples was subjected to uniaxial compression combined with oedometer and Constant Rate of Strain (CRS) apparatus up to: 2, 90, 360, 2,000, 5,000 and $11,000 \mathrm{kPa}$. Specimens of these samples were then freeze-dried by the lyophilization process and lastly subjected to the Mercury Intrusion Porosimetry (MIP) test. Additionally, the initial suction of a few samples of the three soils was measured. From the results of the laboratory tests carried out, two conceptual models were proposed: one for the clays and one for the transitional soil. The results of the consolidation test were modelled using an adaptation of the constitutive model, SCLAY-1S (Koskinen et al., 2002), in which the variable $\mathrm{x}$ describes the structure rather than bonding as originally proposed. Furthermore, the pH9 sample was considered the reference state; thus this state has $\mathrm{x}=0$, while all other states have some structure, according to the methodology herein proposed. Results showed that the methodology proposed for obtaining the specimens is adequate. The initial suction measured was satisfactorily correlated to the preconsolidation stress. Results of the MIP confirmed that the $\mathrm{pH} 9$ state is the most suitable to represent a reference state, rather than the reconstituted state. The pH9 state presents a disperse structure, as the edges of the kaolinite particle are charged negatively as well as the faces. Therefore, as the loading increases there are not many possible configurations for this sample, hence the structure will orient in a preferential direction. The same happens for the samples in other states. The undisturbed sample has the most open structure, followed by the reconstituted and remoulded states. As the loading progresses, the structure of these samples tends towards the dispersed configuration with the kaolinite particles well-oriented and aligned in parallel with each other. The constitutive
\end{abstract}


modelling is appropriate; however, there is still room for improvement studies to correlate the parameter $\mathrm{a}_{\mathrm{x}}$ with the state variable $\mathrm{x}$.

Key words: Clays, Transitional soils, Mercury Intrusion Porosimetry, Microstructure, SCLAY1S 


\section{LIST OF CONTENTS}

ACKNOWLEDGMENTS iv

RESUMO vi

ABSTRACT viii

1 - INTRODUCTION 1

1.1 - MOTIVATION

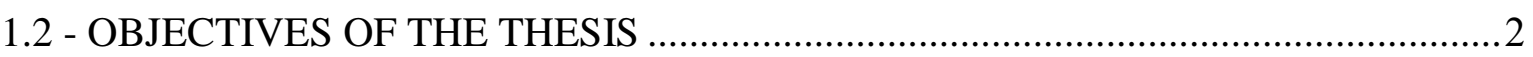

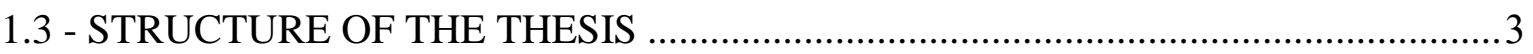

2 - LITERATURE REVIEW ………………………………………………………….

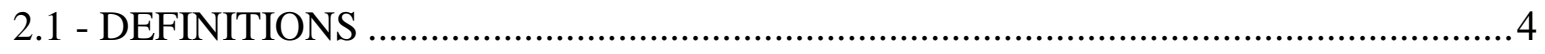

2.1.1 - DEFINITION OF FABRIC, STRUCTURE AND SOIL STATE .............................

2.1.2 - DEFINITION OF TRANSITIONAL SOILS .......................................................

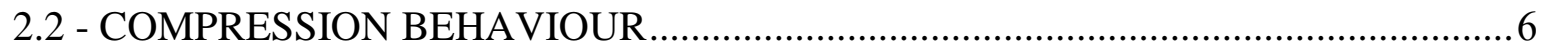

2.2.1 - CONSOLIDATION TESTS .........................................................................

2.2.2 - SOIL BEHAVIOUR UNDER 1-D COMPRESSION ..........................................

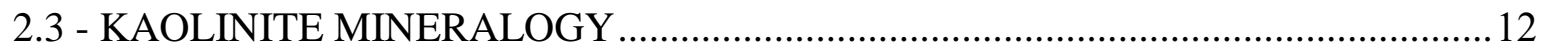

2.3.1 - CHARACTERISTICS OF SURFACE CHARGES ……………………….........14

2.3.2 - INTERPARTICLE FORCES AND FABRIC ASSOCIATIONS ……………......15

2.4 - MICROSTRUCTURE INVESTIGATION ……………………………………..... 19

2.4.1 - SPECIMEN PREPARATION ……………………….................................... 19

2.4.2 - TECHNIQUES FOR FABRIC STUDY …………………………………......22

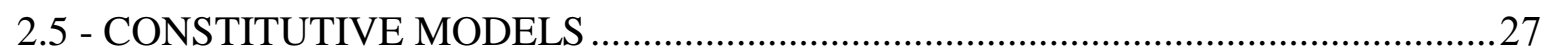

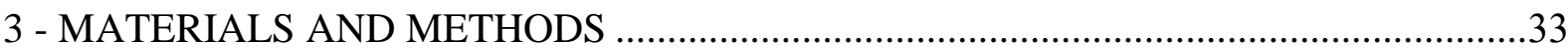

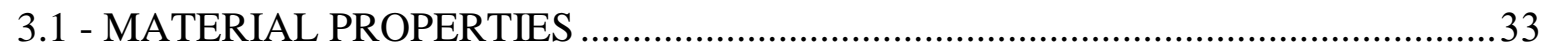

3.2 - +SPECIMENS PREPARATION AND TESTING PROGRAMME ……………….....37

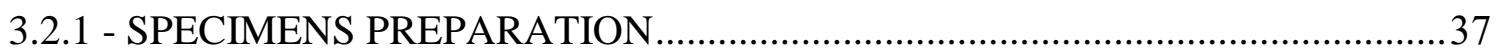




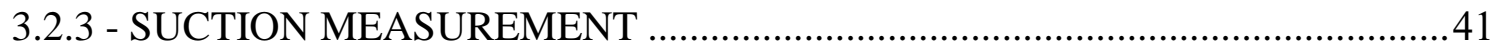

3.2.4 - ONE-DIMENSIONAL COMPRESSION TESTS ….......................................... 42

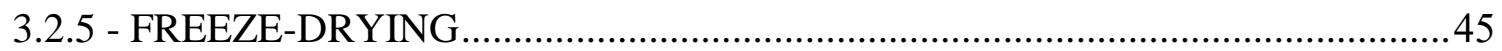

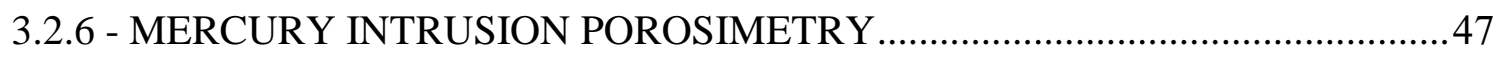

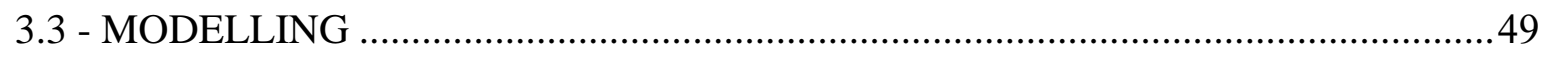

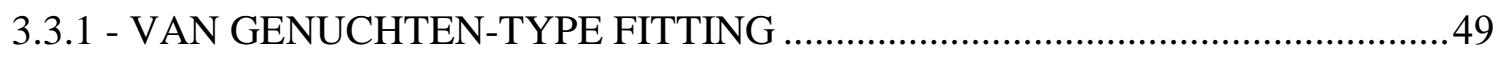

3.3.2 - CONSTITUTIVE MODELLING ................................................................. 50

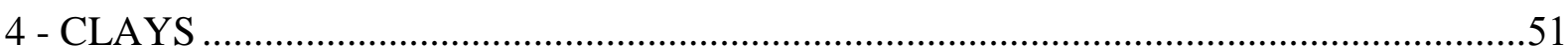

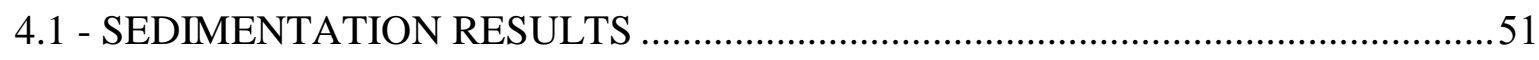

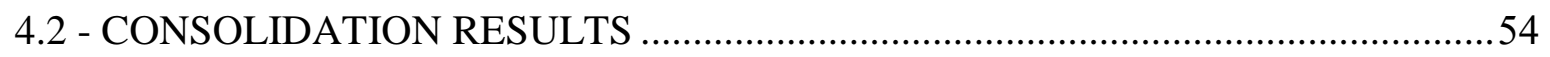

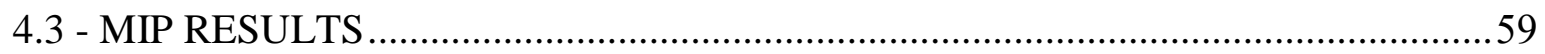

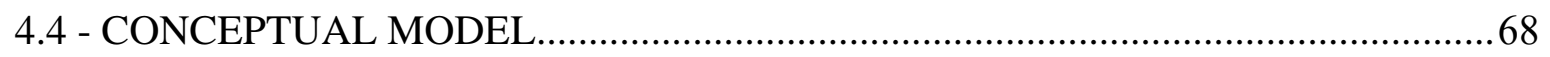

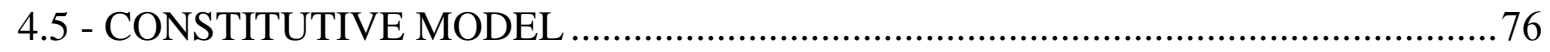

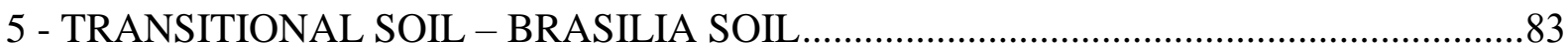

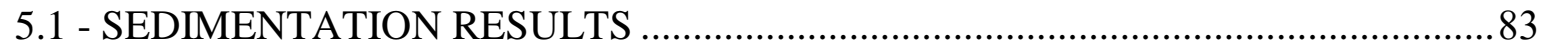

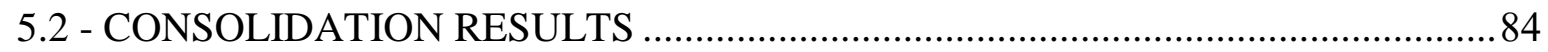

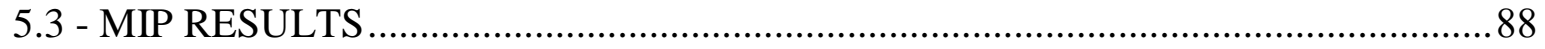

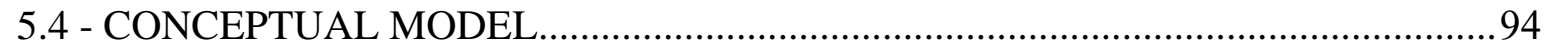

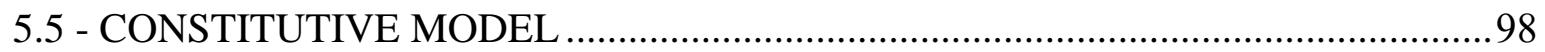

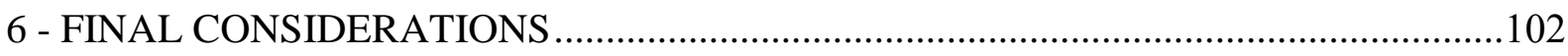

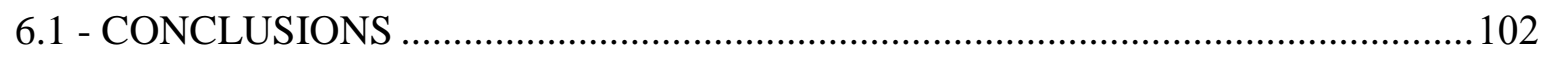

6.2 - SUGGESTIONS FOR FUTURE WORK …...................................................... 105

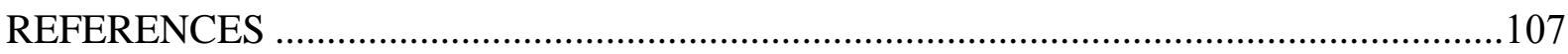

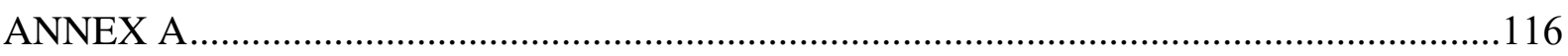

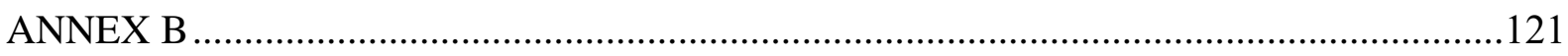


ANNEX C

.126

ANNEX D..

128 


\section{LIST OF FIGURES}

Figure 2.1 - (a) Schematics of Oedometer cell, (b) Oedometer cell ...................................... 7

Figure 2.2 - 1-D Consolidation of reconstituted samples of Speswhite Kaolin, each curve representing an initial water content between $\mathrm{w}_{\mathrm{L}}$ and $1.5 \mathrm{w}_{\mathrm{L}}$ (source: Shipton \& Coop, 2012) 9

Figure 2.3 - Reconstituted samples: (a) Lianyungang clay, (b) Baimahu clay, (c) Kemen clay (source: Hong et al., 2010) and (d) Natural samples of Ariake clay (source: Hong et al., 2012)

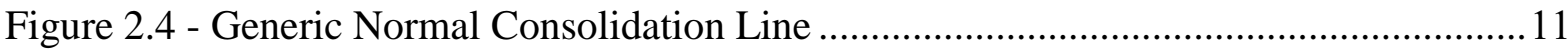

Figure 2.5 - Soil Particle size (after Mitchell \& Soga, 2005)............................................. 13

Figure 2.6 - (a) Silica tetrahedron sheet, (b) Gibbsite octahedron sheet, (c) Kaolinite layer and (d) Kaolinite mineral representation (after Mitchell \& Soga, 2005) ............................... 14

Figure 2.7 - Surface charges on Kaolin particles (after Pedrotti, 2016)............................... 15

Figure 2.8 - Final void ratio of kaolin suspension at various pHs after 4 months (source:

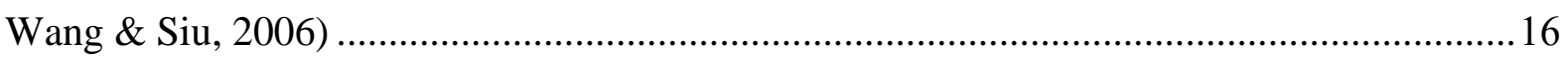

Figure 2.9 - CRS consolidation test (source: Prashant \& Penumadu, 2007) ......................... 17

Figure 2.10 - MIP results of flocculated and dispersed samples: (a) Pore Size Density and (b) Intrusion curve (source: Prashant \& Penumadu, 2007) ......................................................... 18

Figure 2.11 - SEM images of clay samples: (a) flocculated and (b) dispersed (source:

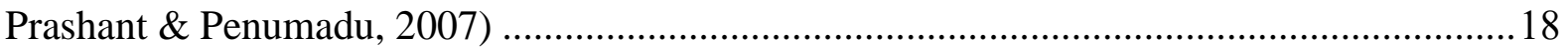

Figure 2.12 - Water phase diagram (modified from CoolSafe, 2006) ..................................20

Figure 2.13 - (a) MIP data, bi-modal and mono-modal fitting functions - experimental data from reconstituted Kaolin sample (Pedrotti, 2016) and (b) Frequency PSDs generated with various interval sizes for a reconstituted Kaolin sample - experimental data from Pedrotti (2016)

Figure 2.14 - Elastoplastic models where $\sigma$ represents stress and $\varepsilon$ strain (modified from Wood, 2004) .27

Figure 2.15 - Elastoplastic hardening model (after Wood, 2004) .28 
Figure 2.16 - Oedometer curve for natural and reconstituted soils (source: Karstunen et al., 2006)

Figure 2.17 - S-CLAY1S yield surface in (a) 3-D stress space (b) triaxial stress space (source: Karstunen et al., 2005) 31

Figure 3.1 - (a) Ball Clay and (b) Kaolin Clay .34

Figure 3.2 - Removal of the Brasilia Soil in the experimental field of University of Brasilia, Brasilia, Brazil (a) Location map of the extraction point (source: Google Earth, 2013) (b) Removal of the undisturbed block at $2 \mathrm{~m}$ deep (c) Bags of disturbed soil and undisturbed block being covered with paraffin and wrapped in cling film for transportation 34

Figure 3.3 - Particle size distribution curves according to BS1377-2 (1990) .36

Figure 3.4 - Compaction plot, $\rho_{\mathrm{d}} \mathrm{x} \mathrm{w}$ (a) Ball Clay samples (b) Brasilia Soil Samples (c) Kaolin Clay samples .38

Figure 3.5 - Ball Clay sample preparation (a) Reconstituted sample, $\mathrm{w}=94.5 \%$ (b) Remoulded sample, $\mathrm{w}=47.25 \%$ (c) $\mathrm{pH} 9$ sample, $\mathrm{w}=46 \%$ .39

Figure 3.6 - Brasilia Soil sample preparation (a) Reconstituted sample, $w=63 \%$ (b) Reconstituted sample, $\mathrm{w}=52.5 \%$ (c) Remoulded sample, $\mathrm{w}=32.5 \%$ (d) $\mathrm{pH} 9$ sample, $\mathrm{w}=$ $31.5 \%$ (e) and (f) Undisturbed sample preparation. .39

Figure 3.7 - Kaolin Clay sample preparation (a) Reconstituted sample, $\mathrm{w}=96 \%$ (b) Remoulded sample, $\mathrm{w}=45 \%$ (c) $\mathrm{pH} 9$ sample, $\mathrm{w}=55 \%$

Figure 3.8 - Tensiometer (a) Schematic layout (modified from Tarantino \& Mongiovi, 2002) (b) Setup in the Geomechanics laboratory of the University of Strathclyde 41

Figure 3.9 - Schematic layout of the Suction Measurement box (source: Tarantino \& Mongiovi, 2003) 42

Figure 3.10 - 1-D Compression equipment at the Geomechanics laboratory of the University of Strathclyde (a) Front loading oedometer (b) and (c) Detail of oedometer cell (d) Constant Rate of Strain Consolidometer 43

Figure 3.11 - Consolidation curves of the Kaolin Clay specimen $\mathrm{w}_{\mathrm{i}}=96 \%$, conventional oedometer and CRS of $0.008,0.005$ and $0.0035 \mathrm{~mm} / \mathrm{min}$ 44

Figure 3.12 - Cutter and extruder used to prepare specimens for freeze-drying .46 
Figure 3.13 - Specimens prepared for freeze-drying (a) Brasilia Soil prepared with the cutter and extruder and (b) Ball Clay prepared with stylus knife 46

Figure 3.14 - Freezing process .46

Figure 3.15 - (a) Lyophilization and vacuum pump at the Biotechnology laboratory of the University of Strathclyde and (b) Close-up of the lyophilizer chamber drying samples. .47

Figure 3.16 - Samples stored in a labelled plastic bag under vacuum .47

Figure 3.17 - (a) PoreMaster ${ }^{\circledR} 60$ at the Mechanical Engineering Laboratory of University of Strathclyde and (b) Close-up of the low pressure cell 48

Figure 3.18- (a) Sample weighed before MIP test (b) Sample sealed inside the penetrometer and (c) Penetrometer with sample placed in the low pressure cell 49

Figure 4.1 - Kaolin Clay: Particle size distribution at different pHs (source: Pedrotti, 2016) 52

Figure 4.2 - Kaolin Clay: pH4 (only distilled water) and pH9 .52

Figure 4.3 - Kaolin Clay: Final void ratio of the sediments .53

Figure 4.4 - Ball Clay: pH4.8 (only distilled water), 7, 8, 9, 10 and 12 ...............................53

Figure 4.5 - Ball Clay: Final void ratio of the sediments. .54

Figure 4.6 - Consolidation curves: (a) Kaolin Clay and (b) Ball Clay .55

Figure 4.7 - Initial void ratio against initial water content for Kaolin and Ball Clay specimens

Figure 4.8 - Variation of void ratio at 100,1,000 and 10,000kPa with initial void ratio for (a) Kaolin Clay and (b) Ball Clay .59

Figure 4.9 - Kaolin Clay: Relationship between (a) void ratio at the consolidation curve and void ratio after the oedometer/CRS test, (b) void ratio after the oedometer/CRS test and void ratio before freeze-drying and (c) void ratio before freeze-drying and MIP void ratio. Full lines are 1:1 and dashed lines are: (a) and (c) 30\% span tolerance and (b) 10\% span tolerance, (d) legend. 61

Figure 4.10 - Ball Clay: Relationship between (a) void ratio at the consolidation curve and void ratio after the oedometer/CRS test, (b) void ratio after the oedometer/CRS test and void ratio before freeze-drying and (c) void ratio before freeze-drying and MIP void ratio. Full 
lines are 1:1 and dashed lines are: (a) and (c) 30\% span tolerance and (b) 10\% span tolerance, (d) legend

Figure 4.11 - Kaolin Clay: (a) Cumulative intrusion curve $\mathrm{w}_{\mathrm{i}}=96 \%$, (b) Pore Size Density curve $\mathrm{w}_{\mathrm{i}}=96 \%$, (c) Cumulative intrusion curve $\mathrm{w}_{\mathrm{i}}=45 \%$, (d) Pore Size Density curve $\mathrm{w}_{\mathrm{i}}=$ $45 \%$, (e) Cumulative intrusion curve pH9, (f) Pore Size Density curve pH9

Figure 4.12 - Ball Clay: (a) Cumulative intrusion curve $\mathrm{w}_{\mathrm{i}}=94.5 \%$, (b) Pore Size Density curve $\mathrm{w}_{\mathrm{i}}=94.5 \%$, (c) Cumulative intrusion curve $\mathrm{w}_{\mathrm{i}}=47.25 \%$, (d) Pore Size Density curve $\mathrm{w}_{\mathrm{i}}=47.25 \%$, (e) Cumulative intrusion curve $\mathrm{pH} 9$ and (f) Pore Size Density curve $\mathrm{pH} 9$.......64

Figure 4.13 - PSD of Kaolin Clay: (a) $2 \mathrm{kPa}$, (b) $90 \mathrm{kPa}$, (c) $360 \mathrm{kPa}$, (d) 2,000kPa, (e) $5,000 \mathrm{kPa}$ and (f) $11,000 \mathrm{kPa}$.

Figure 4.14 - PSD of Ball Clay: (a) $2 \mathrm{kPa}$, (b) $90 \mathrm{kPa}$, (c) $360 \mathrm{kPa}$, (d) $2,000 \mathrm{kPa}$, (e) $5,000 \mathrm{kPa}$ and (f) $11,000 \mathrm{kPa}$

Figure 4.15 - Kaolin Clay specimens (a) Consolidation test: Curves $\mathrm{w}_{\mathrm{i}}=96 \%$ and $45 \%$ loaded to $2,000 \mathrm{kPa}$ and $\mathrm{w}_{\mathrm{i}}=96 \%$ loaded to $40 \mathrm{kPa}$, unloaded and reloaded to $2,000 \mathrm{kPa}$ and (b) MIP results of $\mathrm{w}_{\mathrm{i}}=45 \%$ loaded to 2 and 40kPa: Cumulative intrusion curve and PSD ... 69

Figure 4.16 - Idealized clay arrangement (source: Barden \& Sides, 1971) .70

Figure 4.17 - Summary of the particles' arrangement change with loading for reconstituted, remoulded and pH9 specimens (Idealized clay arrangements after Barden \& Sides, 1971).. 71 Figure 4.18 - Illustrative differences in pore sizes of (a) face-to-face (non-contact), (b) edgeto-face arrangements (contact) and (c) non-contact, non-parallel arrangement considered EF by the van Genuchten fitting

Figure 4.19 - Kaolin Clay MIP data of: (a) $e_{\mathrm{FF}} \mathrm{x} \log \sigma_{\mathrm{v}}{ }_{\mathrm{v}}$, (b) $\mathrm{e}_{\mathrm{EF}} \mathrm{x} \log \sigma^{\prime}{ }_{\mathrm{v}}$, (c) $\mathrm{d}_{\mathrm{FF}} \mathrm{x} \log \sigma_{\mathrm{v}}$, , (d) $d_{E F} \times \log \sigma_{v},(e) n_{F F} \times \log \sigma^{\prime}$, (f) $n_{E F} \times \log \sigma^{\prime},(g) e_{F F} \times n_{F F}$ and (h) $e_{E F} \times n_{E F}$ .74

Figure 4.20 - Ball Clay MIP data of: (a) $e_{F F} x \log \sigma^{\prime}$, (b) $e_{E F} x \log \sigma^{\prime}$, , (c) $d_{F F} x \log \sigma^{\prime}$, , (d) $d_{E F}$ $x \log \sigma^{\prime},{ }^{\prime},(e) n_{F F} x \log \sigma^{\prime}{ }_{v}$, (f) $n_{E F} \times \log \sigma^{\prime}{ }_{v},(g) e_{F F} \times n_{F F}$ and (h) $e_{E F} \times n_{E F}$ .76

Figure 4.21 - Obtaining $\mathrm{pm}_{\mathrm{i}}$

Figure 4.22 - Variation of the degradation ratio parameter $\mathrm{a}_{\mathrm{x}}$ in a void ratio against effective stress semi-log plot .78 
Figure 4.23 - Experimental data and S-CLAY1S modelling of (a) Kaolin Clay specimens and (b) Ball Clay specimens

Figure 4.24 - Variation in initial amount of structure against initial void ratio: (a) Kaolin Clay specimens and (b) Ball Clay specimens

Figure 4.25 - Experimental data and S-CLAY1S modelling of (a) Lianyungang Clay, (b) Baimahu Clay and (c) Kemen Clay specimens.

Figure 4.26 - Variation in initial amount of structure against initial void ratio: (a) Lianyungang Clay, (b) Baimahu Clay and (c) Kemen Clay specimens 82

Figure 5.1 - Brasilia Soil: (a) pH6.3 (only distilled water), 7.5, 8.5, 9 and 12 and (b) detail of pH6.3 and 9 after two months 84

Figure 5.2 - Brasilia Soil: Final void ratio of the sediments .84

Figure 5.3 - Brasilia Soil: Consolidation curves.... .85

Figure 5.4 - Initial void ratio against initial water content for Kaolin and Ball Clay and Brasilia Soil specimens .87

Figure 5.5 - Variation of void ratio at 100, 1,000 and 10,000 kPa with initial void ratio for Brasilia Soil .88

Figure 5.6 - Brasilia Soil: Relationship between (a) void ratio at the consolidation curve and void ratio after the oedometer/CRS test, (b) void ratio after the oedometer/CRS test and void ratio before freeze-drying and (c) void ratio before freeze-drying and MIP void ratio. Full lines are 1:1 and dashed lines are: (a) and (c) 30\% span tolerance and (b) 10\% span tolerance, (d) legend

Figure 5.7 - Brasilia Soil: (a) Cumulative intrusion curve Natural, (b) Pore Size Density curve Natural, (c) Cumulative intrusion curve $\mathrm{w}_{\mathrm{i}}=52.5 \%$, (d) Pore Size Density curve $\mathrm{w}_{\mathrm{i}}=$ $52.5 \%$, (e) Cumulative intrusion curve $\mathrm{w}_{\mathrm{i}}=31.5 \%$, (f) Pore Size Density curve $\mathrm{w}_{\mathrm{i}}=31.5 \%$, (g) Cumulative intrusion curve pH9 and (h) Pore Size Density curve pH9 91

Figure 5.8 - PSD of Brasilia Soil: (a) $2 \mathrm{kPa}$, (b) $90 \mathrm{kPa}$, (c) $360 \mathrm{kPa}$, (d) $2,000 \mathrm{kPa}$, (e) $5,000 \mathrm{kPa}$ and (f) $11,000 \mathrm{kPa}$ .93 
Figure 5.9 - Summary of the particles' arrangement change with loading for natural, reconstituted, remoulded and $\mathrm{pH} 9$ specimens (idealized clay arrangement after Barden \& Sides, 1971) 95

Figure 5.10 - MIP void ratio of: (a) micro pores and (b) macro pores of the four specimens.97 Figure 5.11 - Experimental data and S-CLAY1S modelling of Brasilia Soil specimens: (a) Natural $\left(\mathrm{w}_{\mathrm{i}}=21 \%\right)$, Reconstituted $\left(\mathrm{w}_{\mathrm{i}}=52.5 \%\right.$ and $\left.42 \%\right)$, Remoulded $\left(\mathrm{w}_{\mathrm{i}}=31.5 \%\right)$ and $\mathrm{pH} 9$ and (b) pH9 and Compacted - wet side (WS) $\mathrm{w}=28 \%$, optimum (OP) $\mathrm{w}=24 \%$ and dry side (DS) $\mathrm{w}=20 \%$ (experimental data of compacted specimens from Otalvaro, 2013) 100

Figure 5.12 - Variation in initial amount of structure against initial void ratio: (a) in a semi$\log$ plot for the natural, reconstituted, remoulded and pH9 specimens of Brasilia Soil and (b) compacted and pH9 specimens of the Brasilia Soil 101

Figure A.1 - Kaolin Clay, $\mathrm{w}_{\mathrm{i}}=96 \%$, MIP data of specimen loaded in many steps and unloaded quickly in one step and loaded and unloaded in many steps: (a) 90kPa Cumulative intrusion curve, (b) $90 \mathrm{kPa}$ PSD curve, (c) $360 \mathrm{kPa}$ Cumulative intrusion curve, (d) $360 \mathrm{kPa}$ PSD curve, (e) $2,000 \mathrm{kPa}$ Cumulative intrusion curve, (f) $2,000 \mathrm{kPa}$ PSD curve, (g) $5,000 \mathrm{kPa}$ Cumulative intrusion curve, (h) $5,000 \mathrm{kPa}$ PSD curve, (i) $11,000 \mathrm{kPa}$ Cumulative intrusion curve and (j) $11,000 \mathrm{kPa}$ PSD curve

Figure A.2 - Kaolin Clay, $\mathrm{w}_{\mathrm{i}}=45 \%$, MIP data of specimen loaded in many steps and unloaded quickly in one step and loaded and unloaded in many steps: (a) 90kPa Cumulative intrusion curve, (b) $90 \mathrm{kPa}$ PSD curve, (c) $360 \mathrm{kPa}$ Cumulative intrusion curve, (d) $360 \mathrm{kPa}$ PSD curve, (e) 2,000kPa Cumulative intrusion curve, (f) 2,000kPa PSD curve, (g) 5,000kPa Cumulative intrusion curve, (h) $5,000 \mathrm{kPa}$ PSD curve, (i) $11,000 \mathrm{kPa}$ Cumulative intrusion curve and (j) 11,000kPa PSD curve. 118

Figure A.3 - Kaolin Clay, pH9 - load 11,000kPa, MIP data of specimen loaded in many steps and unloaded quickly in one step and loaded and unloaded in many steps: (a) Cumulative intrusion curve, (b) PSD curve

Figure A.4 - Ball Clay, 2,000kPa MIP data of specimen loaded in many steps and unloaded quickly in one step and loaded and unloaded in many steps: (a) $\mathrm{w}_{\mathrm{i}}=94.5 \%$ Cumulative intrusion curve, (b) $\mathrm{w}_{\mathrm{i}}=94.5 \%$ PSD curve, (c) $\mathrm{w}_{\mathrm{i}}=47.25 \%$ Cumulative intrusion curve and (d) $\mathrm{w}_{\mathrm{i}}=47.25 \%$ PSD curve 119 
Figure A.5 - Brasilia Soil, $\mathrm{w}_{\mathrm{i}}=31.5 \%, 2,000 \mathrm{kPa}$ MIP data of specimen loaded in many steps and unloaded quickly in one step and loaded and unloaded in many steps: (a) Cumulative intrusion curve, (b) PSD curve

Figure C.1 - (a) Sample after the MIP test, (b) and (c) Penetrometer after MIP test and after removal of mercury and sample 126

Figure C.2 - Ball Clay pH9 specimen loaded up to 5Mpa (a) right after MIP test intrusion and extrusion, (b) specimen sliced open showing an external crack filled with mercury and also small internal and external voids filled with a diameter of mercury much larger than their sizes

Figure C.3 - Diameters that can be assumed by mercury when filling a pore 127

Figure D.1- Sensitivity analysis carried out for the van Genuchten-type mono-modal equation: (a) Cumulative intrusion curve, $e=1.5,1.0$ and 0.5 and $\alpha$ and $n=$ constant, (b) PSD, $e=1.5,1.0$ and 0.5 and $\alpha$ and $n=$ constant, (c) Cumulative intrusion curve, $\alpha=100,50$ and 20 and e and $n=$ constant, (d) PSD, $\alpha=100,50$ and 20 and e and $n=$ constant, (e) Cumulative intrusion curve, $n=-2.0,-1.5$ and -1.0 and $e$ and $\alpha=$ constant and (f) PSD, $n=-$ 2.0, -1.5 and -1.0 and $e$ and $\alpha=$ constant

Figure D.2 - Kaolin Clay: (a) Reconstituted Sample. Cumulative intrusion curve of an apparent mono-modal distribution fitted with a bi-modal van Genuchten-type equation (data from Pedrotti, 2016) and (b) Compacted Sample. Cumulative intrusion curve of a bi-modal distribution (data from Tarantino \& De Col, 2008)

Figure D. 3 - PSD curves of $\mathrm{w}_{\mathrm{i}}=96 \%$ (a) normal distribution of FF pores, (b) log-normal distribution of EF pores; $\mathrm{w}_{\mathrm{i}}=45 \%$, (c) normal distribution of FF pores, (d) log-normal distribution of $\mathrm{EF}$ pores; and $\mathrm{pH} 9$ (e) normal distribution of FF pores, (f) log-normal distribution of EF pores 133 


\section{LIST OF TABLES}

Table 2.1 - Summary of the methods used for fabric study ..............................................22

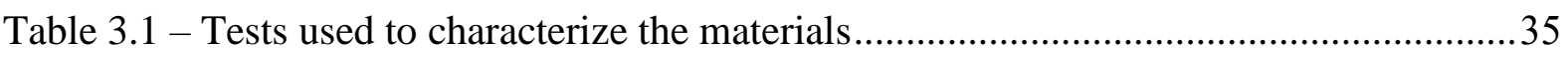

Table 3.2 - Soil Properties ............................................................................................. 35

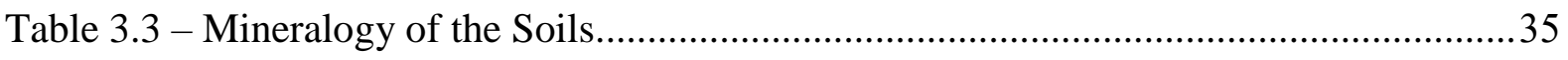

Table 3.4 - Strain Rates used in the CRS consolidometer for each specimen ........................45

Table 4.1 - Suction measurements and preconsolidation stresses of Kaolin Clay specimens 56

Table 4.2 - Suction measurements and preconsolidation stresses of Ball Clay specimens .....56

Table 4.3 - Compression and Swelling indexes of Kaolin Clay specimens ..........................58

Table 4.4 - Compression and Swelling indexes of Ball Clay specimens...............................58

Table 4.5 - Kaolin Clay: difference in overall porosity between $96 \%$ or $45 \%$ and pH9

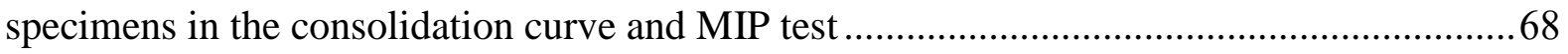

Table 4.6 - Ball Clay: difference in overall porosity between $94.5 \%$ or $47.25 \%$ and $\mathrm{pH} 9$ specimens in the consolidation curve and MIP test.....

Table 4.7 - S-CLAY1S model parameters and state variables for Kaolin Clay specimens .... 77

Table 4.8 - S-CLAY1S model parameters and state variables for Ball Clay specimens ......... 77

Table 4.9 - S-CLAY1S model parameters and state variables for Lianyungang Clay, Baimahu Clay and Kemen Clay specimens .80

Table 5.1- Suction measurements and preconsolidation stresses of Brasilia Soil specimens .86

Table 5.2 - Compression and Swelling indexes of Brasilia Soil specimens

Table 5.3 - Brasilia Soil: difference in overall porosity between natural or $52.5 \%$ or $31.5 \%$ and $\mathrm{pH} 9$ specimens in the consolidation curve and MIP test 94

Table 5.4 - S-CLAY1S model parameters and state variables for Brasilia Soil specimens ....98

Table B.1 - ANOVA statistical test for Kaolin Clay void ratios........................................ 122

Table B.2 - ANOVA statistical test for Ball Clay void ratios ............................................. 123

Table B.3 - ANOVA statistical test for Brasilia Soil void ratios ........................................ 124 
Table D.1 - Results interpretation of the sensitivity analysis carried out for a van Genuchtentype mono-modal equation

Table D.2 - Kaolin Clay: van Genuchten fitting parameters ............................................. 131

Table D.3 - Ball Clay: van Genuchten fitting parameters .................................................. 132

Table D.4 - Brasilia Soil: van Genuchten fitting parameters ............................................. 132 


\section{LIST OF SYMBOLS, NOMENCLATURE AND ABBREVIATIONS}

1-D One dimensional

$2 \mathrm{SiO}_{2} \mathrm{Al}_{2} \mathrm{O}_{3} \cdot 2 \mathrm{H}_{2} \mathrm{O}$ Kaolinite

A Area of sample

A-2 Clayey soils

A-5 Silty soils

AASHTO American Association of State Highway and Transportation Officials

$\mathrm{a}_{\mathrm{x}}$ Degradation (or destructuration) ratio

ABNT Brazilian Society of Technical Standards (in Portuguese: Associação Brasileira de Normas Técnicas)

Al Aluminium

$\mathrm{Al}(\mathrm{OH})_{6} \quad$ Aluminium-Oxygen hydroxyl octahedron

ASTM American Society for Testing and Materials

b controls the relative effectiveness of plastic deviatoric strains and plastic volumetric strains in destroying the bonding

BS British Standard

$\mathrm{C}_{\mathrm{C}}$ Compression index

$\mathrm{CO}_{2}$ Carbon Dioxide

Con Consolidation

$\mathrm{CoV}$ Coefficient of variation

CRS Constant Rate of Strain

$\mathrm{C}_{\mathrm{S}} \quad$ Swelling index

$\mathrm{CH}$ Clay of high plasticity 
D Pore diameter

D Diameter of sample ring

D Constitutive matrix

d Entrance pore size $\begin{array}{ll}\text { DLVO theory } & \begin{array}{l}\text { Boris Derjaguin and Lev Landau, Evert Verwey and Theodoor } \\ \text { Overbeek, Double Layer and van der Waals interactions theory }\end{array}\end{array}$

DS Dry side of optimum

e Void ratio

e elastic

$\mathrm{e}_{0} \quad$ Void ratio at point 0 of stress

$\mathrm{e}_{\mathrm{o}}$ Initial void ratio

$\mathrm{e}_{1}$ Void ratio at point 1 of stress

$\mathrm{e}^{*}{ }_{100}$ Void ratio at $100 \mathrm{kPa}$ in the reconstituted sample

$\mathrm{e}^{*}{ }_{1000}$ Void ratio at $1000 \mathrm{kPa}$ in the reconstituted sample

EF Edge-to-face

$\mathrm{e}_{\text {curve }}$ Void ratio obtained at the oedometer curve

$\mathrm{e}_{\mathrm{EF}} \quad$ Edge-to-face void ratio

$\mathrm{e}_{\mathrm{F}-\mathrm{D}}$ Void ratio obtained before freeze-drying

$\mathrm{e}_{\mathrm{FF}}$ Face-to-face void ratio

$\mathrm{e}_{\mathrm{i}}$ Initial void ratio

EM Electron Microscope 


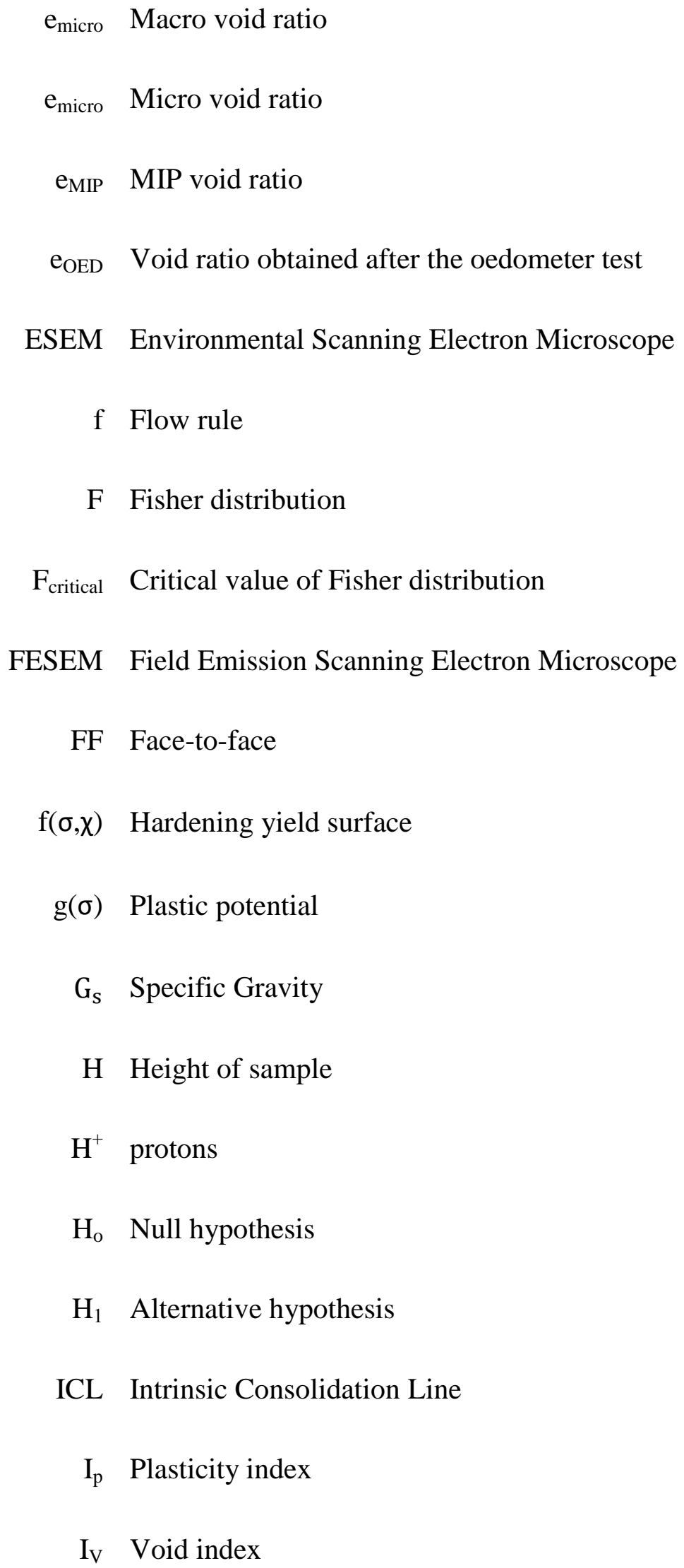


k Number of samples

$\mathrm{k} \quad$ Number of modes

$\mathrm{k}_{\mathrm{o}}$ Coefficient of earth pressure at rest

$\mathrm{KOH}$ Potassium hydroxide

M critical state value of the stress ratio in triaxial space

MCC Modified Cam Clay

MIP Mercury Intrusion Porosimetry

$\mathrm{M}_{\mathrm{S}} \quad$ Mass of solids

$\left(\mathrm{NaPO}_{3}\right)_{6} \quad$ Sodium hexametaphosphate

NBR Brazilian Standard (in Portuguese: Norma Brasileira)

NCL Normal Consolidation Line

ML Clay of low plasticity

n porosity

n Fitting parameter of van Genuchten-type equation

$\mathrm{N}_{2} \quad$ Nitrogen

$\mathrm{n}_{\mathrm{EF}} \quad$ Edge-to-face fitting parameter of van Genuchten-type equation

$\mathrm{n}_{\mathrm{FF}} \quad$ Face-to-face fitting parameter of van Genuchten-type equation

$\mathrm{n}_{\text {macro }}$ Macro fitting parameter of van Genuchten-type equation

$\mathrm{n}_{\text {micro }}$ Micro Fitting parameter of van Genuchten-type equation

O Oxygen 
OCR Over Consolidation Ratio

OH Oxygen hydroxyl

$\mathrm{OH}^{-}$Hydroxyl anions

OP Optimum water content

p Absolute pressure applied to mercury

p' Mean effective stress

$\mathrm{p}_{\text {cr }}$ Critical pressure

$\mathrm{p}_{\mathrm{tp}} \quad$ Pressure at the triple point

$\mathrm{pH}$ Potential of hydrogen

$\mathrm{pH}_{\mathrm{PZC}}$ Potential of hydrogen at the Point of Zero Charge

$\mathrm{p}_{\mathrm{m}} \quad$ size of the natural (or structured) yield surface

$\mathrm{p}^{\prime}{ }_{\mathrm{mi}} \quad$ size of the intrinsic yield surface

PSD Pore Size Density

PZC Point of Zero Charge

$\mathrm{R}^{2}$ Coefficient of multiple determination for multiple regression

s Matric suction

S Saturation

$\mathrm{S}_{\mathrm{B}}{ }^{2} \quad$ Variance between populations

S-CLAY1 Constitutive model (Wheeler et al., 2003)

S-CLAY1S Constitutive model (Koskinen et al., 2002) 
SEM Scanning Electron Microscope

Si Silica

$\mathrm{SiO}$ Silica-Oxygen tetrahedron

SQB Square errors between populations

SQW Square errors within populations

$\mathrm{S}_{\mathrm{w}}{ }^{2}$ Variance within populations

$\mathrm{T}_{\mathrm{cr}} \quad$ Critical Temperature

TEM Transmission Electron Microscope

$\mathrm{T}_{\mathrm{tp}}$ Temperature at the triple point

$\mathrm{u}_{\mathrm{b}} \quad$ Excess pore water pressure

UK United Kingdom

USCS United Soil Classification System

UTM Universal Transverse Mercator

$\mathrm{V}_{\mathrm{S}} \quad$ Volume of solids

$\mathrm{V}_{\mathrm{V}} \quad$ Volume of voids

$\mathrm{V}_{\mathrm{T}} \quad$ Total volume

w Water content

WD Wet side of optimum

$\mathrm{w}_{\mathrm{i}}$ Initial water content

$w_{L} \quad$ Liquid limit 
$w_{P} \quad$ Plastic limit

$\mathrm{w}_{\mathrm{pH} 9} \quad$ Water content of $\mathrm{pH} 9$ sample

$\mathrm{W}_{\mathrm{und}} \quad$ Water content of undisturbed sample

$\mathrm{x}$ Amount of bonding/structure

$\mathrm{x}_{\mathrm{o}}$ Initial amount of bonding/structure

$\alpha \quad$ Fitting parameter of van Genuchten-type equation

$\alpha_{E F}$ Edge-to-face fitting parameter of van Genuchten-type equation

$\alpha_{\mathrm{FF}} \quad$ Face-to-face fitting parameter of van Genuchten-type equation

$\alpha_{\text {macro }}$ Macro fitting parameter of van Genuchten-type equation

$\alpha_{\text {micro }}$ Micro Fitting parameter of van Genuchten-type equation

$\alpha_{d}$ dimensionless second order tensor describing the fabric anisotropy

$\beta$ the relative effectiveness of plastic deviatoric strains and plastic volumetric strains in rotating the yield surface

$\delta \varepsilon_{d}^{p} \quad$ increment of plastic deviatoric strain

$\delta \varepsilon^{\mathrm{p}}{ }_{\mathrm{v}} \quad$ increment of plastic volumetric strain

$\varepsilon$ deformation

$\kappa$ slope of a swelling line in the compression plane

$\lambda$ Compression index

$\lambda_{\mathrm{i}}$ slope of the intrinsic normal compression line in the compression plane

$\mu$ the absolute rate at which $\alpha_{d}$ heads toward its current target value 
$\mu$ average

$\eta$ tensorial equivalent of the stress ratio

$\checkmark$ specific volume

$v$ Poisson's ratio

$\rho_{\mathrm{d}} \quad$ Dry density of soils

$\rho_{\mathrm{w}} \quad$ Water density

$\Lambda$ Scalar that controls the magnitude of plastic deformations

$\sigma \quad$ stress

$\sigma_{d}^{\prime} \quad$ deviatoric stress tensor

$\sigma^{\prime}{ }_{\mathrm{v} 0} \quad$ Vertical effective stress at point 0

$\sigma_{\mathrm{Hg}}$ surface tension of mercury

$\sigma_{0}^{\prime} \quad$ Initial effective stress

$\sigma_{\mathrm{v} 1}^{\prime} \quad$ Vertical effective stress at point 1

$\sigma_{\mathrm{vp}}^{\prime} \quad$ Pre-consolidation stress

$\sigma_{\mathrm{v}} \quad$ Vertical total stress

$\sigma_{\mathrm{v}}^{\prime} \quad$ Vertical effective stress

$\sigma_{\text {vmax }}^{\prime}$ Maximum past vertical effective stress

$\phi \quad$ Soil friction angle

$\theta$ contact angle between the mercury and the pore wall

$\chi$ Hardening parameter 


\section{1 - INTRODUCTION}

Nowadays, engineering practice still involves a wide range of simplifications and hypotheses, due to the complexity of introducing the real characteristics of the soil behaviour. Indeed, clay is a very complex material. There is a conceptual lack of understanding of clay behaviour from a microstructural standpoint. For example, the fundamental features of compression behaviour, i.e., plastic and elastic response, are explained from a microstructural standpoint by either referring to granular 'interactions', or to electro-chemical interactions borrowed from colloidal theories, not representative of clay behaviour. Hence, in practice there is no conceptual model able to describe the behaviour of clay.

It is clear that the clay structure has an important impact on the clay behaviour; however, most of the investigations available in the literature regarding soil microstructure are related to unsaturated soils. Very few studies (Delage \& Lefebvre, 1984; Griffiths \& Joshi, 1990; Monroy et al., 2010) have considered the microstructure as one of the responsible factors for the behaviour of saturated soil samples. Nonetheless, many authors have been attributing the difference in behaviour between natural and reconstituted soil samples to its structure (Leroueil et al., 1979, 1985; Locat \& Lefebvre, 1986; Schmertmann, 1991).

Multi-structural constitutive frameworks have been built through hypotheses for micro- and macrostructural interactions based on microstructural experimental evidence (Alonso et al., 1999; Loret \& Khalili, 2000; Sanchez et al., 2005; Alonso et al., 2010; Romero et al., 2011; Alonso et al., 2013; Della Vecchia et al., 2013).

The Mercury Intrusion Porosimetry (MIP) test is one of the most popular experiments used for microstructure investigation, which allows understanding of the macroscopic behaviour and the physical properties of the soil. The data obtained through MIP are used to supply information about factors that influence the relationship between properties and structure and the changes in the structure.

The future of engineering is to incorporate aspects of the microstructure into the macroscopic characteristics of the soils, in order to reduce the geotechnical analysis into simpler and realistic analysis. Therefore, it is fundamentally important to understand the structure of soils in various states (undisturbed, reconstituted, remoulded, compacted, etc.) and correlate them, as it is already known that the initial state of the soil dictates its behaviour. 


\section{1 - MOTIVATION}

Burland (1990) standardized a way to obtain the reconstituted state of a sample and introduced the concept of intrinsic state to link the reconstituted and the natural states of clay soils. However, Fearon \& Coop (2000) questioned the methodology of reconstitution proposed by Burland (1990), when they demonstrated that soils reconstituted using high- and low-energy methods may have very different characteristics, which seems to indicate that the preparation method used highly influences the intrinsic behaviour.

In addition, the literature in general separates the behaviour of clays and clean sands from other intermediate graded soils (Been \& Jefferies, 1985; Coop \& Lee, 1993; McDowell \& Bolton, 1998; etc.), called 'Transitional Soils'. According to the literature, clays and clean sand have a unique normal consolidation and critical state lines, while transitional soils do not (Ferreira \& Bica, 2006; Nocilla et al., 2006; Shipton \& Coop, 2012). This concept was questioned by Shipton \& Coop (2012), when the authors presented three different clays that do not have unique normal consolidation lines.

This study was motivated by the contradictory information published and briefly introduced here. It was identified a necessity to better understand the differences and similarities between clays and clean sands and intermediate graded soils and also to establish a reliable way to connect the behaviour of soils in different states using the understanding of their microstructure and changes under unidimensional loading.

\section{2 - OBJECTIVES OF THE THESIS}

The main aim of this research is to develop an understanding of the changes in the soil structure through its pore sizes and distribution under mechanical loading, as well as to determine which state is appropriate to describe a reference state of the soil behaviour. The specific objectives are:

- Evaluate the mechanical behaviour, from consolidation tests in saturated conditions;

- Study the evolution of the microstructure of the soils, under various mechanical loadings;

- Determine a reference state, which all other states tend towards;

- Analyse how the structure of the soil affects the compressibility and the distribution of the pore sizes; 
- Propose a conceptual model for the microstructure evolution with load;

- Model the results of the mechanical behaviour obtained through the experiments.

\section{3 - STRUCTURE OF THE THESIS}

This thesis contains six chapters comprising introduction and objectives, literature review, materials and methods used, results and discussions of the experiments, numerical analyses performed on two clays and a transitional soil, and conclusions. The present chapter exposes the general aspects of this research, describing its importance, motivation and the main objectives of the thesis. Chapter 2 describes in a general way all the relevant subjects covered by this thesis. Initially some concepts of terms and expressions used in this thesis are defined. A literature review into the compression behaviour of soils is then developed, followed by a review of the kaolinite mineralogy, microstructure investigation and, finally, constitutive modelling. In Chapter 3 the materials and methods used in this thesis are presented. Firstly, the properties of the three soils studied are presented. The methods were divided into two stages: 1) experimental analysis - sedimentation, compression and microstructure and 2) the modelling - van Genuchten-type fitting and constitutive modelling. Chapters 4 and 5 expose the experimental and numerical results and analyses of the clay materials and transitional soil material respectively. Finally, Chapter 6 shows the conclusions and suggestions for future studies. 


\section{2 - LITERATURE REVIEW}

This chapter presents an overview of the main topics covered in this work. Firstly, a few concepts are defined, followed by discussions of the compression behaviour of soils, kaolinite mineral, microstructure investigation and, finally, constitutive modelling.

\section{1 - DEFINITIONS}

\subsection{1 - DEFINITION OF FABRIC, STRUCTURE AND SOIL STATE}

Early concepts of clay fabric were given by Terzaghi (1925) and Casagrande (1932), when they proposed a honeycomb structure for cohesive soils. Subsequently to Terzaghi's (1925) publication, Goldschmidt (1926) proposed that clay particles form an unstable cardhouse structure with edge-to-face dominant contacts. Lambe (1953) then presented a diagram of clay arrangements very similar to the cardhouse proposed by Goldschmidt (1926) and additional ones of the remoulded state.

Lambe \& Whitman (1969), Mitchell (1976) and Mitchell \& Soga (2005) defined fabric as the arrangement of particles, particle groups and pore spaces in the soil and structure as the combined effects of fabric, composition and interparticle forces. Mitchell \& Soga (2005) also acknowledge the fact that both terms are sometimes used interchangeably. Subsequent studies have almost always quoted one of these three books when defining the term structure of the soil. However, in the majority of cases the definition neglects the existence of any other interparticle forces that do not include bonding and/or cementation (Burland, 1990; Liu \& Carter, 2000; Baudet \& Stallebrass, 2004; amongst others).

In addition, some authors have defined structured soil as a synonym for the natural, undisturbed state and introduced the term destructured soil to describe reconstituted soils (Burland, 1990; Leroueil \& Vaughan, 1990; Liu \& Carter, 1999; Hong, 2007; Hong et al., 2010, 2012). However, Cotecchia \& Chandler (1997) showed, using electron microscopy, that reconstituted samples were not unstructured but instead had a sedimentation structure different from the natural structure. Such a conclusion can also be derived from the definition of structure provided by early studies, which suggest that all soils have structures since interactions between particles will always be present. Hence, in terms of structure, the difference between the natural and reconstituted soils is that both states have different structures, as opposed to earlier beliefs that assumed the natural soil to have a structure and reconstituted soils to have no structure at all. 
Furthermore, in the discussions of Carrier \& Beckman (1985), Leroueil et al. classified four different structure states in which clay soils can be encountered: the intact state, the destructured state, the remoulded state and the resedimented state. The intact state is as occurs in natural deposits; the destructured state can be observed when an initially intact clay is submitted to volumetric or shear deformations of such magnitude that the original clay structure is broken, which occurs, for example, in an oedometer test; the remoulded state is obtained when the clay mass is subjected to sufficient mechanical energy to reduce its strength to a minimum; and the resedimented state is obtained by deposition of clay particles originally remoulded and mixed to a slurry and by consolidation under the self-weight of the soil column of increasing thickness, which depends on the mineralogy and grain size of the soil, the salinity of the slurry, the rate of sedimentation and other environmental factors.

Burland (1990) introduced the concept of reconstituted soils. The author suggested that a reconstituted sample should be made from a natural sample, mixed with water to form a slurry. The slurry should have water content between the liquid limit $\left(\mathrm{w}_{\mathrm{L}}\right)$ and $1.5 \mathrm{w}_{\mathrm{L}}$. Until the publication of Burland's study, all of the disturbed samples were called remoulded samples.

In this study, the term natural is used to describe undisturbed samples (the terms intact, undisturbed and natural are used as synonyms), while the term reconstituted is used to describe disturbed samples of soil in slurry form with water content between $\mathrm{w}_{\mathrm{L}}$ and $1.5 \mathrm{w}_{\mathrm{L}}$; finally, the term remoulded is used to define all the other disturbed samples. The term destructured state and/or soil is not used in this document, except in this chapter as part of the literature review, where it cannot be avoided.

\subsection{2 - DEFINITION OF TRANSITIONAL SOILS}

The behaviour of clean sands and clays has been similarly described in the literature within a critical state framework (Been \& Jefferies, 1985; Coop \& Lee, 1993; McDowell \& Bolton, 1998). According to these studies, there are two key differences between these soils. The first one is the mechanisms of plastic volumetric compression frameworks, where in clays the behaviour is governed by physical-chemical forces between the particles, while in sands the behaviour is due to particle breakage if the stress applied is sufficiently large. The second difference is that, although both clays and clean sands are believed to have a unique Normal Consolidation Line (NCL), sands are deposited at much denser states than clays; therefore sands reach their NCL at much higher stresses than clays. 
Recent studies have shown that unique normal consolidation and critical state lines cannot be identified in many intermediate graded soils (from gap-graded to well-graded silts and sands). These soils have been called 'transitional' (Ferreira \& Bica, 2006; Nocilla et al., 2006; Shipton \& Coop, 2012).

Many soil mechanics theories assume soils to have unique normal compression and/or critical state lines. For soils that do not show such behaviour it would therefore be difficult to identify the effects of structure on the mechanics, since there is no unique behaviour of the soil when reconstituted, according to the methodology proposed by Burland (1990).

The abovementioned issue is supposed to affect only transition soils; however, Hong (2007), Hong et al. (2010) and Hong et al. (2012) showed a series of three reconstituted and remoulded clays, Lianyungang Clay, Baimahu Clay and Kemen Clay, that presented nonconvergent behaviour in 1-D compression, i.e., a unique NCL was not identified. Despite the evidence, the authors of the aforementioned papers did not acknowledge the fact. Similarly, Shipton \& Coop (2012) also showed three clays, London Clay, Oxford Clay and Speswhite Kaolin, that also indicated non-convergent behaviour, also contrary to common belief. In this sense the concept of transitional soil is put into question and the need to separate its study from the study of clays and clean sands is also challenged.

\section{2 - COMPRESSION BEHAVIOUR}

\subsection{1 - CONSOLIDATION TESTS}

Settlement is defined as the compression of a soil layer due to the loading applied at or near its top surface (Craig, 2004). The total settlement of a soil consists of compression due to immediate compression, primary consolidation and secondary consolidation or creep.

Consolidation in saturated conditions is the gradual reduction of volume of a saturated soil due to drainage of the pore water. It is an ongoing process up to the point when the excess pore water pressure caused by an increase in total stress is completely dissipated (Craig, 2004). The one-dimensional consolidation is the simplest case in which the zero lateral strain condition is implied. The swelling process is the reverse of consolidation, where the gradual increase in volume of a soil occurs under negative excess pore water pressure.

The consolidation theory is required for the prediction of both the magnitude and the rate of consolidation settlements to ensure the serviceability of structures founded on a compressive layer. 
The oedometer, shown in Figure 2.1, is the equipment developed based on Therzaghi's onedimensional consolidation theory for fine-grained soils, in which the effective vertical stressstrain response of the soil is unique, linear, and time-independent, although it has been already recognized that time is an issue, since the soil experience decreases in volume under constant load (creep). Herein, this test is called the conventional oedometer test. In this apparatus, the soil specimen is held by a metal ring and placed above the lower pore stone. On top of the specimen, there is the upper pore stone. All this is placed and screwed in the oedometer cell, into which water is poured surrounding the metal ring. This water can drain in or out of the specimen through both pore stones. On top of the upper pore stone there is a cap where the pressure is applied.

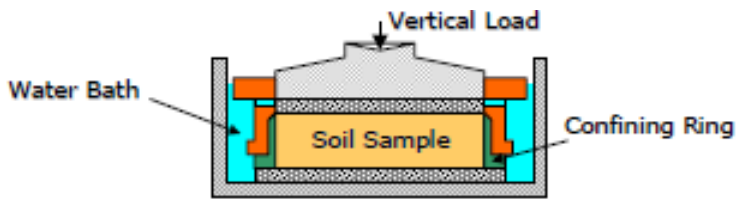

(a)

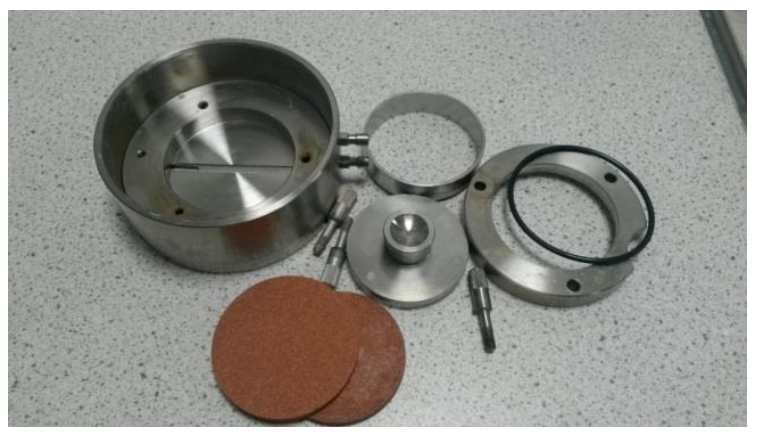

(b)

Figure 2.1 - (a) Schematics of Oedometer cell, (b) Oedometer cell

The test procedure has been standardized by several standards (e.g., BS 1377, ASTM D 2435, NBR 12007:1990), in which basically the same procedure is recommended. The initial pressure will depend on the soil tested; a sequence of pressures is then applied, each one double the value of the previous one. The pressure is usually maintained for 24 hours. The excess pore water pressure is believed to be completely dissipated after the end of primary consolidation; thus the applied pressure is equal to the effective vertical stress. The results are presented in a semi-logarithm plot of void ratio at the end of the increment period against the respective vertical effective stress. The slope of the loading curve is called the Compression Index, $\lambda$, and is dimensionless. It is defined as:

$$
\lambda=-\frac{\mathrm{e}_{1}-\mathrm{e}_{0}}{\ln \left(\sigma^{\prime}{ }_{\mathrm{v} 1} / \sigma^{\prime}{ }_{\mathrm{v} 0}\right)}
$$

The slope of the unloading curve is called the Swelling Index, $\mathrm{K}$, and is calculated using the same procedure. The overconsolidation ratio (OCR) is defined as the ratio of maximum past 
vertical effective stress $\left(\sigma^{\prime}{ }_{\text {vmax }}\right)$ over present vertical effective stress $\left(\sigma^{\prime}{ }_{\mathrm{v}}\right)$. The maximum vertical effective stress ever experienced by the soil is called the preconsolidation stress $\left(\sigma^{\prime}{ }_{\text {vp }}\right)$ and in the consolidation curve it corresponds to the yield stress.

The conventional oedometer test consists of applying a certain pressure and reading the strain caused in the specimen. The test can last one or two weeks depending on the soil type tested. Smith \& Wahls (1969) developed the Constant Rate of Strain (CRS) consolidation test, which consists of applying a certain displacement to the soil specimen and reading the pressure induced on it. According to Wijaya et al. (2014), the test duration using the CRS apparatus can be shortened to one or two days, depending on the strain rate used.

The CRS consolidation test should ensure that Therzaghi's one-dimensional consolidation theory is still valid by certifying that all the excess pore water pressure has dissipated before another increment of displacement is applied to the specimen. Thus, the challenge of the experiment is to establish a strain rate adequate to ensure that the excess pore water pressure has dissipated at the end of primary consolidation in every single displacement stage. ASTM standard D4186 has standardized the procedure for the CRS consolidation test since 1982 (latest version 2008), establishing the rates that should be applied for each soil type; however, there are several other studies into the subject that propose different rates for different soils based on empirical and base excess pore pressure to vertical total stress pore pressure ratio, ub/ $\sigma_{v}$, approaches (Smith \& Wahls, 1969; Wissa et al., 1971; Gorman et al., 1978; Vaid et al., 1979; Lee, 1981; Leroueil et al., 1983, 1985; Larsson \& Sallfors, 1985; Znidarčić et al., 1986; Silvestri et al., 1986; Nash et al., 1992; Lee et al., 1993; Sheahan \& Watters, 1997). The best practice, however, seems to be to compare the results of the conventional oedometer test and the CRS consolidation test when setting up the strain ratio to be used in the latter test for each soil to be tested.

\subsection{2 - SOIL BEHAVIOUR UNDER 1-D COMPRESSION}

As already reported in section 2.1.2, the behaviour of both clean sands and clays has been described as similar in the literature, as opposed to transitional soils (intermediate graded soils), which do not present a unique normal consolidation and critical state lines. This concept, however, was put into question when Shipton \& Coop (2012) tested three different clays, London Clay, Oxford Clay and Speswhite Kaolin (Figure 2.2), at different water contents within the range between $\mathrm{w}_{\mathrm{L}}$ and $1.5 \mathrm{w}_{\mathrm{L}}$, i.e., all samples were reconstituted according to Burland's (1990) criteria of reconstitution. The authors reported non-convergent 
compression, as opposed to the expected results from literature, which assume that unique intrinsic properties would be seen from slurry samples of clays.

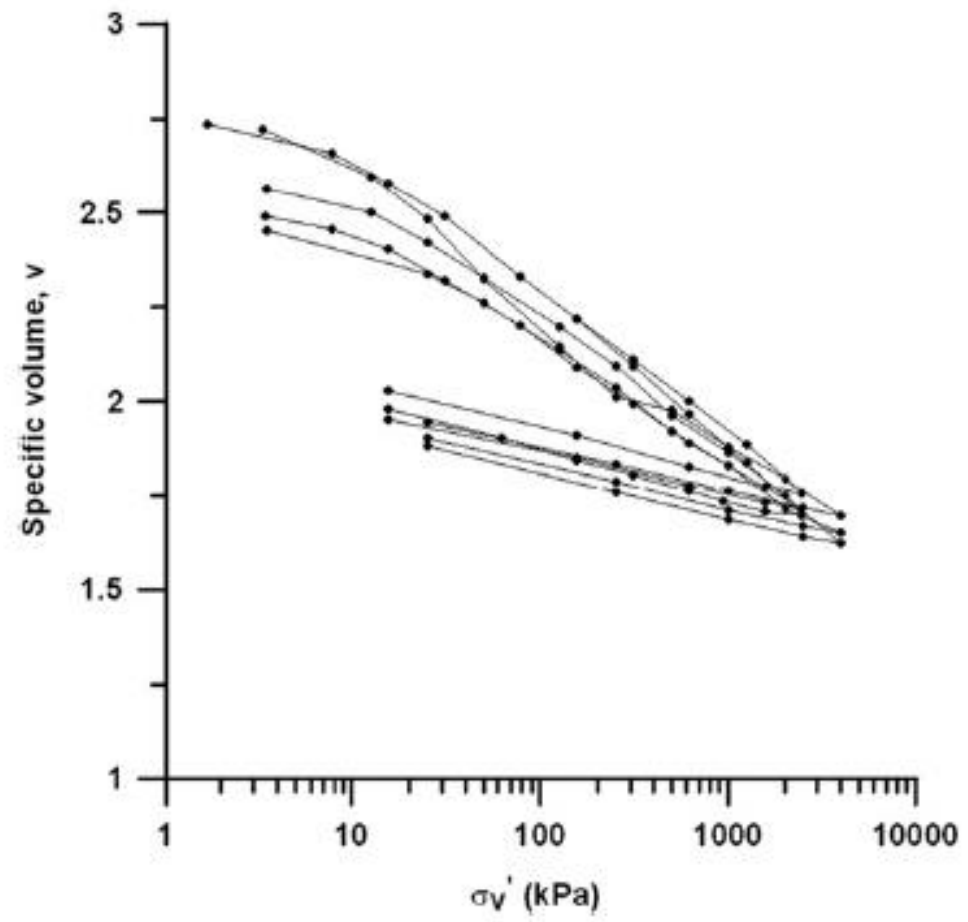

Figure 2.2 - 1-D Consolidation of reconstituted samples of Speswhite Kaolin, each curve representing an initial water content between $\mathrm{w}_{\mathrm{L}}$ and $1.5 \mathrm{w}_{\mathrm{L}}$ (source: Shipton \& Coop, 2012)

Hong (2007), Hong et al. (2010) and Hong et al. (2012) also presented three different clays, Lianyungang Clay, Baimahu Clay and Kemen Clay (Figure 2.3a to c respectively), in the reconstituted and remoulded state with non-convergent compression behaviour. In these publications the authors attributed this difference to the suction induced into the samples by the preparation procedure, which generates different preconsolidation stresses (remoulded yield stresses) and, consequently, different consolidation curves. However, the authors believed that the convergence between the remoulded and reconstituted curves will occur at some point along the line after the remoulded yield stress, which is slightly different from the assumption made by Burland (1990), who believed that this convergence happens at a much earlier state, around $100 \mathrm{kPa}$ for clays. Hong et al. (2012) also compared the behaviour between various natural samples (Figure 2.3d), finding different yield stresses and NCLs. 


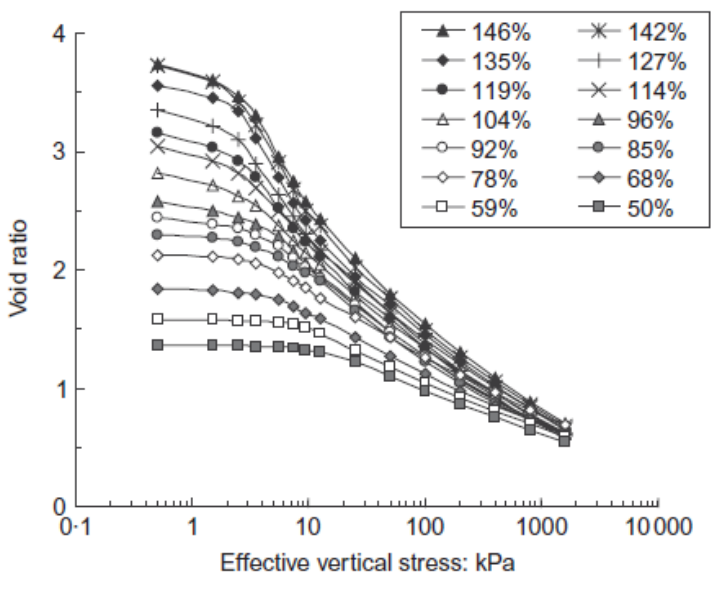

(a)

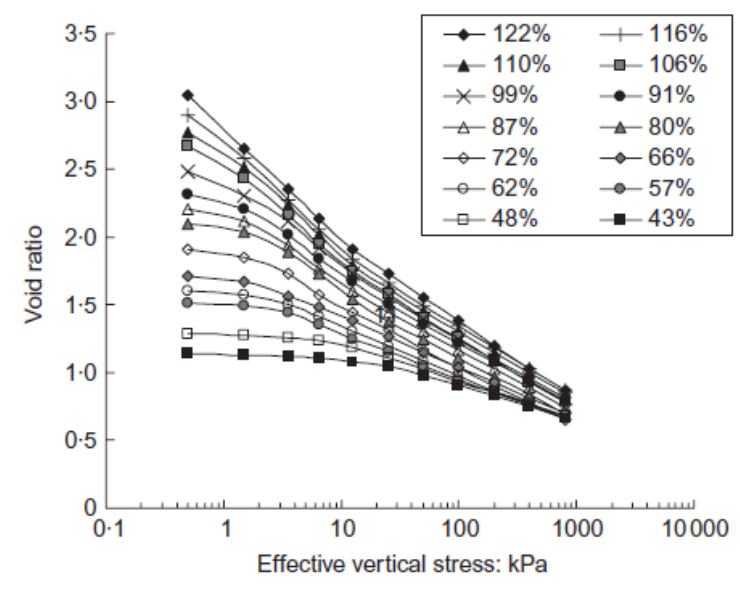

(c)

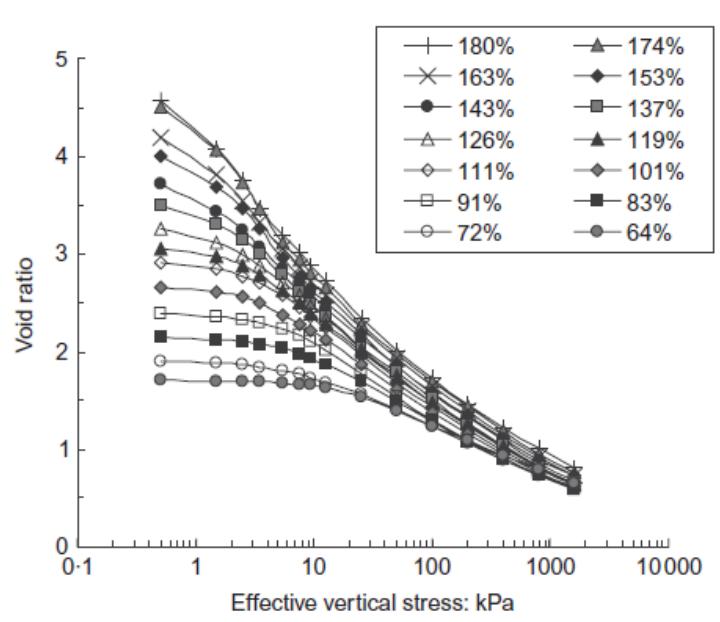

(b)

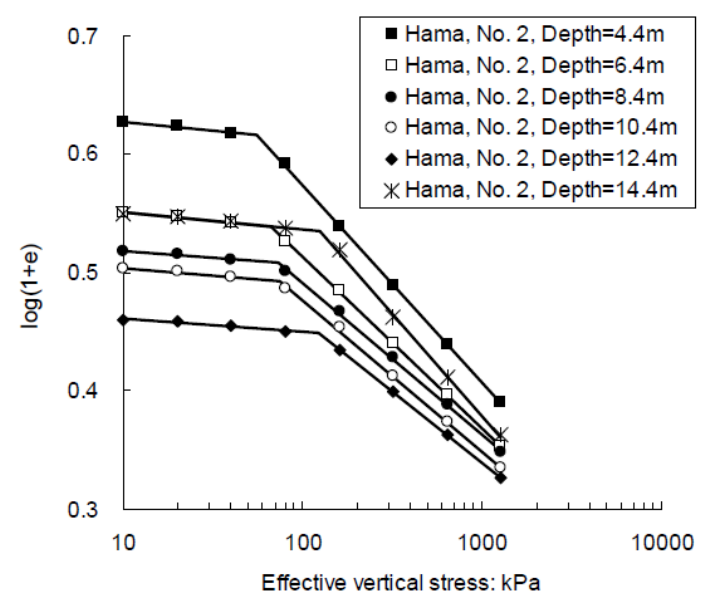

(d)

Figure 2.3 - Reconstituted samples: (a) Lianyungang clay, (b) Baimahu clay, (c) Kemen clay (source: Hong et al., 2010) and (d) Natural samples of Ariake clay (source: Hong et al., 2012)

Burland (1990) introduced a new concept of intrinsic properties, Intrinsic Consolidation Line (ICL), and a normalized parameter called void index to quantify the effects of the structure present in natural samples when compared with samples reconstituted in the laboratory (the usual and simplest way to test soils). According to the author, intrinsic properties are the properties of a sample prepared in a manner defined by the same author as reconstituted (a slurry sample with water content between the liquid limit $\left(\mathrm{w}_{\mathrm{L}}\right)$ and $\left.1.5 \mathrm{w}_{\mathrm{L}}\right)$. The term intrinsic is used due to the fact that these parameters were felt to be unique and inherent for a given soil type.

Burland (1990) defined the void index $\left(I_{v}\right)$ as shown in the following expression:

$$
I_{V}=\frac{e-e_{100}^{*}}{e_{100}^{*}-e_{1000}^{*}}
$$


However, if the graph of Figure 2.4 is considered, by similar triangles, the following expression can be written:

$$
\begin{gathered}
\frac{\mathrm{e}-\mathrm{e}_{100}^{*}}{\mathrm{e}_{100}^{*}-\mathrm{e}_{1000}^{*}}=\frac{\log \left(\frac{\sigma_{\mathrm{v}}^{\prime}}{100}\right)}{\log \left(\frac{100}{1000}\right)} \\
\frac{\mathrm{e}-\mathrm{e}_{100}^{*}}{\mathrm{e}_{100}^{*}-\mathrm{e}_{1000}^{*}}=-\log \left(\frac{\sigma_{\mathrm{v}}^{\prime}}{100}\right)
\end{gathered}
$$

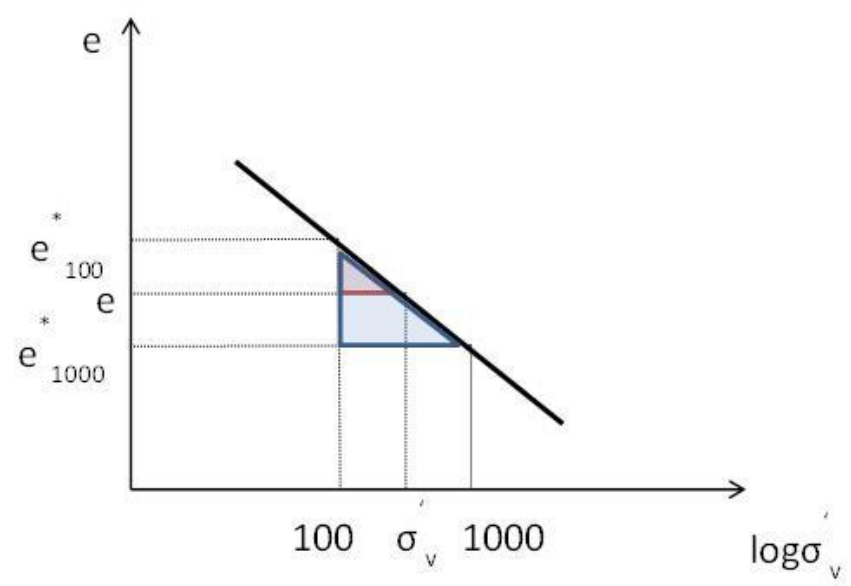

Figure 2.4 - Generic Normal Consolidation Line

Then, substituting expression (2.3) in (2.2):

$$
I_{\mathrm{V}}=-\log \left(\frac{\sigma_{\mathrm{v}}^{\prime}}{100}\right)
$$

Therefore, when Burland (1990) plots the graph of $I_{v}$ against $\log \sigma_{v}^{\prime}$, the author is actually plotting $\log \left(\sigma_{v}^{\prime} / 100\right)$ against $\log \sigma_{v}^{\prime}$, which will result in a line after the yield stress, regardless of the soil being analysed. This may suggest that the void index $\left(I_{v}\right)$ introduced by Burland (1990) is not an intrinsic parameter of the clay materials; thus the ICL may not be unique either.

Hong (2007) and Hong et al. (2010, 2012) compared the consolidation curves in the void index with the effective stress semi-logarithm plot proposed by Burland (1990). In this plot the curves overlap each other after their yield stress, which, according to the authors, justify their thesis that the difference in the curves are due to the stress history induced into the 
samples during their preparation. These findings suggest that the conclusions drawn by the authors could have been misled by the concept of void index.

Fearon \& Coop (2000) also questioned the methodology proposed by Burland (1990) to derive intrinsic properties, when they showed that soils reconstituted using high- and lowenergy methods may have very different characteristics, which seems to indicate that the preparation method used highly influences the intrinsic behaviour.

These results suggest that the intrinsic characteristics of the soil materials could not be obtained through the reconstituted sample as suggested by Burland (1990), as they are not unique but dependent on the initial state of the sample (initial water content chosen). As a consequence of the results presented, one could question whether the reconstituted material has in fact unique characteristics and even if its characteristics are appropriate to use in quantifying the structure of the soil.

\section{3 - KAOLINITE MINERALOGY}

Soil is composed of solid particles, liquid and gas and ranges from very soft, organic deposits through less compressible clays and sands to soft rocks (Mitchell \& Soga, 2005). The size of the solid particles varies from $10^{-6} \mathrm{~mm}$ to large boulders (Lambe \& Whitman, 1969). According to Mitchell \& Soga (2005), particle shapes range from nearly spherical, bulky grains to thin, flat plates and long, slender needles. Soil particles could be formed by any element found in the crust of the Earth, but the most abundant are oxygen, silicon, hydrogen and aluminium. Ninety-nine per cent of the soils' solid mass known are composed of these elements, along with calcium, sodium, potassium, magnesium and carbon. Minerals are formed by the organization of these elements into crystalline forms. Most of the soils found in engineering practice are formed by crystalline minerals and the amount of non-clay material is greater than that of clay; however, clay and organic matter are very influential on the behaviour and properties of the soil regardless of their abundance (Mitchell \& Soga, 2005).

The mineralogy of soils controls their size, shape and properties. Thus, knowledge of the soil mineralogy produces great insights regarding its behaviour. Particles are arbitrarily classified by size, as shown in Figure 2.5. The term clay can refer either to a material smaller than $0.002 \mathrm{~mm}$ and to a class of minerals. The structure of the common clay minerals is formed by two-dimensional arrays of silicon-oxygen tetrahedron (Figure 2.6a) and two-dimensional 
arrays of aluminium- or magnesium-oxygen-hydroxyl octahedron (Figure 2.6b). Different stacking arrangements of tetrahedral and octahedral sheets produce different kinds of clay. The clay minerals in the kaolinite group are composed of alternating sheets of silica and octahedral, as seen in Figure 2.6c and d. The bonding between successive layers is due to van der Waals forces and hydrogen bonds. The bonding in kaolinite is sufficiently strong in a way in which there is no interlayer swelling in the presence of water (Mitchell \& Soga, 2005); thus there is no change in particle dimensions.

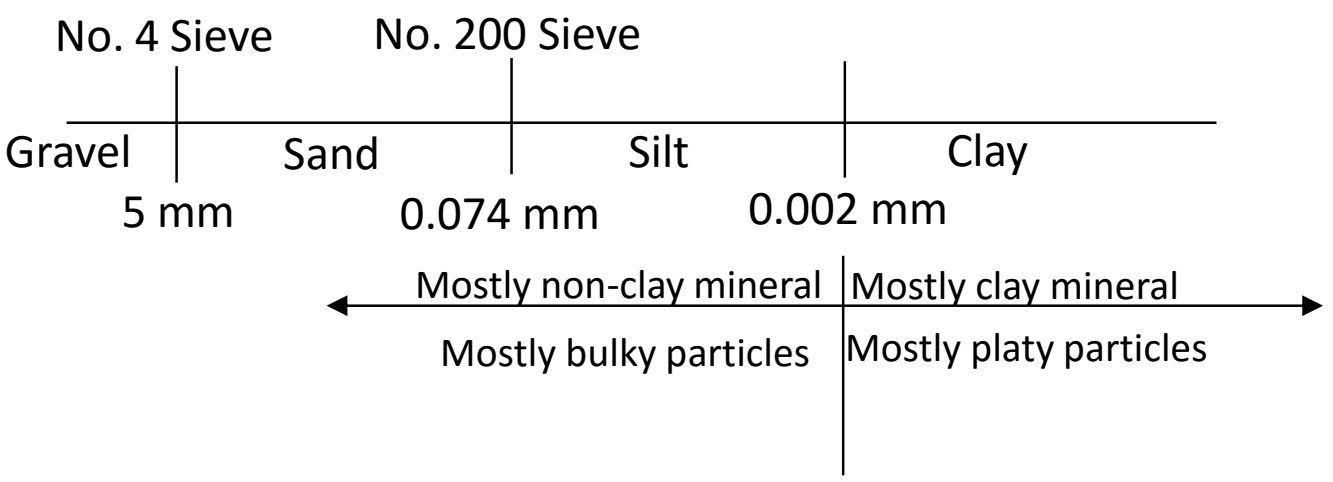

Figure 2.5 - Soil Particle size (after Mitchell \& Soga, 2005)

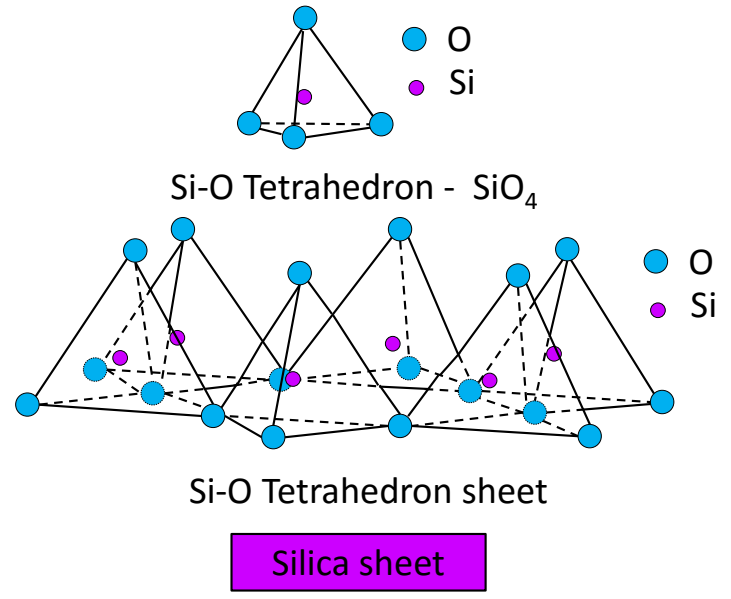

(a)

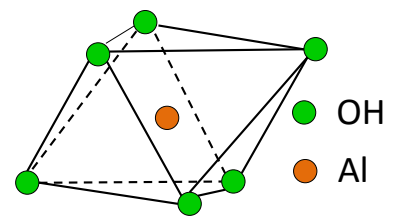

Al-OH octahedron - $\mathrm{Al}(\mathrm{OH})_{6}$

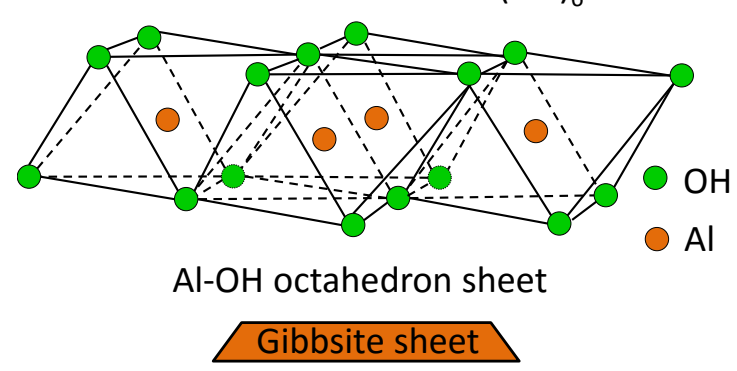

(b) 


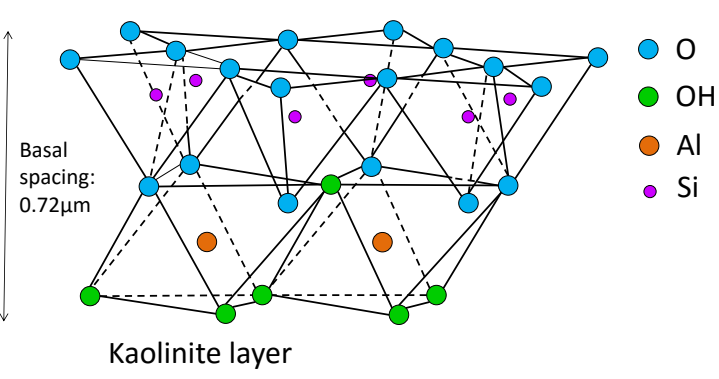

(c)

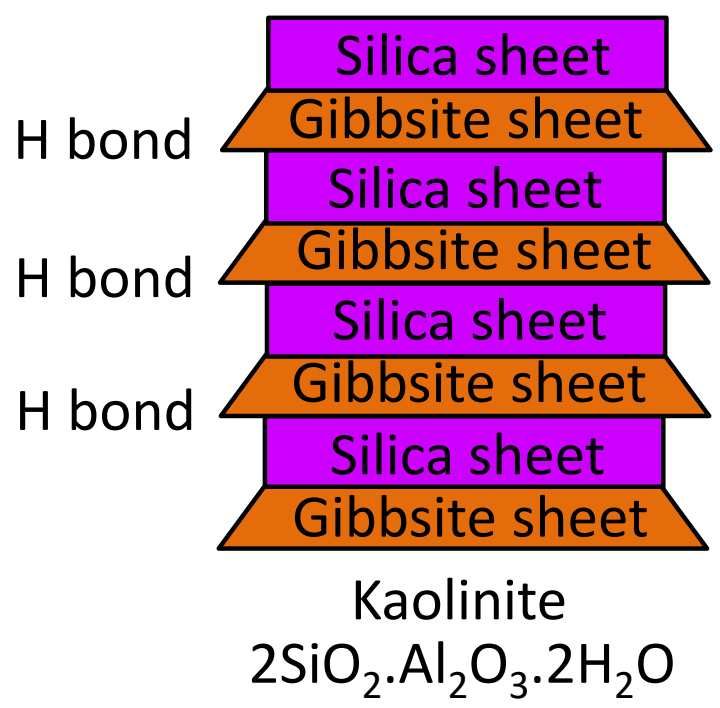

(d)

Figure 2.6 - (a) Silica tetrahedron sheet, (b) Gibbsite octahedron sheet, (c) Kaolinite layer and (d) Kaolinite mineral representation (after Mitchell \& Soga, 2005)

\subsection{1 - CHARACTERISTICS OF SURFACE CHARGES}

The surface of the kaolinite is a result of two combined charges: a permanent charge due to isomorphic substitution on particle faces and a $\mathrm{pH}$-dependent charge due to protonation or deprotonation of hydroxyl groups of the edges. Therefore, according to Wang \& Siu (2006), the overall surface charges on the basal planes (face) are negative at all times because the isomorphic substitution and its magnitude are $\mathrm{pH}$-dependent, while the edge charges are $\mathrm{pH}$ dependent.

According to many authors (Braggs et al., 1994; Huertas et al., 1998; Kretzschmar et al., 1998; Wang \& Siu, 2006; Gupta et al., 2011), the point of zero charge (PZC) of the edges is found to be between pH5 and pH6 for Kaolin Clay. Thus, within an alkaline solution the particles' edges are negatively charged, while within an acid solution they are positively charged (Figure 2.7). $\mathrm{pH}$ measurements are used as guidance when assessing whether the positively charged edge has been neutralized, since the $\mathrm{pH}$ of solutions changes only when the positive edges are all neutralized. The neutralization itself occurs due to deprotonation of the edges, where hydroxyl anions, $\mathrm{OH}^{-}$, are present, when kaolin is mixed in alkaline solutions. The $\mathrm{OH}^{-}$present in high concentrated solution attracts protons, $\mathrm{H}^{+}$, from the edges, resulting in a net negative charge on the edge's surface. Pedrotti (2016) reported that it is common practice to use potassium hydroxide $\mathrm{KOH}$ or similar to raise the $\mathrm{pH}$ of the solution in order to assess the edge charges. Sodium hexametaphosphate, $\left(\mathrm{NaPO}_{3}\right)_{6}$, is also known to 
be a very efficient dispersant for clay solutions due to the highly negative charge of the polyphosphate anions.

Thus, when kaolin is mixed with distilled water $(\mathrm{pH} 7)$, the $\mathrm{pH}$ of the mixture is found to be somewhere below 5. On the contrary, as mentioned before, when kaolin is mixed with very alkaline solutions (e.g., $\mathrm{KOH}$ ) its particle edges are charged negatively and $\mathrm{pH}>6$.

\section{Distilled water}

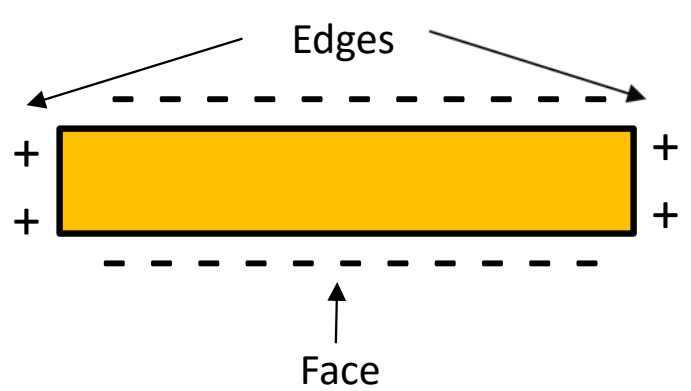

\section{Dispersant solution}

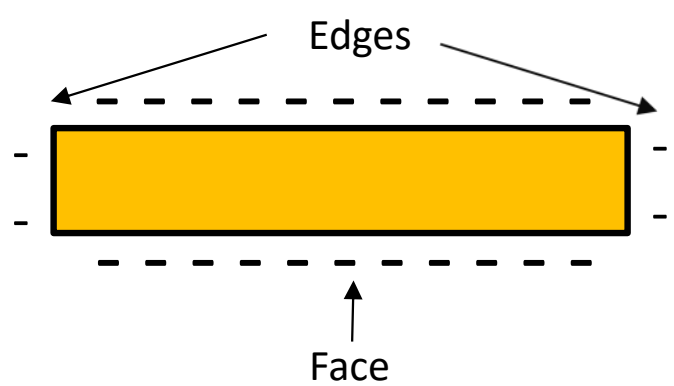

Figure 2.7 - Surface charges on Kaolin particles (after Pedrotti, 2016)

\subsection{2 - INTERPARTICLE FORCES AND FABRIC ASSOCIATIONS}

According to Van Olphen (1977), interactions between Kaolin Clay particles in suspensions are the result of a balance between van der Waals attraction and Coulombian interactions that may be either attractive or repulsive. This theory is often called the DLVO theory, which was named after Boris Derjaguin, Lev Landau, Evert Verwey and Theodoor Overbeek.

Van der Waals forces are dependent on particle shape, particle material properties, interparticle distance and pore fluid properties, while Coulombian interaction force depends on the dielectric constant of the pore fluid, on the electrolyte concentration and on the particle distance (Anandarajah \& Chen, 1997). In addition, Coulombian interaction can be attractive if the surfaces are oppositely charged or repulsive if otherwise.

According to Mitchell \& Soga (2005), van der Waals in suspensions is only relevant, when compared with Coulombian forces, at distances smaller than 10-20nm. Consequently, particle distance is controlled mainly by Coulombian interactions.

Pedrotti (2016) reported that particles are considered to interact in two different ways when kaolin is in an acid suspension (distilled water). The first is Face-to-Face (FF), where 
Coulombian repulsive forces are present between faces, regardless of the $\mathrm{pH}$ of the solution, since faces are always charged negatively, and van der Waals attractions are present. In suspensions Coulombian repulsion is always greater than van der Waals attraction, which results in a repulsive interaction. The second is Edge-to-Face (EF), where Coulombian attraction, as a result of the attraction between negative clay faces and positive clay edges, and van der Waals attraction are both present, therefore resulting in an attractive interaction (as long as the kaolin solution is acid).

On the other hand, if the kaolin suspension is alkaline (mixed with dispersant or $\mathrm{KOH}$ ), the interactions between FF remain the same as the suspension in acid solutions, since faces are not $\mathrm{pH}$-dependent; however, EF interactions present Coulombian repulsive forces between edges and faces, since the alkaline solution changes the charge of the edge from positive to negative, and van der Waals attractions are present, therefore resulting in a repulsive EF interaction.

Wang \& Siu (2006) performed sedimentation tests with kaolin mixed with various $\mathrm{pH}$ solutions. The results can be analysed in Figure 2.8, where it is clear how the macroscopic behaviour of the suspension is affected by the changes in $\mathrm{pH}$. This difference is connected to the electrical charge of the edges of the particle, as the behaviour changes at $\mathrm{pH}$ equal to the PZC value.

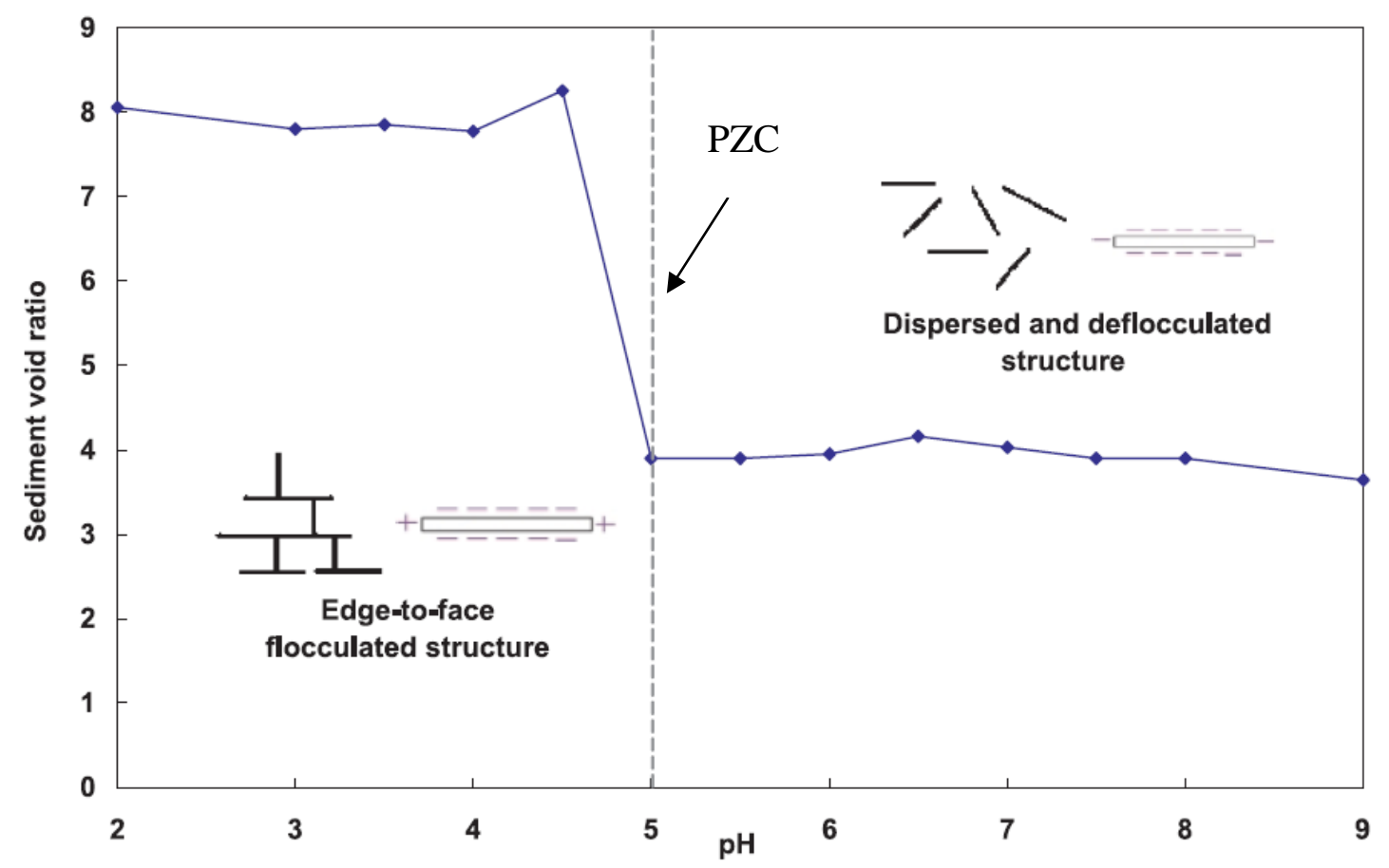

Figure 2.8 - Final void ratio of kaolin suspension at various pHs after 4 months (source: Wang \& Siu, 2006) 
Wang \& Siu (2006) also assumed that the predominant configuration of particles in suspensions is EF when $\mathrm{pH}<\mathrm{pH}_{\mathrm{PZC}}$ (open structure) and non-contact (dispersed) configuration when $\mathrm{pH}>\mathrm{pH}_{\mathrm{PZC}}$ (closed structure).

Typical geotechnical problems, however, involve a concentration of particles much higher than that seen in sedimentation tests. Sedimentation tests involve only about $5 \%$ of solids, while reconstituted samples tested in geomechanical laboratories usually have water content around $100 \%$, which means the mass of solids is equal to the mass of water; thus the solids concentration is much higher. In this context, the study performed by Prashant \& Penumadu (2007) can be cited. The authors carried out Constant Rate of Strain (CRS) consolidation, Mercury Intrusion Porosimetry (MIP) and Scanning Electron Microscopy (SEM) tests, among other tests, in two samples of Kaolin Clay. One sample prepared by mixing kaolin and deaired, distilled and deionized water at $155 \%$ water content was called flocculated and another one prepared at the same water content but with the addition of $2 \%$ of dispersant (Calgon) by weight was called dispersed. The strain rates applied were $0.1 \% / \mathrm{min}$ and $0.015 \%$ for the loading and $0.05 \% / \mathrm{min}$ and $0.01 \% / \mathrm{min}$ for the unloading of the flocculated and dispersed samples respectively. The results of the oedometer test are illustrated in Figure 2.9.

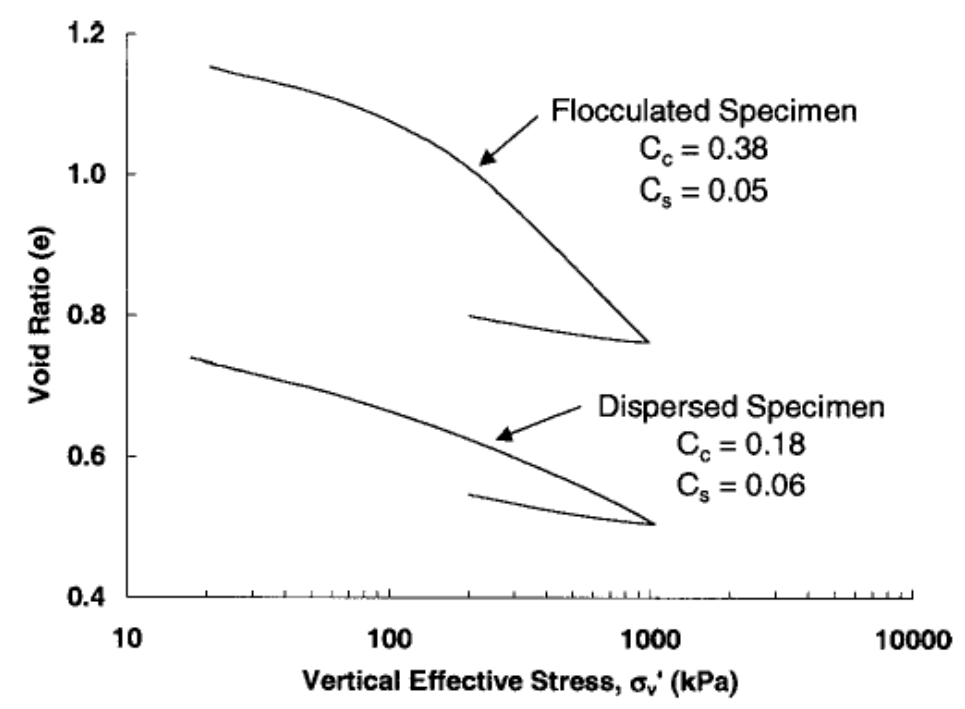

Figure 2.9 - CRS consolidation test (source: Prashant \& Penumadu, 2007)

The flocculated sample appears to be much more compressible than the dispersed sample. For any given vertical stress, the flocculated sample always shows a more open structure than the dispersed sample. At the maximum vertical stress $(1,000 \mathrm{kPa})$, the two samples still show very distinct void ratios, which indicates significant influence of the microfabric on the 1-D 
compression of the soil. On the other hand, the swelling upon unloading appears to be very similar.

The results of MIP tests performed on oven-dried samples loaded in the consolidometer up to $207 \mathrm{kPa}$ are shown in Figure 2.10. SEM images of samples also prepared in the consolidometer and loaded at $207 \mathrm{kPa}$ are illustrated in Figure 2.11. The MIP results show that the overall porosity and the distribution of pores of both samples are very distinct, the dispersed sample only having pores smaller than $0.4 \mu \mathrm{m}$ and the flocculated sample showing a large number of pores between 10 and $0.4 \mu \mathrm{m}$. The SEM images depict a similar scenario - in the dispersed sample, plate-like particles are clearly seen, which is not the case in the image of the flocculated sample.
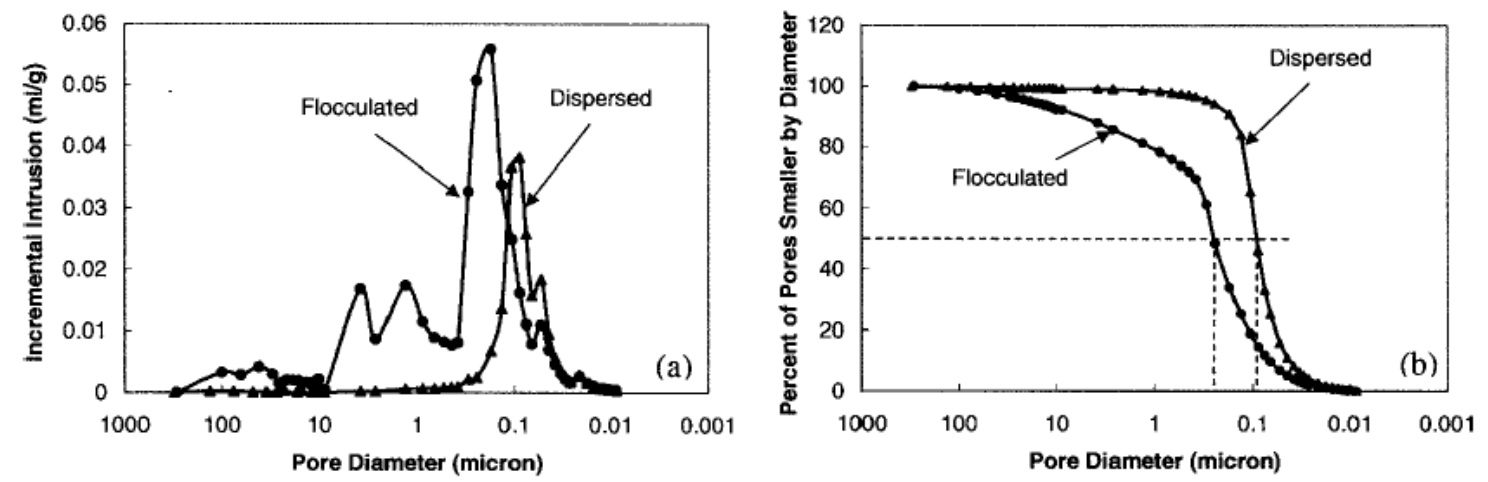

Figure 2.10 - MIP results of flocculated and dispersed samples: (a) Pore Size Density and (b) Intrusion curve (source: Prashant \& Penumadu, 2007)
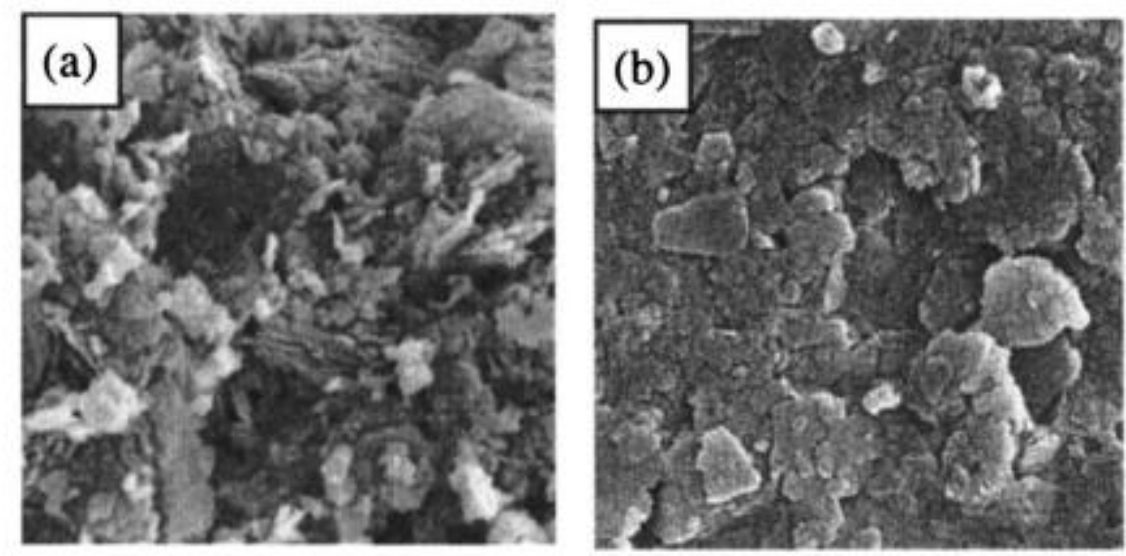

x6000

Figure 2.11 - SEM images of clay samples: (a) flocculated and (b) dispersed (source: Prashant \& Penumadu, 2007)

The results presented by Prashant \& Penumadu (2007) seem to be in agreement with the results of the sedimentation tests, which might indicate that the open structure $(\mathrm{EF})$ controls 
the behaviour of the flocculated sample, while an FF configuration is more apparent in the dispersed sample.

\section{4 - MICROSTRUCTURE INVESTIGATION}

It has long been known that the effect of the soil's structure is as important as the previous stress history and the state of the soil on its mechanical behaviour (Burland, 1990; Leroueil \& Vaughan, 1990; Clayton \& Serratrice, 1993; Gens \& Nova, 1993; Wood, 1995; Burland et al., 1996; Baudet \& Stallebrass, 2004). Experimental evidence of the effects of structure is also reported in a great range of natural soils and weak rocks, including soft clays (Leroueil, 1977; Tavenas \& Leroueil, 1990; Smith et al., 1992), stiff clays and clay shales (Calabresi \& Scarpelli, 1985; Rampello, 1989; Anagnostopoulos et al., 1991; Burland et al., 1996; Cotecchia, 1996), granular soils (Mitchell \& Solymar, 1984; Coop \& Atkinson, 1993), residual soils (Vaughan, 1985, 1988; Wesley, 1990) and weak weathered rocks (Eliot \& Brown, 1985; Addis \& Jones, 1990).

In addition, natural clays generally have a compression curve lying above that of reconstituted clays due to the effect of soil structure (Leroueil et al., 1979, 1985; Locat \& Lefebvre, 1986; Leroueil \& Vaughan, 1990; Schmertmann, 1991; Cotecchia \& Chandler, 1997; Hong \& Tsuchida, 1999). However, although the influence of the structure is recognized as important, it is not taken explicitly into account, only indirectly.

For engineering analysis and design the soil mass is almost always treated as a continuum even though the soil is composed of discrete soil particles and particle groups (Mitchell \& Soga, 2005). The development of the microstructure investigation of fine-grained soils started nearly five decades ago with the study of highly compressible and poorly resistant soils (Cerrolaza \& Delage, 1997). From then on, many other studies and techniques on the investigation have been published and they are discussed in the following topics.

\subsection{1 - SPECIMEN PREPARATION}

According to Mitchell \& Soga (2005), some techniques such as optical and electron microscopy, X-ray diffraction and porosimetry require the pore fluid to be removed. Preparing the sample for the tests without disturbance of the original fabric is a challenge and in most cases there is no way to determine how much disturbance was caused.

According to Romero \& Simms (2008), water can be removed from samples by four techniques: air-drying, oven-drying, critical-point-drying and freeze-drying. Mitchell \& Soga 
(2005) stated that each technique can be more or less suitable for different soils, water contents and type of results expected. For example, air-drying can be successfully used without significant disruption of the natural fabric for soils that do not experience relevant shrinkage, while the same technique is not advisable for soft samples with high water content, since greater particle rearrangement will occur due to the long time required for air-drying. In this case, oven-drying may cause less fabric change than air-drying. However, the stresses induced during oven-drying may result in some particle breakage.

Mitchell \& Soga (2005) also reported that both critical-point and freeze-drying cause less sample disturbance and shrinkage than air- or oven-drying, but they are more difficult and time-consuming. Drying at the critical point is made by raising the temperature and pressure of the sample above the critical values (for water: $374^{\circ} \mathrm{C}$ and $22.5 \mathrm{MPa}$ ) where the liquid and vapour phases co-exist (Figure 2.12); the water can then be removed without the presence of air-water interfaces that can lead to shrinkage. However, as a drawback, the high temperature and pressure may change the clay particles. To overcome this disadvantage, an adjustment can be made by replacing the water with a suitable inert fluid; $\mathrm{CO}_{2}$ is the fluid most commonly used. The critical temperature and pressure of $\mathrm{CO}_{2}$ are $31.1^{\circ} \mathrm{C}$ and $7.19 \mathrm{MPa}$, respectively. However, since $\mathrm{CO}_{2}$ is not sufficiently miscible with water, it is necessary to use an intermediate liquid, miscible with both, to impregnate the sample, usually acetone. It is important to highlight that this technique is not recommended for partly saturated or expansive soils as the impregnation with acetone may lead to swelling in these samples.

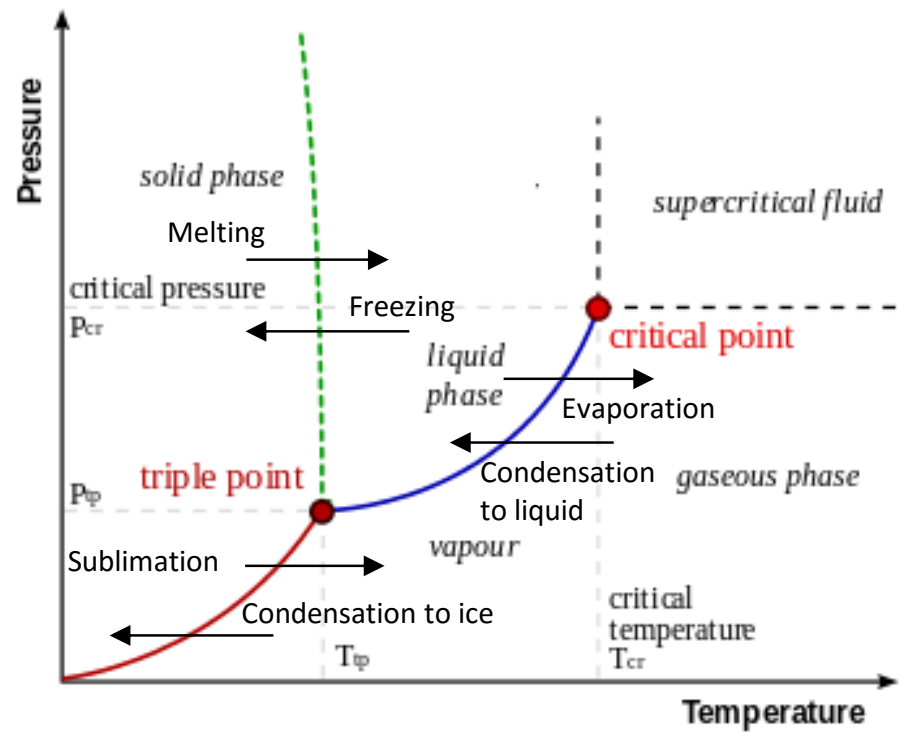

Figure 2.12 - Water phase diagram (modified from CoolSafe, 2006) 
Freeze-drying is another promising technique for water removal. The smaller the sample, the smaller the disruption due to non-uniform freezing. However, if the samples are too small they might not be representative. According to Delage et al. (1982), samples should be thinner than $3 \mathrm{~mm}$ and, in order to avoid gaseous bubbling caused by directly immersing the sample in liquid nitrogen at $-196^{\circ} \mathrm{C}$, a better method of quick freezing is to immerse the sample in a liquid, such as isopentane at $-160^{\circ} \mathrm{C}$ or Freon 22 at $-145^{\circ} \mathrm{C}$, that has been cooled to its melting point in liquid nitrogen. Mitchell \& Soga (2005) emphasize that, to avoid formation of crystalline ice, the freezing temperature should be less than $-130^{\circ} \mathrm{C}$. To increase the rate of water vapour removal, sublimation of the water is done at temperatures between 50 and $-100^{\circ} \mathrm{C}$ rather than at the initial freezing temperature. At temperatures less than $100^{\circ} \mathrm{C}$, the vapour pressure of the ice, about $0.001 \mathrm{~Pa}$, may be less than the capability of the vacuum system. Still, according to Mitchell \& Soga (2005), the problem of air-water interfaces and shrinkage that follows water removal by drying is overcome by sublimation of the ice in a soil that has been rapidly frozen. Nonetheless, the freezing process may produce fabric changes in very high water content systems.

Some researchers (Gillott, 1969; Diamond, 1970; Ahmed et al., 1974; Lawrence et al., 1979; Delage \& Pellerin, 1984) have presented comparative studies of the aforementioned techniques. Gillott (1969) compared air-drying, freeze-drying and critical-point-drying techniques of fine grained limestones and clay soil samples for a Scanning Electron Microscopy (SEM) test. The author observed great shrinkage on the samples prepared by airdrying, while no significant difference was observed in the samples dewatered using either the freeze-drying or the critical-point-drying techniques.

Diamond (1970) investigated oven-drying, freeze-drying and critical-point-drying techniques of clay samples for Mercury Intrusion Porosimetry (MIP). This study suggests that freezedrying and critical-point-drying techniques are the most suitable for the samples tested.

Ahmed et al. (1974) compared two dewatering techniques on compacted samples: freezedrying and oven-drying. The authors concluded that the oven-drying technique induced shrinkage varying greatly with the degree of saturation, in which samples compacted to a high degree of saturation had up to $20 \%$ volume reduction, while at low degrees of saturation the shrinkage was quite small.

Lawrence et al. (1979) reported that clay samples prepared by freeze-drying shrank less than those prepared by critical-point-drying. Delage \& Pellerin (1984) investigated the drying of sensitive clay samples for MIP using the freeze-drying technique directly in liquid nitrogen 
and in Freon 22. The authors concluded that the ice crystallization affects the weak points of the structure, which are the platelet aggregate bridges. The formation of ice crystals is minimized with quick freezing, with the freezing in Freon 22 then regarded as the most successful approach.

\subsection{2 - TECHNIQUES FOR FABRIC STUDY}

There are direct and indirect methods for fabric study. Table 2.1 summarizes the techniques. In the context of soil mechanics, microstructure investigation is mostly used on characterization of unsaturated soils and the techniques commonly adopted are the electron microscope and the pore size density (Romero \& Simms, 2008).

Table 2.1 - Summary of the methods used for fabric study

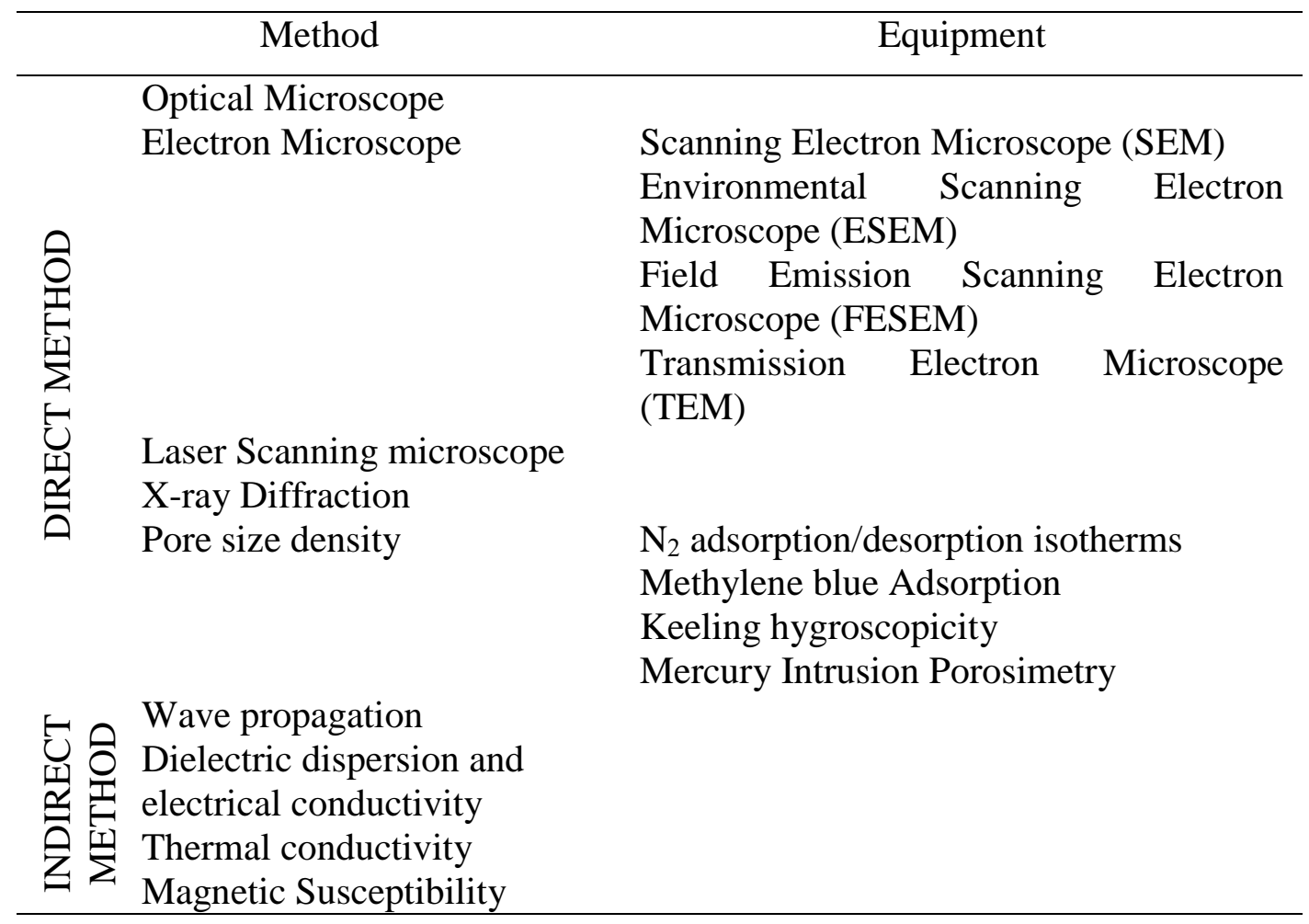

According to Mitchell \& Soga (2005), all physical properties of soils depend partially on the fabric; hence the measurement of a property provides indirect measurement of the fabric. The indirect methods involve relating some of the soil's fabric features to an indirect measurement, such as velocity of wave propagation (wave propagation), flow of electricity (dielectric dispersion and electrical conductivity) and flow of temperature (thermal conductivity).

Optical Microscopes are able to identify particles of sand and silt as well as distinguish sizes, orientations, distributions of particles and pore spaces. Although the instrument is not capable 
of identifying single particles of clays, it can distinguish clay plates if they are aligned parallel to each other, as a group, as they behave optically as one large particle with definite optical properties. Mitchell \& Soga (2005) reported that this equipment provides a view of some characteristics, such as distribution of silt and sand grains, silt and sand particle coating, homogeneity of fabric and texture, discontinuities of various types and shear planes, that are too small to be seen by eye and too large to be acknowledged using an electron microscope, but are nevertheless important for understanding the soil behaviour.

Electron Microscopes (EM) are capable of identifying clay particles and their arrangements. In conventional EM, samples have to be dry, vacuum-compatible and electrically conductive. Different types of this instrument have different advantages and limitations. For example, Transmission Electron Microscope (TEM) limitation is less than $0.001 \mu \mathrm{m}$, while Scanning Electron Microscope (SEM) limitation is $0.01 \mu \mathrm{m}$, which allows the former to be capable of identifying atomic planes, while the latter is able to show clay particle details and other very small soil constituents. The main difficulties of this equipment are the preparation of sample surfaces, surface replicas or ultra-thin sections retaining the undisturbed state of the original soil. According to Mitchell \& Soga (2005), the greater the water content and void ratios, the greater the disturbance. Environmental Scanning Electron Microscope (ESEM) allows testing of wet, natural and non-conductive samples. With this instrument one can observe liquids inside the samples and study the dynamic changes in them, such as wetting, drying, absorption, melting, corrosion and crystallization.

Optical and Electron Microscopes are qualitative methods of fabric study; however, both instruments can be used in combination with image analysers to quantify fabric characteristics. With the help of a digital camera, reflected or transmitted light from the sample can be transformed into pixels. The amount of light per pixel is then converted into an analogue signal and each analogue signal is converted to digital form, which allows analysis, manipulation and storage.

X-ray diffraction is a quantitative method that can provide information about clay particle orientation. The limitations of the technique are: difficulty in the interpretation of multimineral soils; data weighted in favour of the fabric nearest the sample surface; and soil volume does not differentiate between mini- and micro-fabric. According to Mitchell \& Soga (2005), the technique is best used for single mineral clays, but can also be very helpful if used 
in conjunction with other techniques that can provide details on other aspects of the microfabric.

Transmission X-ray and computed tomography scan are non-destructive methods capable of providing information on the soil stratigraphy, homogeneity and micro-fabric. X-radiography on sample tubes is also able to provide information about the texture and disturbance. With the latter technique it is possible to identify deformation patterns in soils and the results can also be used to locate shear zones and compute strains and their variations throughout the material.

Pore size density analysis provides information about the pores. There are a number of instruments that can perform the job, each with a different limitation. Mitchell \& Soga (2005) reported that the maximum pore size measured using the capillary condensation method is $0.1 \mu \mathrm{m}$, while using the Mercury Intrusion Porosimetry (MIP) method it is $0.01 \mu \mathrm{m}$. Hence clayey, silty and sandy soils are best analysed using the MIP technique.

MIP seems to be the most popular technique for studying the soil structure (Delage \& Lefebvre, 1984; Griffiths \& Joshi, 1990; Delage et al., 1996; Romero, 1999; Penumadu \& Dean, 2000; Simms \& Yanful, 2001; Buenfil, 2007; Romero \& Simms, 2008; Mascarenha, 2008; Sivakumar et al., 2010; Koliji et al., 2010; Alonso et al., 2011, 2013; Borges, 2014).

According to Yanful \& Simms (2004), the major sources of error of the MIP technique are:

1. the effects of sample preparation to remove water;

2. the effect of pressure generated during MIP on soil structure; and

3. the influence of pore accessibility on the generated PSD.

Regarding the effects of sample preparation, Mitchell \& Soga (2005) reported that the technique chosen for water removal is a key factor for obtaining consistent MIP results. As described in section 2.4.1, four drying techniques are available: air-drying, oven-drying, critical-point-drying and freeze-drying. Studies, such as Ahmed et al. (1974) and Delage \& Pellerin (1984), suggest that freeze-drying with quick freezing in liquids that have been cooled to melting point in liquid nitrogen (isopentane or Freon 22, for instance) is the drying technique that least affects the structure of clayey soils.

In addition, Lawrence (1978) performed several tests regarding the effect caused on the sample structure due to the pressure applied to the mercury. Results suggested that any 
damage to the pore structure was negligible. For compacted soils, mercury percolates through the sample at relatively low pressures (Simms \& Yanful, 2002), therefore should not cause concern.

Finally, regarding the pore accessibility, Simms \& Yanful (2004) reported that the lack of variation in the measured PSD with sample size in the many tests performed by the authors suggests that the measured pore size distribution must be a good estimate of the actual PSD. However, MIP often reports a smaller average pore size than SEM analysis does, which is not surprising as MIP measures pore entrance diameter, not the actual diameter.

Romero \& Simms (2008) also reported that, when a clay sample is intruded by mercury, the intruded void ratio estimated under the maximum applied pressure does not coincide with the estimated void ratio of the sample by, for example, the oedometer test. Differences mainly arise due to the non-intruded porosity with entrance pore sizes lower than $10 \mathrm{~nm}$ and the nondetectable porosity for pore sizes larger than $400 \mu \mathrm{m}$. There is also a concern about entrapping pores - pores that are accessible only through smaller ones (constricted porosity) - which are not detected until the smaller pores are penetrated. Therefore, the authors stated that the PSD is not necessarily the true distribution of pores, due to various issues including pore accessibility and sample treatment, yet it gives a useful quantitative characterization of the microstructure.

The result of the MIP test is the cumulative intrusion curve - volume of mercury intruded against pore entrance diameter. The Pore Size Density (PSD) of a sample is obtained by deriving this cumulative intrusion curve produced during the MIP test. Romero (1999) suggested the selection of equally spaced interval sizes of diameters to avoid distortion caused by the semi-log plot. However, there is an uncertainty associated with the selection of the interval size required to derive the PSD from raw cumulative data. Different interval sizes can lead to different PSD and there are no objective criteria to identify the 'right' interval size, making its selection more art than science.

Lopes et al. (2014) showed that clayey soils can be successfully fitted with a van Genuchtentype bi-modal cumulative distribution (Durner, 1994), which can be written as follows: 


$$
e_{M I P}=\sum_{i=1}^{k} e_{i}\left[\frac{1}{1+\left(\frac{D}{d_{i}}\right)^{n_{i}}}\right]^{1-\frac{1}{n_{i}}}
$$

where: $e_{M I P}$ is the ratio between the volume intruded and the volume of solids; $D$ is the pore entrance diameter; $e_{i}, d_{i}$, and $n_{i}$ are fitting parameters referring to mode size $\mathrm{i}$ and $\mathrm{k}$ refers to the number of modes existent, if bi-modal $\mathrm{k}=2$, etc. The assumption made by Lopes et al. (2014) is that cumulative intrusion data always need to be fitted by a bi-modal function even when the cumulative intrusion curve is apparently mono-modal. Figure 2.13a shows the fitting of an apparent mono-modal cumulative intrusion curve using a mono-modal and a bimodal function. It is clearly shown that the mono-modal function is not adequate to fit the experimental data.

If the parameters $e_{i}, d_{i}$, and $n_{i}$ are determined as best-fit parameters using non-linear regression, the frequency PSD can be derived as density function by deriving the cumulative intrusion given by Eq. 2.5:

$$
\frac{d e_{M I P}}{d(\ln D)}=\sum_{i=1}^{k} \frac{e_{i} \cdot n_{i} \cdot\left(\frac{D}{d_{i}}\right)^{n_{i}} \cdot\left(1-\frac{1}{n_{i}}\right) \cdot\left(\frac{1}{1+\left(\frac{D}{d_{i}}\right)^{n_{i}}}\right)^{1-\frac{1}{n_{i}}}}{\left(1+\left(\frac{D}{d_{i}}\right)^{n_{i}}\right)}
$$

The density function given by Eq. 2.6 overcomes the uncertainty associated with the selection of the interval size. This is clearly shown in Figure 2.13b, where the PSD of the MIP data presented in Figure 2.13a is obtained for three different interval sizes (irregular, 0.1 and $0.4 \mu \mathrm{m}$ ), as well as the derivative of the bi-modal fitting leading to significantly different frequency curves. Furthermore, Eq. 2.6 allows isolating the pore size density function associated with each individual class of pores if only one mode is considered. 


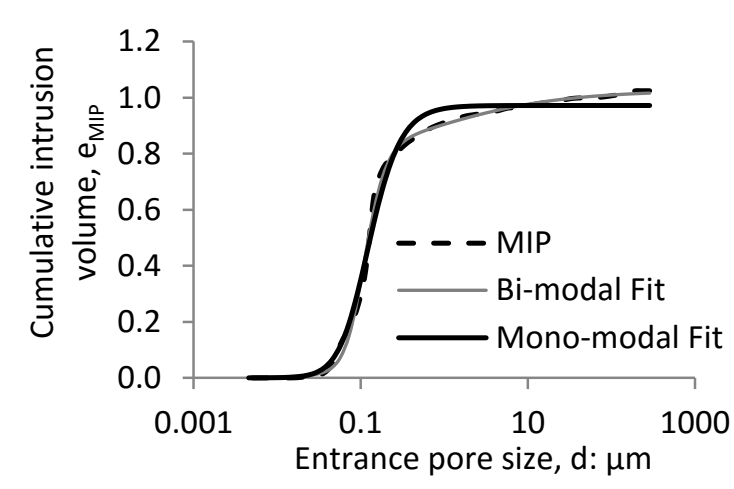

(a)

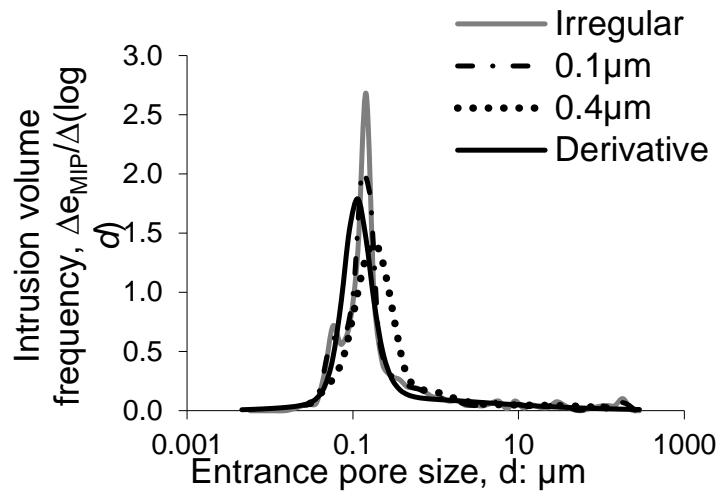

(b)

Figure 2.13 - (a) MIP data, bi-modal and mono-modal fitting functions - experimental data from reconstituted Kaolin sample (Pedrotti, 2016) and (b) Frequency PSDs generated with various interval sizes for a reconstituted Kaolin sample - experimental data from Pedrotti (2016)

\section{5 - CONSTITUTIVE MODELS}

The response of materials to load is an ordinary concern for civil engineers. Geotechnical engineers and engineering geologists are mainly interested in the behaviour of soils and rocks. The geo-engineer will generally be interested in the deformations that may occur when the loads that the soil and rocks are subjected to are small, the critical load that will bring about failure and what happens if failure does occur. Constitutive models for soil materials are a representation, usually mathematic, of the real soil behaviour.

Soils behave as an elastoplastic material, i.e., part of their strains is recoverable and another part is not; therefore, the most successfully used constitutive relationships for soils are elastoplastic. There are a number of different models that are able to reproduce idealized elastoplastic behaviour, such as rigid perfectly plastic, elastic-perfectly plastic, elastoplastic hardening and elastoplastic softening (Figure 2.14); the elastoplastic hardening model is the most popular amongst geo-engineers.
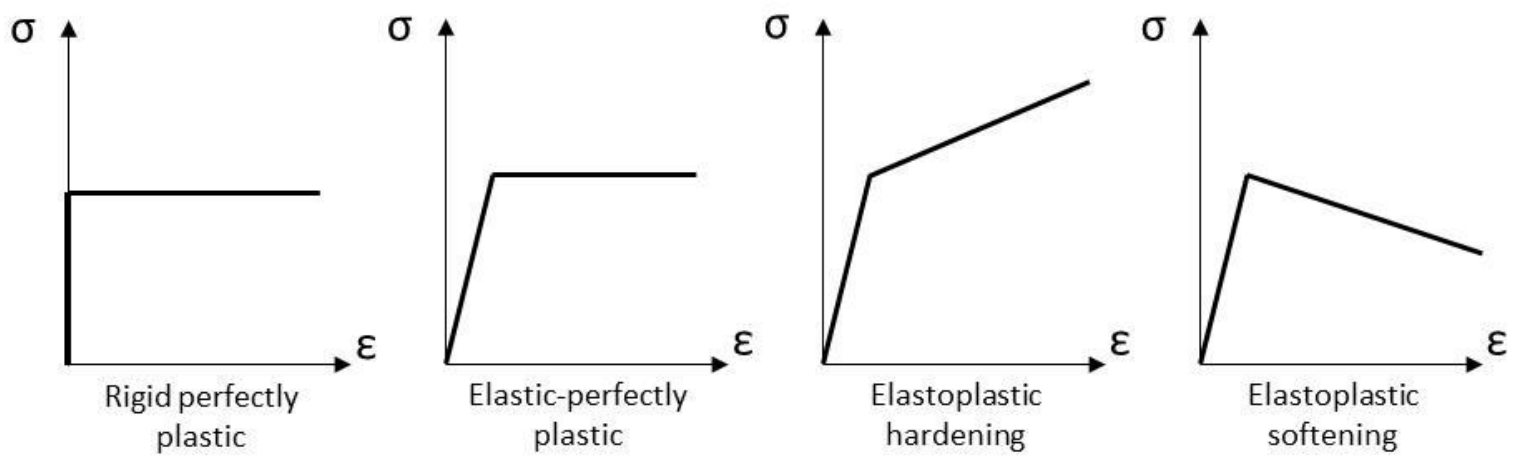

Figure 2.14 - Elastoplastic models where $\sigma$ represents stress and $\varepsilon$ strain (modified from Wood, 2004) 
In order to describe any hardening-plastic model, it is necessary to define four features, three of which (the top three in the following list) are also needed to define perfectly-plastic models. According to Wood (2004), these features are:

1. Elastic properties: relating changes in stress to changes in elastic strains. For simplicity, isotropic elastic behaviour may be assumed, which is not an essential assumption. Then

$$
\{\Delta \sigma\}=[\mathrm{D}]\left\{\Delta \varepsilon^{\mathrm{e}}\right\}
$$

where: $\Delta \sigma$ is the increment of stress, $\mathrm{D}$ is the constitutive matrix and $\Delta \varepsilon^{\mathrm{e}}$ is the increment of elastic strains.

2. Yield function: The yield function delimits the elastic domain (Figure 2.15). In the hardening models the boundary is not fixed and the yield surface is allowed to expand, depending on the history of loading of the soil, to accommodate the imposed stress changes. The yield criterion is written as a function of the hardening parameter $\chi$, as follows:

$$
\mathrm{f}(\{\sigma\}, \chi)=0
$$

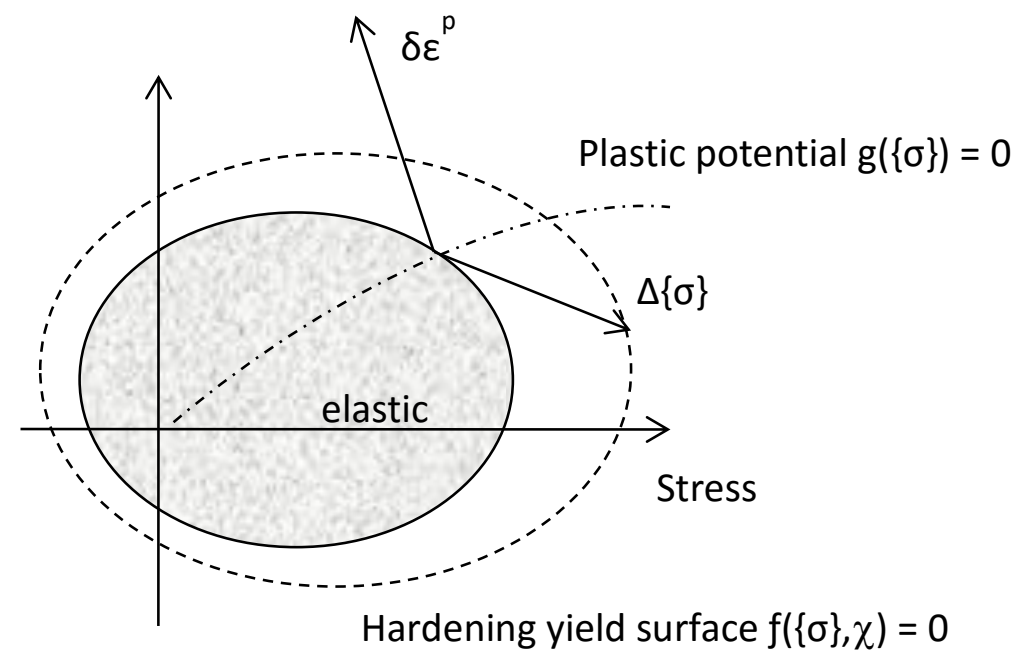

Figure 2.15 - Elastoplastic hardening model (after Wood, 2004)

There is a restriction in which, when plastic strains are occurring, the stress state must remain on the yield surface, known as consistency condition, expressed as: 


$$
\mathrm{f}(\{\sigma\}, \chi)=0 ; \delta \mathrm{f}=\frac{\partial \mathrm{f}^{\mathrm{T}}}{\partial\{\sigma\}^{\mathrm{T}}} \delta\{\sigma\}+\frac{\partial \mathrm{f}}{\partial \chi} \delta \chi=0
$$

3. Flow rule: The flow rule describes the mechanism of plastic deformations at every stress state. For simplicity it can be defined using a plastic potential function to determine the ratio of the strain components and to show that plastic strains are controlled by the current stresses at yield rather than by the stress increments that caused the yielding in the soil. The flow rule can then be written as:

$$
\delta \varepsilon^{\mathrm{p}}=\Lambda \frac{\partial \mathrm{g}}{\partial\{\sigma\}}
$$

where $\Lambda$ is a scalar that controls the magnitude of the plastic deformations and $g$ is the plastic potential function and controls the direction of the plastic deformations.

If $f=g$ the flow rule is said to be associated with the yield function; if the contrary applies then the flow rule is said to be non-associated. Assuming associated flow rule, calculations take simpler formats, as in this way the constitutive matrix and the global stiffness matrix are symmetric.

Flow rule plays an important role in constitutive modelling as it governs the dilatancy effects, which in turn have a significant influence on volume changes and on strength.

4. Hardening rule: The hardening rule is a relationship capable of associating the changes in size and or position of the yield surface with the magnitude of the plastic strain. In other words, it describes how the state parameter, $\chi$, varies with plastic straining $(\Lambda)$.

The Modified Cam Clay (MCC) model developed by Roscoe \& Burland (1968) revolutionized the soil modelling field. However, the model was developed originally for reconstituted samples of Kaolin Clay. Due to the fact that its applications are restricted to saturated and reconstituted soils, the MCC has been widely used as the base framework for the development of more complex models, extending its uses to unsaturated soil (Axelsson et al., 1989; Alonso et al., 1990; Kohgo et al., 1993; Wheeler \& Sivakumar, 1995; Loret \& Khalili, 2002, amongst others) and also structured (in this context structured meaning natural, undisturbed) or bonded soils (Gens \& Nova, 1993; Wheeler, 1997; Kavvadas \& Amorosi, 2000; Rouainia \& Wood, 2000; Baudet \& Stallebrass, 2001; Liu \& Carter, 2002; Nova et al., 2003). 
Gens \& Nova (1993) presented a general framework for bonded soils and weak rocks that incorporates bonding and destructuration as an extension of the MCC model. In addition to the real yield surface for the natural material (with bonding), another yield surface called intrinsic is introduced, to represent the size that the yield surface should have without bonding. The difference in size of the real yield surface and the intrinsic yield surface (expressed either as a ratio or as a difference) is a measure of the bonding effect. Increase in size of the intrinsic yield surface is related to plastic strain increments by a conventional hardening law for unbonded (reconstituted) soil, while the reduction of bonding effect is related to plastic strain increments by a destructuration law. Figure 2.16 shows the oedometer curve of a natural and a reconstituted soil, where the destructuration of the natural soil can be seen after it reaches its yield stress.

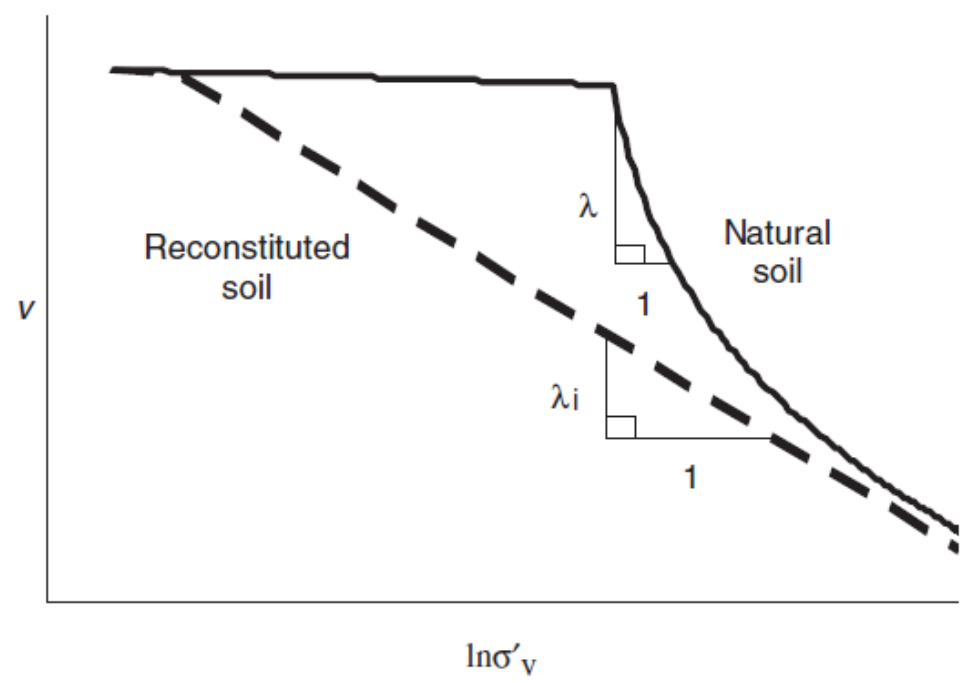

Figure 2.16 - Oedometer curve for natural and reconstituted soils (source: Karstunen et al., 2006)

Extensions and adaptations of the bonded model proposed by Gens \& Nova (1993) are easily found in the literature. One of these models is the S-CLAY1S model, which is also an extension of the S-CLAY1 model, which takes into account the soil anisotropy (Wheeler et al., 2003). In addition, the S-CLAY1S also incorporates the effect of bonding and destructuration. The model was proposed by Koskinen et al. (2002) and is characterized by a second yield surface in the same way as that proposed by Gens \& Nova (1993): a yield surface for the natural material with bonding and another one called intrinsic, which represents the size of the yield surface in the case of inexistence of bonding. The difference in size between the two yield surfaces is also a measure of the bonding effect. 
The three-dimension stress space yield surface is presented in Figure 2.17 and is expressed by the function:

$$
\mathrm{f}=\frac{3}{2}\left\{\left[\sigma_{\mathrm{d}}-\mathrm{p}^{\prime} \alpha_{\mathrm{d}}\right]^{\mathrm{T}}\right\}-\left\{\mathrm{M}^{2}-\frac{3}{2}\left[\alpha_{\mathrm{d}}\right]^{\mathrm{T}}\left[\alpha_{\mathrm{d}}\right]\right\}\left(\mathrm{p}^{\prime}{ }_{\mathrm{m}}-\mathrm{p}^{\prime}\right) \mathrm{p}^{\prime}=0
$$

where: $\sigma_{d}$ is a deviatoric stress tensor; $p$ ' is mean effective stress; $\alpha_{d}$ is a dimensionless second order tensor describing the fabric anisotropy (deviatoric fabric tensor); $M$ is the critical state value of the stress ratio in triaxial space; $p^{\prime}{ }_{m}$ defines the size of the natural yield surface of the clay.
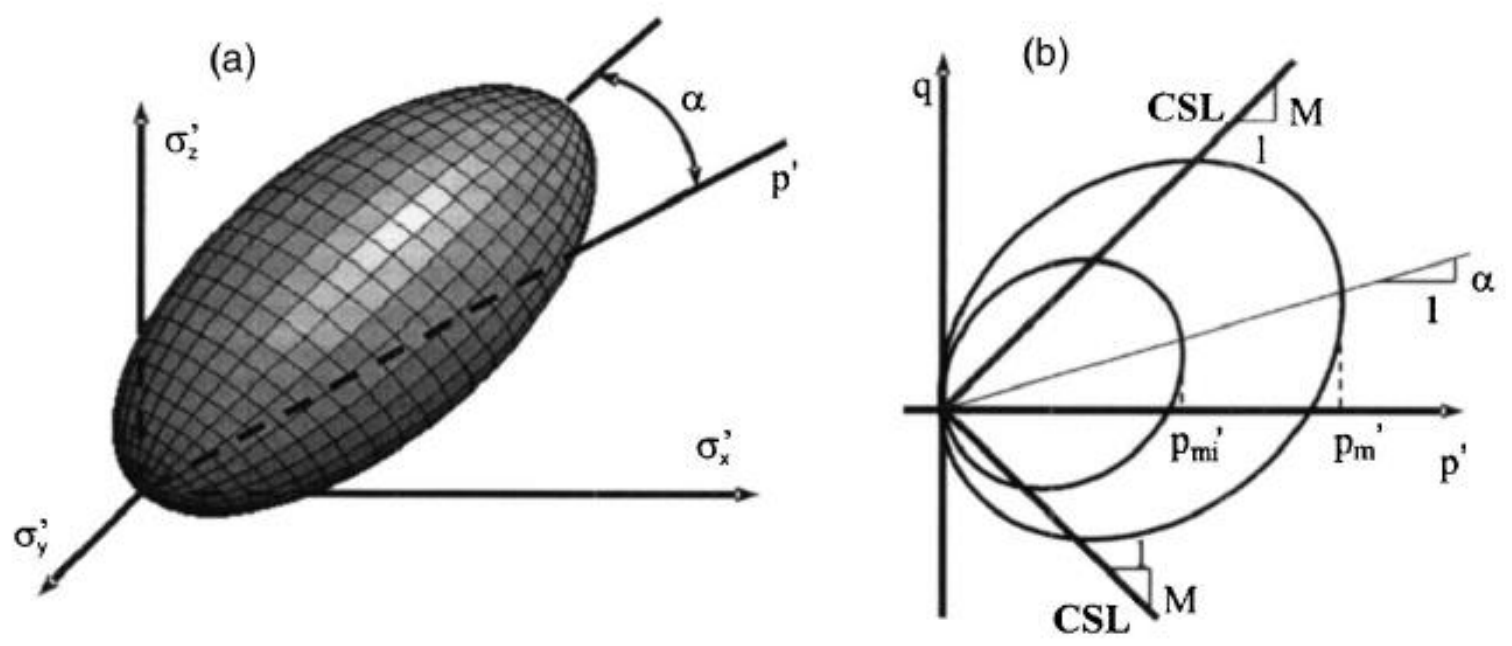

Figure 2.17 - S-CLAY1S yield surface in (a) 3-D stress space (b) triaxial stress space (source: Karstunen et al., 2005)

The effect of bonding is reproduced by the intrinsic yield surface, which has the same shape as the yield surface for the natural soil, except that the size of these two yield surfaces are different; however, they are related as follows:

$$
\mathrm{p}_{\mathrm{m}}^{\prime}=(1+\mathrm{x}) \mathrm{p}_{\mathrm{mi}}^{\prime}
$$

where: $p_{m}^{\prime}$ is the size of yield surface for the natural soil; $x$ is the amount of bonding; $p_{m i}^{\prime}$ is the size of the intrinsic yield surface.

The model has, then, three hardening laws, as follows: the first describes the increase in size of the intrinsic yield surface, the second describes the rotation of the yield surface due to plastic straining and the last represents the degradation of the bonding. 


$$
\begin{gathered}
\delta p_{m i}^{\prime}=\frac{v p_{m i}^{\prime}}{\lambda_{i}-\kappa} \delta \varepsilon_{v}^{p} \\
\delta \alpha_{d}=\mu\left[\left[\frac{3 \eta}{4}-\alpha_{d}\right]\left\langle\delta \varepsilon_{v}^{\mathrm{p}}\right\rangle+\beta\left[\frac{\eta}{3}-\alpha_{d}\right] \delta \varepsilon_{d}^{\mathrm{p}}\right] \\
\delta \mathrm{x}=-\mathrm{ax}\left[\left|\delta \varepsilon_{v}^{\mathrm{p}}\right|+\mathrm{b}\left|\delta \varepsilon_{\mathrm{d}}^{\mathrm{p}}\right|\right]
\end{gathered}
$$

where: $v$ is specific volume; $\lambda_{i}$ is the slope of the intrinsic normal compression line in the compression plane ( $\ln p^{\prime}-v$ space); $k$ is the slope of a swelling line in the compression plane; $\eta$ is the tensorial equivalent of the stress ratio, $\left(\eta=\sigma_{d} / p^{\prime}\right) ; \delta \varepsilon_{d}^{p}$ is the increment of plastic deviatoric strain. $\mu$ and $\beta$ control, respectively, the absolute rate at which $\alpha_{d}$ heads towards its current target value and the relative effectiveness of plastic deviatoric strains and plastic volumetric strains in rotating the yield surface; $a$ controls the absolute rate of destructuration; and $b$ controls the relative effectiveness of plastic deviatoric strains and plastic volumetric strains in destroying the bonding.

Karstunen \& Koskinen (2004) suggested two possible ways to determine the value of the initial amount of bonding, $\mathrm{x}_{0}$, for natural soils. A conservative estimation can be derived from the sensitivity measurement, which is taken as a lower bound estimate of $1+\mathrm{x}_{0}$, due to the fact that some portion of the bonding can be lost during sampling and testing. A second way is based on the initial void ratio and the size of the initial yield curve for natural soil ( $e_{0}$ and $\mathrm{p}_{\text {mo }}$ ) and the position of the intrinsic normal compression line for reconstituted soil in lnp'-e space. The values of $\mathrm{x}_{0}$ for different samples can vary significantly, since different samples of the same clay can have different void ratios due to disturbance and/or variations in sampling depth and location; thus a geometrical average of $\mathrm{x}_{0}$ should be used.

In other words, the amount of bonding in S-CLAY1S represents the difference between the mechanical behaviour of two samples, the reconstituted and the natural samples. However, this concept can be extrapolated to represent differences in mechanical behaviour amongst other types of samples, as presented in the following chapters of this work. 


\section{3 - MATERIALS AND METHODS}

This chapter presents all the soil materials used in this research as well as their characterization. Moreover, this chapter also discusses the tests involved in determining the microstructure that influences the mechanical behaviour of the soils studied and the numerical modelling used to reproduce the behaviour analysed in laboratory tests.

First, all of the relevant properties of the materials studied were assessed and presented, including geotechnical and mineralogical properties and basic information concerning the origin and/or extraction point of the materials.

Regarding the tests, firstly the different samples prepared for laboratory tests are presented, which include: reconstituted, remoulded, $\mathrm{pH} 9$ and undisturbed (only for one of the materials tested) samples. The first test presented is the sedimentation test, which was carried out in order to assess the differences in sedimentation in distilled water and in various concentrations of potassium hydroxide $(\mathrm{KOH})$ solution, i.e., with increasing pHs. Following that, samples had their initial matric suction measured with tensiometers, as it is believed that the preparation of the samples induces the appearance of suction even in saturated samples. The subsequent test is the consolidation performed in reconstituted, remoulded, $\mathrm{pH} 9$ and undisturbed specimens. Each of these four states of samples was consolidated at different loads for microstructural testing. The technique chosen to prepare the specimens for the microstructural testing was freeze-drying, due to the nature of the materials and state of the samples tested, and the procedure followed is described in this chapter. Mercury Intrusion Porosimetry (MIP) was the test chosen to study the structure of the materials. MIP was found to be the most appropriate test due to the type of results it provides.

The results of the MIP test, the intrusion curves, were fitted with a van Genuchten-type equation (Lopes et al., 2014) for the reasons discussed in Chapter 2. Finally, the consolidation results were modelled with a modification of S-CLAY1S (Koskinen et al., 2002) constituted model, which takes into account the structure of the materials tested.

\section{1 - MATERIAL PROPERTIES}

The materials used in this research were the two commercially available clays mined from Cornwall, England, and supplied by Imerys Minerals: Kaolin Clay and Ball Clay, the latter being a sub-product of the Kaolin Clay (Figure 3.1). A natural tropical soil was used, 
Brasilia Soil (Figure 3.2), extracted from the experimental field of the University of Brasilia in Brasilia, Brazil.

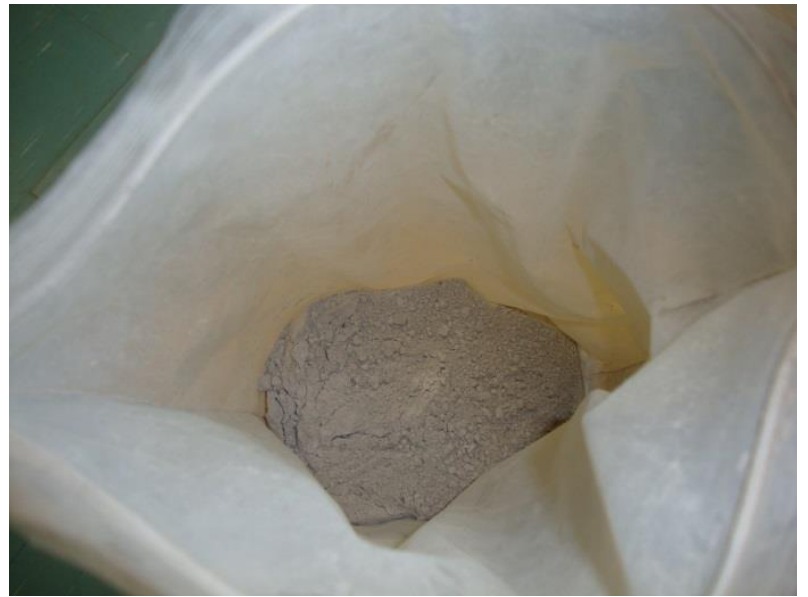

(a)

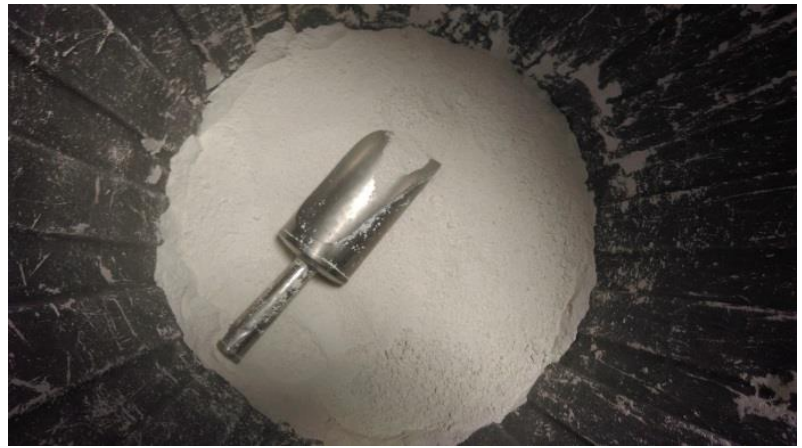

(b)

Figure 3.1 - (a) Ball Clay and (b) Kaolin Clay

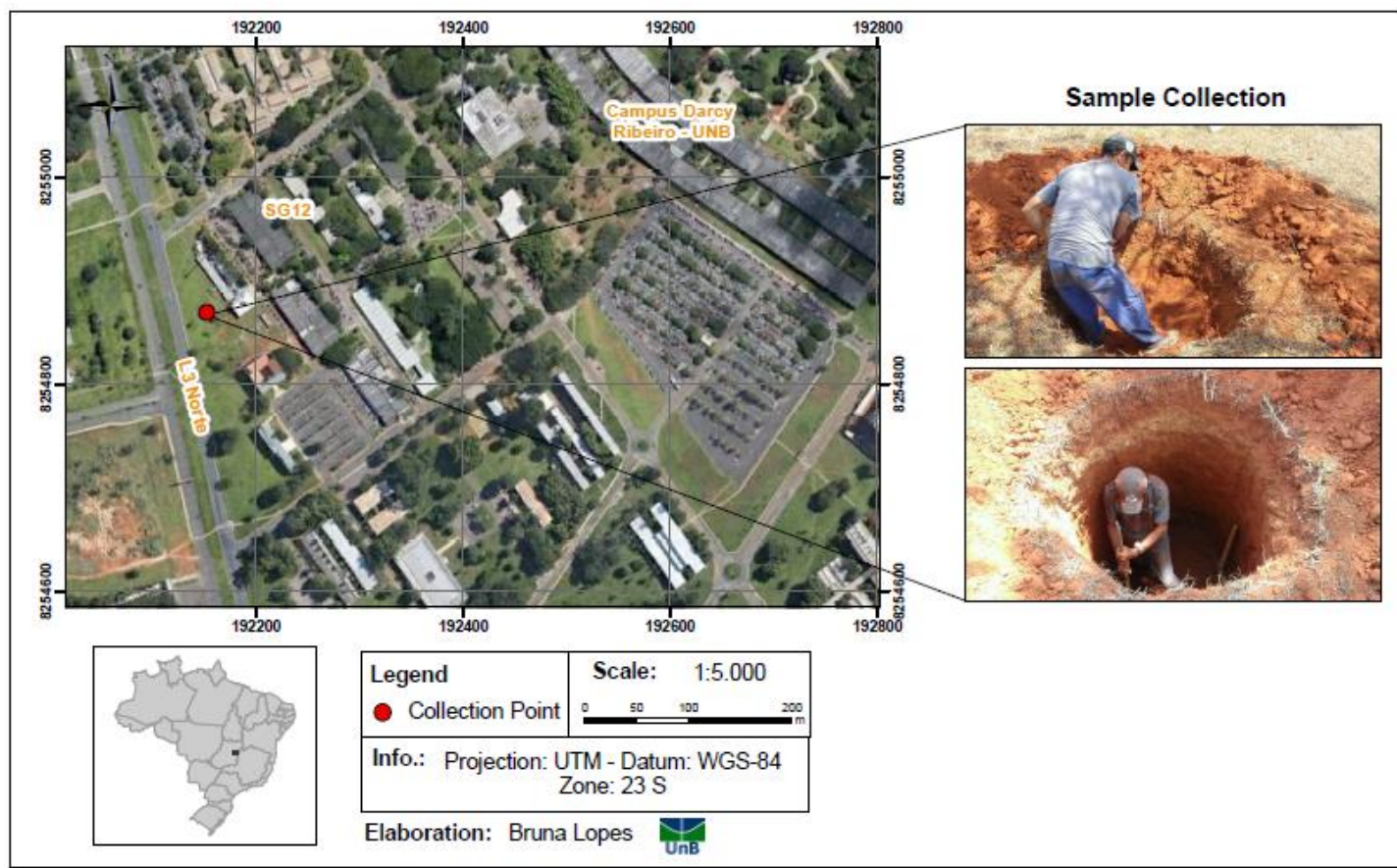

(a)

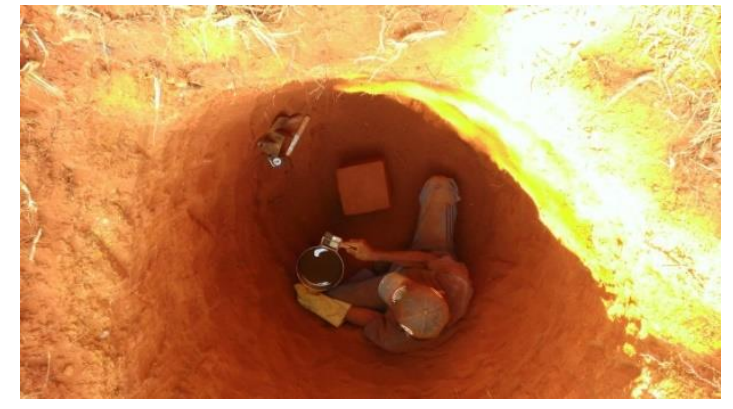

(b)

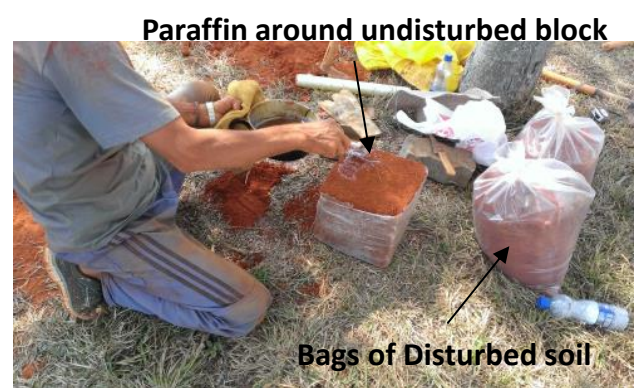

(c)

Figure 3.2 - Removal of the Brasilia Soil in the experimental field of University of Brasilia, Brasilia, Brazil (a) Location map of the extraction point (source: Google Earth, 2013) (b) Removal of the undisturbed block at $2 \mathrm{~m}$ 
deep (c) Bags of disturbed soil and undisturbed block being covered with paraffin and wrapped in cling film for transportation

Table 3.1 shows the three tests used to characterize the materials used in this research and the respective standards followed, while

Table 3.2 presents the most relevant properties of the soils tested. The specific gravities of the three materials were obtained from previous studies conducted with samples of Kaolin Clay (Tarantino \& De Col, 2008; Pedrotti, 2016), Ball Clay (Imerys Minerals, 2015) and Brasilia Soil (Borges, 2014). The pH9 water content was determined by this research using the trial and error approach, taking into account the experience provided by Pedrotti (2016) in samples of Kaolin Clay. The pH9 water content is then the highest value that can be sustained by the material without producing significant extrusion in the consolidation test. The undisturbed water content of the Brasilia Soil was measured by the loss of water in the process of drying a small portion of the undisturbed material in the oven. Furthermore,

Table 3.3 shows the mineralogy of the soils. Finally, Figure 3.3 shows the particle size distribution with dispersant of the three soils.

Table 3.1 - Tests used to characterize the materials

\begin{tabular}{lll}
\hline \multicolumn{1}{c}{ Test } & \multicolumn{1}{c}{ Method } & \multicolumn{1}{c}{ Standard } \\
\hline Liquid Limit & Casagrande Apparatus & BS1377-2(1990) \\
Plastic Limit & Rolling thread of soil & BS1377-2 (1990) \\
Particle Size Distribution & Sieves \& Hydrometer & BS1377-2 (1990) \\
\hline
\end{tabular}

Table 3.2 - Soil Properties

\begin{tabular}{lccc}
\hline \multicolumn{1}{c}{ Properties } & Ball & Brasilia & Kaolin \\
& Clay & Soil & Clay \\
\hline Specific gravity, $\mathrm{G}_{\mathrm{s}}[-]$ & 2.600 & 2.740 & 2.605 \\
Liquid Limit, $\mathrm{w}_{\mathrm{L}}[\%]$ & 63 & 42 & 64 \\
Plastic Limit, $\mathrm{w}_{\mathrm{P}}[\%]$ & 24 & 36 & 32 \\
Plasticity Index, $\mathrm{I}_{\mathrm{P}}[\%]$ & 39 & 6 & 32 \\
pH9 water content, $\mathrm{w}_{\mathrm{pH} 9}[\%]$ & 47 & 31.5 & 55 \\
Undisturbed water content, $\mathrm{w}_{\text {und }}[\%]$ & - & 21 & - \\
\hline
\end{tabular}

Table 3.3 - Mineralogy of the Soils

\begin{tabular}{ll}
\hline \multicolumn{1}{c}{ Soil } & \multicolumn{1}{c}{ Mineralogy } \\
\hline \multirow{2}{*}{ Kaolin Clay } & Kaolinite with minor amounts of mica, quartz and feldspar or \\
& ilmenite (Imerys Minerals, 2015) \\
Ball Clay & Kaolin with varying amounts of mica, feldspar, quartz and \\
& organic matter (Imerys Minerals, 2015) \\
& $42-50 \%$ kaolinite, 18-20\% gypsite, 16-22\% quartz, 4-9\% illite, \\
Brasilia Soil & $4-8 \%$ goethite and 1-10\% hematite. 44\% iron and 36\% \\
& aluminium (Martins, 2000) \\
\hline
\end{tabular}




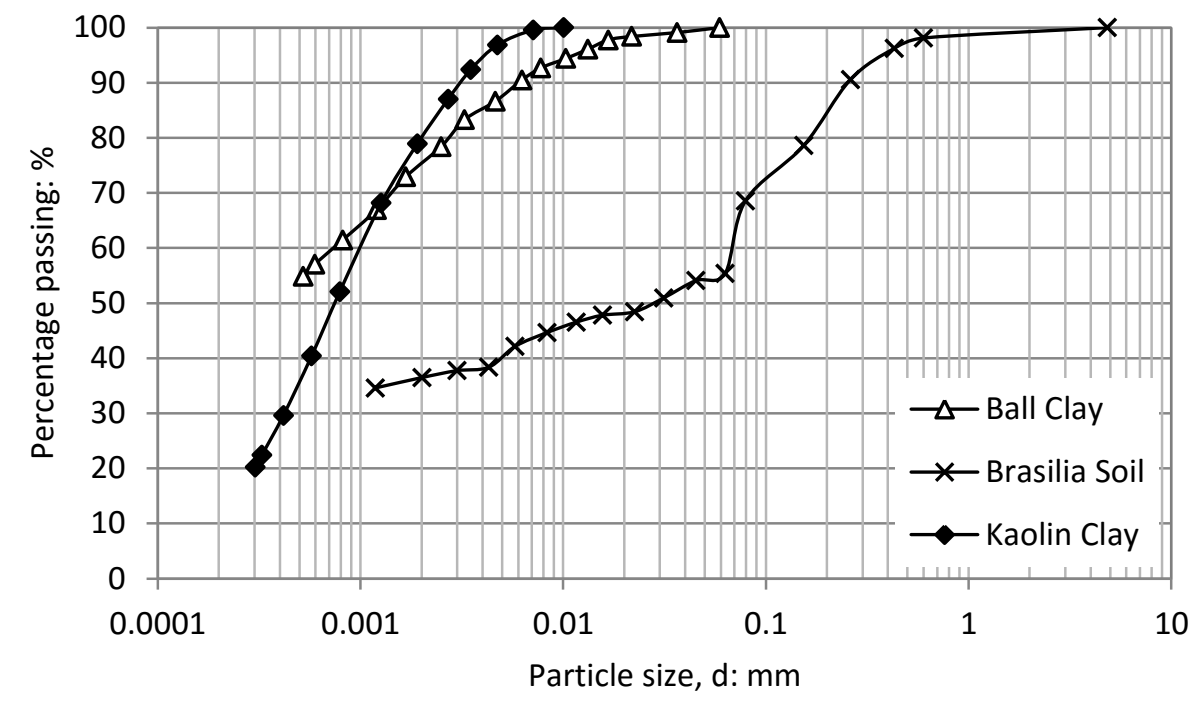

\begin{tabular}{lccccc}
\hline \multicolumn{1}{c}{ Soil } & \% Clay & \% Silt & \% Fine Sand & \% Medium Sand & \% Coarse Sand \\
\hline Kaolin Clay & 80 & 20 & - & - & - \\
Ball Clay & 74 & 26 & - & - & - \\
Brasilia Soil & 36 & 19 & 35 & 8 & 2 \\
\hline
\end{tabular}

Figure 3.3 - Particle size distribution curves according to BS1377-2 (1990)

As Figure 3.3 suggests, Kaolin and Ball Clay could both be described as Silty Clay soils, while Brasilia soil could be described as Clayey Sand soil. According to the Unified Soil Classification System (USCS), Kaolin and Ball Clay are classified as clay of high plasticity $(\mathrm{CH})$ and Brasilia Soil as clay of low plasticity (CL). However, according to the AASHTO Soil Classification System, Kaolin and Ball Clays are classified as A-7 Clayey Soils, while Brasilia Soil is classified as A-5 Silty soil.

The Kaolin Clay material was selected for this study because it is basically composed only of kaolinite mineral; therefore it is a pure and classic material also chosen to be used in the development of the constitutive model Modified Cam Clay (Roscoe \& Burland, 1968). The choice of the Ball Clay material is because, although very similar to the Kaolin Clay, this material is not as pure as the Kaolin Clay. Finally, the reason the Brasilia Soil was chosen is due to the fact that it is a very complex soil, exhaustively studied by the geotechnical research group of the University of Brasilia and this material can also be used as validation of the results observed for the clays, since the kaolinite mineral is also heavily present in the mineralogy of the Brasilia Soil. 


\section{2 - +SPECIMENS PREPARATION AND TESTING PROGRAMME}

All experiments of this thesis were carried out at the laboratories of the Department of Civil and Environmental Engineering and the Department of Mechanical and Aerospace Engineering of the University of Strathclyde in Glasgow, UK.

\subsection{1 - SPECIMENS PREPARATION}

Samples were prepared to reproduce the soil at distinct states: reconstituted, remoulded and $\mathrm{pH} 9$. Reconstituted samples were prepared by mixing the dried soil with distilled water in such a way that the water content was between the soil liquid limit $\left(\mathrm{w}_{\mathrm{L}}\right)$ and 1.5 times this value. Ball and Kaolin Clay samples were reconstituted at $1.5 \mathrm{w}_{\mathrm{L}}$ (Figure 3.5a and Figure 3.7a respectively). Brasilia Soil could not be reconstituted at this water content as the mixture was not homogenous and the solids tend to segregate as soon as the mixing stops (Figure 3.6a). For this reason, reconstituted samples of Brasilia Soil were prepared at $1.25 \mathrm{w}_{\mathrm{L}}$ (Figure 3.6b).

Remoulded samples were prepared in the same way; however, the water content was lower than the liquid limit and the degree of saturation was always greater than $80 \%$ (Ball Clay $82 \%$, Kaolin Clay $-86 \%$ and Brasilia Soil $-81 \%$ ), but never lower than $0.7 \mathrm{w}_{\mathrm{L}}$. All three soils had remoulded samples prepared at $0.7-0.75 \mathrm{w}_{\mathrm{L}}$ (Figure 3.5b, Figure 3.6c, Figure 3.7b). Samples with $\mathrm{pH}$ altered were prepared in such a way as to sustain the highest water content possible, ensuring the whole mixture was at $\mathrm{pH} 9$ (Figure 3.5c, Figure 3.6d, Figure 3.7c). Brasilia Soil had a fourth specimen that was prepared by moulding the undisturbed block with a cutter ring (Figure 3.6e and f).

Specimens of these samples were prepared for consolidation and microstructural testing. Furthermore, reconstituted and remoulded samples of Kaolin Clay were prepared at a variety of different water contents for more detailed consolidation studies.

The dry density of the samples was calculated, according to the following expression, at the beginning and at the end of the consolidation test and plotted against water content in the graphs of Figure 3.4 .

$$
\rho_{\mathrm{d}}=\frac{\rho_{\mathrm{w}} \mathrm{G}_{\mathrm{s}}}{1+\mathrm{e}}
$$

where: $\rho_{d}$ is the dry density of the soil, $\rho_{\mathrm{w}}$ is the density of water, $\mathrm{G}_{\mathrm{s}}$ is the specific gravity and $\mathrm{e}$ is the void ratio. 


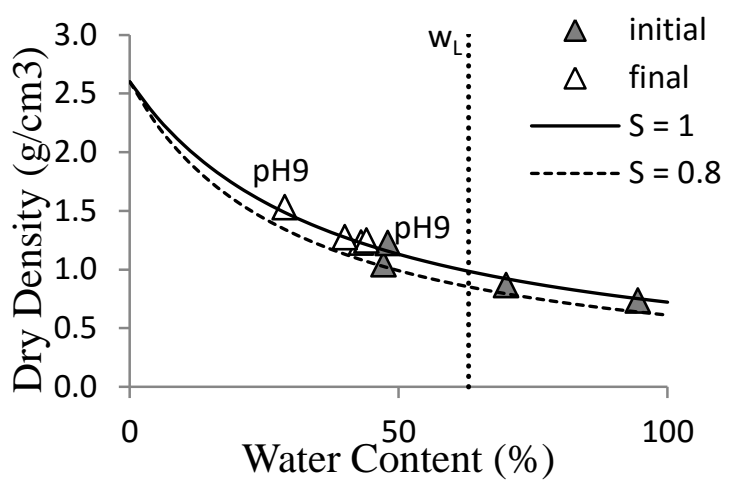

(a)

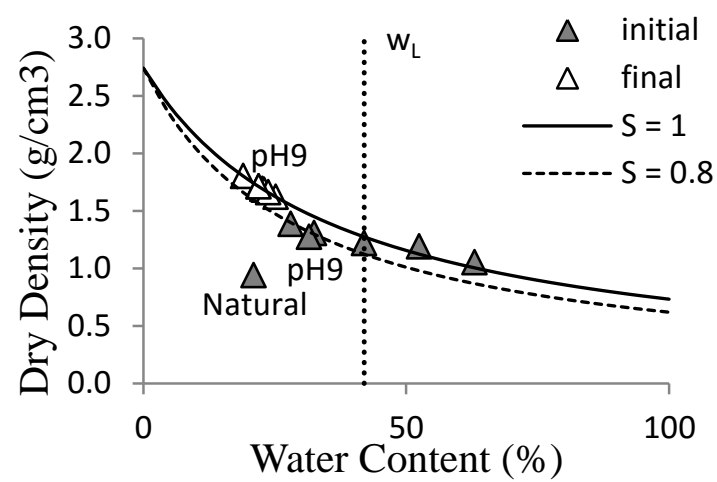

(b)

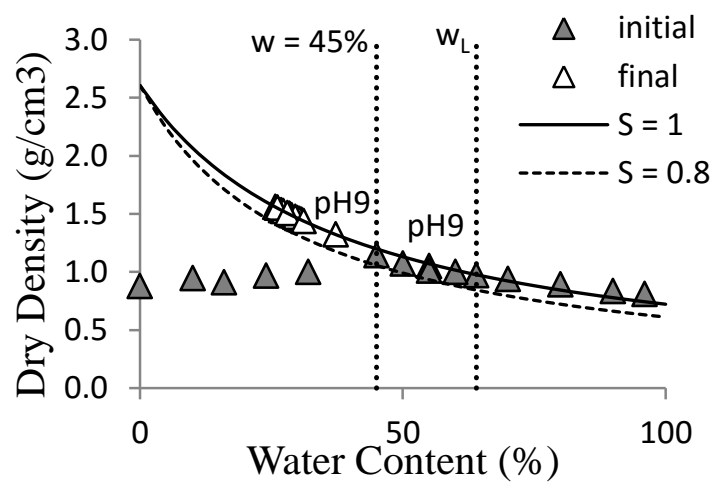

(c)

Figure 3.4 - Compaction plot, $\rho_{\mathrm{d}} \mathrm{X}$ w (a) Ball Clay samples (b) Brasilia Soil Samples (c) Kaolin Clay samples

Figure 3.4 shows that all of the reconstituted, remoulded and $\mathrm{pH} 9$ samples have more than $80 \%$ degree of saturation at the beginning of the consolidation test and $100 \%$ saturation at the end of the test.

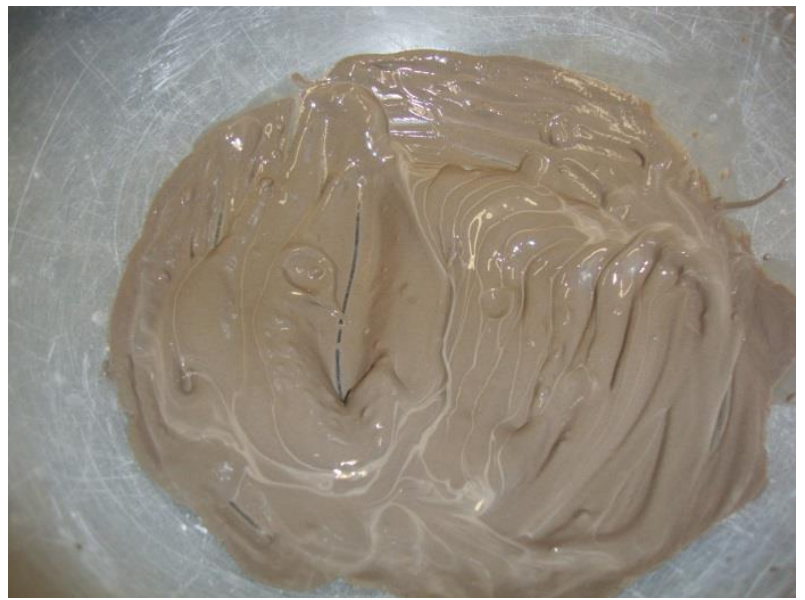

(a) 


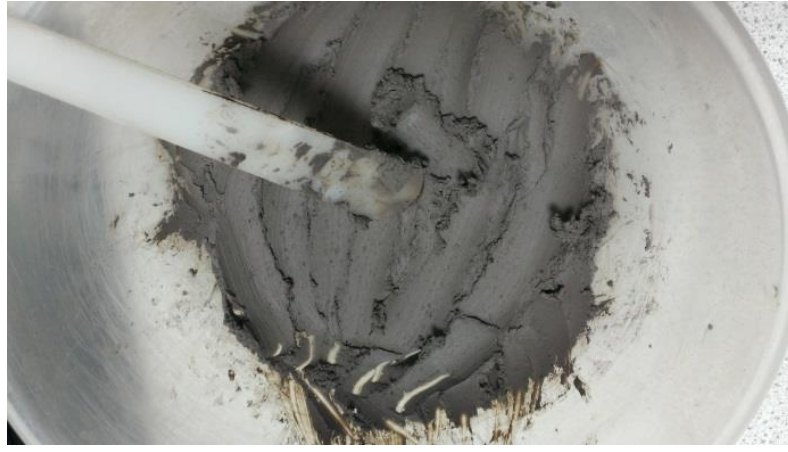

(b)

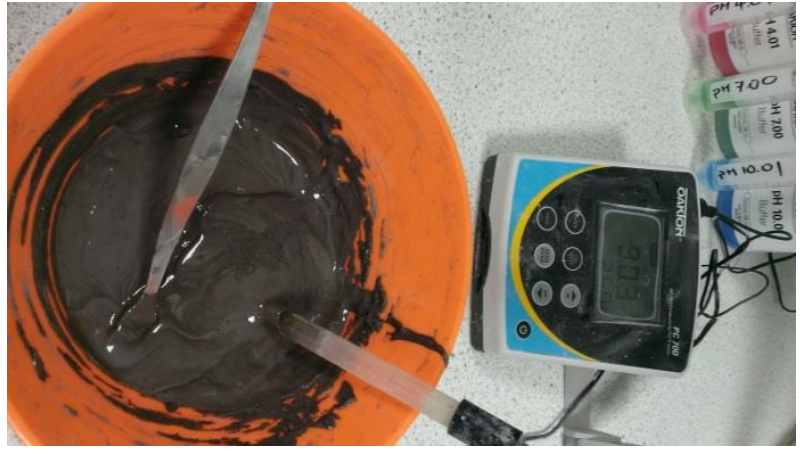

(c)

Figure 3.5 - Ball Clay sample preparation (a) Reconstituted sample, $w=94.5 \%$ (b) Remoulded sample, $\mathrm{w}=$ $47.25 \%$ (c) $\mathrm{pH} 9$ sample, $\mathrm{w}=46 \%$

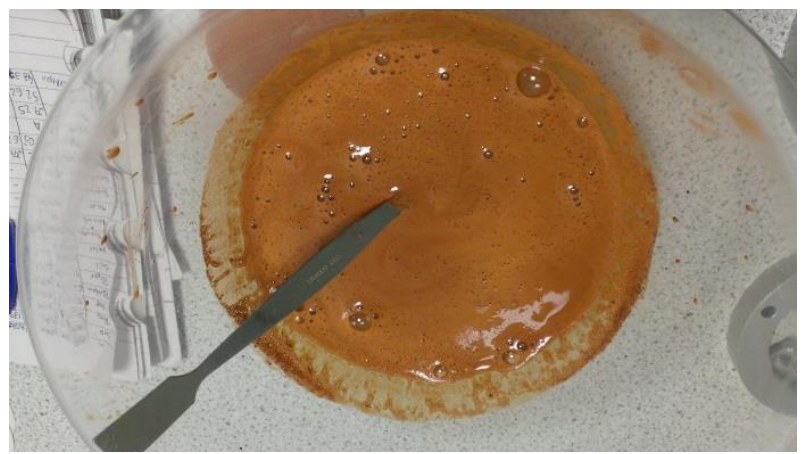

(a)

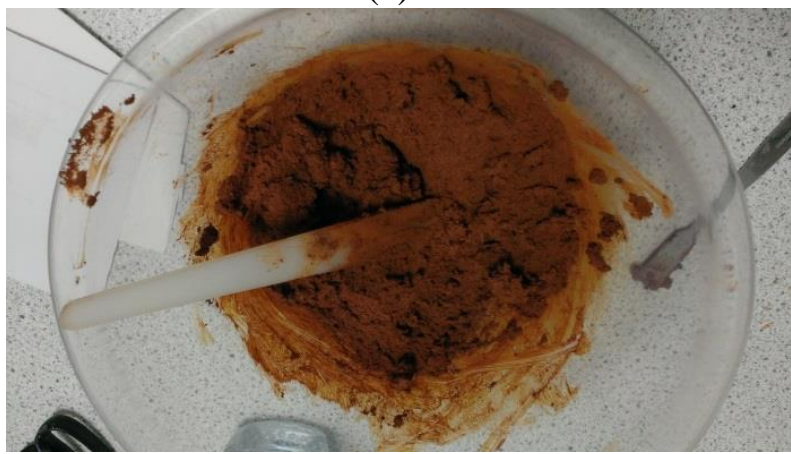

(c)

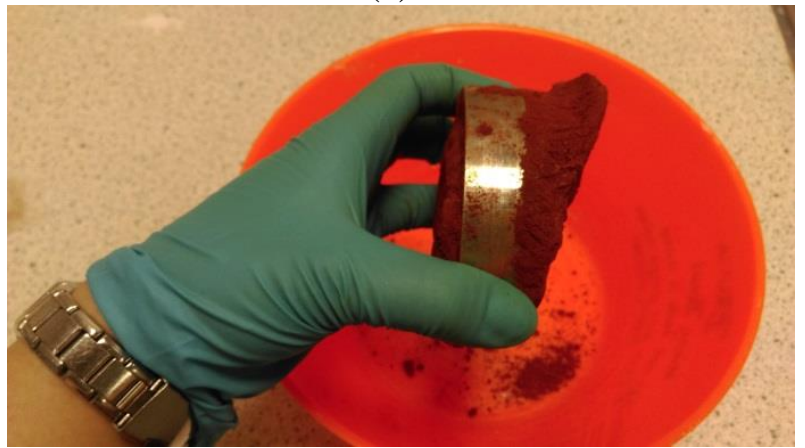

(e)

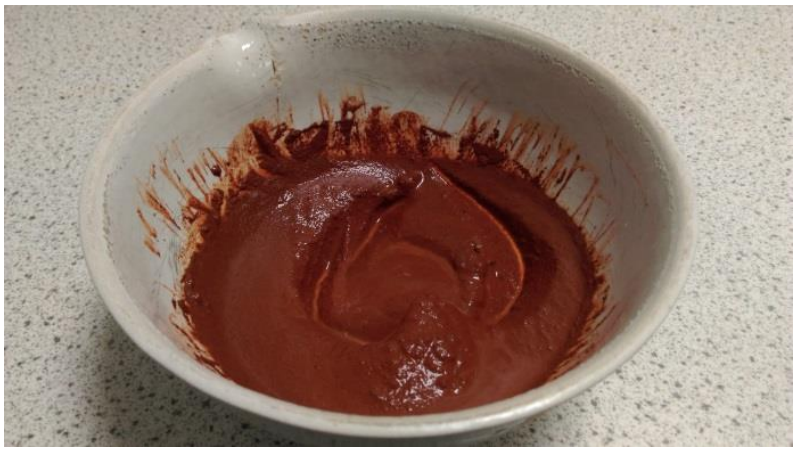

(b)

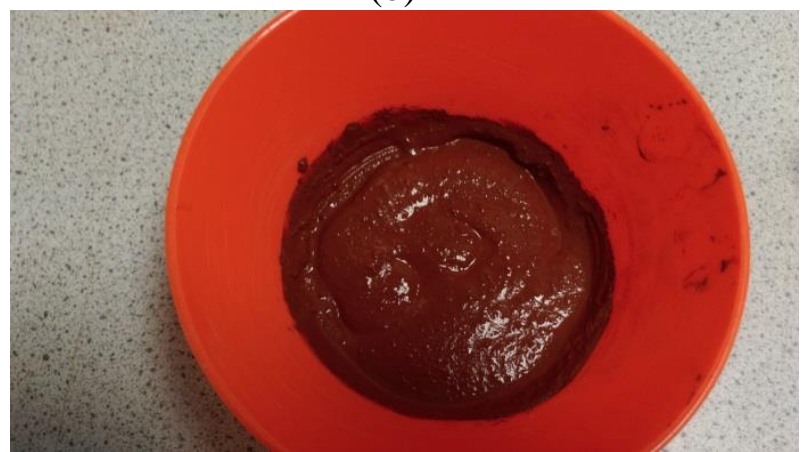

(d)

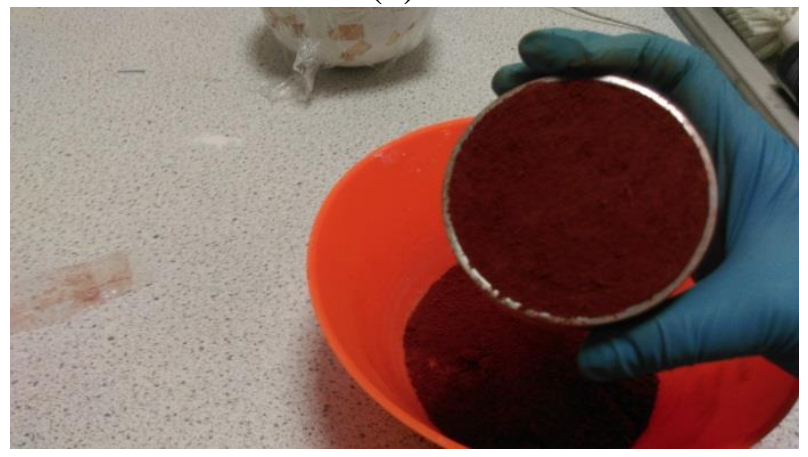

(f)

Figure 3.6 - Brasilia Soil sample preparation (a) Reconstituted sample, $w=63 \%$ (b) Reconstituted sample, $w=$ $52.5 \%$ (c) Remoulded sample, $\mathrm{w}=32.5 \%$ (d) $\mathrm{pH} 9$ sample, $\mathrm{w}=31.5 \%$ (e) and (f) Undisturbed sample preparation 


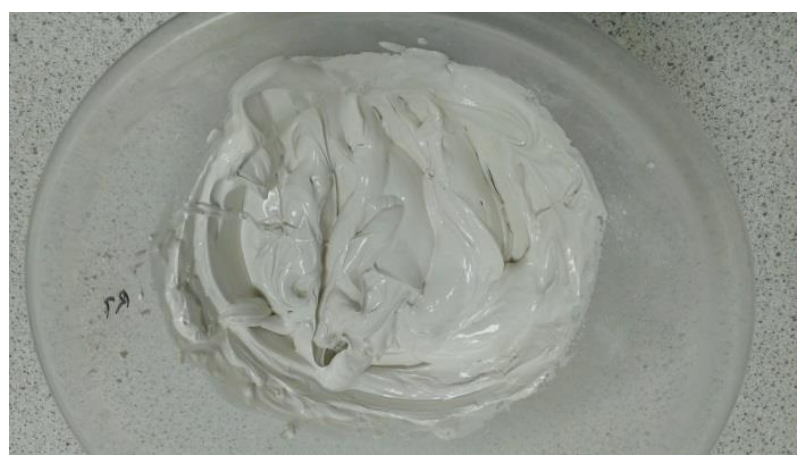

(a)

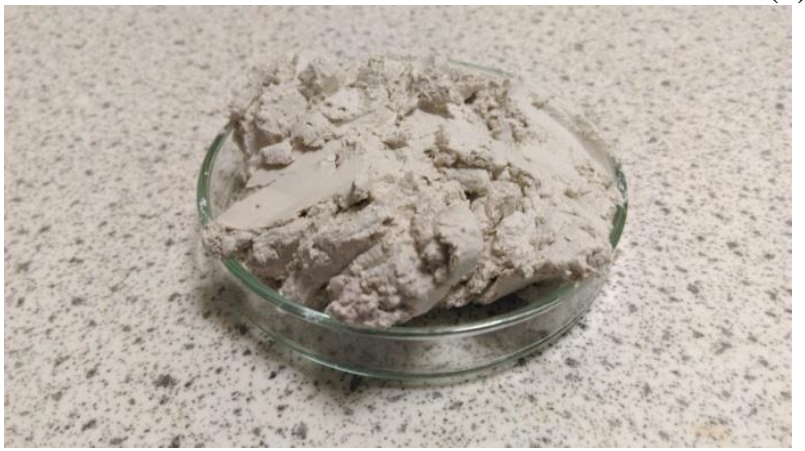

(b)

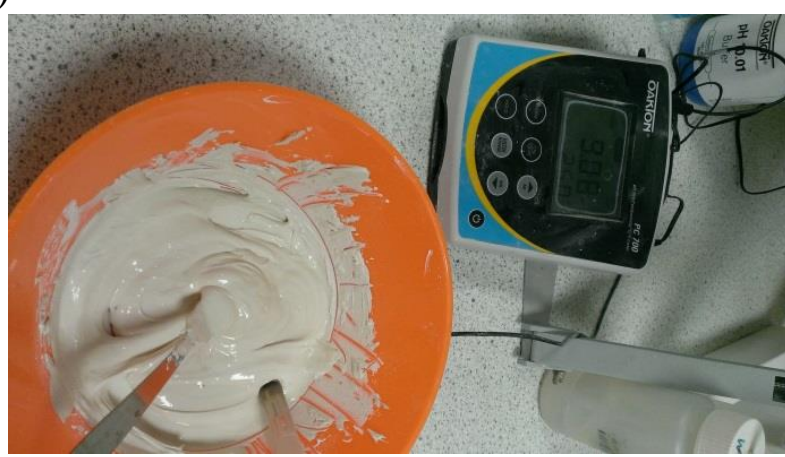

(c)

Figure 3.7 - Kaolin Clay sample preparation (a) Reconstituted sample, $w=96 \%$ (b) Remoulded sample, $w=$ $45 \%$ (c) $\mathrm{pH} 9$ sample, $\mathrm{w}=55 \%$

\subsection{2 - SEDIMENTATION TEST}

Sedimentation tests of the three soils were carried out with various molar concentrations of potassium hydroxide $(\mathrm{KOH})$ solutions in order to assess the influence of the changes in $\mathrm{pH}$ on the particles' associations. Sedimentation tests were performed following the British Standard BS 1377-2 specifications.

The void ratio of the final sediment was obtained by letting suspensions sediment in $50 \mathrm{ml}$ backers. Following the procedure adopted by Pedrotti (2016), all the suspensions were prepared at the same time and measurements of the final height of the sediment were also taken at the same time, when the slower suspension showed the same reading for two consecutive days. To obtain the void ratio of the final sediment, the following equation is applied:

$$
\begin{gathered}
\mathrm{e}=\frac{\mathrm{V}_{\mathrm{V}}}{\mathrm{V}_{\mathrm{S}}}=\frac{\mathrm{V}_{\mathrm{T}}-\mathrm{V}_{\mathrm{S}}}{\mathrm{V}_{\mathrm{S}}} \therefore \mathrm{V}_{\mathrm{S}}=\frac{\mathrm{M}_{\mathrm{S}}}{\mathrm{G}_{\mathrm{s}}} \\
\mathrm{e}=\frac{\mathrm{V}_{\mathrm{T}}-\left(\mathrm{M}_{\mathrm{S}} / \mathrm{G}_{\mathrm{S}}\right)}{\left(\mathrm{M}_{\mathrm{S}} / \mathrm{G}_{\mathrm{S}}\right)}
\end{gathered}
$$


where: $\mathrm{e}$ is the void ratio of the final sediment, $\mathrm{V}_{\mathrm{V}}$ is the volume of voids, $\mathrm{V}_{\mathrm{T}}$ is the total volume of sediment, $V_{S}$ is the volume of solids, $M_{S}$ is the mass of solids added and $G_{S}$ is the specific gravity.

\subsection{3 - SUCTION MEASUREMENT}

Tensiometers were used to assess the value of matric suction induced in the preparation of a few samples of all soils studied. Figure 3.8a shows the schematic layout of the tensiometers used, while Figure $3.8 \mathrm{~b}$ shows the setup to keep the tensiometers' porous ceramic saturated at the Geomechanics Laboratory of the Department of Civil and Environmental Engineering.

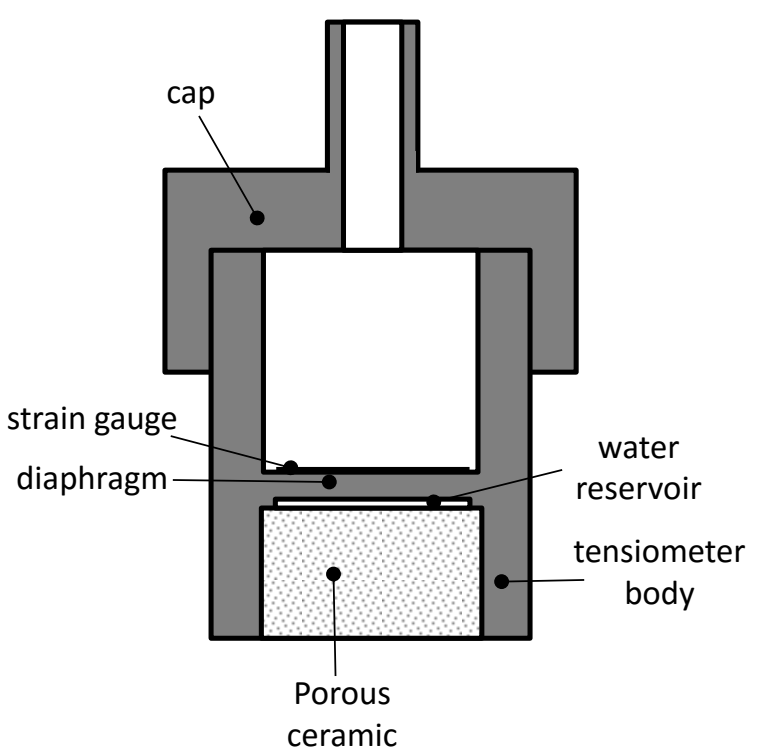

(a)

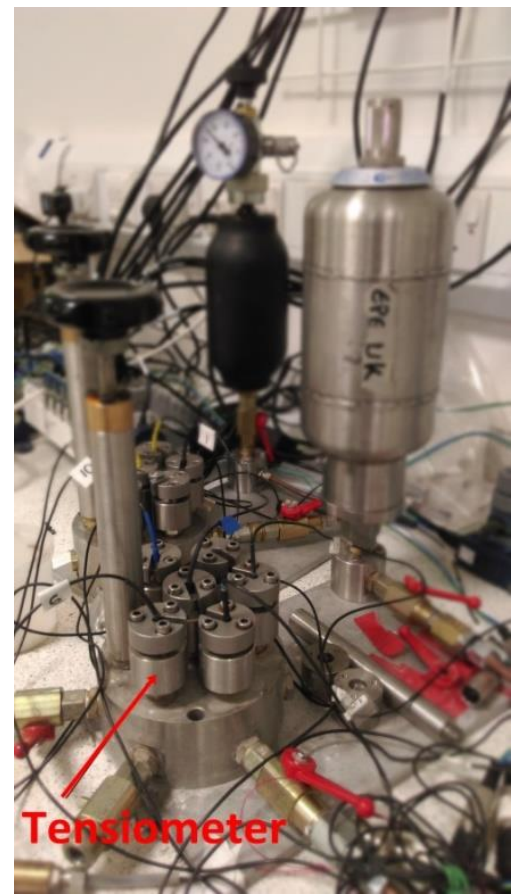

(b)

Figure 3.8 - Tensiometer (a) Schematic layout (modified from Tarantino \& Mongiovi, 2002) (b) Setup in the Geomechanics laboratory of the University of Strathclyde

The tensiometer designed and constructed at the University of Trento (Tarantino \& Mongiovi, 2002) and used at the University of Strathclyde is essentially similar to the tensiometer manufactured at Imperial College, with some modifications (Tarantino \& Mongiovi, 2002). The measurement diaphragm and the porous ceramic interface are the two key elements that control the performance of the tensiometer. The major drawbacks of these instruments are the water cavitation, the high air-water interface and the saturation of the porous ceramic, since if the porous ceramic is not adequately saturated it may lead to inaccurate results that might be difficult to detect. These tensiometers have been extensively 
used in studies at the Geomechanics laboratory of the University of Strathclyde, producing reliable results. Calibration procedures for direct measurement of matric suction can be found in detail in Tarantino \& Mongiovì (2003). Figure 3.9 shows the schematic layout of the box used to carry out the suction measurements. The box is equipped with an O-ring to ensure airtightness. The experimental procedure to carry out tensiometer measurement is described in Tarantino \& Mongiovì (2001). Two quick cycles down to -1,000kPa were applied prior to the measurement and the differences in the pressures recorded were less than $3 \mathrm{kPa}$. Two tensiometers were placed in each sample to ensure the trustworthiness of the results.

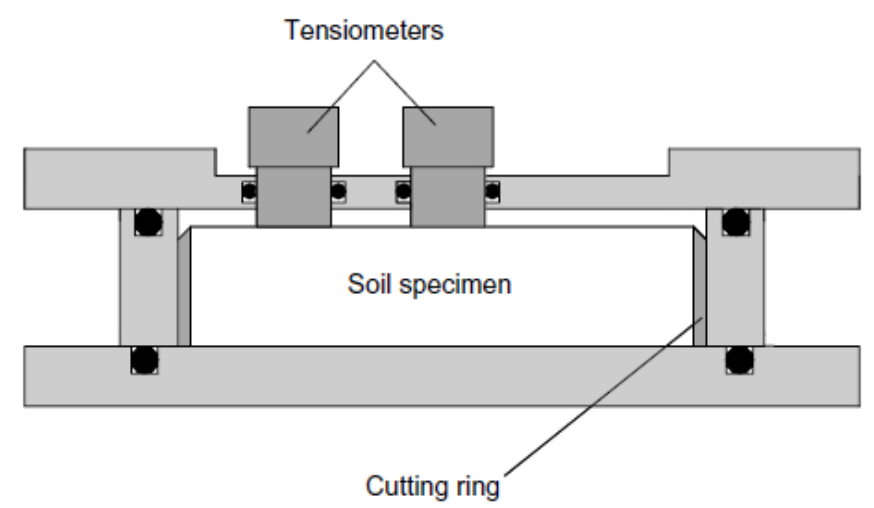

Figure 3.9 - Schematic layout of the Suction Measurement box (source: Tarantino \& Mongiovi, 2003)

\subsection{4 - ONE-DIMENSIONAL COMPRESSION TESTS}

Two pieces of equipment were used to assess the one-dimensional compression behaviour of the materials tested: the traditional oedometer at incremental loads and the constant rate of strain (CRS) consolidometer. Both pieces of equipment are available at the Geomechanics Laboratory of the Department of Civil and Environmental Engineering (Figure 3.10).

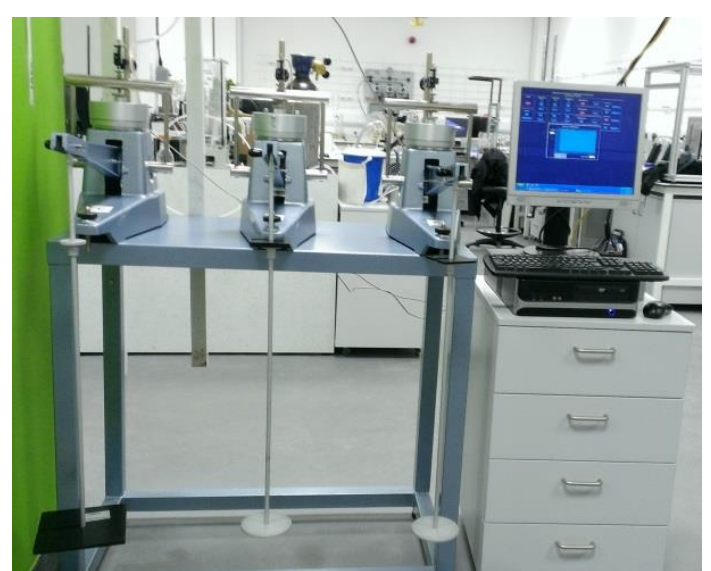

(a)

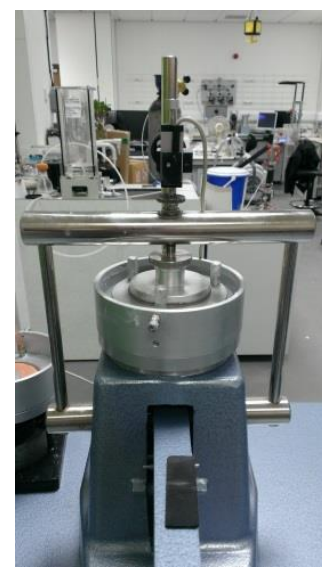

(b) 


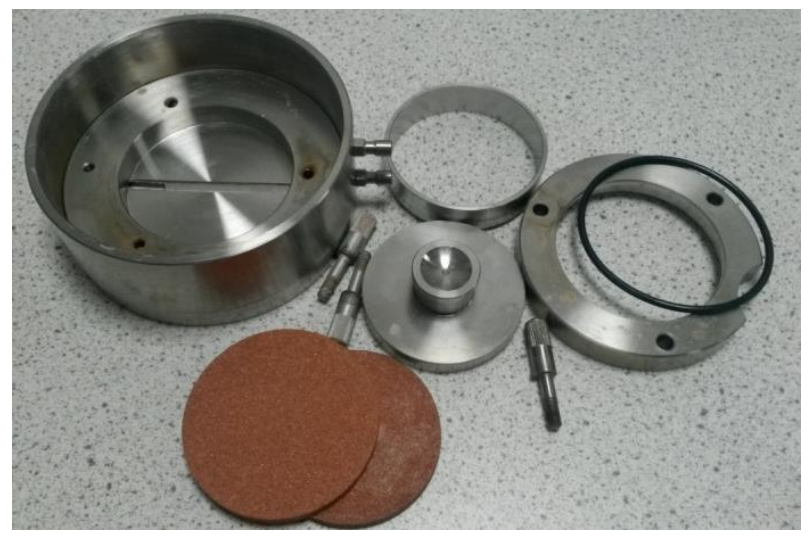

(c)

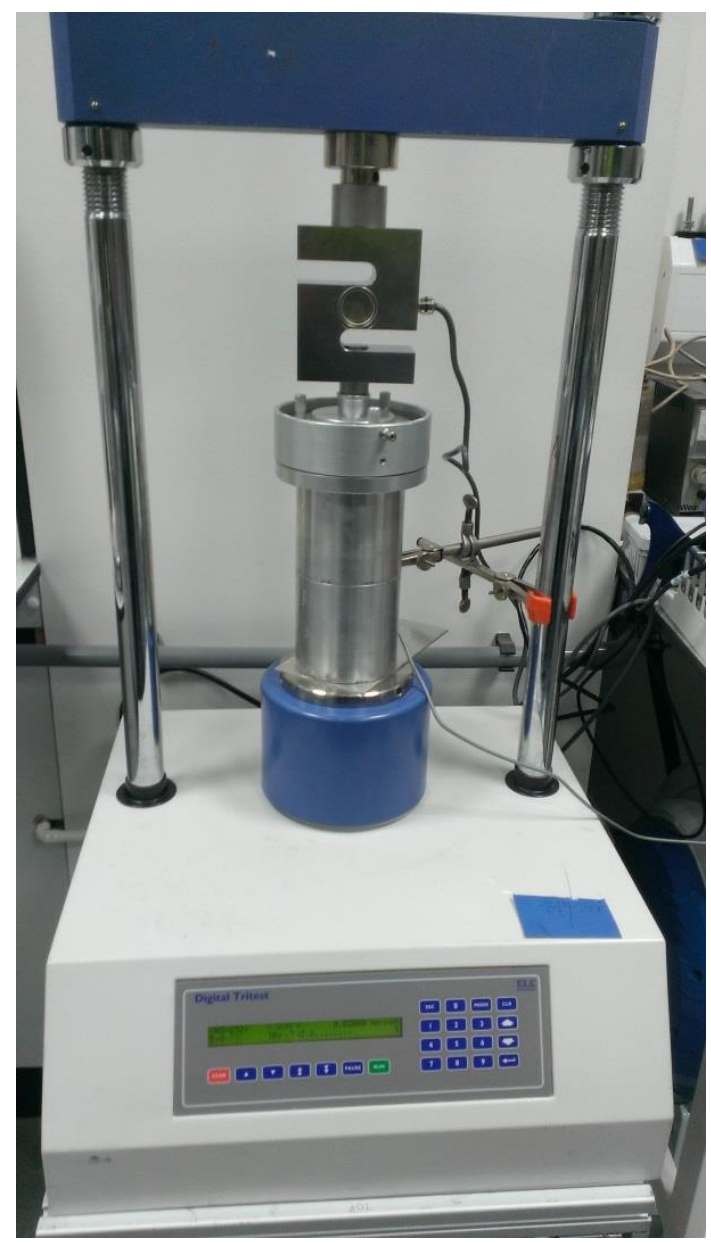

(d)

Figure 3.10 - 1-D Compression equipment at the Geomechanics laboratory of the University of Strathclyde (a)

Front loading oedometer (b) and (c) Detail of oedometer cell (d) Constant Rate of Strain Consolidometer

In the conventional oedometer, the soil specimen was subjected to successive increments of vertical loads, starting from a small load of $2 \mathrm{kPa}$. Each increment was considered completed once the soil specimen reached primary consolidation. The loads were doubled at each new step up to the nominal maximum load allowed for the equipment, which was $2,000 \mathrm{kPa}$.

The unloading followed two different procedures depending on the future use of the sample under testing. Therefore, if the objective of the test was to generate the consolidation curve, the unloading followed the same loading steps in reverse and each of the steps was considered completed once the swelling was stabilized. On the other hand, if the objective of the consolidation test was to prepare samples to undergo the microstructural testing, the unloading was carried out in one single step, with the removal of the whole load as quickly as possible, without allowing time for the swelling to stabilize. The reason for this last procedure was to perform the microstructural investigation on the sample under loading, not after loading and unloading. Obviously, it is not possible to stop the swelling completely; 
therefore some differences should be expected between the void ratios at a corresponding loading stage of the sample that undergoes unloading in multiple steps and in one single step (see MIP results of this comparison in Annex A).

The CRS consolidometer was used to enable the specimens to reach greater loads. The maximum nominal load of the load cell used is $50 \mathrm{kN}$, which means approximately $11 \mathrm{MPa}$ for the consolidation cell (Ring: $\mathrm{D}=75 \mathrm{~mm}$ and $\mathrm{H}=20 \mathrm{~mm}, \mathrm{~A}=0.0044 \mathrm{~m}^{2}$ ) used in the experiments (Figure 3.10c). An initial study was carried out to determine the strain rate for each soil and initial moisture content/state of the specimens tested. An example carried out for the Kaolin Clay specimen with initial water content of $96 \%$ is shown in Figure 3.11. Three different strain rates were tested $(0.008,0.005$ and $0.0035 \mathrm{~mm} / \mathrm{min})$ and compared with the consolidation test performed in the conventional oedometer. The criterion used to define whether the strain rate was appropriate was the comparison with the consolidation curve obtained for the same specimen in the oedometer test. Table 3.4 shows the final strain rates, i.e., the rates that agree with the consolidation curve obtained for the respective sample carried out in the conventional oedometer, for each specimen of the three soils tested. The unloading procedure was either carried out at the same rate of the loading in the opposite direction (if the objective of the test was to generate the consolidation curve), or at an extremely high rate, where the unloading was finished in a matter of seconds (if the objective of the test was to prepare samples to undergo the microstructural testing).

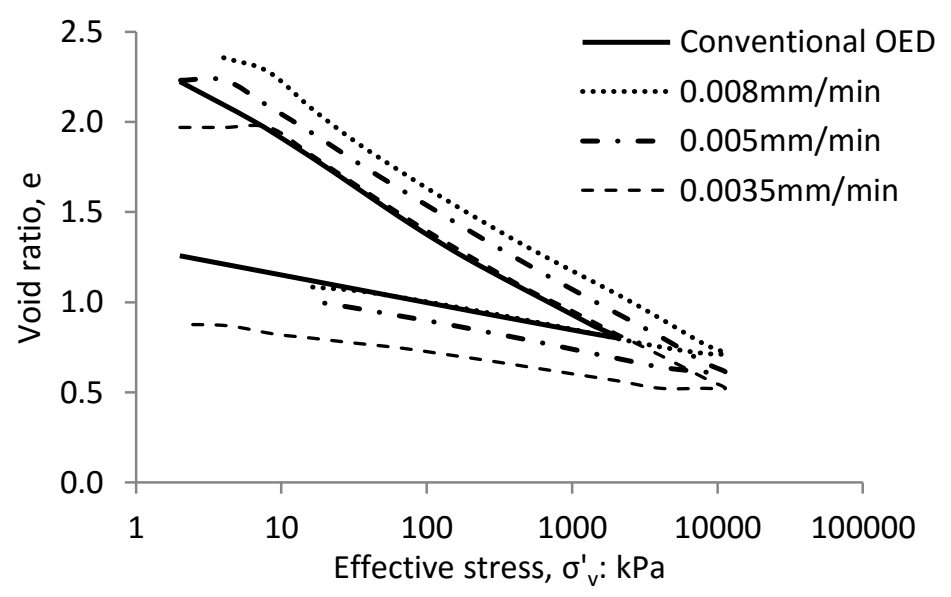

Figure 3.11 - Consolidation curves of the Kaolin Clay specimen $\mathrm{w}_{\mathrm{i}}=96 \%$, conventional oedometer and CRS of $0.008,0.005$ and $0.0035 \mathrm{~mm} / \mathrm{min}$ 
Table 3.4 - Strain Rates used in the CRS consolidometer for each specimen

\begin{tabular}{llc}
\hline Soil & $\begin{array}{c}\text { Initial state/water } \\
\text { content }\end{array}$ & $\begin{array}{c}\text { Strain Rate } \\
\text { (mm/min) }\end{array}$ \\
\hline \multirow{2}{*}{ Ball Clay } & $94.5 \%$ to $47.25 \%$ & 0.005 \\
& pH 9 & 0.0035 \\
Brasilia Soil & $52.5 \%$ to 32.5\% & 0.01 \\
& pH 9 & 0.0035 \\
\multirow{2}{*}{ Kaolin Clay } & $96 \%$ to $45 \%$ & 0.005 \\
& pH 9 & 0.0035 \\
\hline
\end{tabular}

The water content of the samples was measured at the end of the test. The void ratio was then back-calculated at each step of the test, since the vertical displacement was recorded during the consolidation process.

\subsection{5 - FREEZE-DRYING}

The freeze-drying was carried out in the Biotechnology laboratory of the Department of Civil and Environmental Engineering and the technique adopted in this research followed the procedure proposed by Delage \& Pellerin (1984), consisting of the following steps:

- Specimens of about $1 \mathrm{~cm}^{3}$ were prepared. If the consistency of the sample allowed, the cutter and extruder shown in Figure 3.12 were used to ensure a standard sample shape (Figure 3.13a); otherwise, specimens were prepared with the help of a stylus knife (Figure 3.13b);

- Quick-freezing the specimen in a liquid isopentane that had been cooled to its melting point $\left(-160^{\circ} \mathrm{C}\right)$ in liquid nitrogen was performed as presented in Figure 3.14;

- Sublimation occurred in the CoolSafe ${ }^{\circledR}$ lyophilizer (Figure 3.15a and b), in which the samples were stored in a vacuum-induced environment, the pressure was dropped to under the water critical point $(\approx 5 \mathrm{~Pa})$ and temperature increased $\left(\approx-50^{\circ} \mathrm{C}\right)$ to allow quicker sublimation;

- After $24 \mathrm{hrs}$ in the lyophilizer, the samples were stored in a plastic bag sealed under vacuum (Figure 3.16) until they were ready to be tested in the mercury intrusion porosimeter. 


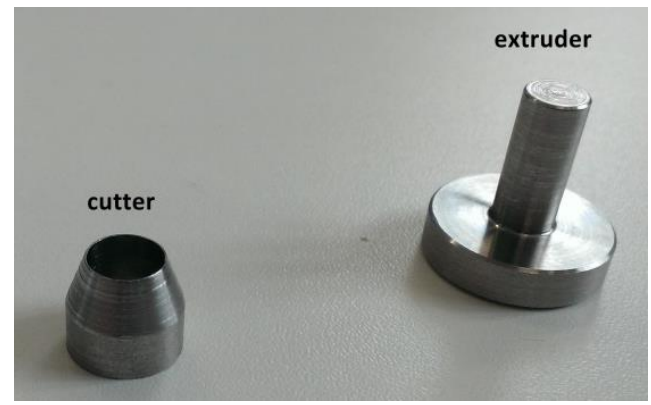

Figure 3.12 - Cutter and extruder used to prepare specimens for freeze-drying

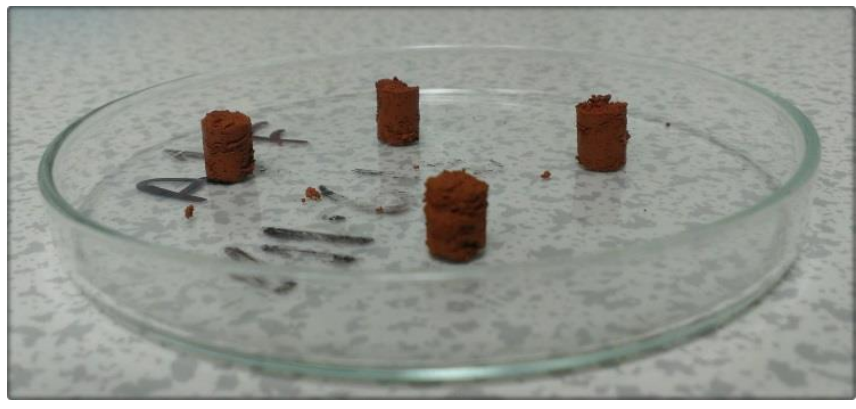

(a)

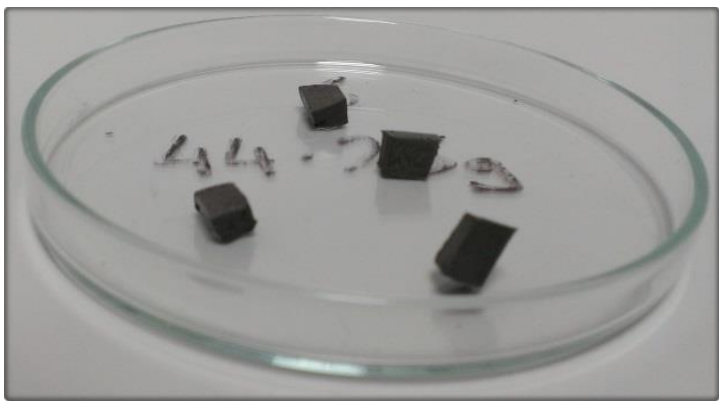

(b)

Figure 3.13 - Specimens prepared for freeze-drying (a) Brasilia Soil prepared with the cutter and extruder and (b) Ball Clay prepared with stylus knife

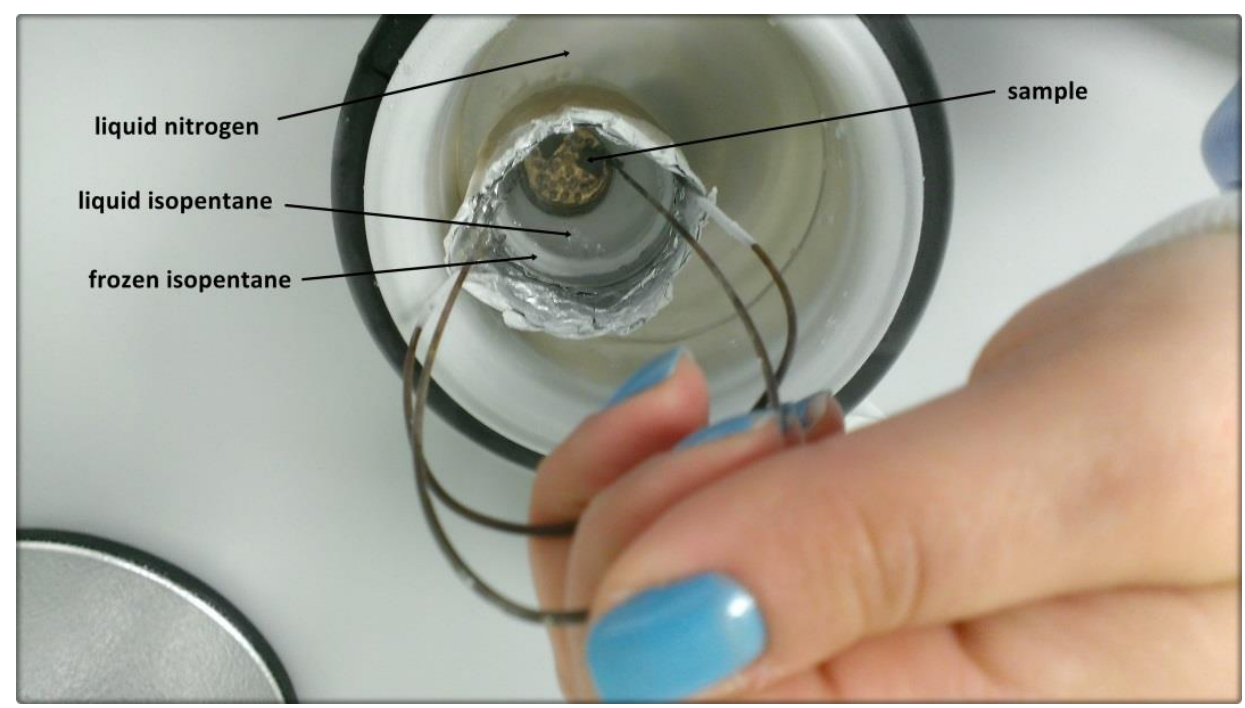

Figure 3.14 - Freezing process 


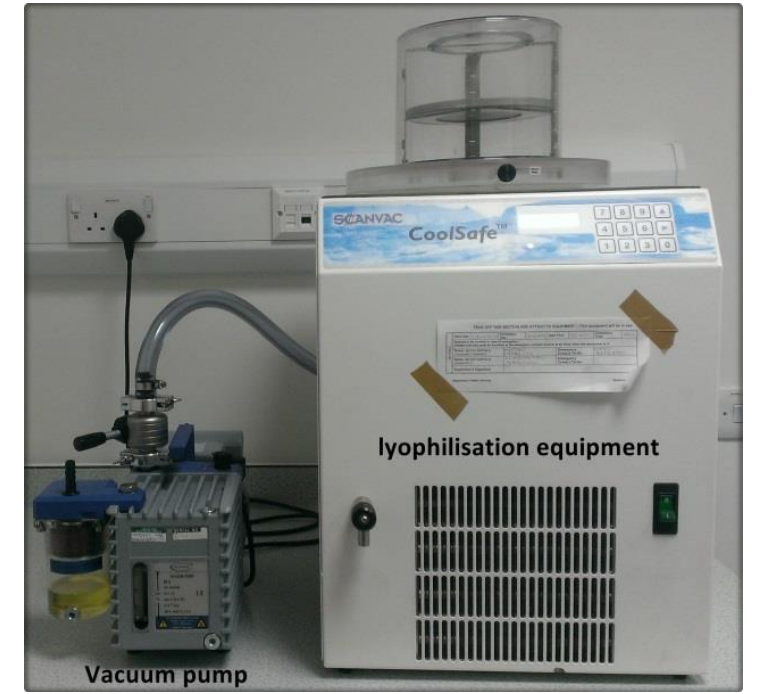

(a)

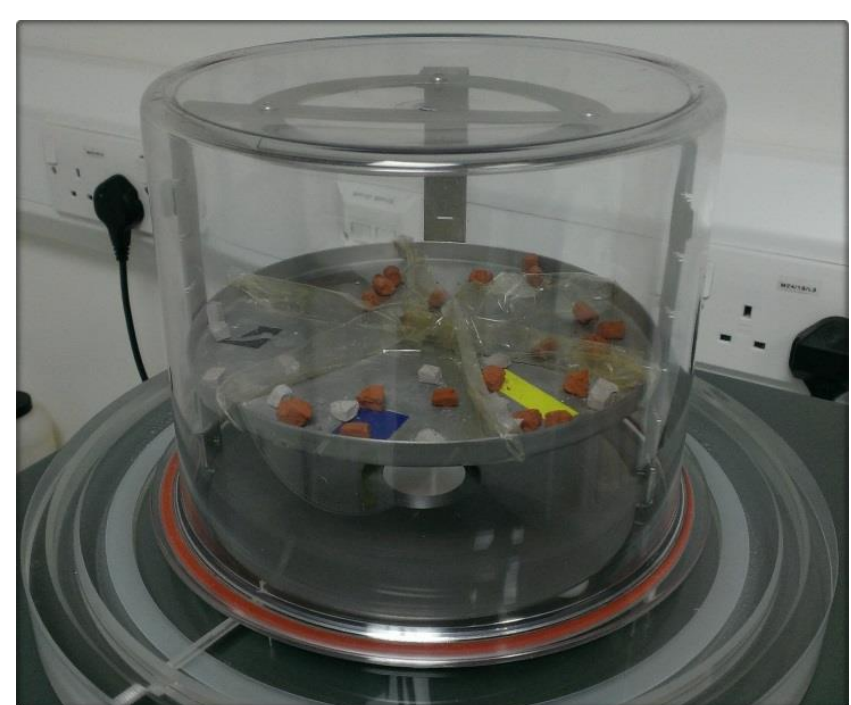

(b)

Figure 3.15 - (a) Lyophilization and vacuum pump at the Biotechnology laboratory of the University of Strathclyde and (b) Close-up of the lyophilizer chamber drying samples

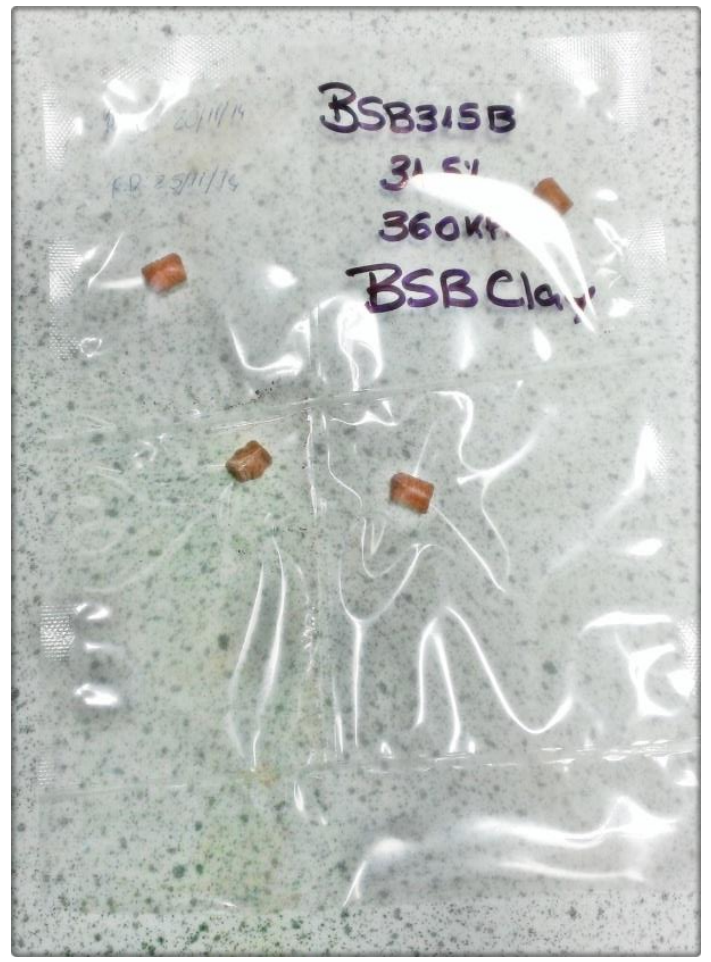

Figure 3.16 - Samples stored in a labelled plastic bag under vacuum

\subsection{6 - MERCURY INTRUSION POROSIMETRY}

Microstructure analysis was carried out using a porosimeter named PoreMaster® 60 (Figure 3.17a), produced by Quantachrome Instruments and available at the Advanced Materials Research Laboratory of the Department of Mechanical and Aerospace Engineering. The equipment is designed to measure pore volumes in the range of about 1,000 to $0.0035 \mu \mathrm{m}$ diameter, corresponding to $1.5 \mathrm{kPa}$ to $420 \mathrm{MPa}$ (0.2 to $60,000 \mathrm{psi}$ ) respectively (Quantachrome, 
2009). PoreMaster® 60 is designed to operate in two different stations: the low pressure cell (Figure $3.17 \mathrm{~b}$ ), in which the applied pressure ranges between 1.5 and $350 \mathrm{kPa}(0.2$ and $50 \mathrm{psi})$ and the high pressure cell, in which the applied pressure ranges from $140 \mathrm{kPa}$ to $420 \mathrm{MPa}(20$ to $60,000 \mathrm{psi})$.

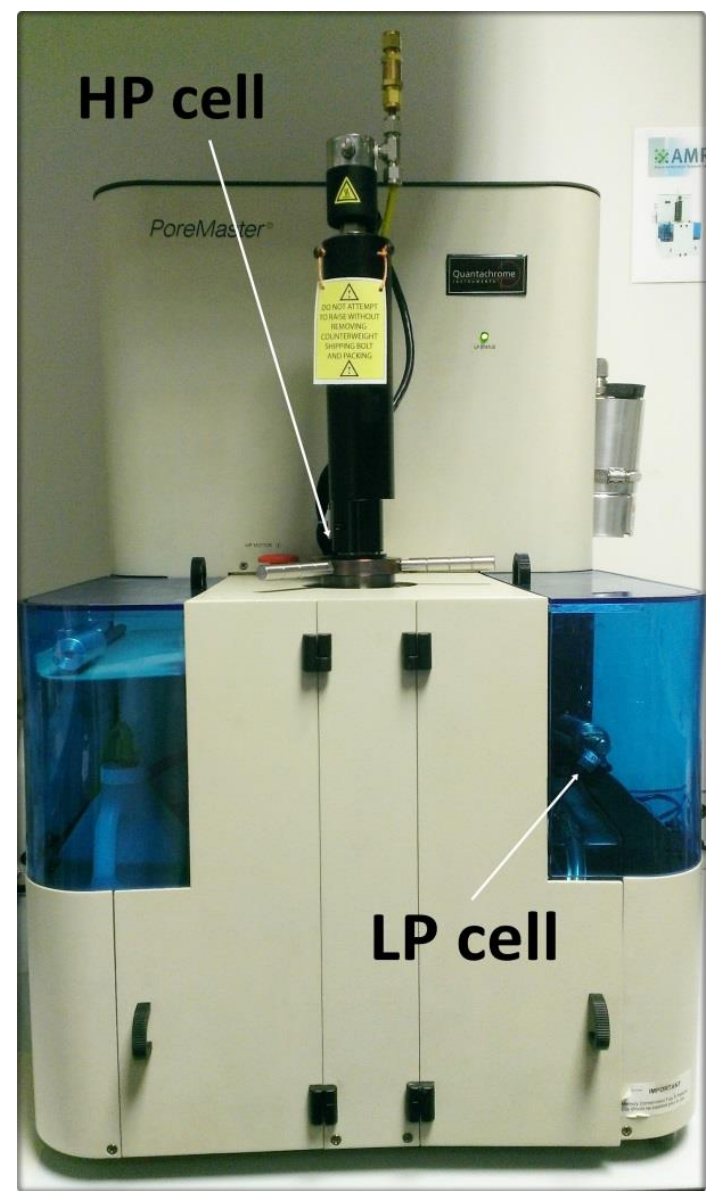

(a)

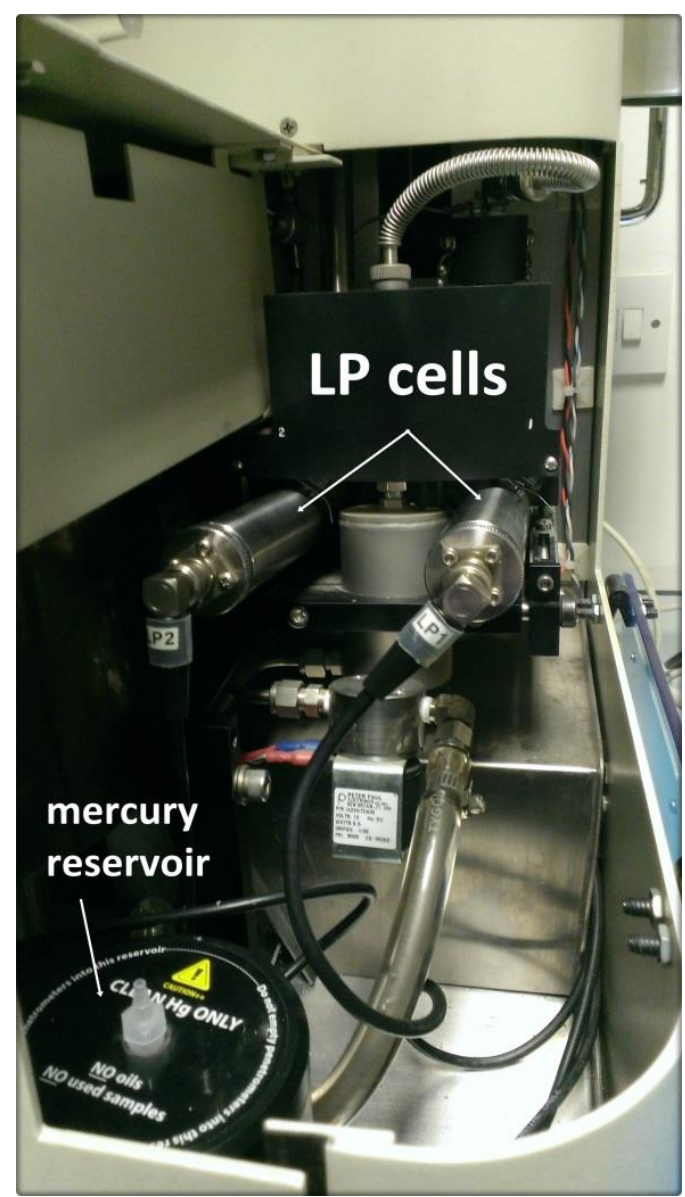

(b)

Figure 3.17 - (a) PoreMaster ${ }^{\circledR} 60$ at the Mechanical Engineering Laboratory of University of Strathclyde and (b) Close-up of the low pressure cell

The freeze-dried samples were weighed (Figure 3.18a), placed in the penetrometer (Figure $3.18 b$ ) and inserted in the low pressure cell of the PoreMaster ${ }^{\circledR} 60$ (Figure 3.18c).

In the low pressure cell, the pressure was increased gradually up to $350 \mathrm{kPa}$ and the volume of mercury intruded in the sample recorded. After reaching the target pressure of $350 \mathrm{kPa}$, the pressure was gradually released and the volume of mercury that extruded the sample was also recorded. The penetrometer was then taken out of the low pressure cell, the height of the mercury in it was measured and hydraulic oil was injected into the penetrometer filling the rest of the stem. The penetrometer was then placed in the high pressure cell and the pressure was once more increased gradually to $420 \mathrm{MPa}$; the volume of mercury intruded was again 
recorded and the extrusion of mercury was also recorded once the pressure was released. The pressure was converted into diameter according to the following Washburn equation:

$\mathrm{D}=\frac{-4 \sigma_{\mathrm{Hg}} \cos \theta}{\mathrm{p}}$

where: $D$ is the smaller diameter of the pores intruded by mercury (considering the pores cylindrical) at a certain associated applied pressure $p, \sigma_{H g}$ is the surface tension of mercury, $\theta$ is the contact angle between the mercury and the pore wall and $p$ is the absolute pressure applied to the mercury.

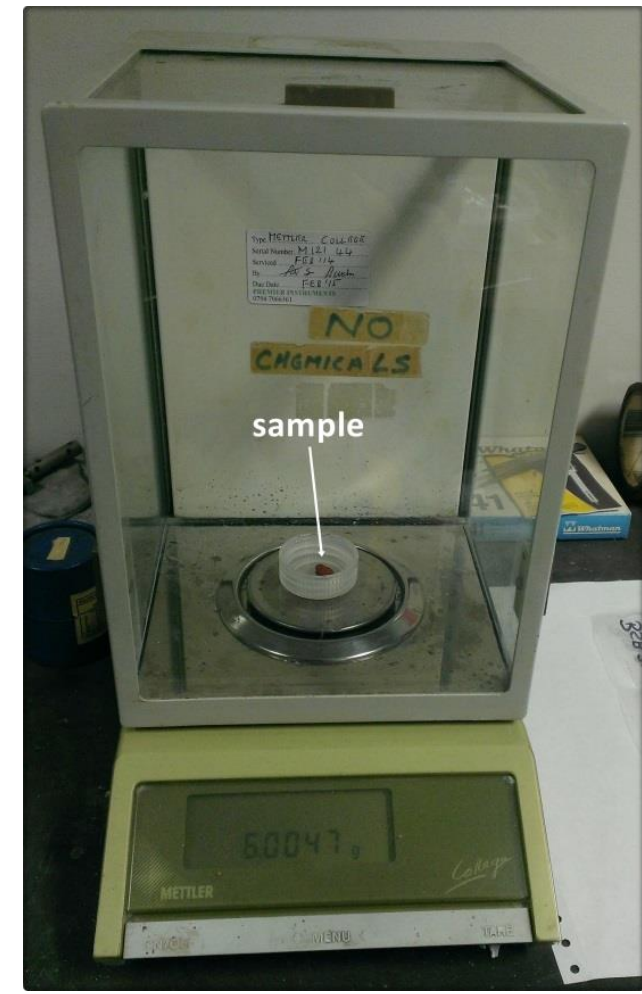

(a)

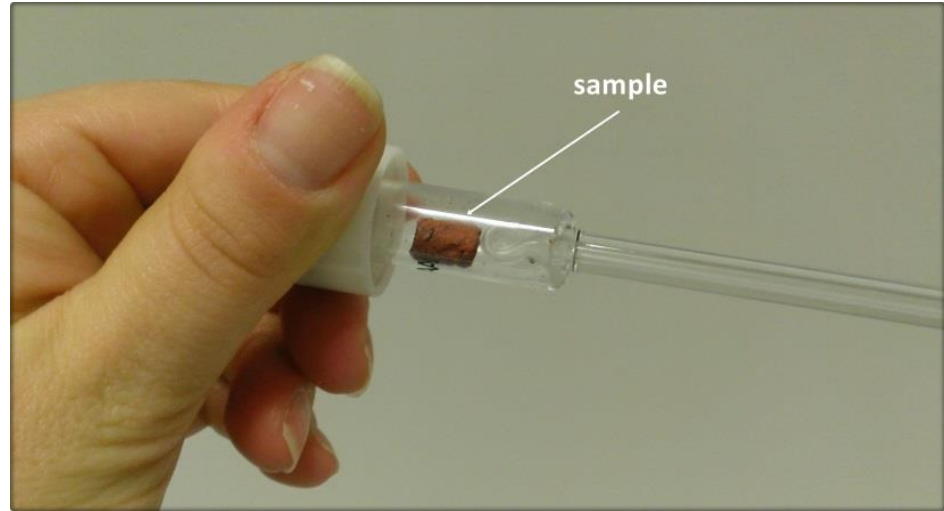

(b)

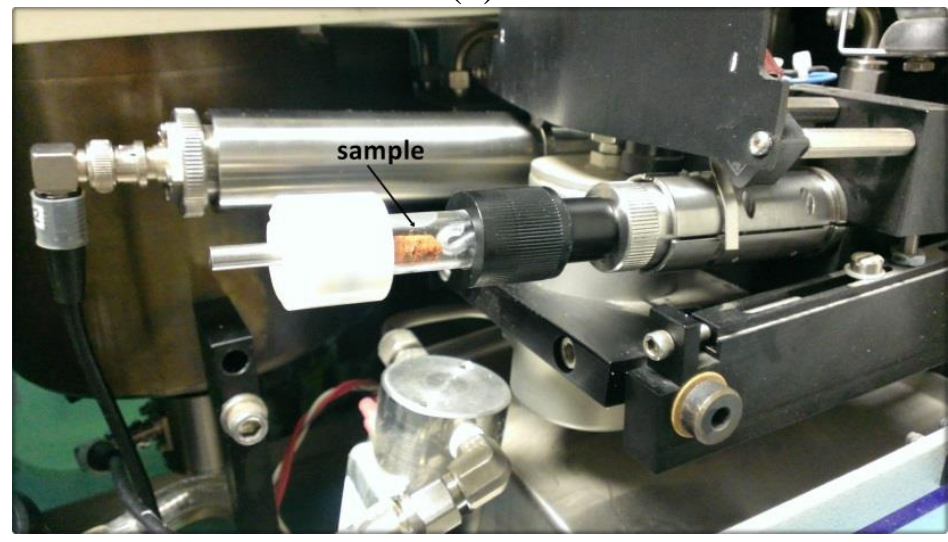

(c)

Figure 3.18- (a) Sample weighed before MIP test (b) Sample sealed inside the penetrometer and (c) Penetrometer with sample placed in the low pressure cell

\section{3 - MODELLING}

\subsection{1 - VAN GENUCHTEN-TYPE FITTING}

The cumulative intrusion curve obtained from the Mercury Intrusion Porosimetry (MIP) test was fitted using the van Genuchten-type bi-modal cumulative distribution equation and 
its derivative was used to draw the Pore Size Density (PSD) curve, as proposed by Lopes et al. (2014). Both equations are detailed in section 2.4.2 of this document.

Thus, as a general rule, the results presented in the following chapters are given in such a way that:

- The intrusion curve is presented as the data obtained from the MIP test, unless stated otherwise;

- The PSD is presented as the derivative of the van Genuchten-type bi-modal equation of the respective sample analysed.

Although the van Genuchten-type bi-modal fitting of the intrusion curve is not shown for all samples presented in this document, the fitting was performed successfully for all of the samples obtained for the derivative (PSD) curve, as reported in the following chapters and demonstrated in Annex D.

\subsection{2 - CONSTITUTIVE MODELLING}

The results of the consolidation tests performed in the samples of Kaolin Clay, Ball Clay and Brasilia Soil were modelled using the elastoplastic hardening model, S-CLAY1S (Koskinen et al., 2002). Although the model is capable of modelling the anisotropic behaviour, this function was turned off in the analysis herein presented.

The bonding and destructuration effects were taken into account in a different way. First of all, in this document the reconstituted soil is not considered unstructured. Indeed, it is considered to have structure just as the natural soil does, although they are regarded as having distinct structures. Thus, the amount of bonding, $x$, is here referred to as the amount of structure, since it was used to quantify the structure of the various sample states, not only bonding. The $\mathrm{pH} 9$ sample is the one considered here as the reference soil; thus for modelling purposes its amount of structure was conventionally set to zero, although the authors are aware that even this sample does have a structure. The destructuration effect is called degradation to be consistent with the definitions provided in Chapter 2, since all samples are considered to have structure. 


\section{4 - CLAYS}

In this chapter, the results of the several experiments carried out for the two clay soils tested, Kaolin and Ball Clay, are presented and discussed. These experiments involve: sedimentation tests, which were carried out in order to assess the differences in sedimentation between distilled water and various concentrations of potassium hydroxide $(\mathrm{KOH})$ solution, i.e., with increasing $\mathrm{pHs}$; and consolidation tests performed in reconstituted, remoulded and pH9 samples. Each of these three states of samples was consolidated at different loads for microstructural testing and suction measurement with tensiometers, as it is believed that the preparation of the samples induces the appearance of suction even in saturated samples and Mercury Intrusion Porosimetry tests chosen to study the structure of the materials. In addition, a conceptual model relating the consolidation behaviour of the clay soils to their microstructure was proposed and, finally, the consolidation results were modelled using the constitutive model S-CLAY1S (Koskinen et al., 2002), with a slight modification to the model's use. Herein, the parameter $\mathrm{x}$ of the model was used to quantify the amount of structure as defined in this research, i.e., all soils were considered to have some structure.

\section{1 - SEDIMENTATION RESULTS}

Figure 4.1 shows the particle size distribution for suspensions at $\mathrm{pH} 4$ (only distilled water) and at $\mathrm{pH} 9$ of Kaolin Clay carried out by Pedrotti (2016). The curves show that $\mathrm{D}_{50}$ of the suspension prepared at $\mathrm{pH} 4$ is $6.4 \mathrm{~mm}$, while at $\mathrm{pH} 9$ it is $0.98 \mathrm{~mm}$. The difference between the two samples is only the electrical charge of the edges, which are positive at $\mathrm{pH} 4$ and negative at $\mathrm{pH} 9$. Thus, one could say that the size difference between the two suspensions is directly related to the edge-to-face interactions. In general, $\mathrm{pH} 4$ solutions, whose edges are positively charged, present an attractive interaction between edges and faces, due to the fact that they are oppositely charged. Such attraction forms an open structure configuration where particles are associated in an edge-to-face arrangement. Particles in dispersed suspensions, i.e., suspensions prepared at $\mathrm{pH} 9$ in this case, have edges and faces both negatively charged; hence the high electrical repulsion existing between particles suggests that particles sediment individually. 


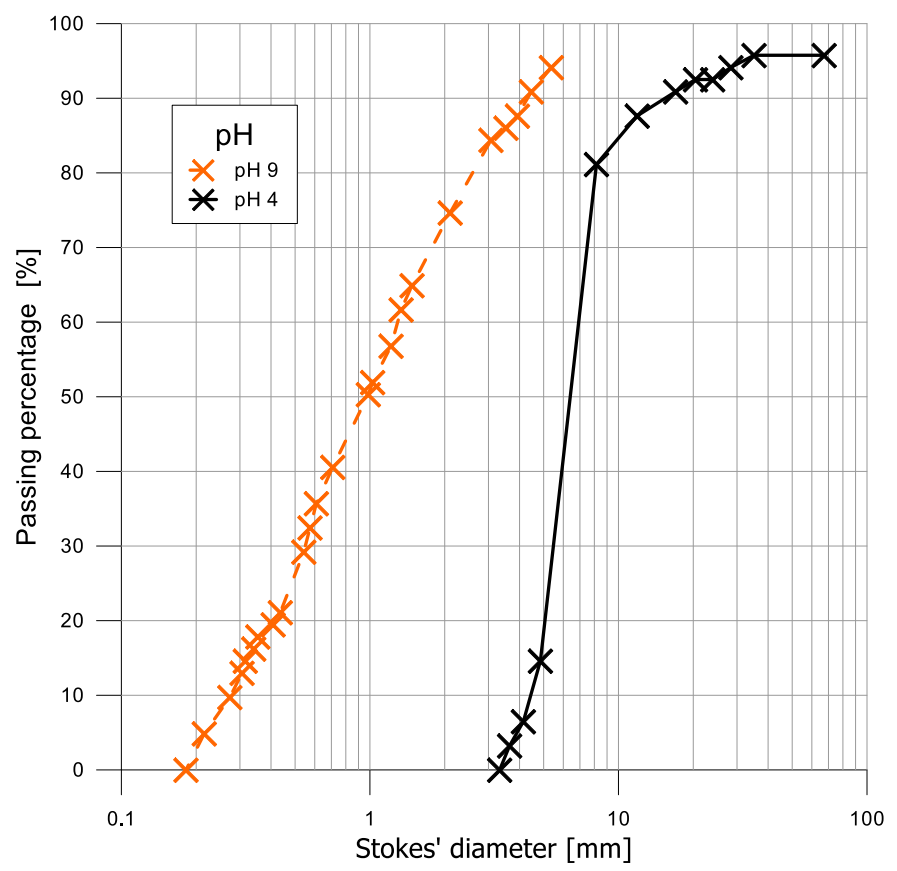

Figure 4.1 - Kaolin Clay: Particle size distribution at different pHs (source: Pedrotti, 2016)

Sedimentation tests were carried out for the Kaolin Clay with two different pHs. Figure 4.2 shows the final volume of sediments, while Figure 4.3 presents the final void ratio of the sediment. The results are in agreement with the particle size distribution shown in Figure 4.1, where the higher final volume is associated with the open structure configuration. The void ratio of the $\mathrm{pH} 4$ suspension is more than three times higher than that of the $\mathrm{pH} 9$, which agrees with previous studies carried out for Kaolin Clay (Wang \& Siu, 2006; Pedrotti, 2016), as illustrated in Figure 4.3.

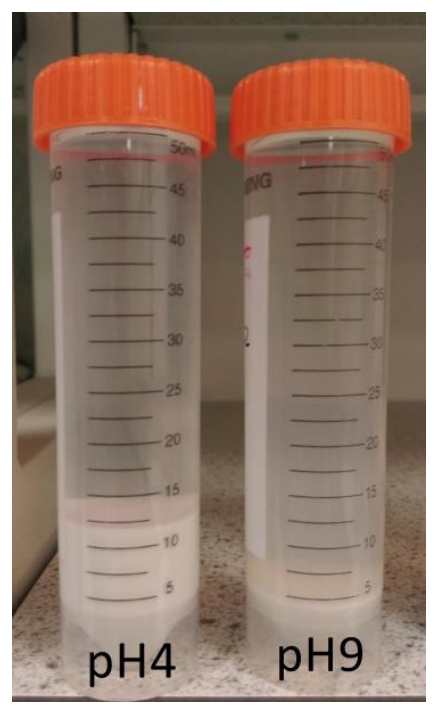

Figure 4.2 - Kaolin Clay: pH4 (only distilled water) and pH9 


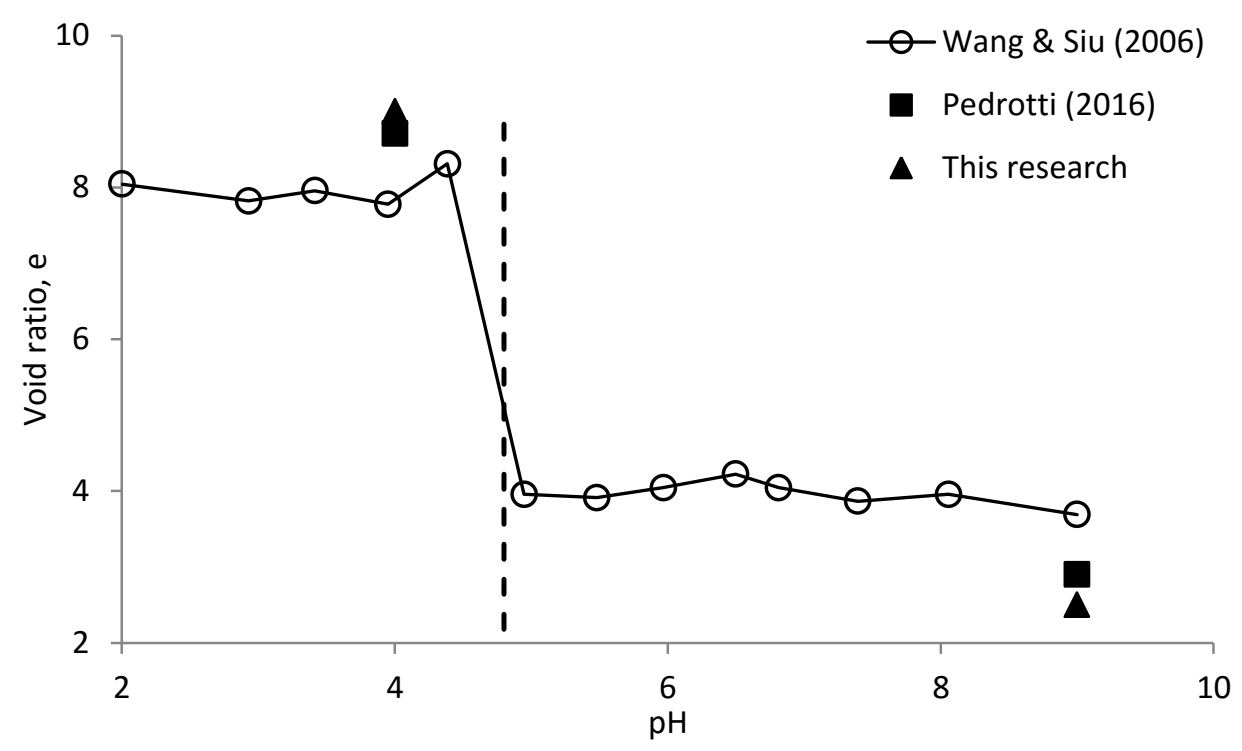

Figure 4.3 - Kaolin Clay: Final void ratio of the sediments

As with the experiment performed for the Kaolin Clay, sedimentation tests were carried out with six different $\mathrm{pHs}$ for the Ball Clay. Figure 4.4 shows the final volume of sediments, while Figure 4.5 presents the final void ratio of the sediments. The results are in agreement with the results obtained for the Kaolin Clay, where the higher final volume is associated with the open structure configuration. The void ratio of the $\mathrm{pH} 4.8$ suspension is almost twice as high as that of the $\mathrm{pH} 9$, this difference being slightly smaller than that shown by the Kaolin Clay. This result is reasonable when the composition of the Ball Clay is taken into account. This soil is not as pure as the Kaolin Clay; in consequence, the amount of kaolinite mineral present in the Ball Clay is proportionally smaller than the amount present in the Kaolin Clay.

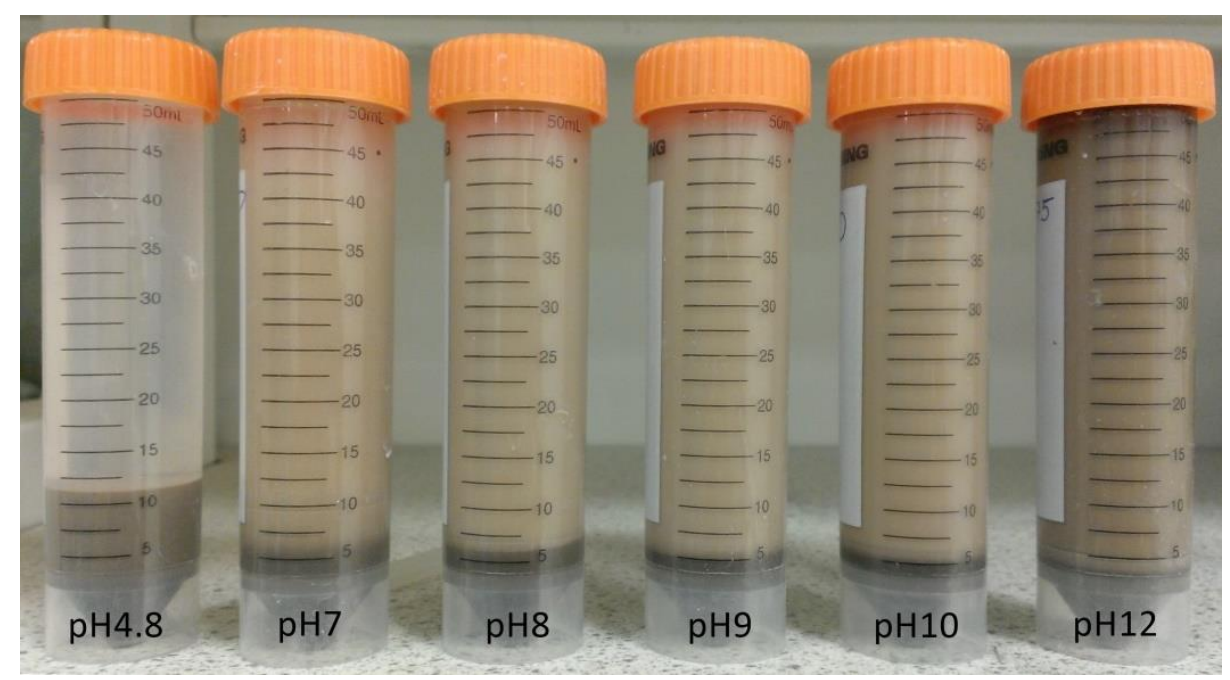

Figure 4.4 - Ball Clay: pH4.8 (only distilled water), 7, 8, 9, 10 and 12 


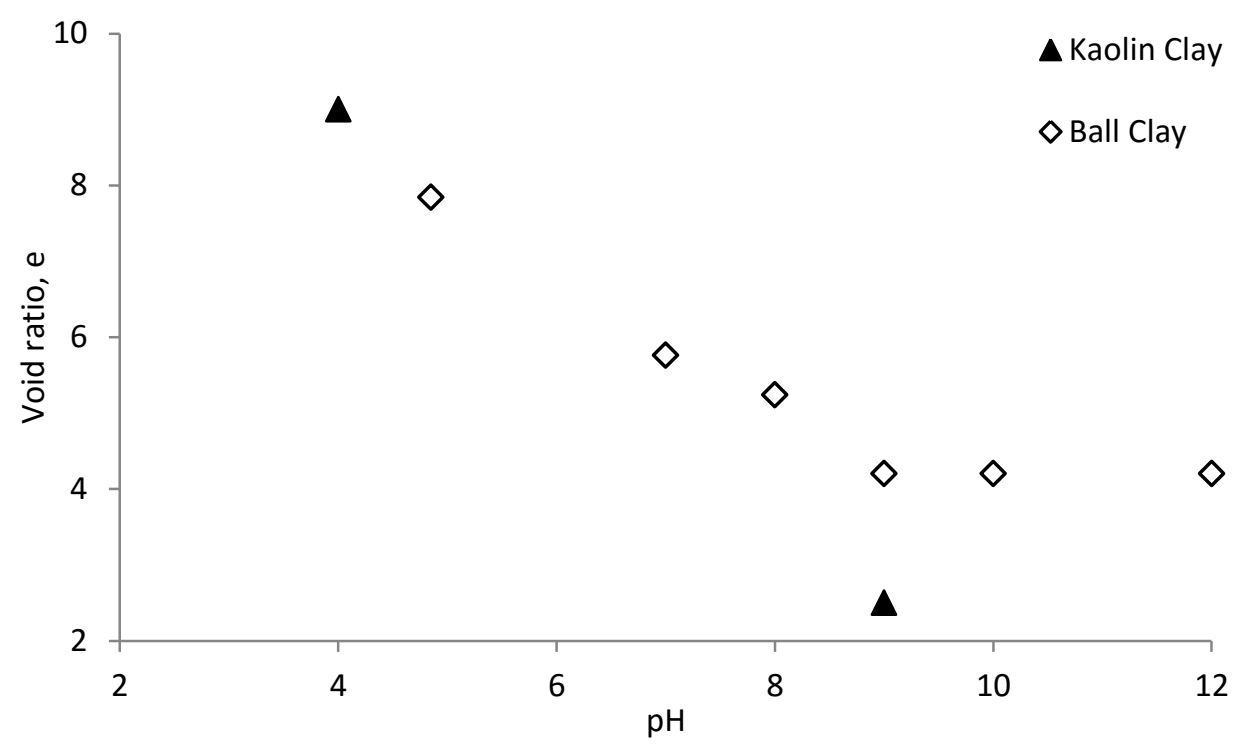

Figure 4.5 - Ball Clay: Final void ratio of the sediments

The results of the sedimentation tests of the Kaolin and Ball Clays with varying values of $\mathrm{pH}$ show that the electrical charge of the edges is responsible for the difference in the particles' configuration while undergoing sedimentation. The following sections investigate whether this observation is still true when the samples are subjected to a mechanical load.

\section{2 - CONSOLIDATION RESULTS}

In this section, samples at different initial states (reconstituted, remoulded and $\mathrm{pH} 9$ ) were consolidated in order to investigate whether such an initial state influences the arrangement of particles when subjected to vertical effective stresses. Figure 4.6a shows the consolidation curves of Kaolin Clay specimens prepared at initial water contents of 96\%, 90\%, 80\%, 70\%, $64 \%, 60 \%, 55 \%$ and $45 \%$ and with $\mathrm{KOH}$ solution resulting in $\mathrm{pH}$, while Figure $4.6 \mathrm{~b}$ presents the consolidation curves of Ball Clay specimens prepared at initial water contents of $94.5 \%, 70 \%$ and $47.25 \%$ and with $\mathrm{KOH}$ solution resulting in $\mathrm{pH} 9$. As explained in Chapter 3 , these curves are a combination of the results from the conventional oedometer test (from $2 \mathrm{kPa}$ to $2 \mathrm{MPa}$ ) and the Constant Rate of Strain (CRS) consolidometer (from $2 \mathrm{MPa}$ to $11 \mathrm{MPa})$. It is notable that the higher the initial water content, the higher the initial void ratio for both clays. 


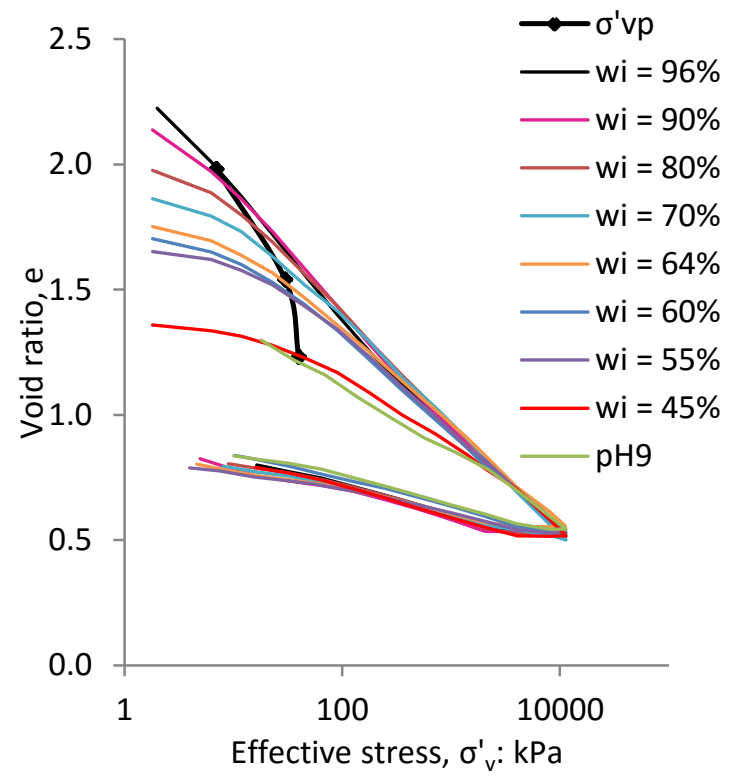

(a)

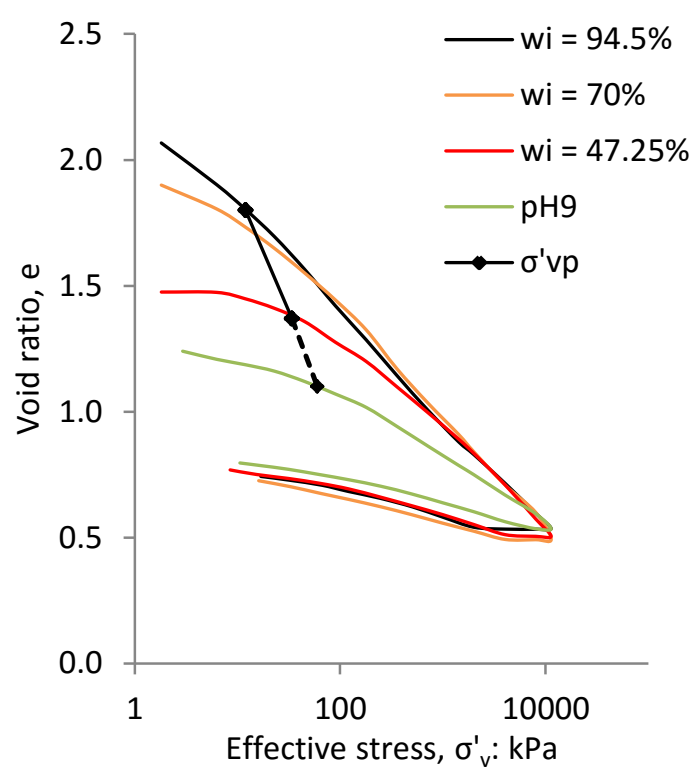

(b)

Figure 4.6 - Consolidation curves: (a) Kaolin Clay and (b) Ball Clay

It is noticeable that the samples' preparation processes at different initial water contents and pH9 affect the curve's behaviour. It is even possible to note a variation in the preconsolidation stress. In order to investigate this effect in detail, it was hypothesized that the samples' preparation procedure induces the appearance of suction and that this suction, on the other hand, is directly related to the preconsolidation stress of the sample. In the graphs of Figure 4.6 it is also possible to note the line of preconsolidation stresses calculated by the relationship shown in the following:

$$
\sigma_{\mathrm{vp}}^{\prime}=\frac{\mathrm{s}}{\frac{\left(1+2 \cdot \mathrm{k}_{0}\right)}{3}}
$$

where: $\sigma^{\prime}{ }_{v p}$ is the preconsolidation stress, $s$ is the matric suction, $\mathrm{k}_{0}=1-\sin \varphi$, for the Kaolin and Ball Clay tested $\varphi=22^{\circ}$. Equation 4.1 relates the suction induced in the samples by the preparation procedure and measured by tensiometers in an isotropic state to the oedometer anisotropic state.

Table 4.1 and Table 4.2 show the values of suction measured, preconsolidation stresses calculated by Eq. 4.1 and preconsolidation stresses obtained by Casagrande's graphical method (Casagrande, 1936) for specimens of Kaolin and Ball Clay respectively. Suction measurements were carried out with tensiometers for three specimens of Kaolin Clay (96\%, $64 \%$ and $45 \%)$ and two specimens of Ball Clay (94.5\% and 47.25\%). Due to the presence of 
$\mathrm{KOH}$ in the $\mathrm{pH} 9$ specimens of both clays, it was not possible to measure the suction with tensiometers of these specimens. Therefore, the specimens with suction measurement had their preconsolidation stresses calculated with Eq. 4.1, while intermediate curves without suction measurements had their values of preconsolidation stresses interpolated. By looking at Table 4.1 and Table 4.2, one can see that the values of preconsolidation stresses determined by Eq. 4.1 are not too far from the values obtained by Casagrande's graphical method. Therefore, although the approach proposed does not influence the results obtained in current practice, it gives them physical meaning. Besides, the preconsolidation stress is directly related to the initial void ratio, which is a state variable. The specimen at $\mathrm{pH} 9$ produces a rearrangement of particles in such a way that it does not allow as many plastic deformations as other specimens. The same effect can also be seen, at different degrees, in the specimens prepared at different initial water contents; the lower the water content, the fewer plastic deformations observed, hence increasing the preconsolidation stress values. The highest preconsolidation stress and the lowest plastic deformations are those associated with the $\mathrm{pH} 9$ specimen.

Table 4.1 - Suction measurements and preconsolidation stresses of Kaolin Clay specimens

\begin{tabular}{cccc}
\hline $\begin{array}{c}\text { Initial water } \\
\text { content, w: } \\
\%\end{array}$ & $\begin{array}{c}\text { Initial suction } \\
\text { measured, s: } \\
\mathrm{kPa}\end{array}$ & $\begin{array}{c}\text { Calculated } \\
\text { preconsolidation stress, } \\
\sigma^{\prime}{ }_{\mathrm{vp}}: \mathrm{kPa}\end{array}$ & $\begin{array}{c}\text { Preconsolidation stress, } \sigma^{\prime}{ }_{\mathrm{vp}}: \mathrm{kPa} \\
\text { determined by Casagrande's } \\
\text { graphical method }\end{array}$ \\
\hline 96 & 5 & 7 & 9 \\
90 & - & 7 & 9 \\
80 & - & 15 & 13 \\
70 & - & 20 & 18 \\
64 & 23 & 30 & 20 \\
60 & - & 35 & 26 \\
55 & - & 35 & 30 \\
45 & 30 & 40 & 50 \\
$\mathrm{pH} 9$ & - & 40 & - \\
\hline
\end{tabular}

Table 4.2 - Suction measurements and preconsolidation stresses of Ball Clay specimens

\begin{tabular}{cccc}
\hline $\begin{array}{c}\text { Initial water } \\
\text { content, w: } \\
\%\end{array}$ & $\begin{array}{c}\text { Initial suction } \\
\text { measured, s: } \\
\mathrm{kPa}\end{array}$ & $\begin{array}{c}\text { Calculated } \\
\text { preconsolidation stress, } \\
\sigma^{\prime}{ }_{\mathrm{vp}}: \mathrm{kPa}\end{array}$ & $\begin{array}{c}\text { Preconsolidation stress, } \sigma_{\mathrm{vp}}: \mathrm{kPa} \\
\text { determined by Casagrande's } \\
\text { graphical method }\end{array}$ \\
\hline 94.50 & 9 & 12 & 10 \\
70.00 & - & 14 & 20 \\
47.25 & 25 & 34 & 40 \\
$\mathrm{pH} 9$ & - & 50 & - \\
\hline
\end{tabular}


The initial void ratio of the Kaolin and Ball Clay specimens before the consolidation test, obtained by the extrapolation of the consolidation curves up to a vertical effective stress close to zero, was plotted against their initial water content and is shown in Figure 4.7. It is clear that, as the water content reduces, the void ratio also reduces for both clays. There is a slight increase in the void ratio for both $\mathrm{pH} 9$ samples. This seems to suggest that the $1.5 \mathrm{w}_{\mathrm{L}}$ uses the excess of water to help maintain the open structure. The smaller the water content, i.e., the availability of water, the greater the suction induced into the specimen and consequently the more difficult it is for the specimen to maintain the open structure. The results of the comparison between the pH9 specimen and the other specimens seem to suggest that the arrangement of particles is also influenced by the fluid, whether only distilled water or a solution of $\mathrm{KOH}$ in distilled water.

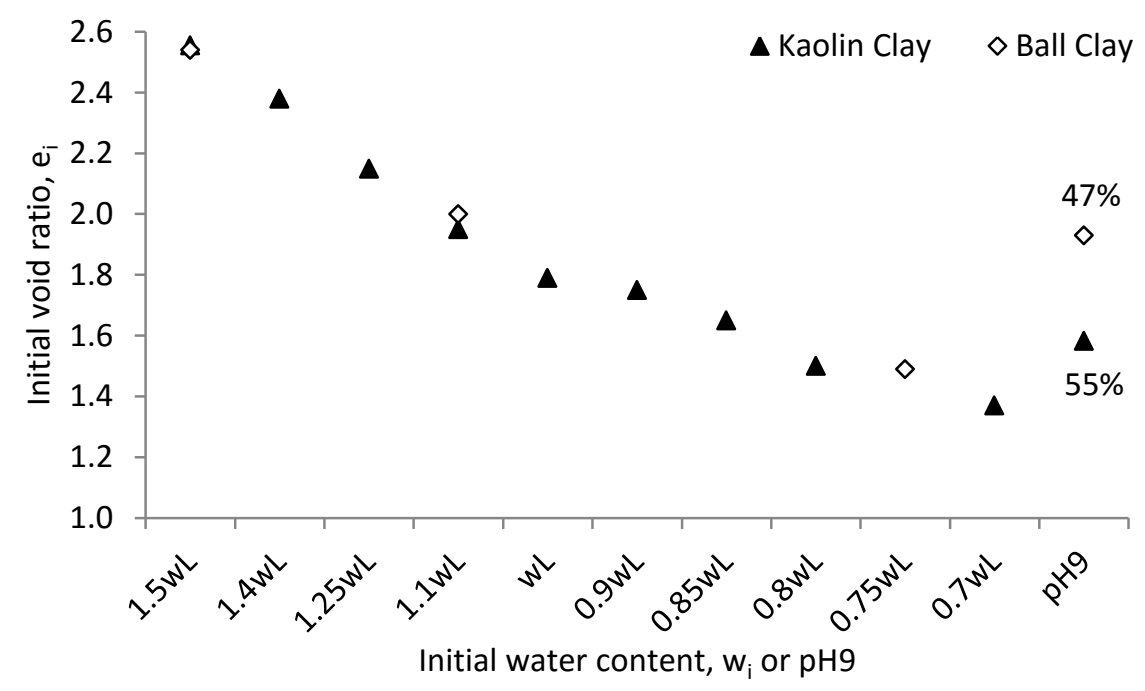

Figure 4.7 - Initial void ratio against initial water content for Kaolin and Ball Clay specimens

As a way to investigate and quantify the structure of the soil, Burland (1990) proposed that the reconstituted specimens (with initial water content between the liquid limit $\left(\mathrm{w}_{\mathrm{L}}\right)$ and $1.5 \mathrm{w}_{\mathrm{L}}$ ) of clay samples are a reference state of the clay material (see Chapter 2 for details). According to the author, the reconstituted state is intrinsic to the clay material, as the parameters of the clay at this state were felt to be unique and inherent for a given soil type. Still, according to Burland (1990), the consolidation curves of the reconstituted specimens should converge in the early stages of consolidation, beyond $100 \mathrm{kPa}$. In fact, Figure 4.6a and $\mathrm{b}$ suggest that the reconstituted specimens of both clays do converge around $200 \mathrm{kPa}\left(\mathrm{w}_{\mathrm{i}}>\right.$ $64 \%$ for the Kaolin Clay and $\mathrm{w}_{\mathrm{i}}>63 \%$ for the Ball Clay). Table 4.3 and Table 4.4 show the Compression and Swelling indexes of the Kaolin Clay and Ball Clay specimens respectively. 
The swelling indexes are fairly similar for both clays and there is a variation between the compression indexes of both clays, even when only the reconstituted specimens are compared. Duncan (2000) reported that the coefficient of variation $(\mathrm{CoV})$ of the compression index is between $10 \%$ and $34 \%$; therefore the difference seen in Table 4.3 and Table 4.4 can be interpreted as statistical.

Table 4.3 - Compression and Swelling indexes of Kaolin Clay specimens

\begin{tabular}{ccc}
\hline Initial water content, w: \% & Compression Index, $\lambda^{*}$ & Swelling Index, $\mathrm{K}$ \\
\hline 96 & 0.17 & 0.05 \\
90 & 0.18 & 0.05 \\
80 & 0.18 & 0.05 \\
70 & 0.17 & 0.05 \\
64 & 0.16 & 0.04 \\
60 & 0.16 & 0.05 \\
55 & 0.17 & 0.04 \\
45 & 0.14 & 0.05 \\
pH9 & 0.13 & 0.05 \\
\hline "calculated between the vertical effective stress of 200 and 11,000kPa &
\end{tabular}

Table 4.4 - Compression and Swelling indexes of Ball Clay specimens

\begin{tabular}{ccc}
\hline Initial water content, w: $\%$ & Compression Index, $\lambda^{*}$ & Swelling Index, K \\
\hline 94.50 & 0.18 & 0.04 \\
70.00 & 0.20 & 0.04 \\
47.25 & 0.17 & 0.04 \\
pH9 & 0.11 & 0.04 \\
\hline${ }^{*}$ calculated between the vertical effective stress of 200 and $11,000 \mathrm{kPa}$ &
\end{tabular}

Figure 4.8a and b show this difference graphically for the Kaolin Clay and Ball Clay respectively. The graphs show the initial void ratio against the void ratio at 100, 1,000 and $10,000 \mathrm{kPa}$. In order to show convergence, each one of the three series of data, between the vertical lines $\mathrm{w}_{\mathrm{L}}$ and $1.5 \mathrm{w}_{\mathrm{L}}$, should be horizontal. It is clear that at $100 \mathrm{kPa}$ the curves are not convergent, but as load progresses the convergence becomes more realistic (1,000 and $10,000 \mathrm{kPa}$ data), not only for the reconstituted specimens but for all the specimens tested. However, other authors (Hong, 2007; Hong et al., 2010, 2012; Shipton \& Coop, 2012) have reported very distinct non-convergent behaviour in clay materials. Furthermore, Fearon \& Coop (2000) have shown that the reconstituted behaviour is dependent on the sample's preparation method. All these results seem to suggest that the reconstituted state, as proposed by Burland (1990), is not appropriate to describe intrinsic properties and consequently be used as a reference material to quantify the soil structure, as part of the particles' initial arrangement seems to be dependent on the availability of water and this initial arrangement 
dictates the subsequent behaviour of the sample once a vertical load is applied in the consolidation test.

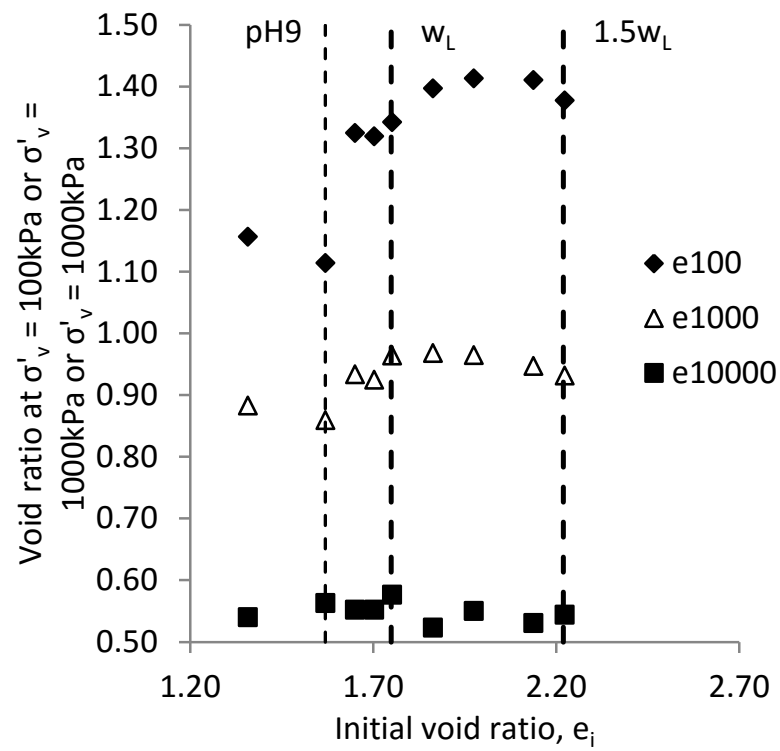

(a)

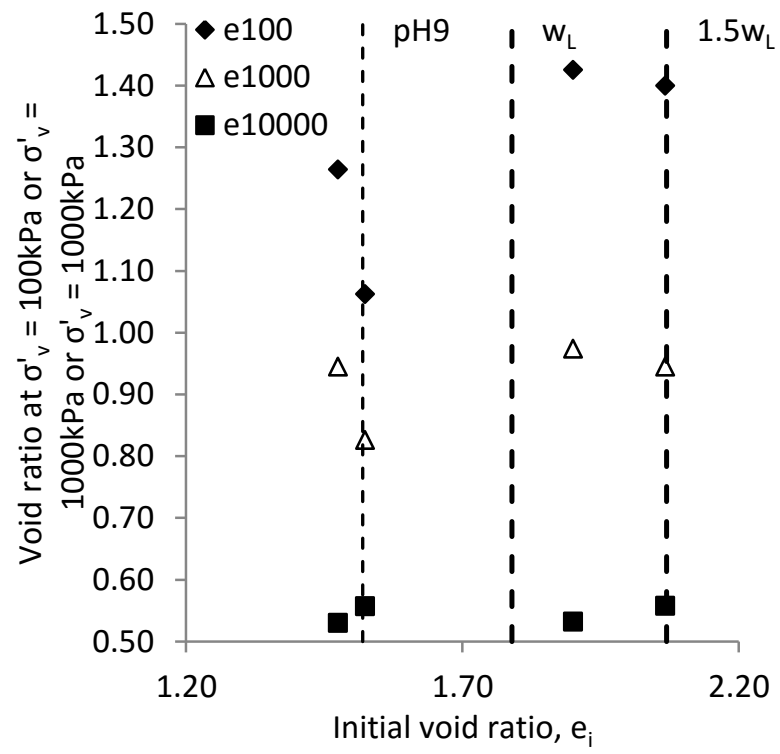

(b)

Figure 4.8 - Variation of void ratio at 100,1,000 and 10,000kPa with initial void ratio for (a) Kaolin Clay and (b) Ball Clay

Herein, the use of $\mathrm{pH} 9$ specimens is proposed as reference, for soils with mineralogy dominated by kaolinite mineral. As described in Chapter 3, the arrangement state (dispersed particles are oriented in a preferential direction) produced by the change in $\mathrm{pH}$ (edges and faces of the kaolinite mineral are charged negatively) is more likely to generate samples with unique characteristics than the reconstituted state, as it is neither dependent on the initial state of the sample nor the preparation method. Therefore, the arrangement produced by altering the sample $\mathrm{pH}$ to 9 is proposed in this study as the state capable of generating the intrinsic characteristics of the clay material. The value of $\mathrm{pH}$ chosen, 9 , is to ensure no change in the edges' charge. Indeed, Figure 4.6a and b show that the pH9 specimens of Kaolin Clay and Ball Clay respectively are the lowest curves within the consolidation spectrum of the specimens tested. As the load increases, all curves tend to converge to a smaller void ratio closer to the void ratio of the $\mathrm{pH} 9$ specimen.

\section{3 - MIP RESULTS}

In order to investigate the microstructure, Mercury Intrusion Porosimetry (MIP) tests were carried out for freeze-dried specimens of Kaolin and Ball Clay previously loaded in the conventional oedometer/CRS consolidometer prepared with initial water contents of $96 \%$, 
$45 \%$ and $\mathrm{pH} 9$ for the Kaolin Clay and 94.5\%, 47.25\% and $\mathrm{pH} 9$ for the Ball Clay. The specimens were loaded up to $2,90,360,2,000,5,000$ and $11,000 \mathrm{kPa}$.

Due to the fact that the objective of these experiments was to understand the microstructure of the specimens at various loading stages, the samples loaded in the conventional oedometer/CRS consolidometer for the MIP test were unloaded quickly in one step, not allowing water to flow out of the sample (in so far as it was possible), unlike the experiments performed for obtaining the consolidation curves; therefore a difference in void ratio between the consolidation curve and these samples is expected. After loading, the samples were freeze-dried, but this did not necessarily happen immediately after the consolidation due to availability of the lyophilizer. Therefore, a difference might be expected between the void ratios after the consolidation test and immediately before the freeze-drying. Finally, it is known that the MIP test has some limitations that cause a difference between the real void ratios of the sample and the MIP ones. Thus, Figure 4.9 and Figure 4.10 show these three differences for the Kaolin Clay and Ball Clay respectively. Annex A shows the difference in results between the MIP tests carried out on those specimens of Kaolin and Ball Clay that were unloaded quickly in the oedometer/CRS consolidometer and those unloaded in as many steps as if the specimen was being prepared for an ordinary consolidation test. In Annex A it is also possible to check the difference in the consolidation curve depending on the unloading method chosen - whether the unloading was done in one single step (removing all the weight at once) and allowing the swelling to stabilize, or the unloading was done in as many steps as used for the loading, allowing the swelling of the specimens to stabilize at every step of the unloading process.

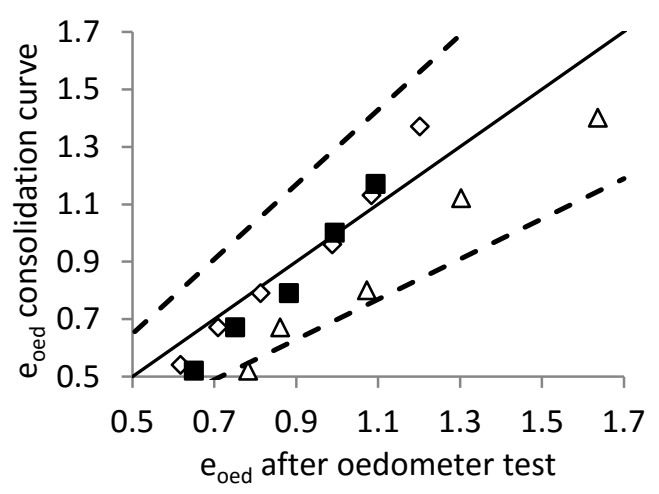

(a)

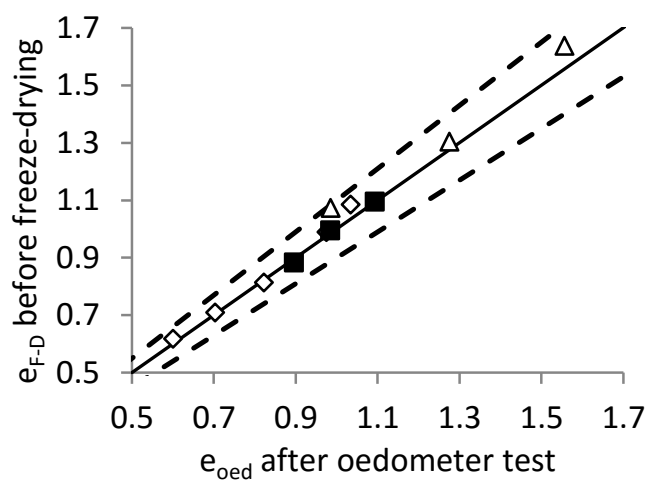

(b) 


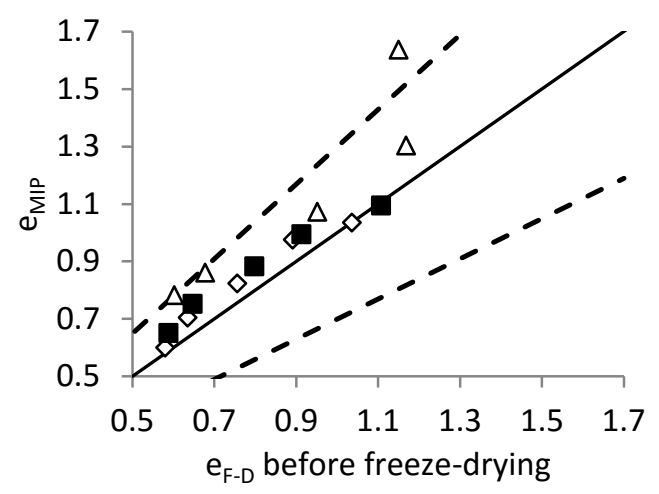

(c)

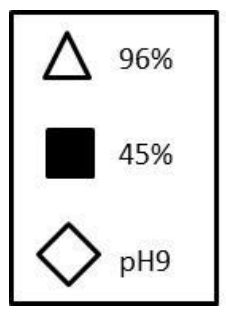

(d)

Figure 4.9 - Kaolin Clay: Relationship between (a) void ratio at the consolidation curve and void ratio after the oedometer/CRS test, (b) void ratio after the oedometer/CRS test and void ratio before freeze-drying and (c) void ratio before freeze-drying and MIP void ratio. Full lines are 1:1 and dashed lines are: (a) and (c) 30\% span tolerance and (b) $10 \%$ span tolerance, (d) legend.

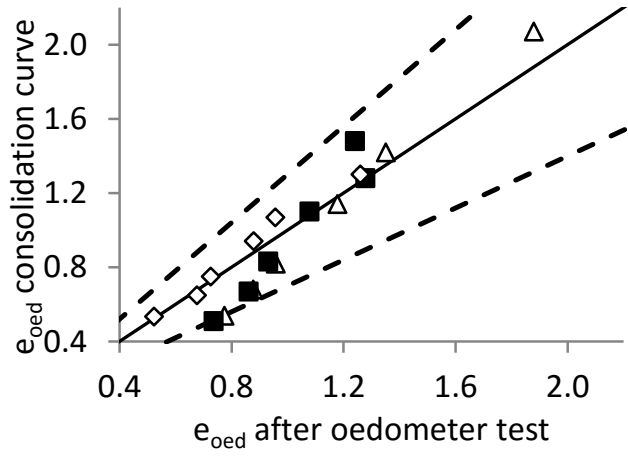

(a)

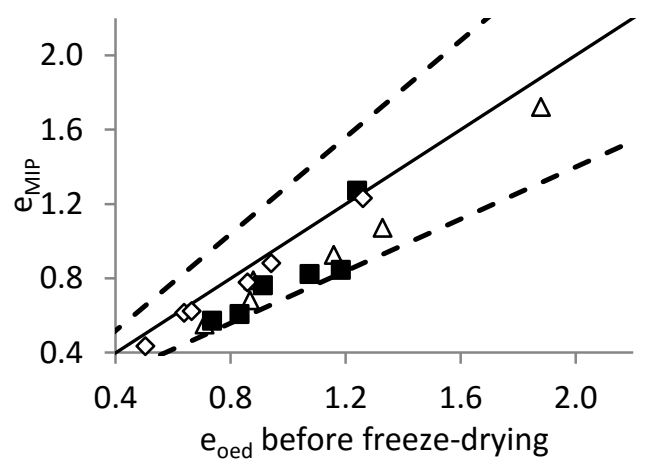

(c)

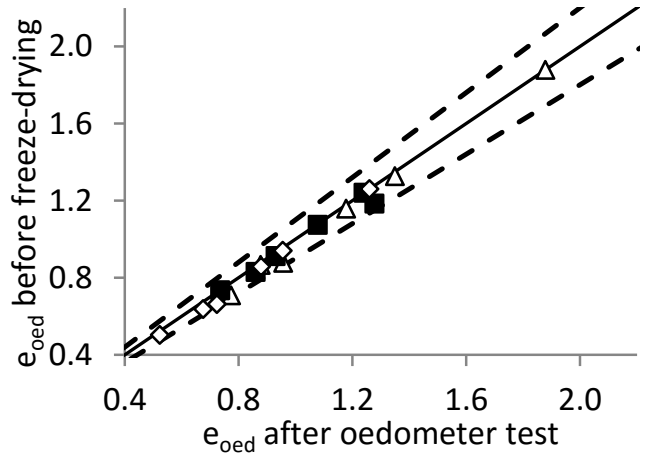

(b)

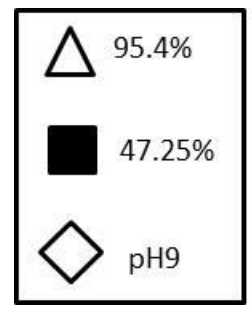

(d)

Figure 4.10 - Ball Clay: Relationship between (a) void ratio at the consolidation curve and void ratio after the oedometer/CRS test, (b) void ratio after the oedometer/CRS test and void ratio before freeze-drying and (c) void ratio before freeze-drying and MIP void ratio. Full lines are 1:1 and dashed lines are: (a) and (c) $30 \%$ span tolerance and (b) $10 \%$ span tolerance, (d) legend

The graphs show that the difference between the void ratio at the consolidation curve and the oedometer/CRS test and between the void ratio before freeze-drying and MIP is within $\pm 30 \%$, while the difference between the void ratio after the oedometer/CRS test and before the freeze-drying is within $\pm 10 \%$. The four groups of data (void ratios: consolidation curve, oedometer/CRS, freeze-drying and MIP) went through the ANOVA statistical test. The 
ANOVA compares the averages of $\mathrm{k}$ samples and decides whether these samples were extracted from populations of the same average value. They were considered to be part of the same group within $95 \%$ of reliability for both clays (Annex B). The differences found were then considered acceptable, especially when it is taken into account that the four groups of data are a result of three different procedures. The major sources of error regarding the MIP test are also highlighted in Annex C. It is noticeable that, as opposed to what the majority of the literature suggests, the void ratio values obtained through the MIP tests are greater than the void ratios obtained before the freeze-drying only for the Kaolin Clay specimens. Similar results were also obtained by Pedrotti (2016) for saturated specimens of Kaolin Clay. It is a challenge to draw definite conclusions regarding the reasons for such behaviour; herein it is speculated that such difference is a combination of possible errors associated with sample preparations, regarding formation of cracks and crystals on the specimens. The fact that the Ball Clay specimens did not present the same behaviour adds more mystery to the problem, since the tests were performed in the same equipment and by the same operator.

Figure 4.11 and Figure 4.12 show the MIP results, in terms of the cumulative intrusion curves and Pore Size Density (PSD) curves, of the loading progress for the specimens of Kaolin Clay and Ball Clay respectively. The van Genuchten fitting parameters used to fit the cumulative intrusion curve for the Kaolin Clay and Ball Clay are presented in Annex D, together with details of the van Genuchten fitting procedure. Herein, it is anticipated that the fittings were adequate, with the smallest $\mathrm{R}^{2}$ of 0.9995 and 0.9984 for the Kaolin and Ball Clay respectively.

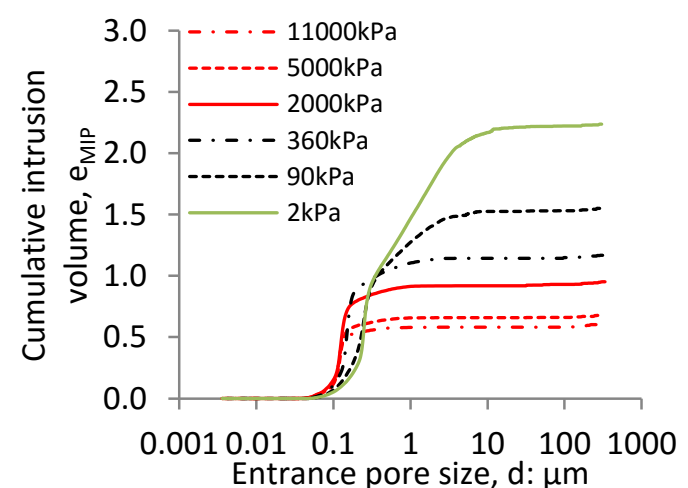

(a)

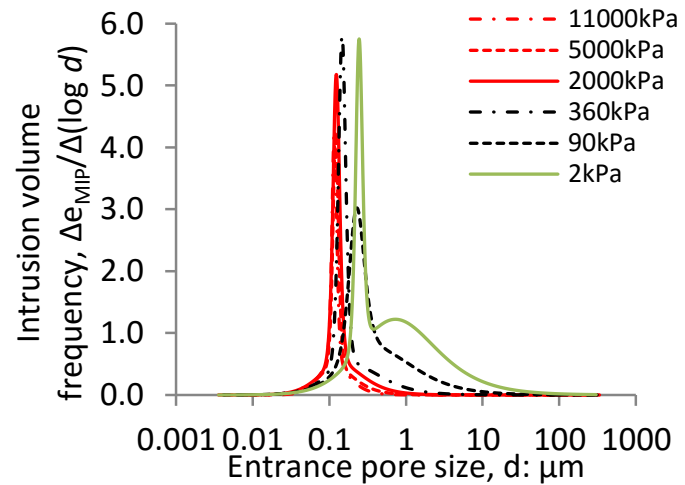

(b) 


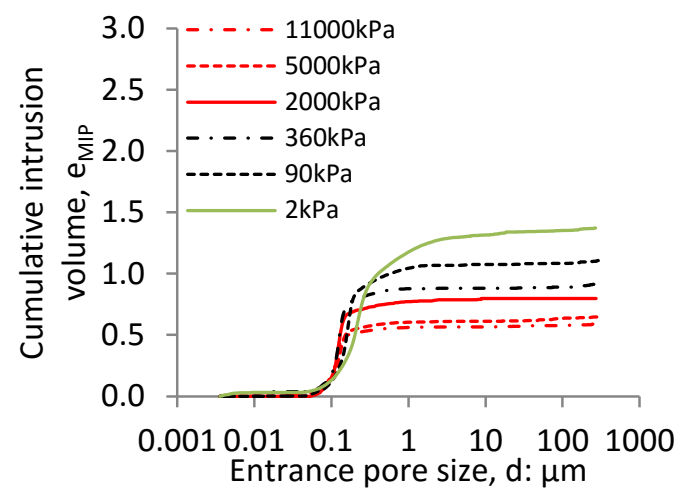

(c)

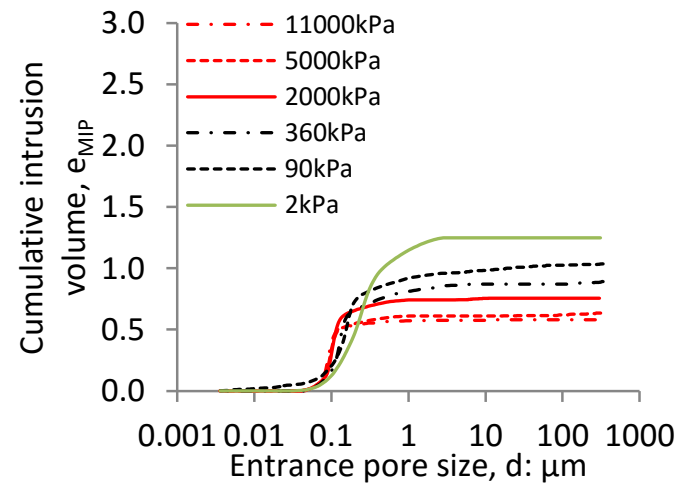

(e)

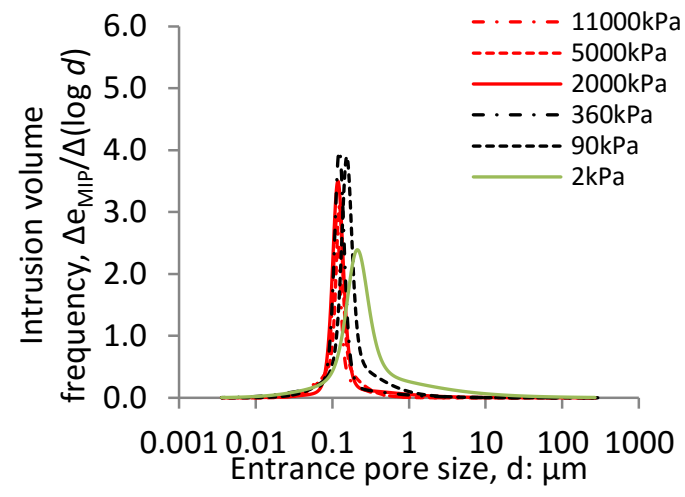

(d)

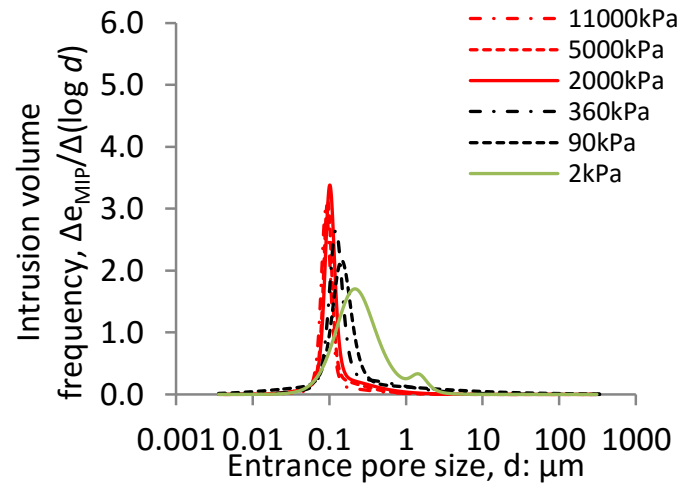

(f)

Figure 4.11 - Kaolin Clay: (a) Cumulative intrusion curve $\mathrm{w}_{\mathrm{i}}=96 \%$, (b) Pore Size Density curve $\mathrm{w}_{\mathrm{i}}=96 \%$, (c) Cumulative intrusion curve $\mathrm{w}_{\mathrm{i}}=45 \%$, (d) Pore Size Density curve $\mathrm{w}_{\mathrm{i}}=45 \%$, (e) Cumulative intrusion curve pH9, (f) Pore Size Density curve pH9

Illustrating the microstructure of the Kaolin Clay, Figure 4.11a and b show the cumulative intrusion curve and PSD of the reconstituted $\left(\mathrm{w}_{\mathrm{i}}=96 \%\right)$ specimens. As expected, the overall void ratio reduces with the increase in the loading. The curve at $2 \mathrm{kPa}$ clearly has two distinct modes (the nature of these modes is explained in the next section), while at all other loading stages they appear to have a single mode. The frequencies of the smallest pores are roughly the same for all loading stages except $90 \mathrm{kPa}$. The dominant pore size of this mode is similar for the 2 and $90 \mathrm{kPa}$ and for the 360,2,000, 5,000 and 11,000kPa.

Figure 4.11c and d show the cumulative intrusion curve and PSD of the remoulded $\left(\mathrm{w}_{\mathrm{i}}=\right.$ 45\%) specimens. Again, the overall void ratio reduces with the increase in the loading. The curves appear to have a single mode for all loading stages. The frequencies of the smallest pores are roughly the same for all loading stages except $2 \mathrm{kPa}$. The dominant pore size of this mode is similar for all loading stages.

Figure 4.11e and $\mathrm{f}$ show the cumulative intrusion curve and PSD of the $\mathrm{pH} 9$ specimens. Once again, the overall void ratio reduces with the increase in the loading. The curves appear to have a single mode for all loading stages. The frequencies of the smallest pores are roughly 
the same for all loading stages except $2 \mathrm{kPa}$. The dominant pore size of this mode is also similar for all loading stages.

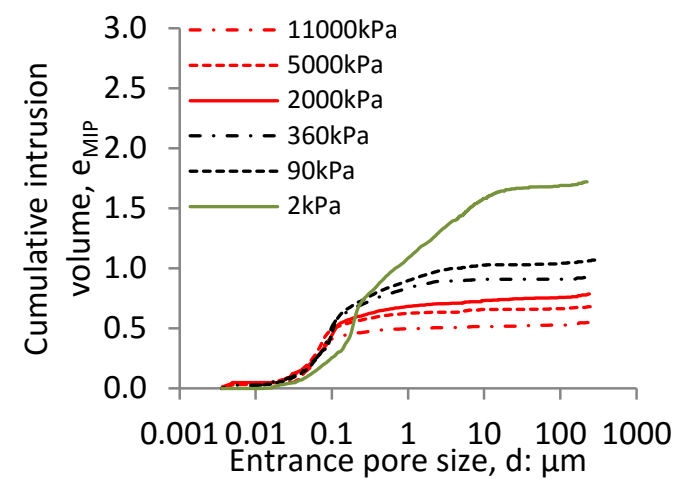

(a)

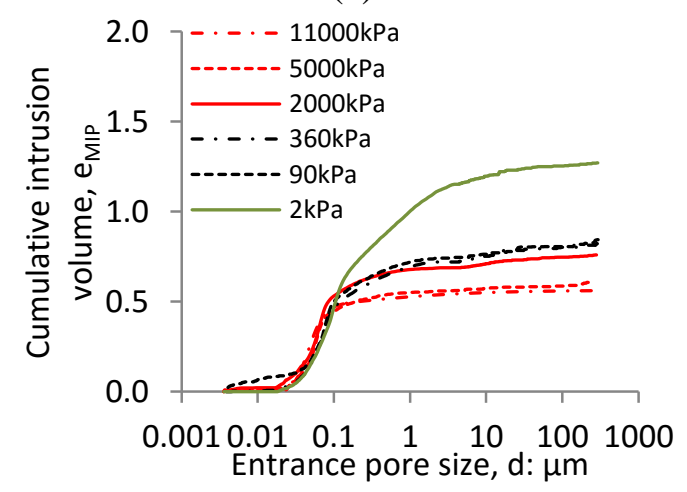

(c)

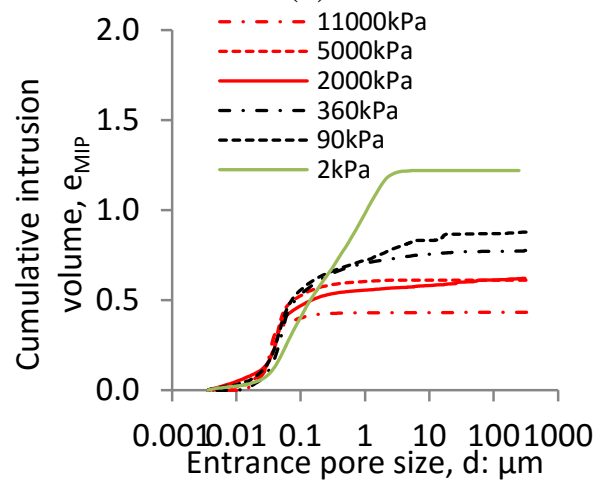

(e)

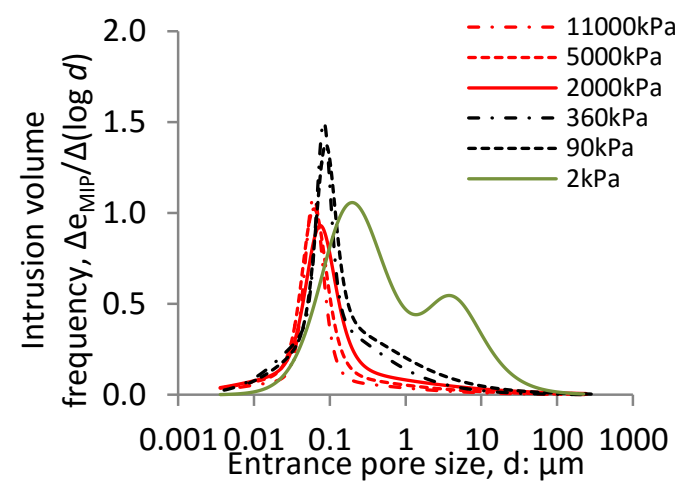

(b)

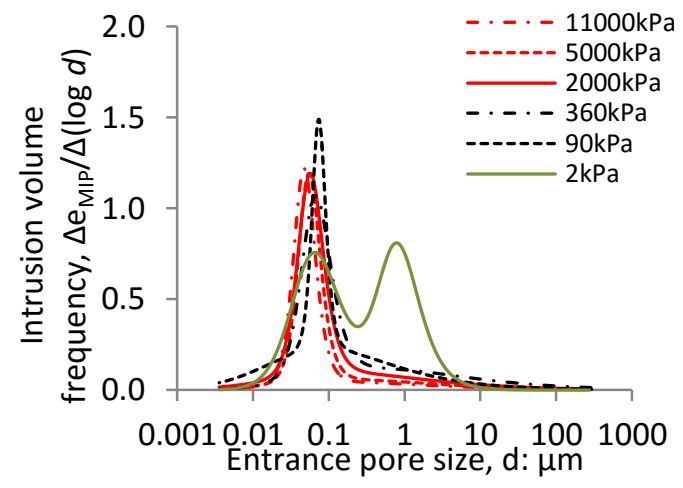

(d)

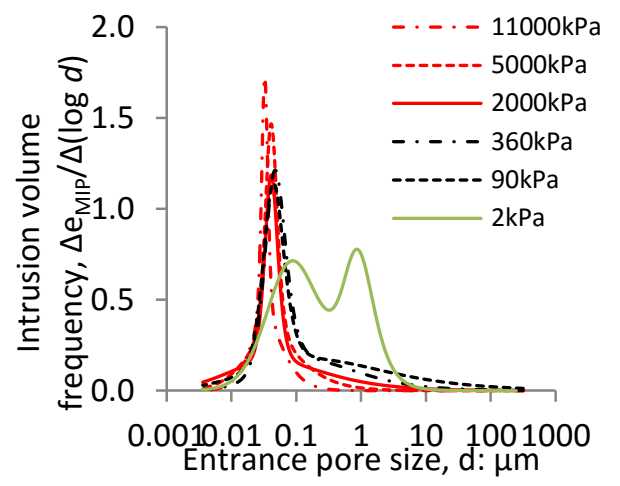

(f)

Figure 4.12 - Ball Clay: (a) Cumulative intrusion curve $\mathrm{w}_{\mathrm{i}}=94.5 \%$, (b) Pore Size Density curve $\mathrm{w}_{\mathrm{i}}=94.5 \%$, (c) Cumulative intrusion curve $\mathrm{w}_{\mathrm{i}}=47.25 \%$, (d) Pore Size Density curve $\mathrm{w}_{\mathrm{i}}=47.25 \%$, (e) Cumulative intrusion curve pH9 and (f) Pore Size Density curve pH9

Regarding the microstructure of the Ball Clay, Figure 4.12a and $\mathrm{b}$ show the cumulative intrusion curve and PSD of the reconstituted $\left(\mathrm{w}_{\mathrm{i}}=94.5 \%\right)$ specimens. As expected, the overall void ratio reduces with the increase in the loading. The curve at $2 \mathrm{kPa}$ clearly has two distinct modes, while at all other loading stages they appear to have a single mode. The frequencies of the smallest pores are roughly the same for the loadings after $2 \mathrm{MPa}$. The 
dominant pore size of this mode is similar for the 90 and $360 \mathrm{kPa}$ and for the 2,000, 5,000 and $11,000 \mathrm{kPa}$.

Figure $4.12 \mathrm{c}$ and $\mathrm{d}$ show the cumulative intrusion curve and PSD of the remoulded $\left(\mathrm{w}_{\mathrm{i}}=\right.$ 47.25\%) specimens. Again, the overall void ratio reduces with the increase in the loading. The curve at $2 \mathrm{kPa}$ clearly has two distinct modes, while at all other loading stages they appear to have a single mode. The frequencies of the smallest pores are roughly the same for all loading stages except 2 and $90 \mathrm{kPa}$. The dominant pore size of this mode is similar for all loading stages.

Figure 4.12e and $\mathrm{f}$ show the cumulative intrusion curve and PSD of the $\mathrm{pH} 9$ specimens. Once again, the overall void ratio reduces with the increase in the loading. The curves appear to have a single mode for all loading stages, except $2 \mathrm{kPa}$. The dominant pore size of this mode is also similar for all loading stages. However, the frequencies increase as loading increases.

To summarize, both clays present the same trend for all specimens. The cumulative curve shows that, as the load progresses, the overall void ratio reduces, while the PSD curve shows that, at the lowest load, the frequency of the pores clearly has two distinct modes for the three specimens of Ball Clay and the reconstituted specimen of the Kaolin Clay. As the load increases, the overall diameter of the pores reduces (shifting the curve towards the smallest pores). At the highest load it is not possible to distinguish between two clear sizes of pores. The same conclusions can be derived from the consolidation curves, where it is possible to see that, as the load increases, the overall void ratio of the specimen reduces; thus the size of the pores also reduces. To analyse these data in more detail, the three specimens of each clay were plotted at different loading stages, as shown in Figure 4.13 and Figure 4.14 for the Kaolin Clay and Ball Clay respectively.

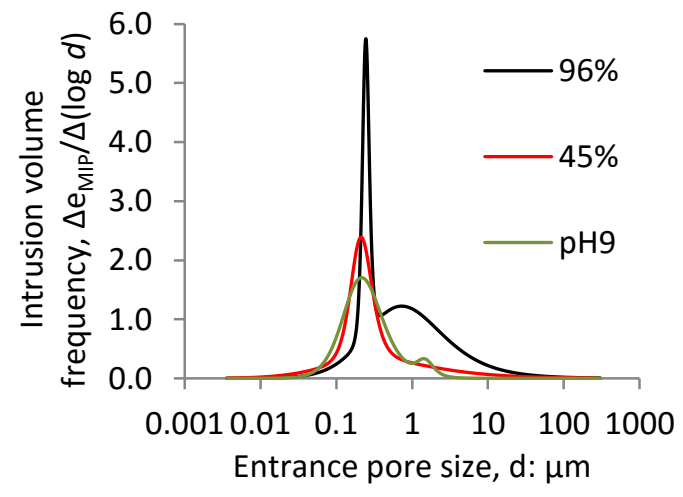

(a)

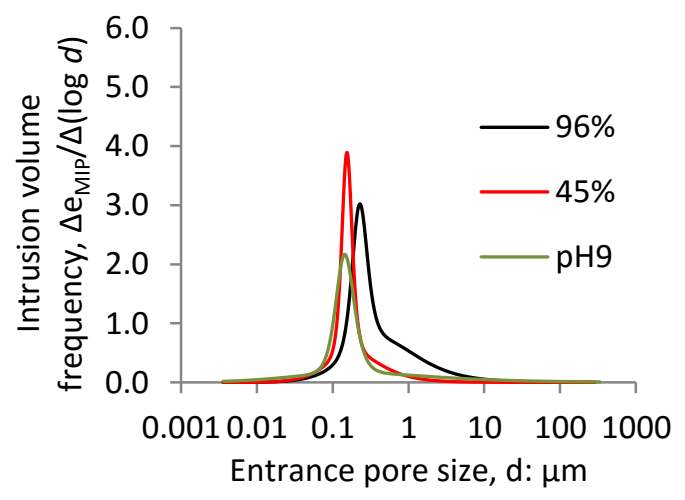

(b) 


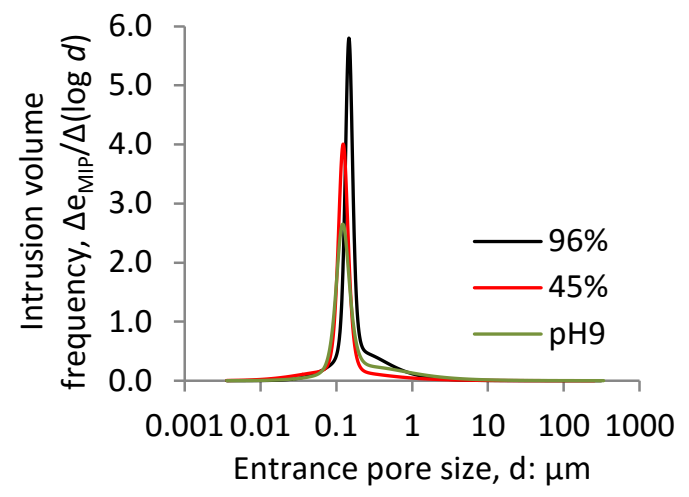

(c)

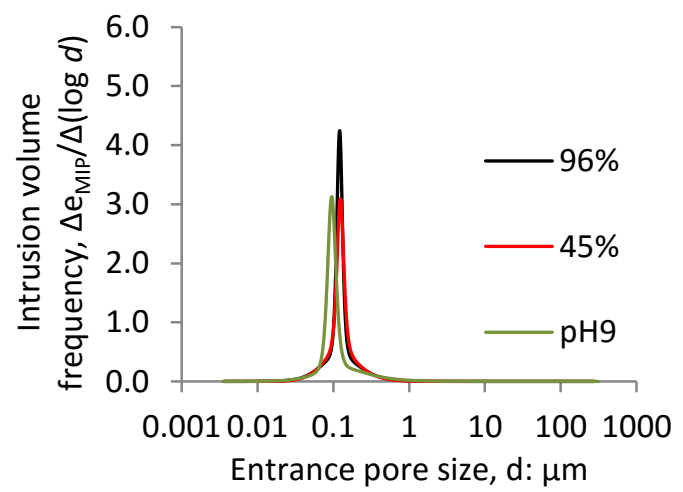

(e)

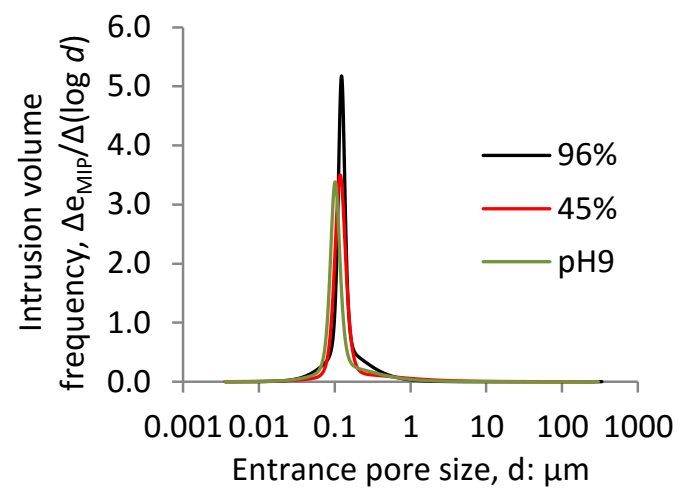

(d)

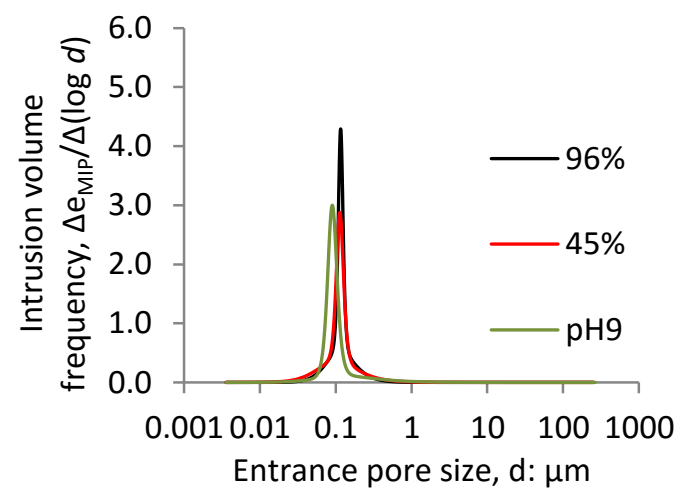

(f)

Figure 4.13 - PSD of Kaolin Clay: (a) $2 \mathrm{kPa}$, (b) $90 \mathrm{kPa}$, (c) $360 \mathrm{kPa}$, (d) $2,000 \mathrm{kPa}$, (e) $5,000 \mathrm{kPa}$ and (f) $11,000 \mathrm{kPa}$

For the Kaolin Clay specimens, at $2 \mathrm{kPa}$ only the reconstituted specimen clearly shows the behaviour of two distinct modes. From 90kPa onwards, all specimens appear to have a single mode distribution. From $360 \mathrm{kPa}$ the dominant pore size is roughly the same for all three specimens and only the frequencies are different, with the reconstituted specimen showing the highest value. It is worth noticing that the effects of suction, induced by the preparation procedure, can only be seen in the samples loaded at $2 \mathrm{kPa}$, as all other samples are loaded to more than the preconsolidation stress values (Table 4.1) of the respective specimen.

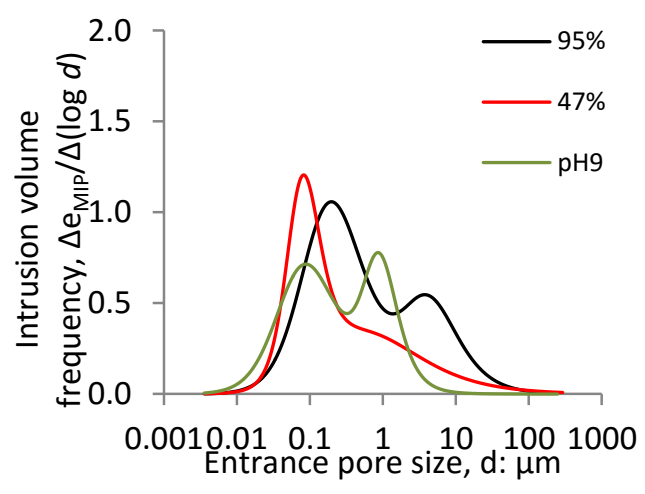

(a)

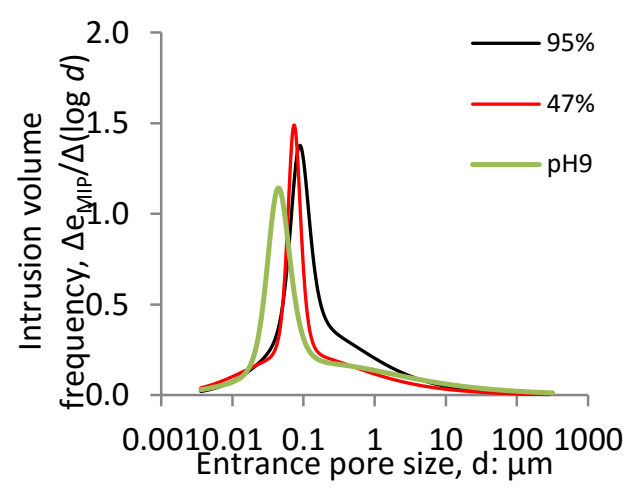

(b) 


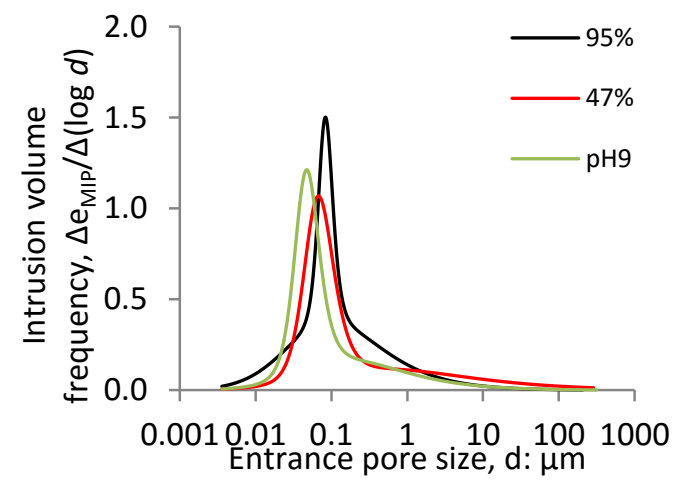

(c)

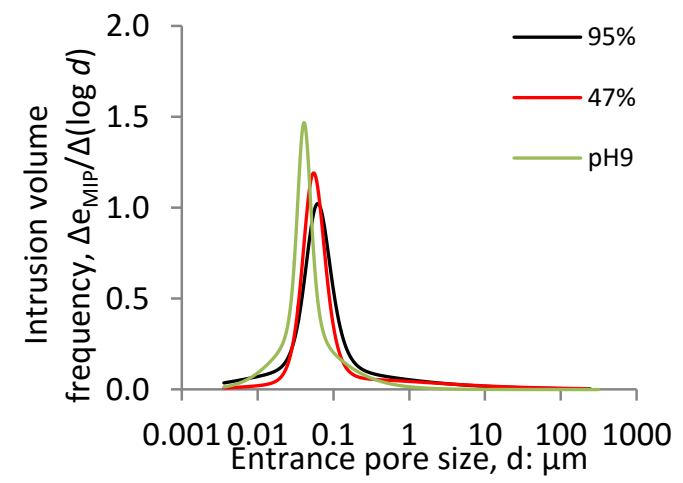

(e)

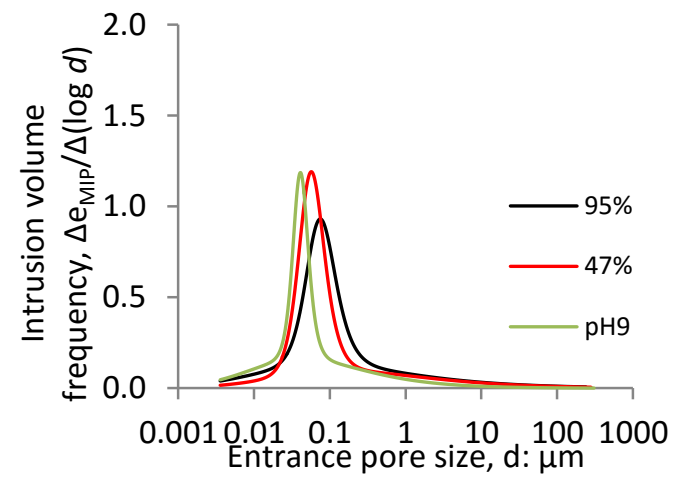

(d)

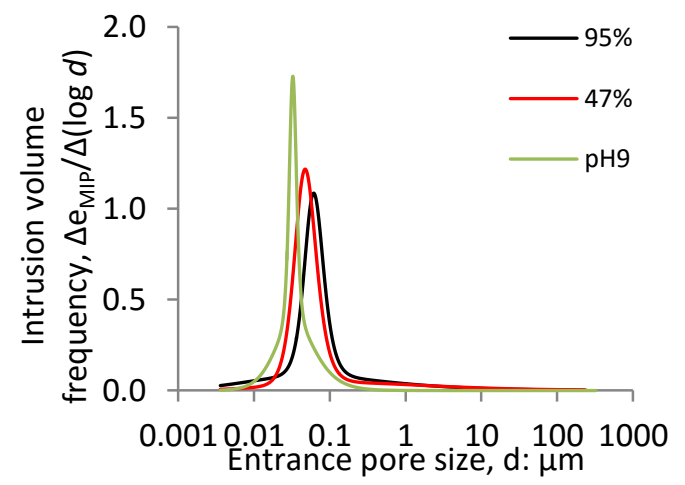

(f)

Figure 4.14 - PSD of Ball Clay: (a) $2 \mathrm{kPa}$, (b) $90 \mathrm{kPa}$, (c) $360 \mathrm{kPa}$, (d) $2,000 \mathrm{kPa}$, (e) $5,000 \mathrm{kPa}$ and (f) $11,000 \mathrm{kPa}$

For the Ball Clay specimens, at $2 \mathrm{kPa}$ all three specimens clearly show the behaviour of two distinct modes. This picture changes from $90 \mathrm{kPa}$ and around $5 \mathrm{MPa}$ all specimens appear to have a single mode distribution. From $360 \mathrm{kPa}$ onwards, the dominant pore size is roughly the same for all three specimens and only the frequencies are different. Herein again the effects of suction, induced by the preparation procedure, can only be seen in the samples loaded at $2 \mathrm{kPa}$, as all other samples are loaded to more than the preconsolidation stress values (Table 4.2) of the respective specimen.

To summarize, when comparing the three specimens of the Kaolin and Ball Clay at each loading stage, it is possible to note that the difference between the three samples reduces as the loading increases; however, even at the highest load applied it is still possible to see some minor differences that could be regarded as a statistical error, as was the case for the consolidation curves. Nonetheless, one can say that the PSD of the three samples at $11,000 \mathrm{kPa}$ is roughly the same, as well as assume that at this stage of loading the consolidation curves are convergent and overlap each other.

Table 4.5 and Table 4.6 show the difference between the overall porosity of the reconstituted (96\% Kaolin Clay and 94.5\% Ball Clay) or remoulded (45\% Kaolin Clay and $47.25 \%$ Ball 
Clay) specimens and the pH9 specimen in the consolidation curve and in the MIP test, as well as the difference in results between these two experiments for the Kaolin Clay and Ball Clay respectively. These data again show what has been previously said - that the difference in the overall porosity between the reconstituted or remoulded and $\mathrm{pH} 9$ specimens reduces as the load increases, with a sporadic small increase seen especially in the MIP test, which is not necessarily real (Annex C).

Table 4.5 - Kaolin Clay: difference in overall porosity between $96 \%$ or $45 \%$ and $\mathrm{pH} 9$ specimens in the consolidation curve and MIP test

\begin{tabular}{ccccccc}
\hline $\begin{array}{c}\text { Load } \\
(\mathrm{kPa})\end{array}$ & $\begin{array}{c}\text { Consolidation } \\
\text { Curve }\end{array}$ & MIP & $\Delta$ (Cons - MIP) & $\begin{array}{c}\text { Consolidation } \\
\text { Curve }\end{array}$ & MIP & $\Delta($ Cons - MIP) \\
\hline 2 & $7.9 \%$ & $13.7 \%$ & $5.8 \%$ & $3.5 \%$ & $6.6 \%$ & $3.1 \%$ \\
90 & $5.3 \%$ & $9.9 \%$ & $4.6 \%$ & $0.9 \%$ & $1.2 \%$ & $0.3 \%$ \\
360 & $3.9 \%$ & $6.7 \%$ & $2.8 \%$ & $1.0 \%$ & $0.3 \%$ & $0.7 \%$ \\
2,000 & $4.0 \%$ & $5.0 \%$ & $1.0 \%$ & $0.1 \%$ & $1.4 \%$ & $1.3 \%$ \\
5,000 & $0.0 \%$ & $1.7 \%$ & $1.7 \%$ & $0.1 \%$ & $0.0 \%$ & $0.1 \%$ \\
11,000 & $0.9 \%$ & $0.1 \%$ & $0.8 \%$ & $1.2 \%$ & $0.5 \%$ & $0.7 \%$ \\
\hline
\end{tabular}

Table 4.6 - Ball Clay: difference in overall porosity between $94.5 \%$ or $47.25 \%$ and $\mathrm{pH} 9$ specimens in the consolidation curve and MIP test

\begin{tabular}{ccccccc}
\hline & \multicolumn{2}{c}{$\Delta \mathrm{n}(94.5 \%-\mathrm{pH})$} & \multicolumn{3}{c}{$\Delta \mathrm{n}(47.25 \%-\mathrm{pH})$} \\
$\begin{array}{c}\text { Load } \\
(\mathrm{kPa})\end{array}$ & $\begin{array}{c}\text { Consolidation } \\
\text { Curve }\end{array}$ & MIP & $\Delta$ (Cons - MIP) & $\begin{array}{c}\text { Consolidation } \\
\text { Curve }\end{array}$ & MIP & $\Delta($ Cons - MIP) \\
\hline 2 & $7.0 \%$ & $8.0 \%$ & $1.0 \%$ & $0.8 \%$ & $0.9 \%$ & $0.1 \%$ \\
90 & $7.0 \%$ & $4.0 \%$ & $3.0 \%$ & $4.4 \%$ & $2.8 \%$ & $1.6 \%$ \\
360 & $4.9 \%$ & $4.3 \%$ & $0.6 \%$ & $3.9 \%$ & $1.5 \%$ & $2.4 \%$ \\
2,000 & $2.5 \%$ & $5.9 \%$ & $3.4 \%$ & $2.6 \%$ & $5.2 \%$ & $2.6 \%$ \\
5,000 & $1.2 \%$ & $2.1 \%$ & $0.9 \%$ & $0.8 \%$ & $0.7 \%$ & $0.1 \%$ \\
11,000 & $0.0 \%$ & $4.4 \%$ & $4.4 \%$ & $1.3 \%$ & $6.0 \%$ & $4.7 \%$ \\
\hline
\end{tabular}

In the following section a conceptual model is introduced to help in the interpretation of the MIP results described in this section.

\section{4 - CONCEPTUAL MODEL}

In this chapter, it has been shown that the suction induced in the remoulded specimen as a result of the preparation procedure is much higher than the suction induced in the reconstituted specimen (Table 4.1 and Table 4.2) and it is translated into the consolidation curve (Figure 4.6) in the same way as the stress history, which means that the specimens keep 
memory of this suction, which in the consolidation curve appears as the preconsolidation stress. Although this suction explains the differences in the value of preconsolidation stresses, it does not help to justify why, after the preconsolidation stress, the consolidation curves do not overlap each other. Figure 4.15a shows the consolidation curves of three specimens of Kaolin Clay samples, two of which were consolidated at $2,000 \mathrm{kPa}\left(\mathrm{w}_{\mathrm{i}}=96 \%\right.$ and $\left.45 \%\right)$ and one of which was prepared at the initial water content of $96 \%$ loaded to $40 \mathrm{kPa}$ (preconsolidation stress calculated for the specimen at $\mathrm{w}_{\mathrm{i}}=45 \%$; see Table 4.1 ), unloaded to $2 \mathrm{kPa}$ and reloaded to $2,000 \mathrm{kPa}$. If the difference between the two specimens, prepared at the initial water contents of $96 \%$ and $45 \%$, was merely due to the suction induced by the preparation procedure, when the sample at $\mathrm{w}_{\mathrm{i}}=96 \%$ was loaded to the preconsolidation value of the sample $\mathrm{w}_{\mathrm{i}}=45 \%$, then from that point on the three samples should be fairly coincident, as all of the effects caused by the induced suction should have disappeared. As observed in Figure 4.15a this does not happen, which suggests that the difference between the $\mathrm{w}_{\mathrm{i}}=96 \%$ and $\mathrm{w}_{\mathrm{i}}=45 \%$ is not only the different values of suction induced by the preparation procedure. Figure $4.15 \mathrm{~b}$ illustrates through the cumulative intrusion and PSD curves the small size of the plastic deformations observed in the samples at the initial water content of $45 \%$ loaded to effective stresses $(2 \mathrm{kPa}$ and $40 \mathrm{kPa})$ smaller than or equal to the preconsolidation stress of the referred sample. Herein, it is proposed that the explanation for this difference in behaviour comes from the microstructure. As such, a conceptual model is proposed based on the following information:

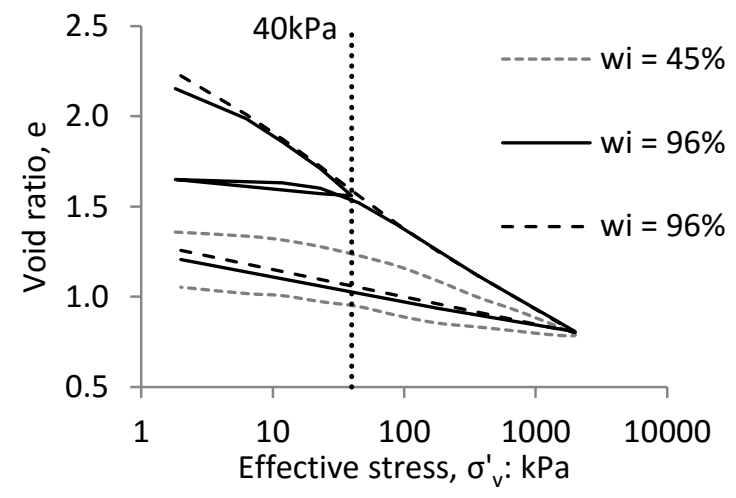

(a)

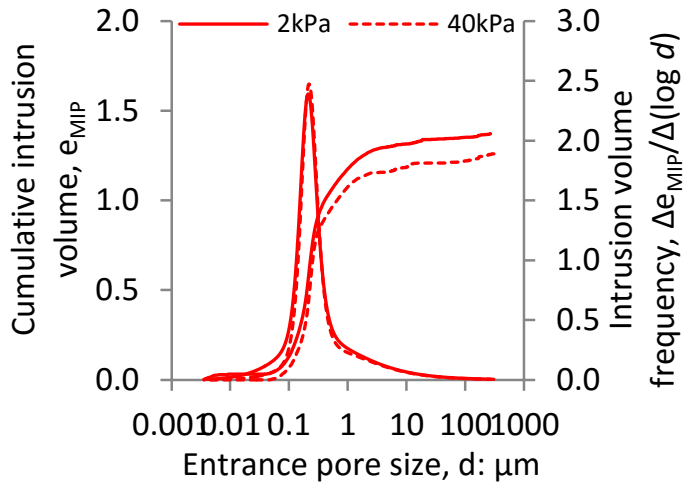

(b)

Figure 4.15 - Kaolin Clay specimens (a) Consolidation test: Curves $\mathrm{w}_{\mathrm{i}}=96 \%$ and $45 \%$ loaded to $2,000 \mathrm{kPa}$ and $\mathrm{w}_{\mathrm{i}}=96 \%$ loaded to $40 \mathrm{kPa}$, unloaded and reloaded to $2,000 \mathrm{kPa}$ and (b) MIP results of $\mathrm{w}_{\mathrm{i}}=45 \%$ loaded to 2 and 40kPa: Cumulative intrusion curve and PSD

Barden \& Sides (1971) proposed an idealized arrangement for clay structures, as shown in Figure 4.16. Based on the results found in the previous topics of this chapter, it is proposed that the reconstituted samples subjected to zero or very low loading have a configuration of 
cardhouse. When the specimen is subjected to significant loading under 1-D consolidation, a change in this configuration is expected, due to the rearrangement of particles similar to the turbostatic and, eventually, dispersed arrangement, depending on the level of loading. It is expected that somewhere along the 1-D consolidation, at very high stresses, this configuration would become more similar to the stack.

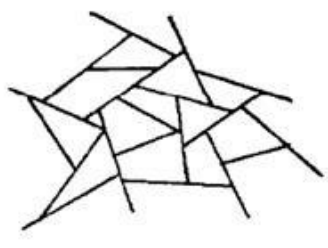

(a) Cardhouse

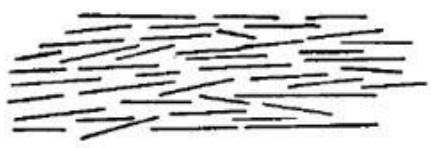

(d) Dispersed

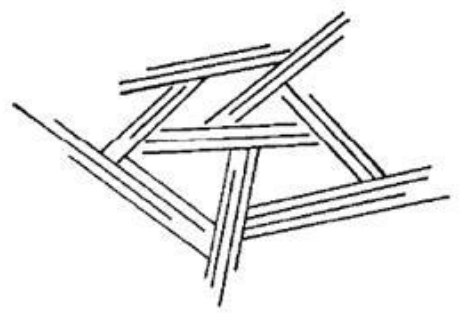

(b) Bookhouse

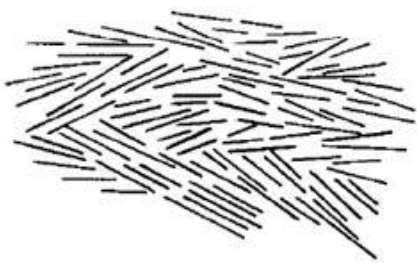

(e) Turbostatic

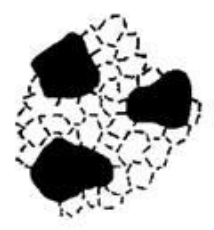

(c) Honeycomb

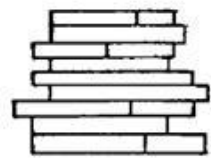

(f) Stack

Figure 4.16 - Idealized clay arrangement (source: Barden \& Sides, 1971)

The smaller void ratio observed in the remoulded specimens, as seen in Figure 4.6, suggest that their particles' arrangement is more turbostatic-like (Figure 4.16). There are fewer edgeto-face contacts in these specimens than in the reconstituted ones. One-dimensional loading will rearrange the particles and, if the load is sufficiently high, this arrangement will be similar to the dispersed one. At very high stresses, this configuration would become more similar to the stack. All these changes in configuration happen at much lower stresses than for the reconstituted specimens, due to the initial configuration of the remoulded samples.

The dispersed-deflocculated fabric created when the $\mathrm{pH}$ increases beyond 5 for soils dominated by kaolinite mineral is similar to the dispersed idealized clay arrangements of Figure 4.16 (Barden \& Sides, 1971). When undergoing 1-D consolidation the rearrangement of particles allowed is very restricted, compared with the reconstituted or remoulded specimen, since contacts between edges and faces are non-existent. If the stress applied to the sample is sufficiently large, the anisotropy induced by 1-D loading orients the particles in an arrangement close to the stack arrangement in the same way as it does for the reconstituted or 
remoulded specimens; however, the pH9 specimens will be oriented at much lower loads, since the arrangements allowed by these specimens are much more restricted than those allowed for the reconstituted or remoulded ones.

Figure 4.17 summarizes the rearrangement of particles with increase in loading for the reconstituted, remoulded and $\mathrm{pH} 9$ specimens.

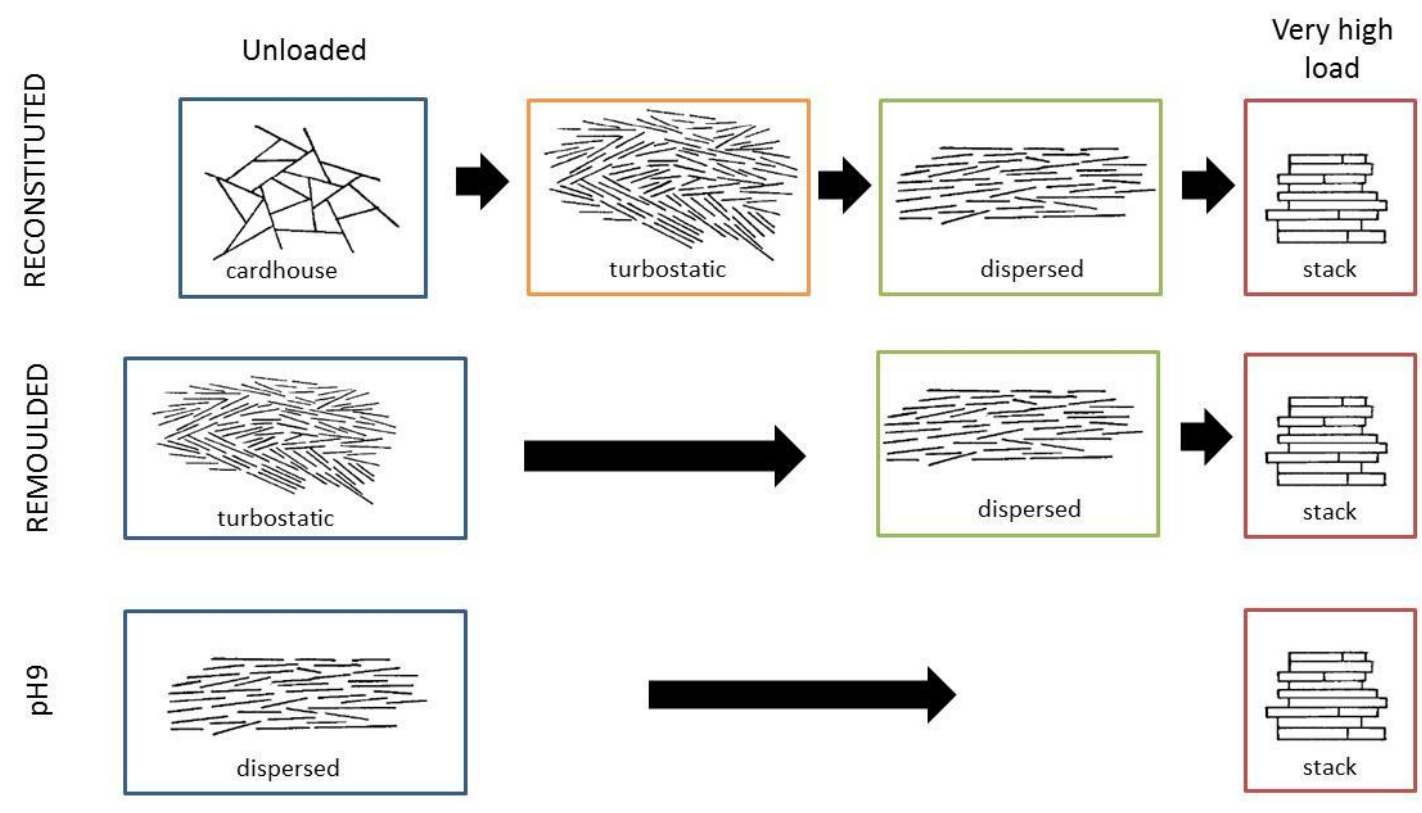

Direction of loading

Figure 4.17 - Summary of the particles' arrangement change with loading for reconstituted, remoulded and pH9 specimens (Idealized clay arrangements after Barden \& Sides, 1971)

Hence, for soils with mineralogy dominated by kaolinite mineral, the arrangement state produced by the change in $\mathrm{pH}$ is more likely to generate samples with unique characteristics than the reconstituted state, since by increasing the $\mathrm{pH}$ to 9 the sample arrangement is compulsorily dispersed, thus has limited deformation, i.e., capabilities and room for different arrangements. Therefore, the arrangement produced by altering the sample $\mathrm{pH}$ to 9 is proposed in this study as the state capable of generating the intrinsic characteristics of the clay material.

Taking into account the MIP results of section 4.3 , it is assumed that pores around $1 \mu \mathrm{m}$ are definitely edge-to-face (EF) pores, while pores around $0.1 \mu \mathrm{m}$ are face-to-face (FF) pores, based on the dimensions of the kaolinite and the pores sizes likely to be created depending on the particles' configuration (Mitchell \& Soga, 2005). Having said that, it is important to note that the magnitude of the EF and FF pores can be very similar, as shown in Figure 4.18. The 
pH9 specimens do not allow contacts between edges and faces; therefore, these specimens only have FF pores and EF pores without contacts. Reconstituted specimens have more EF pores, but as load is applied to the specimens it gradually changes the configuration of the pores from EF to FF. The remoulded sample has a fabric very similar to the $\mathrm{pH} 9$ sample, with very few EF pores at the beginning of loading, which can also be observed in the consolidation curves (Figure 4.6). Thus, rather than nominate the pore sizes micro and macro (as the majority of the literature does), for the clays they are referred to as face-to-face (FF) for the smaller voids and edge-to-face $(\mathrm{EF})$ for the larger ones.

As already mentioned in Chapter 3, the fitting of the cumulative intrusion data from the MIP tests was carried out with a van Genuchten-type bi-modal equation even for the data that had an apparent single mode distribution. The assumption made here is that the two modes fitted by the van Genuchten-type bi-modal equation are the FF and EF pores, where the EF pores count as contact EF and the non-contact, non-parallel arrangement is also considered EF, as shown in Figure 4.18c. This hypothesis is reasonable if we take into account the fact that FF and EF pores can have pores of the same order of magnitude. Furthermore, the range of pore sizes in a face-to-face arrangement is very narrow, while in edge-to-face it is wider, which statistically suggests that FF pores follow a normal distribution, while EF pores follow a lognormal distribution. Proof of these assumptions is presented in Annex D (Figure C.3). These hypotheses were considered for the Kaolin Clay soil and extrapolated to the Ball Clay; however, the authors are aware that these are simplifications of the real mechanism since Ball Clay is not composed of exclusively kaolinite minerals.

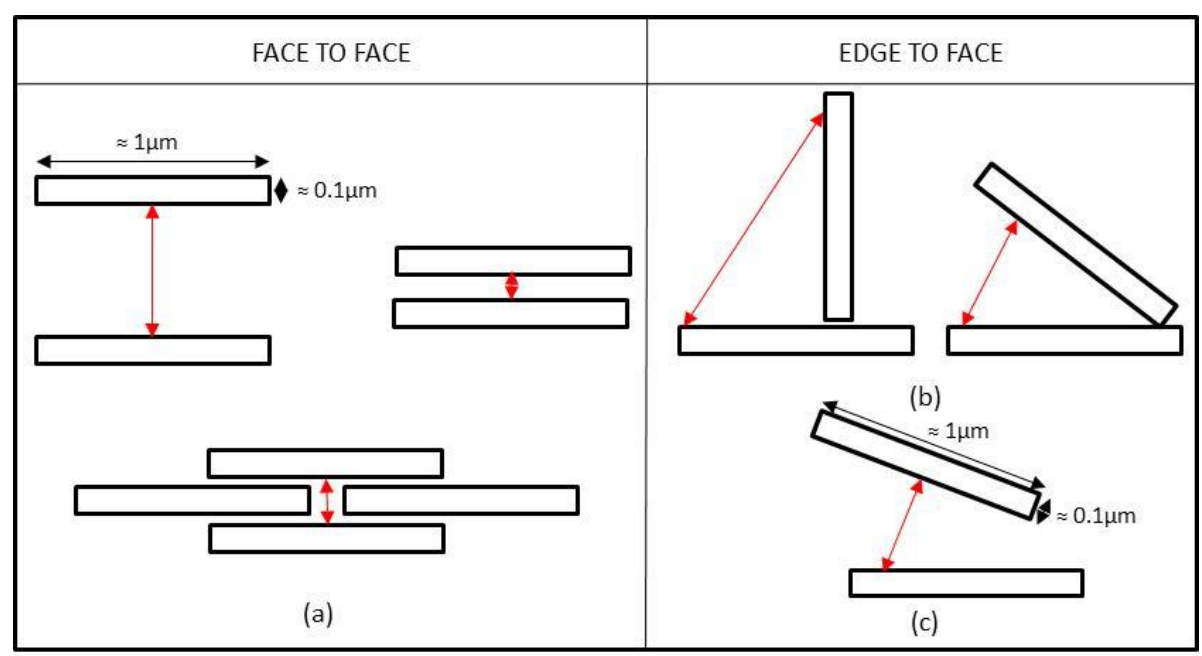

Figure 4.18 - Illustrative differences in pore sizes of (a) face-to-face (non-contact), (b) edge-to-face arrangements (contact) and (c) non-contact, non-parallel arrangement considered EF by the van Genuchten fitting 
Having established these assumptions, it can now be said that the difference between the reconstituted and $\mathrm{pH} 9$ specimens is the $\mathrm{EF}$ contact pores (noting that $\mathrm{pH} 9$ does not allow contacts; therefore all the EF pores of these specimens are due to the non-contact, nonparallel arrangement), while the difference between the reconstituted and the remoulded specimens is the number of pores, since there is no restriction in EF pores for these two.

Figure 4.19a and $\mathrm{b}$ show the FF and EF void ratios obtained in the MIP test against effective stress for the reconstituted, remoulded and $\mathrm{pH} 9$ specimens of Kaolin Clay. The FF void ratio is roughly constant and around the same value for all loads and all specimens, except $2 \mathrm{kPa}$. This may be a result of the randomness of the $2 \mathrm{kPa}$ specimens. The real difference is then due to the EF arrangement. Again, as mentioned many times in this chapter, this difference reduces as the load increases. Figure $4.19 \mathrm{c}$ and d show the dominant diameter of the FF and EF pores of the Kaolin Clay specimens respectively against the vertical effective stress. It is clear that the dominant FF pores change slightly and at $2 \mathrm{MPa}$ all specimens have the same value of dominant FF pores. The dominant EF pores are widely distributed at the lowest loads, but after $2 \mathrm{MPa}$ it tends towards zero for all specimens, which implies the change in arrangement to dispersed. Figure 4.19e and f show the $\mathrm{n}$ fitting parameter of the FF and EF pores of the Kaolin Clay specimens respectively against the vertical effective stress. There is no clear pattern of the $n_{F F}$ against vertical effective stress; the $n_{E F}$, on the other hand, shows a line trend and low values. Finally, Figure $4.19 \mathrm{~g}$ and h show the FF and EF void ratios against the fitting parameters $n_{\mathrm{FF}}$ and $\mathrm{n}_{\mathrm{EF}}$ of the Kaolin Clay specimens respectively. It can be seen that the values of $n_{F F}$ reduce with the decrease in the $e_{F F}$ and the same observation is drawn for the relation $\mathrm{n}_{\mathrm{EF}}$ and $\mathrm{e}_{\mathrm{FF}}$; however, the reduction in $\mathrm{n}_{\mathrm{FF}}$ values is much larger than the reduction in $\mathrm{n}_{\mathrm{EF}}$ values.

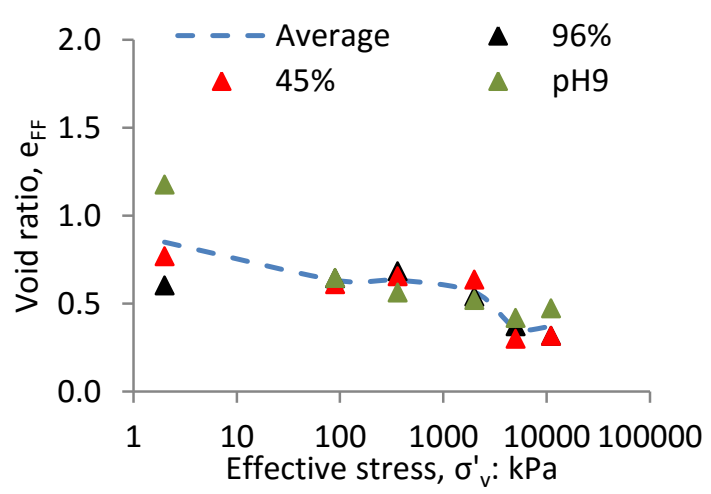

(a)

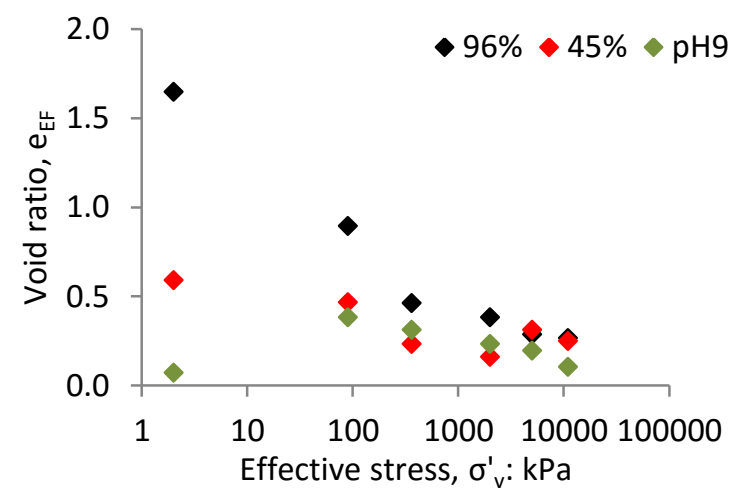

(b) 


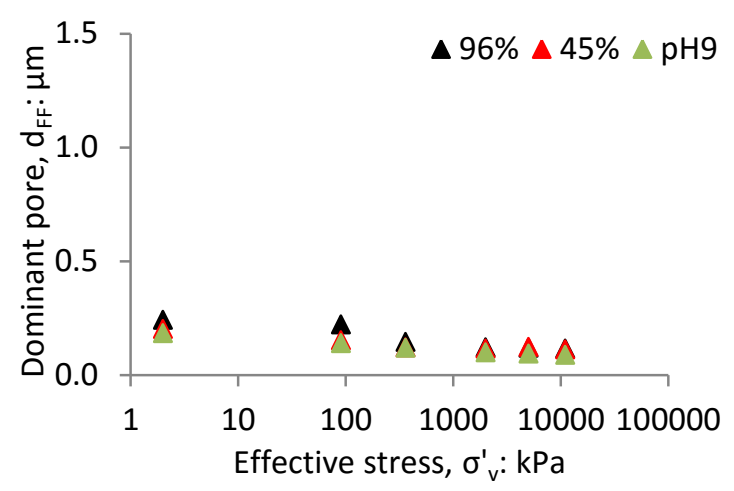

(c)

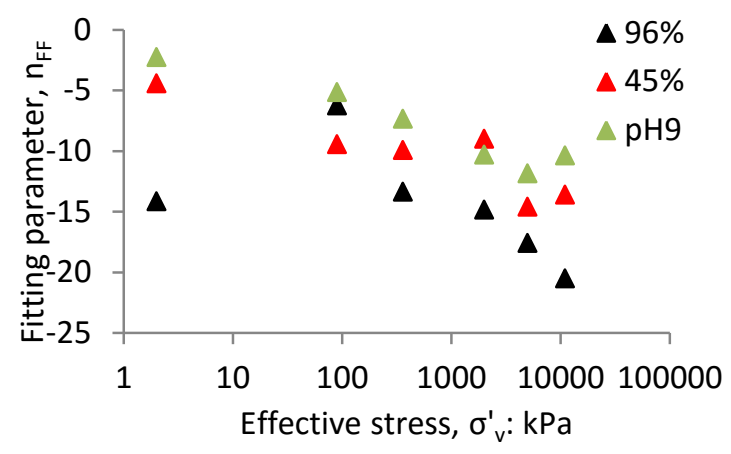

(e)

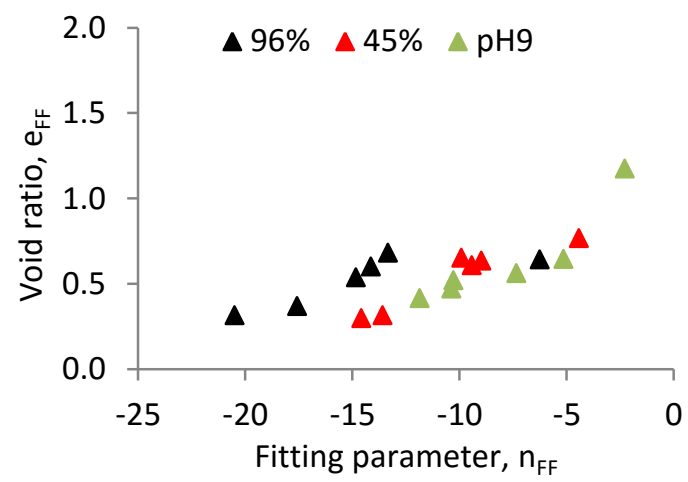

(g)

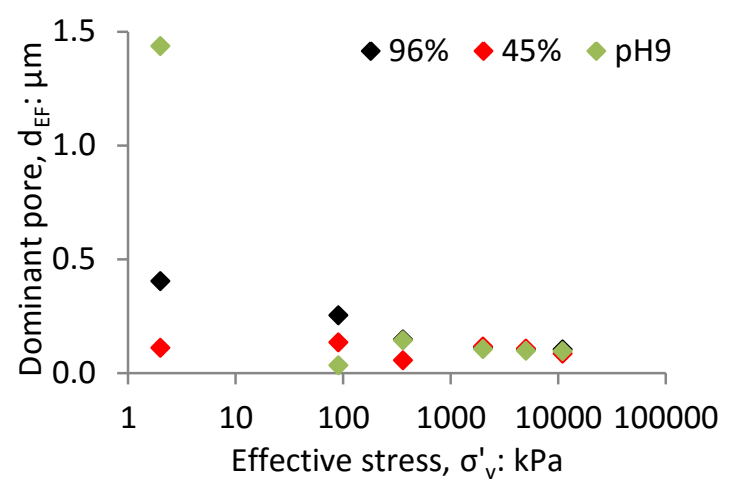

(d)

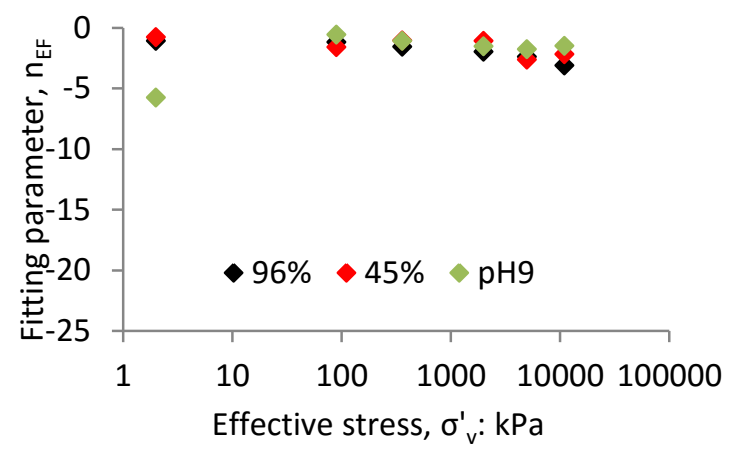

(f)

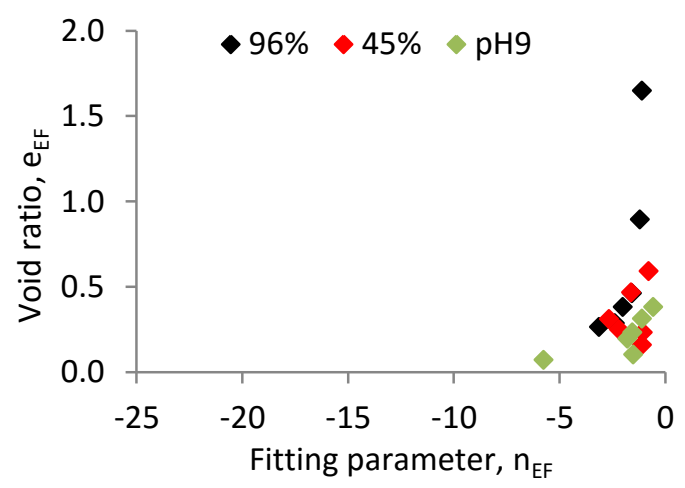

(h)

Figure 4.19 - Kaolin Clay MIP data of: (a) $\mathrm{e}_{\mathrm{FF}} \mathrm{x} \log \sigma_{\mathrm{v}}{ }_{\mathrm{v}}$, (b) $\mathrm{e}_{\mathrm{EF}} \mathrm{x} \log \sigma^{\prime}{ }_{\mathrm{v}}$, (c) $\mathrm{d}_{\mathrm{FF}} \mathrm{x} \log \sigma^{\prime}{ }_{\mathrm{v}}$, (d) $d_{\mathrm{EF}} \mathrm{x} \log \sigma^{\prime}{ }_{\mathrm{v}}$, (e) $\mathrm{n}_{\mathrm{FF}}$ $\mathrm{x} \log \sigma_{\mathrm{v}}^{\prime},(\mathrm{f}) \mathrm{n}_{\mathrm{EF}} \mathrm{X} \log \sigma_{\mathrm{v}}^{\prime},(\mathrm{g}) \mathrm{e}_{\mathrm{FF}} \mathrm{X} \mathrm{n}_{\mathrm{FF}}$ and (h) $\mathrm{e}_{\mathrm{EF}} \mathrm{X} \mathrm{n}_{\mathrm{EF}}$

Figure 4.20a and $\mathrm{b}$ show the FF and EF void ratios obtained in the MIP test against effective stress for the reconstituted, remoulded and pH9 specimens of Ball Clay. The FF and EF void ratio reduces as the load increases. Figure $4.20 \mathrm{c}$ and $\mathrm{d}$ show the dominant diameter of the FF and EF pores of the Ball Clay specimens respectively against the vertical effective stress. It is clear that the dominant FF pores change slightly and at $2 \mathrm{MPa}$ all specimens have almost the same value of dominant FF pores. The dominant EF pores have high values for specimens loaded at $2 \mathrm{kPa}$, then as load progresses this value reduces significantly for all specimens. At $2 \mathrm{MPa}$ all specimens seem to have similar dominant EF pore values, very close to zero, which 
implies the change in arrangement to dispersed. Figure $4.20 \mathrm{e}$ and $\mathrm{f}$ show the $\mathrm{n}$ fitting parameter of the FF and EF pores of the Ball Clay specimens respectively against the vertical effective stress. There is a decrease in the $n_{F F}$ parameter as the vertical effective stress increases; the $\mathrm{n}_{\mathrm{EF}}$ shows a line trend and low values. Finally, Figure $4.20 \mathrm{~g}$ and $\mathrm{h}$ show the FF and EF void ratios against the fitting parameters $n_{F F}$ and $n_{E F}$ of the Ball Clay specimens respectively. It can be seen that the values of $n_{F F}$ reduce with the decrease in the $e_{F F}$ in an exponential manner; $\mathrm{n}_{\mathrm{EF}}$ values are kept almost constant with the reduction of the EF void ratio and a slight variation is seen for the $\mathrm{pH} 9$ specimens.

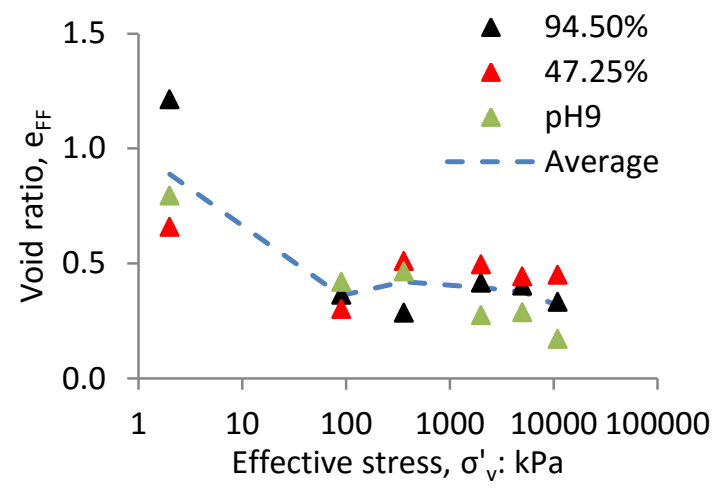

(a)

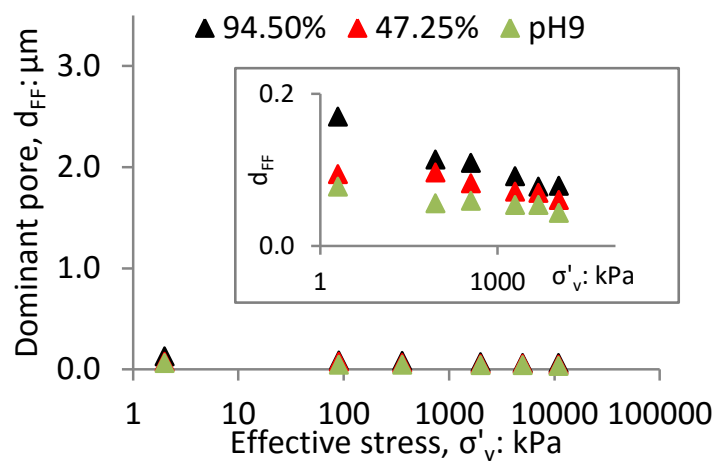

(c)

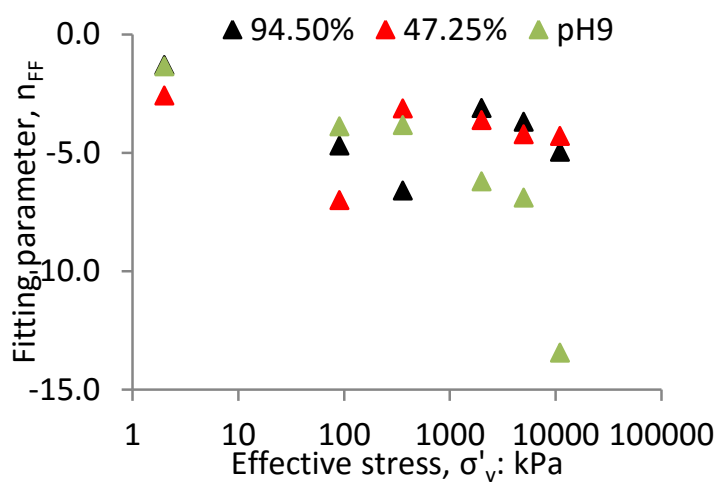

(e)

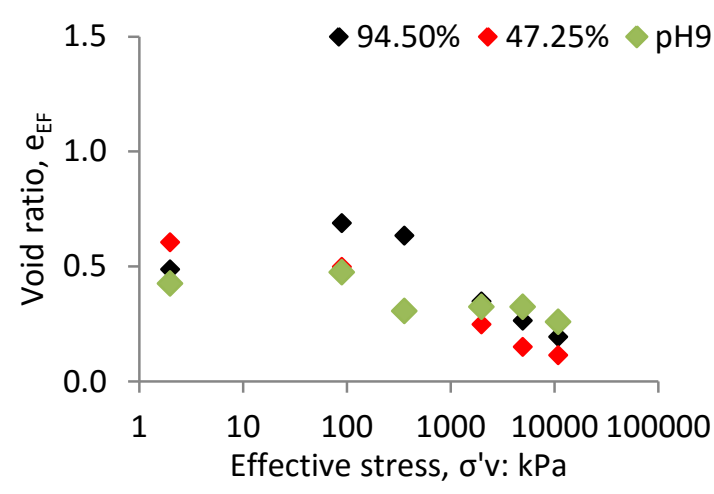

(b)

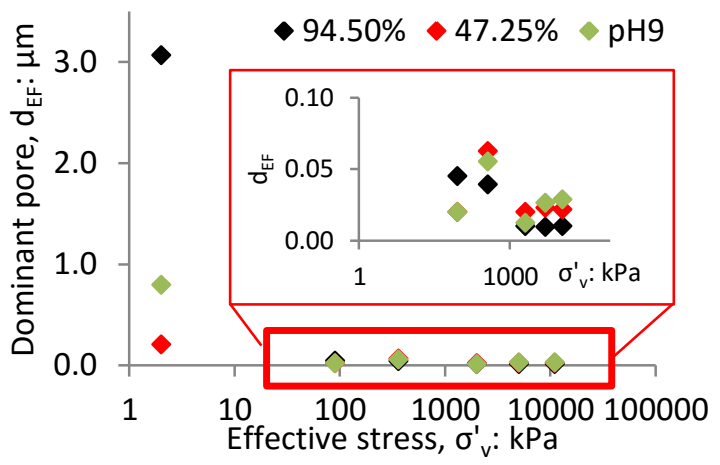

(d)

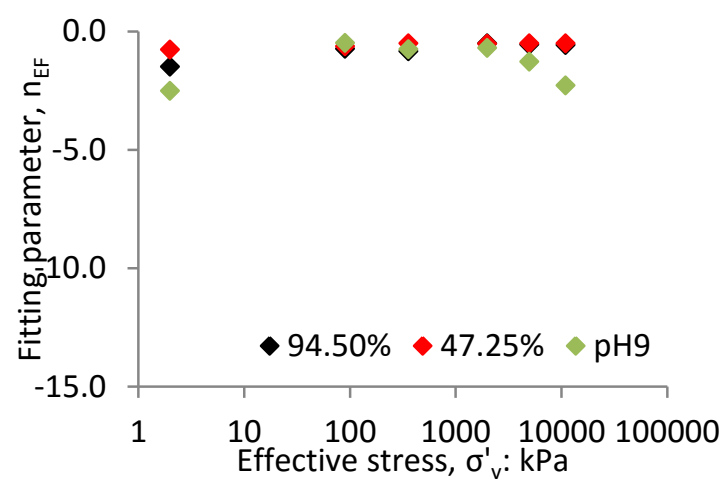

(f) 


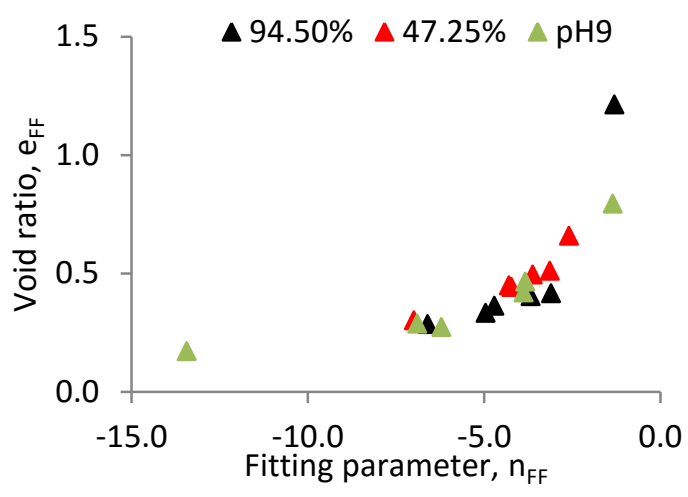

(g)

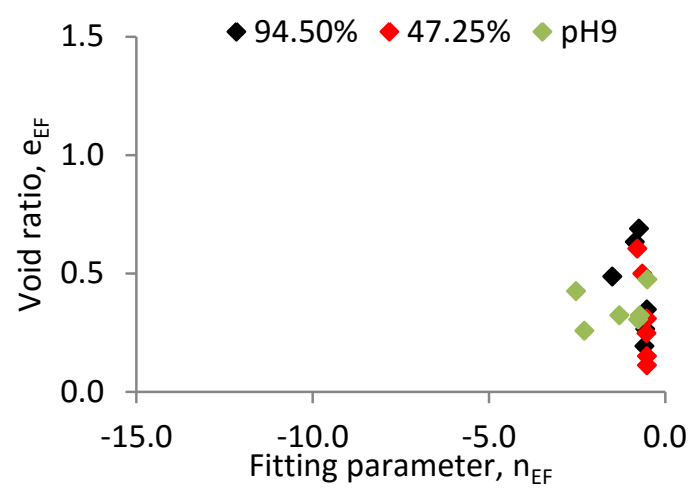

(h)

Figure 4.20 - Ball Clay MIP data of: (a) $e_{F F} x \log \sigma^{\prime}{ }_{v}$, (b) $e_{E F} x \log \sigma^{\prime}{ }_{v},(c) d_{F F} x \log \sigma{ }_{v}$, (d) $d_{E F} x \log \sigma^{\prime},(e) n_{F F} x$ $\log \sigma^{\prime}$, , (f) $n_{E F} \times \log \sigma_{v}$, , (g) $e_{F F} \times n_{F F}$ and (h) $e_{E F} \times n_{E F}$

\section{5 - CONSTITUTIVE MODEL}

As discussed in Chapter 3, the results of the consolidation test carried out for the Kaolin Clay and Ball Clay specimens were modelled using the elastoplastic hardening model SCLAY1S (Koskinen et al., 2002). Although the model is capable of taking into account the anisotropy, it was turned off for the analyses herein presented. The amount of structure, $x$, was also used differently from the way in which it was proposed in the model. Here the $\mathrm{pH} 9$ specimen was the reference; therefore the reconstituted specimens were considered to have structure as well as the remoulded specimens. It has been said in Chapter 3 that all soils have a structure; therefore there is no such thing as unstructured soil. However, for modelling purposes, in this section the structure of $\mathrm{pH} 9$ was taken as a reference and set as zero for comparison with other types of structures of the reconstituted and remoulded specimens.

Table 4.7 and Table 4.8 show the parameters used in the modelling for the Kaolin and Ball Clay specimens respectively. It is worth noticing that the preconsolidation stress $\left(\sigma{ }_{\mathrm{vp}}\right)$ was taken as the calculated value based on the initial suction of the sample presented in section 4.2 (Eq. 4.1). The compression index, $\lambda$, and the swelling index, $\mathrm{k}$, are all the same for all specimens of each soil and are taken as the compression and swelling indexes of the $\mathrm{pH} 9$ curve. The critical state value of the stress ratio in triaxial space, $\mathrm{M}$, is a parameter of the soil; thus it is the same for all specimens of each soil. The initial effective stress, $\sigma^{\prime}{ }_{0}$, and the initial void ratio, $\mathrm{e}_{\mathrm{o}}$, are the initial pair of results from each experiment. The size of the intrinsic yield surface, $\mathrm{p}_{\mathrm{mi}}$, was obtained graphically according to Figure 4.21. The initial amount of structure, $x_{o}$, was calculated according to Eq. (2.12) and the degradation rate, $\mathrm{a}_{\mathrm{x}}$, is merely a best-fit parameter. 
Table 4.7 - S-CLAY1S model parameters and state variables for Kaolin Clay specimens

\begin{tabular}{cccccccccc}
\hline Specimen & $\sigma_{\mathrm{vp}}^{\prime}(\mathrm{kPa})$ & $\mathrm{M}$ & $\mathrm{p}_{\mathrm{mi}}$ & $\lambda$ & $\mathrm{k}$ & $\mathrm{e}_{\mathrm{o}}$ & $\mathrm{x}_{\mathrm{o}}$ & $\mathrm{a}_{\mathrm{x}}$ & $\sigma_{\mathrm{o}}(\mathrm{kPa})$ \\
\hline $96 \%$ & 7 & 0.86 & 0.08 & 0.13 & 0.04 & 2.01 & 57 & 15 & 6 \\
$90 \%$ & 7 & 0.86 & 0.12 & 0.13 & 0.04 & 1.89 & 40 & 13 & 6 \\
$80 \%$ & 15 & 0.86 & 0.21 & 0.13 & 0.04 & 1.98 & 49 & 13 & 6 \\
$70 \%$ & 20 & 0.86 & 0.57 & 0.13 & 0.04 & 1.79 & 24 & 13 & 6 \\
$64 \%$ & 30 & 0.86 & 1.41 & 0.13 & 0.04 & 1.69 & 14 & 13 & 6 \\
$60 \%$ & 35 & 0.86 & 1.84 & 0.13 & 0.04 & 1.65 & 12 & 13 & 6 \\
$55 \%$ & 35 & 0.86 & 2.61 & 0.13 & 0.04 & 1.62 & 8 & 13 & 6 \\
$\mathbf{4 5 \%}$ & 40 & 0.86 & $\mathbf{2 8 . 2 7}$ & 0.13 & 0.04 & 1.34 & 0.03 & 10 & 6 \\
$\mathbf{p H 9}$ & $\mathbf{4 0}$ & $\mathbf{0 . 8 6}$ & $\mathbf{2 7 . 5 6}$ & $\mathbf{0 . 1 3}$ & $\mathbf{0 . 0 4}$ & $\mathbf{1 . 3 0}$ & $\mathbf{0}$ & $\mathbf{0}$ & $\mathbf{1 8}$ \\
\hline
\end{tabular}

Table 4.8 - S-CLAY1S model parameters and state variables for Ball Clay specimens

\begin{tabular}{cccccccccc}
\hline Specimen & $\sigma_{\text {vp }}^{\prime}(\mathrm{kPa})$ & $\mathrm{M}$ & $\mathrm{p}_{\mathrm{mi}}$ & $\lambda$ & $\mathrm{k}$ & $\mathrm{e}_{\mathrm{o}}$ & $\mathrm{x}_{\mathrm{o}}$ & $\mathrm{a}_{\mathrm{x}}$ & $\sigma_{\mathrm{o}}(\mathrm{kPa})$ \\
\hline $94.5 \%$ & 12 & 0.86 & 0.01 & 0.11 & 0.04 & 1.90 & 1199 & 20 & 6 \\
$70 \%$ & 14 & 0.86 & 0.02 & 0.11 & 0.04 & 1.81 & 465 & 15 & 6 \\
$47.25 \%$ & 34 & 0.86 & 1.41 & 0.11 & 0.04 & 1.47 & 16 & 13 & 6 \\
$\mathbf{p H 9}$ & $\mathbf{5 0}$ & $\mathbf{0 . 8 6}$ & $\mathbf{3 5 . 3 3}$ & $\mathbf{0 . 1 1}$ & $\mathbf{0 . 0 4}$ & $\mathbf{1 . 2 4}$ & $\mathbf{0}$ & $\mathbf{0}$ & $\mathbf{3}$ \\
\hline
\end{tabular}

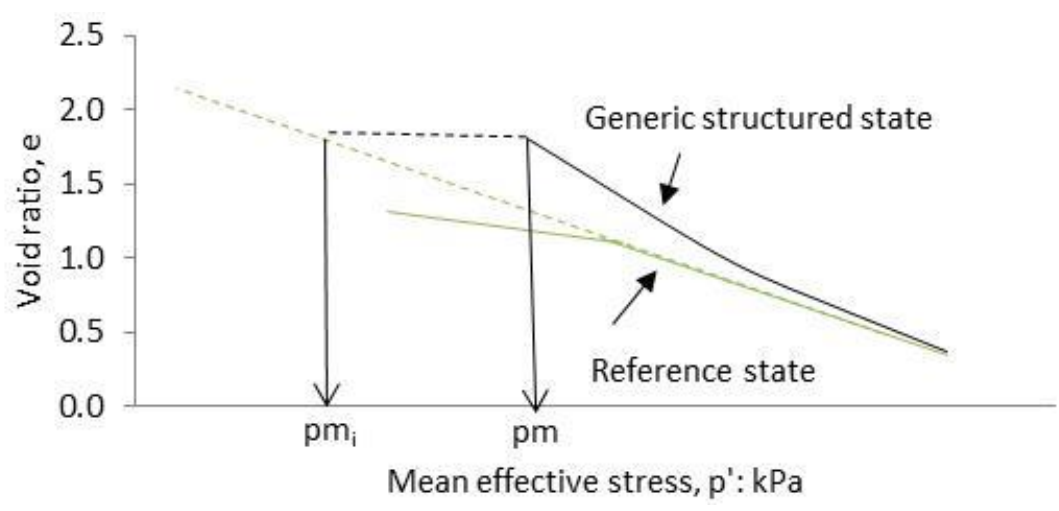

Figure 4.21 - Obtaining $\mathrm{pm}_{\mathrm{i}}$

The evolution law of the amount of structure, $\mathrm{x}$, was given by the following equation:

$$
X=X_{0} e^{\left(a_{x} \varepsilon_{v}^{p}\right)}
$$

where: $x$ is a generic amount of structure, $x_{0}$ is the initial amount of structure, $a_{x}$ is the absolute rate of degradation and $\varepsilon_{v}^{p}$ is the plastic volumetric strain. The effect of parameter $a_{x}$ can be seen in Figure 4.22. 


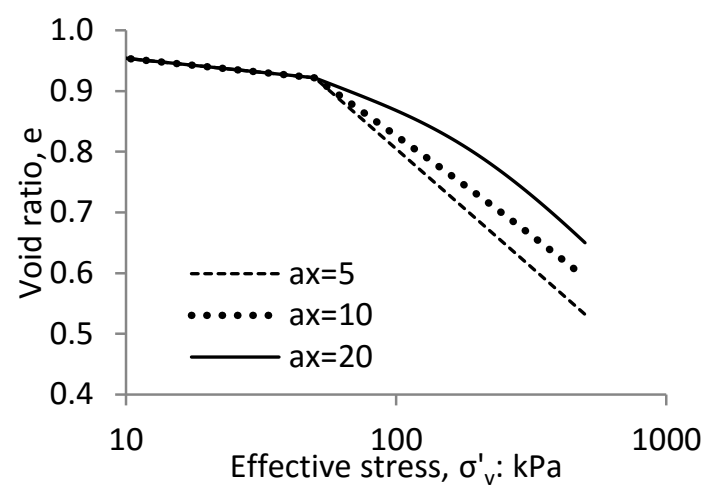

Figure 4.22 - Variation of the degradation ratio parameter $\mathrm{a}_{\mathrm{x}}$ in a void ratio against effective stress semi-log plot

Figure 4.23 shows the results of the modelling as well as the experimental data for each specimen of the Kaolin and Ball Clays. It is important to note that, although the fitting was appropriate, in any of the cases, it was not possible to carry out the modelling with the first pair of points of the consolidation curve.

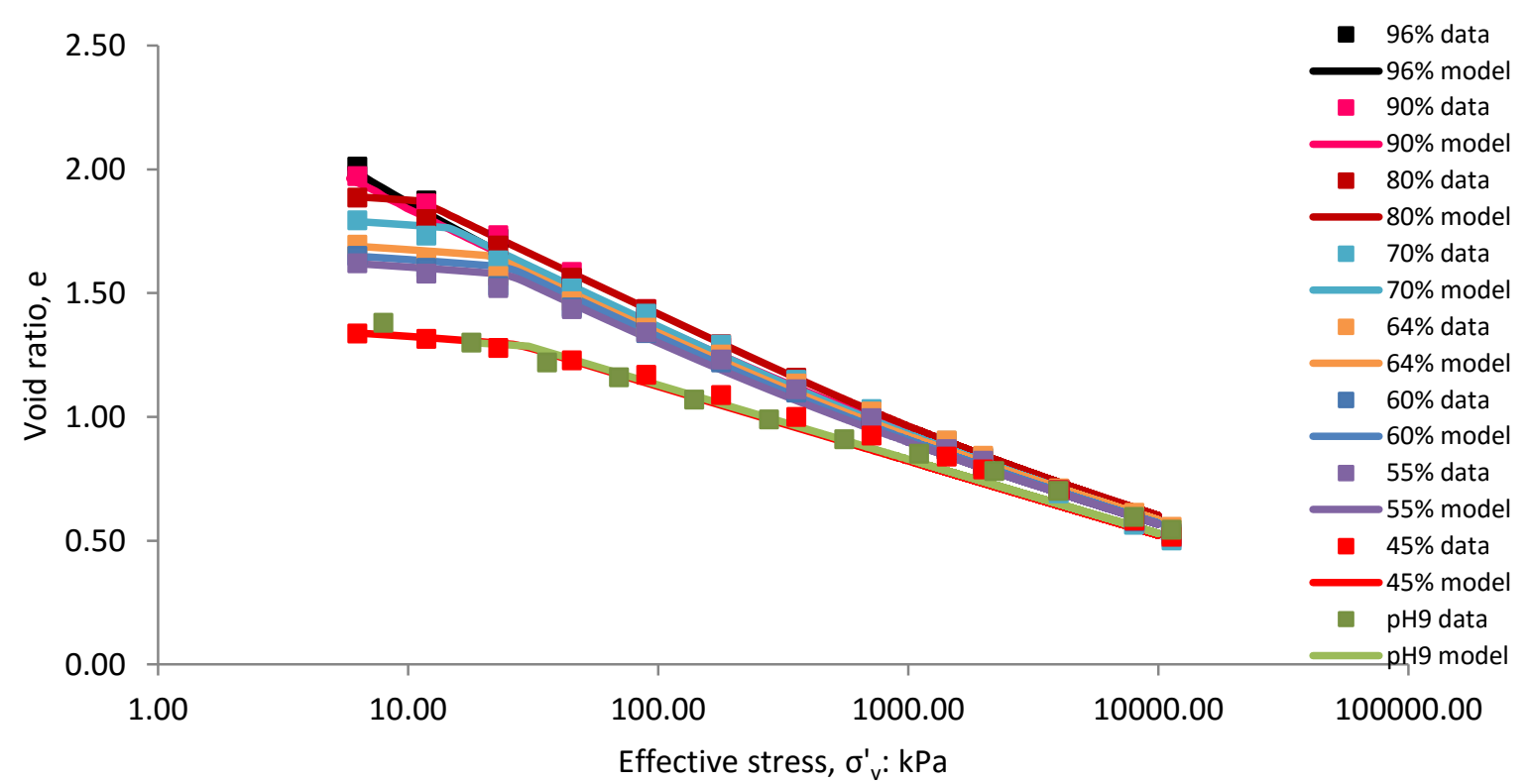

(a) 


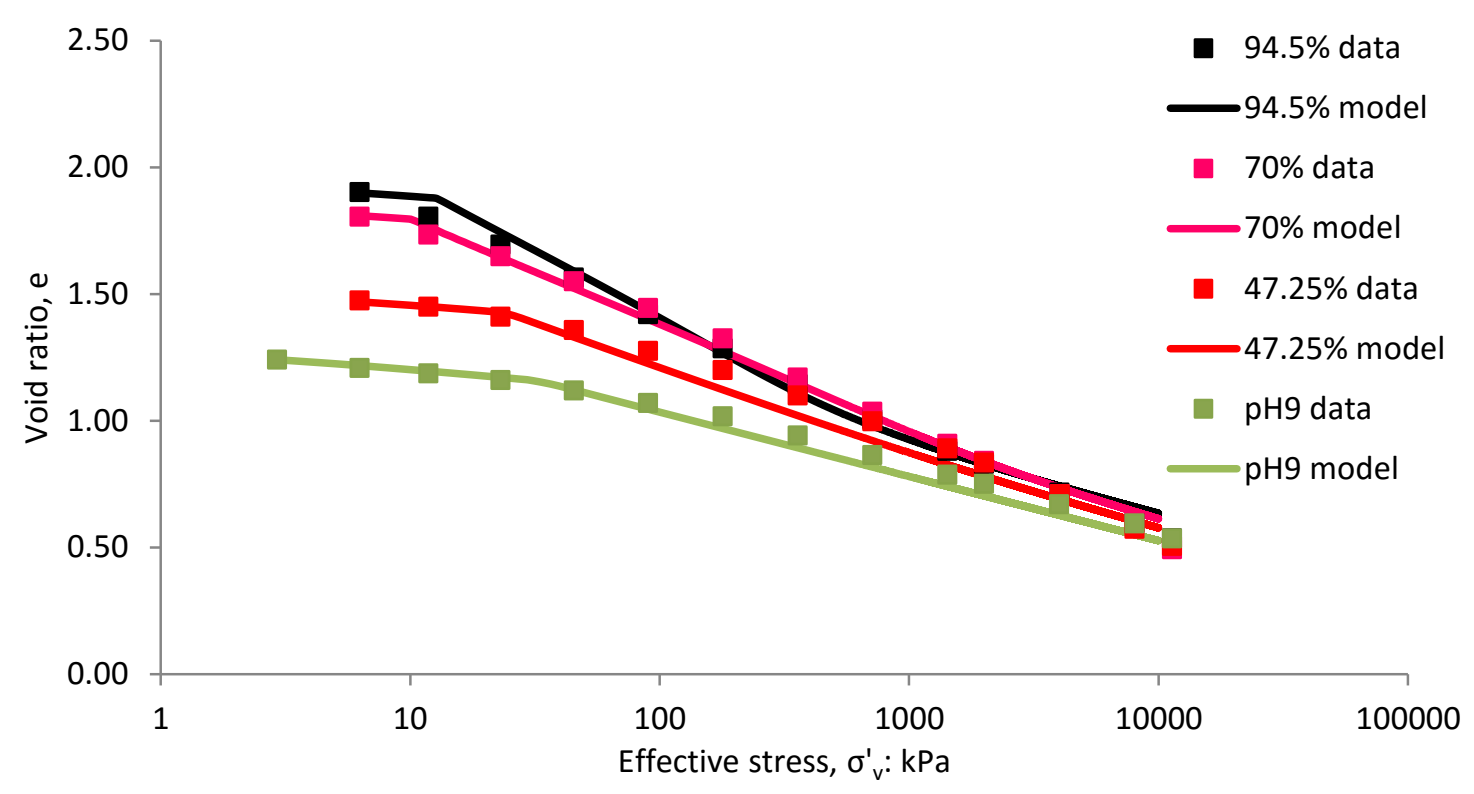

(b)

Figure 4.23 - Experimental data and S-CLAY1S modelling of (a) Kaolin Clay specimens and (b) Ball Clay specimens

The authors are aware of the fact that the best-fit is not the best way of deriving the values of the degradation rate; however, more detailed studies, especially concerning the microstructure, should be carried out in order to obtain an appropriate way to derive this parameter, possibly correlating it with the amount of structure $x$.

Although the state variable $x$ - initial amount of structure - has not been associated with the conceptual model proposed, the graphical values obtained for the modelling are coherent with the microstructure results obtained and shown in section 4.3 , with the values decreasing as the initial water content decreases. Figure 4.24 shows the variation in the initial amount of structure with initial void ratio of Kaolin and Ball Clay specimens.

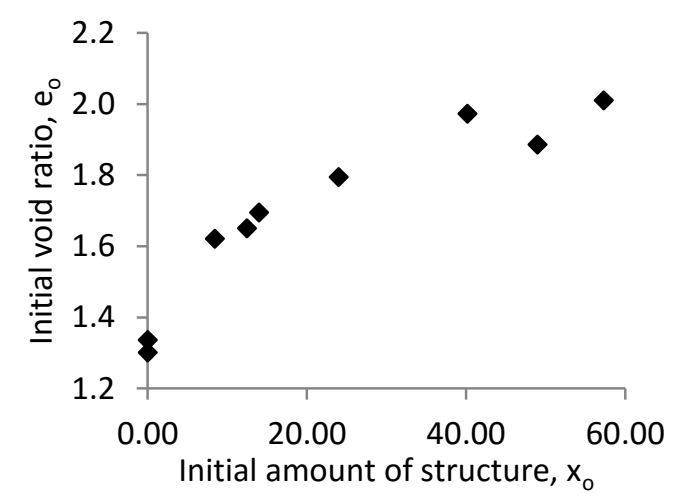

(a)

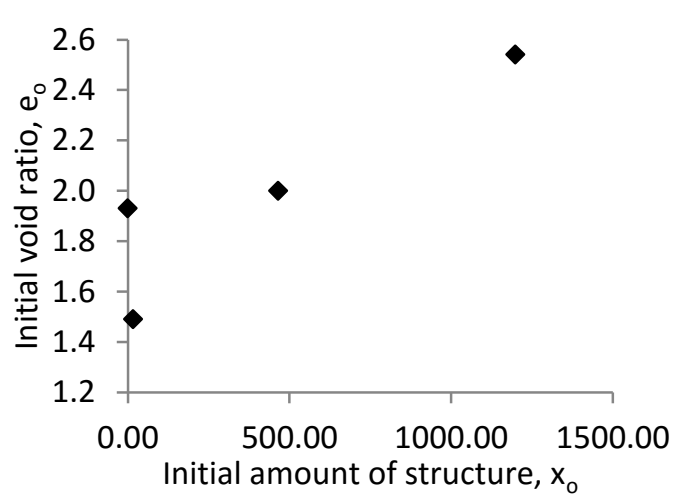

(b)

Figure 4.24 - Variation in initial amount of structure against initial void ratio: (a) Kaolin Clay specimens and (b) Ball Clay specimens 
In order to further analyse the capabilities of the modelling, other experimental data from consolidation tests of reconstituted and remoulded specimens carried out by Hong et al. (2010) for Lianyungang Clay $\left(\mathrm{w}_{\mathrm{L}}=74 \%\right)$, Baimahu Clay $\left(\mathrm{w}_{\mathrm{L}}=91 \%\right)$ and Kemen Clay $\left(\mathrm{w}_{\mathrm{L}}=\right.$ $61 \%$ ) were performed, as presented in Figure 4.25. The model parameters used are shown in Table 4.9. In the absence of a pH9 specimen, the remoulded curve of $0.7 \mathrm{w}_{\mathrm{L}}$ initial water content (50\% for Lianyungang Clay, $64 \%$ for Baimahu Clay and $43 \%$ for Kemen Clay) was used as the reference line, which means that this consolidation curve was considered to have zero amount of structure. It can be highlighted that it is not a bad simplification, since the remoulded curve of $0.7 \mathrm{w}_{\mathrm{L}}$ initial water content of the Kaolin Clay is very close to the $\mathrm{pH} 9$ specimen. The values of preconsolidation stress were taken graphically according to Casagrande's graphical method (Casagrande, 1936) and all the other parameters were taken in the same way as for the Kaolin and Ball Clays.

Table 4.9 - S-CLAY1S model parameters and state variables for Lianyungang Clay, Baimahu Clay and Kemen Clay specimens

\begin{tabular}{|c|c|c|c|c|c|c|c|c|c|}
\hline \multicolumn{10}{|c|}{ Lianyungang Clay } \\
\hline Specimen & $\sigma_{\mathrm{vp}}^{\prime}(\mathrm{kPa})$ & $\mathrm{M}$ & $\mathrm{p}_{\mathrm{mi}}$ & $\lambda$ & $\mathrm{K}$ & $e_{o}$ & $x_{0}$ & $a_{x}$ & $\sigma_{o}(\mathrm{kPa})$ \\
\hline $114 \%$ & 1.5 & 0.86 & 0.0002 & 0.16 & 0.01 & 2.93 & 4999 & 10 & 1.5 \\
\hline $96 \%$ & 2 & 0.86 & 0.0008 & 0.16 & 0.01 & 2.70 & 1666 & 10 & 1 \\
\hline $68 \%$ & 5.6 & 0.86 & 0.35 & 0.16 & 0.01 & 1.80 & 10 & 7 & 1 \\
\hline $50 \%$ & 9.1 & 0.86 & 6.43 & 0.16 & 0.01 & 1.35 & 0 & 0 & 0.5 \\
\hline \multicolumn{10}{|c|}{ Baimahu Clay } \\
\hline Specimen & $\sigma_{\text {vp }}^{\prime}(\mathrm{kPa})$ & $\mathrm{M}$ & $\mathrm{p}_{\mathrm{mi}}$ & $\lambda$ & K & $e_{o}$ & $x_{0}$ & $a_{x}$ & $\sigma_{o}(\mathrm{kPa})$ \\
\hline $137 \%$ & 1.60 & 0.86 & 0.001 & 0.2 & 0.01 & 3.49 & 1066 & 9 & 0.5 \\
\hline $119 \%$ & 2.89 & 0.86 & 0.012 & 0.2 & 0.01 & 3.00 & 160 & 10 & 0.5 \\
\hline $83 \%$ & 5.50 & 0.86 & 1 & 0.2 & 0.01 & 2.11 & 2 & 7 & 0.5 \\
\hline $64 \%$ & 13.2 & 0.86 & 9 & 0.2 & 0.01 & 1.68 & 0 & 0 & 0.5 \\
\hline \multicolumn{10}{|c|}{ Kemen Clay } \\
\hline Specimen & $\sigma_{\mathrm{vp}}^{\prime}(\mathrm{kPa})$ & $M$ & $\mathrm{p}_{\mathrm{mi}}$ & $\lambda$ & K & $e_{o}$ & $x_{0}$ & $a_{x}$ & $\sigma_{o}(\mathrm{kPa})$ \\
\hline $91 \%$ & 1.0 & 0.86 & 0.0001 & 0.11 & 0.01 & 2.30 & 9090 & 11 & 0.5 \\
\hline $80 \%$ & 1.5 & 0.86 & 0.0007 & 0.11 & 0.01 & 2.06 & 1499 & 10 & 0.5 \\
\hline $57 \%$ & 3.6 & 0.86 & 0.2 & 0.11 & 0.01 & 1.49 & 9 & 10 & 0.5 \\
\hline $43 \%$ & 12.7 & 0.86 & 9 & 0.11 & 0.01 & 1.13 & 0 & 0 & 0.5 \\
\hline
\end{tabular}

The results of the modelling of these three clays (Figure 4.25) seem to agree reasonably well with the experimental data provided. The amount of structure also follows the same pattern seen for the Kaolin and Ball Clay specimens, with the values decreasing as the initial water content decreases (Figure 4.26). 


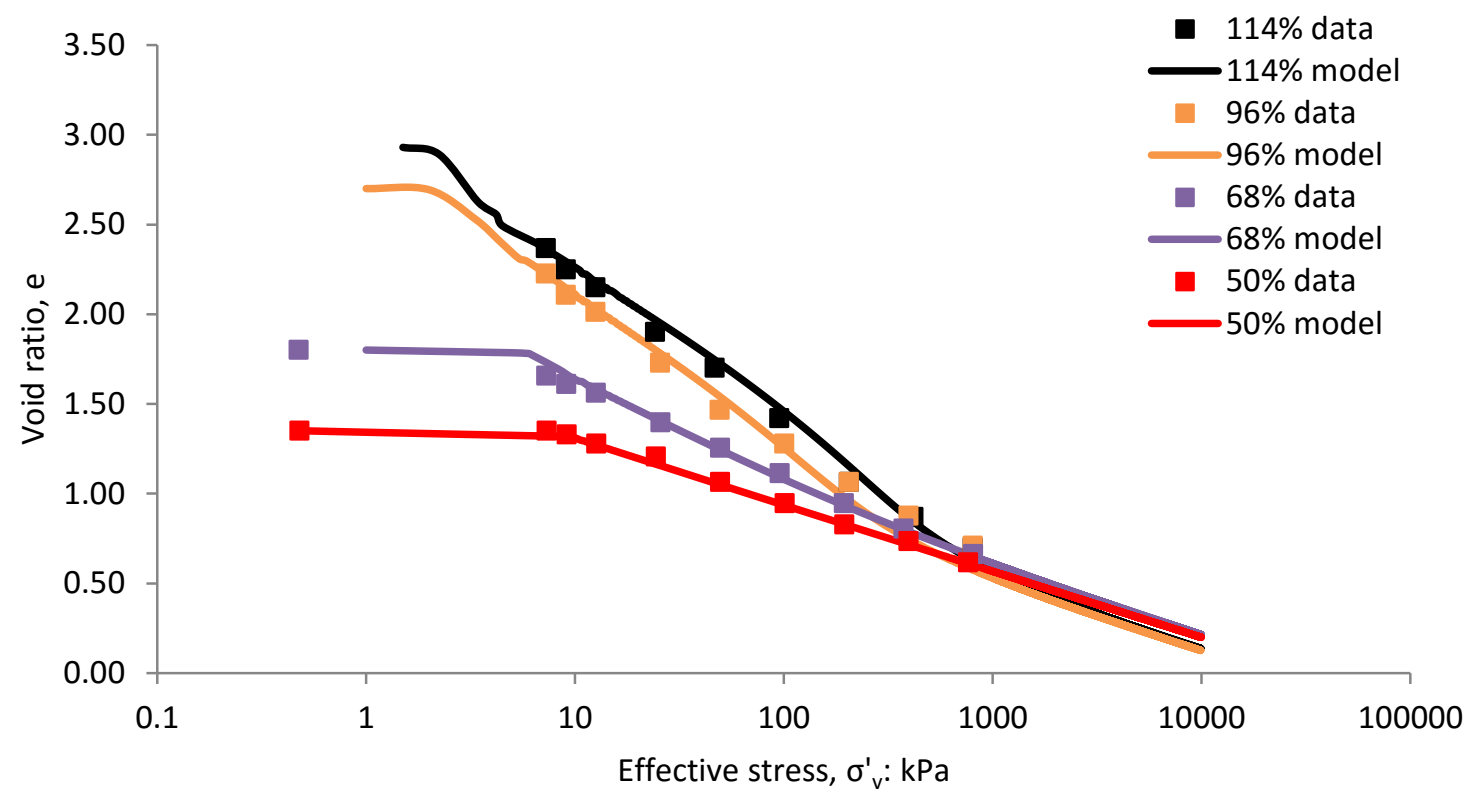

(a)

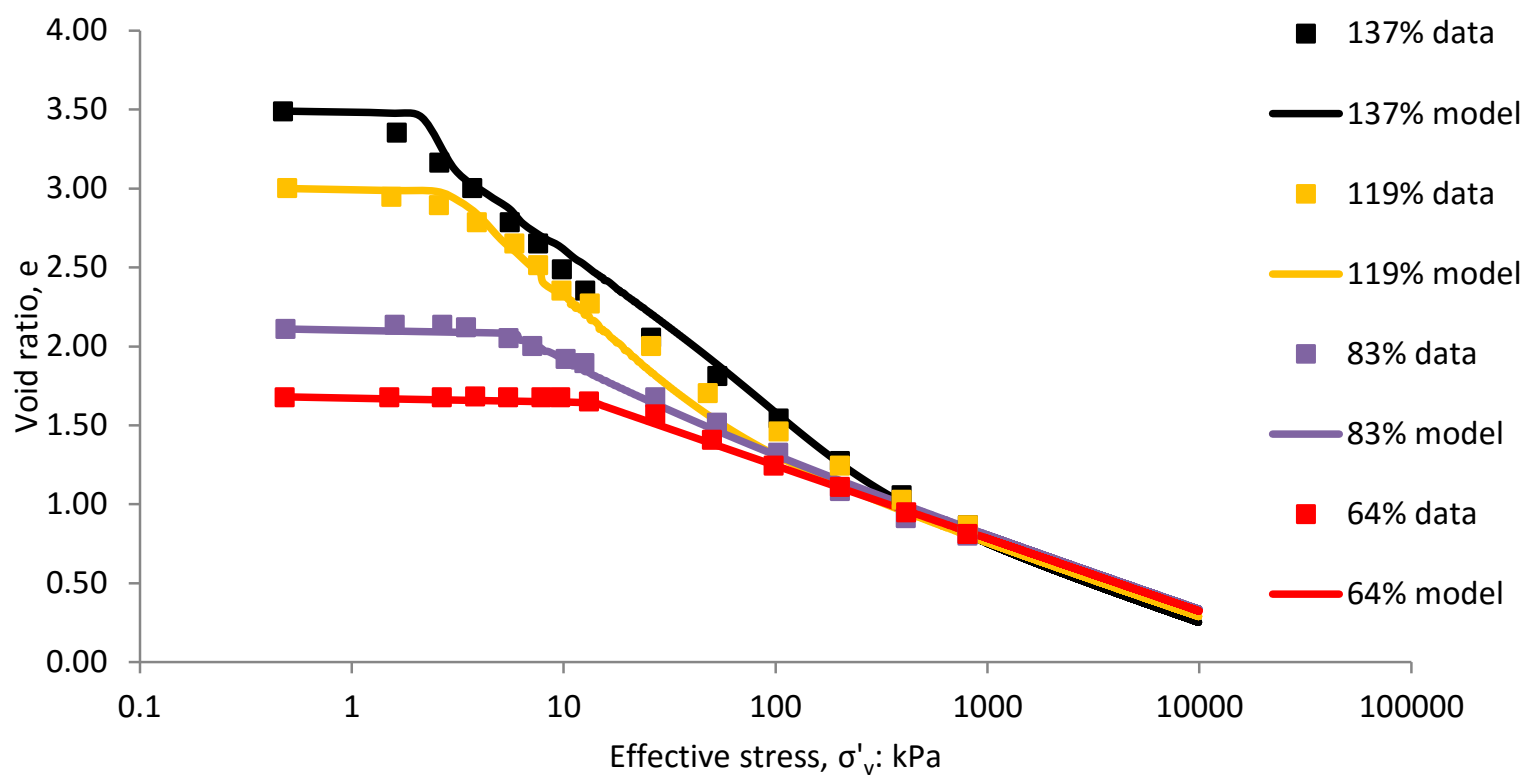

(b) 


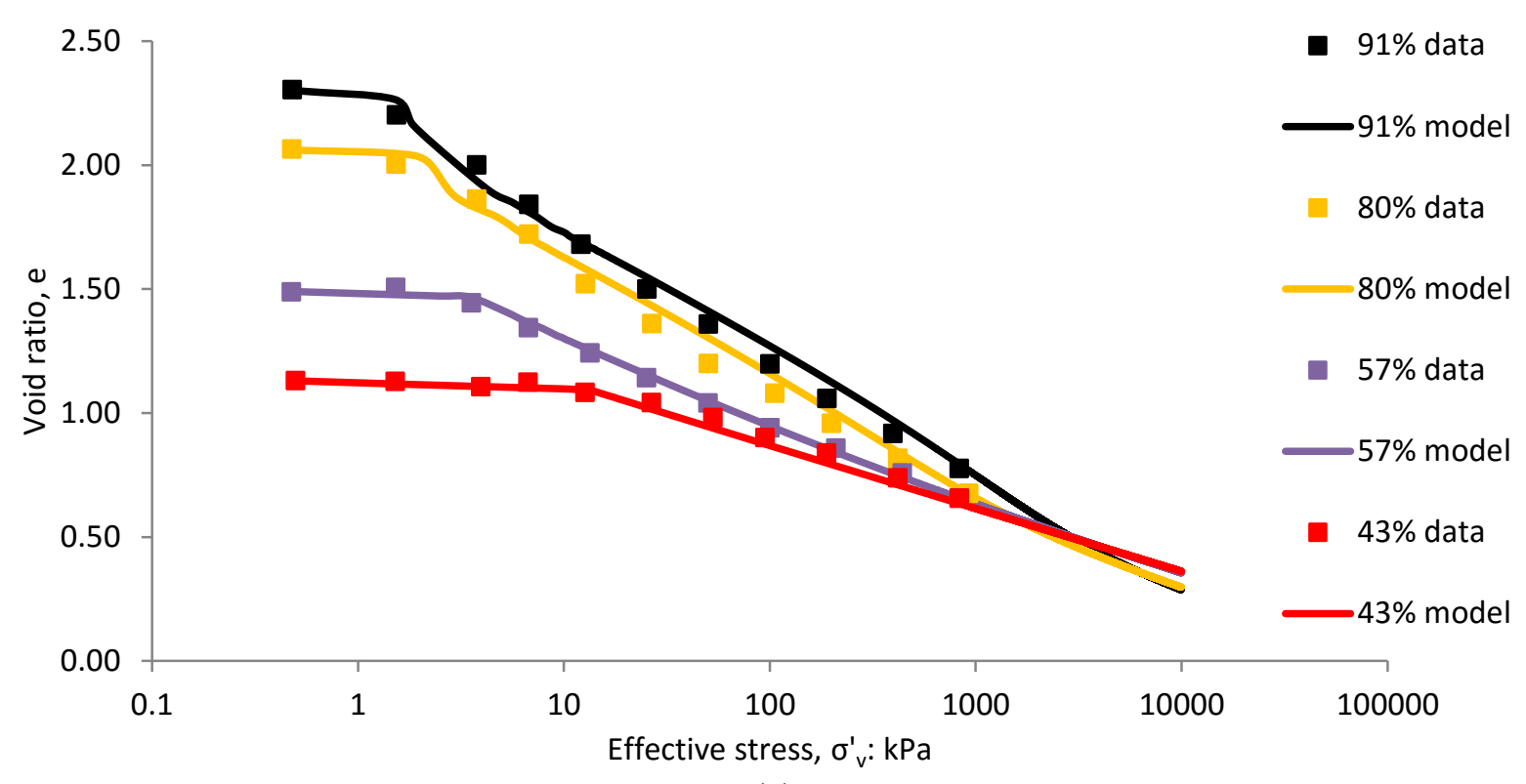

(c)

Figure 4.25 - Experimental data and S-CLAY1S modelling of (a) Lianyungang Clay, (b) Baimahu Clay and (c) Kemen Clay specimens

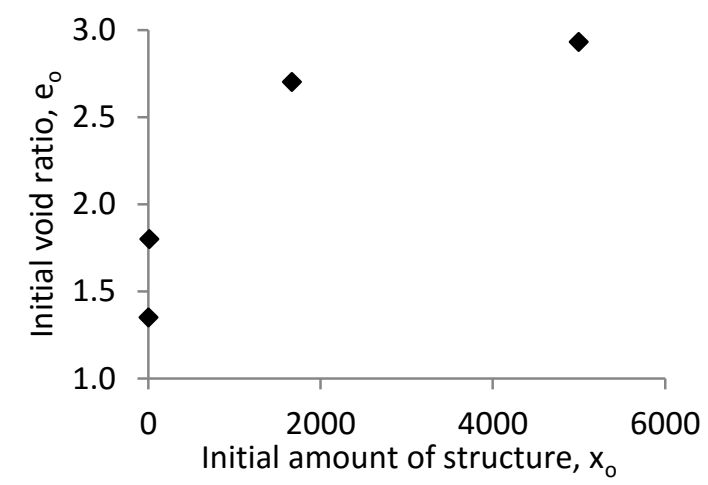

(a)

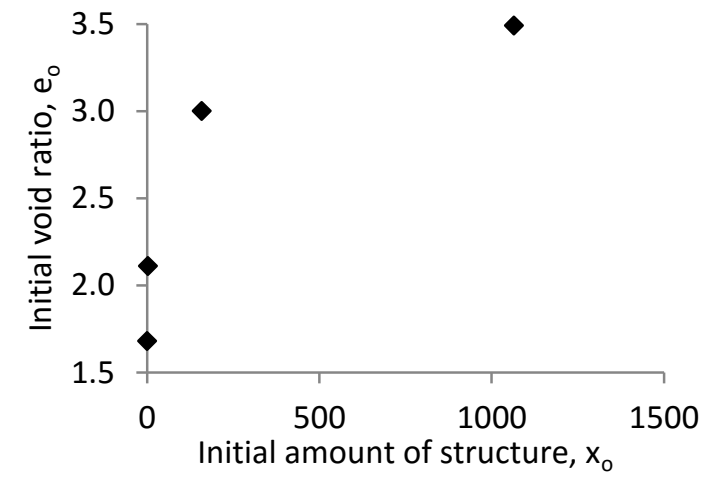

(b)

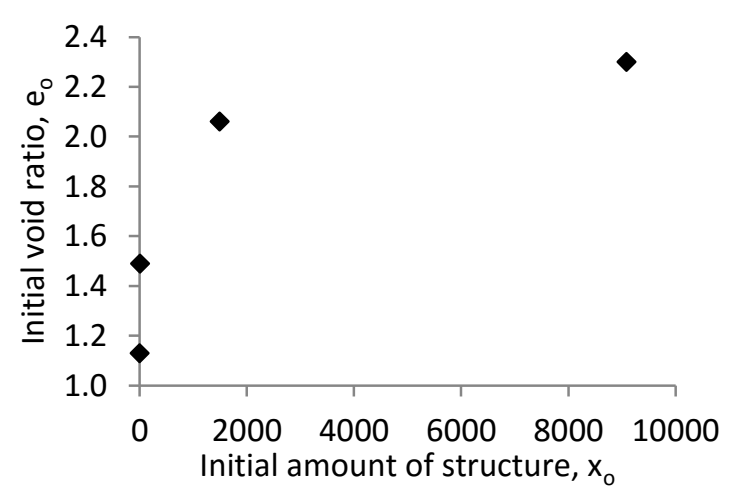

(c)

Figure 4.26 - Variation in initial amount of structure against initial void ratio: (a) Lianyungang Clay, (b) Baimahu Clay and (c) Kemen Clay specimens 


\section{5 - TRANSITIONAL SOIL - BRASILIA SOIL}

In this chapter, results of the several experiments carried out for the tropical transitional soil tested, Brasilia Soil, are presented and discussed. These experiments involve: sedimentation tests, which were carried out in order to assess the differences in sedimentation between distilled water and various concentrations of potassium hydroxide $(\mathrm{KOH})$ solution, i.e., with increasing $\mathrm{pHs}$; and consolidation tests performed in natural, reconstituted, remoulded and $\mathrm{pH} 9$ samples. Each of these four states of samples was consolidated at different loads for microstructural testing and suction measurement with tensiometers, as it is believed that the preparation of the samples induces the appearance of suction even in saturated samples and Mercury Intrusion Porosimetry tests chosen to study the structure of the materials. In addition, a conceptual model relating the consolidation behaviour of the transitional soil to its microstructure was proposed and, finally, the consolidation results were modelled using the constitutive model S-CLAY1S (Koskinen et al., 2002), with a slight modification to the model's use. Herein, the parameter $\mathrm{x}$ of the model was used to quantify the amount of structure as defined in this research, i.e., all soils were considered to have some structure.

\section{1 - SEDIMENTATION RESULTS}

In the same way as for the Kaolin and Ball Clays, sedimentation tests were carried out with five different $\mathrm{pHs}$ for the Brasilia Soil. Figure 5.1 shows the final volume of sediments, while Figure 5.2 presents the final void ratio of the sediment. The results are different from the results obtained for the Kaolin and Ball Clays. The first difference is the $\mathrm{pH}$ of the soil with distilled water only, which is 6.3 for the Brasilia Soil, 4 for the Kaolin Clay and 4.8 for the Ball Clay. It can also be noted that there is not much difference in the total volume of sediments when the $\mathrm{pH}$ of the mixture is altered. The void ratio of $\mathrm{pH} 6.3$ suspension is only 1.2 times higher than that of the pH9. As well as for the Ball Clay, this result is reasonable when the composition of the Brasilia Soil is taken into account. This soil is composed of 42 to $50 \%$ kaolinite and 50 to $58 \%$ other minerals (see Chapter 3 ); in consequence, the amount of kaolinite mineral present in the Brasilia Soil is proportionally smaller than the amount present in the Kaolin Clay and Ball Clay, which influences the volume of sediments deposited. 


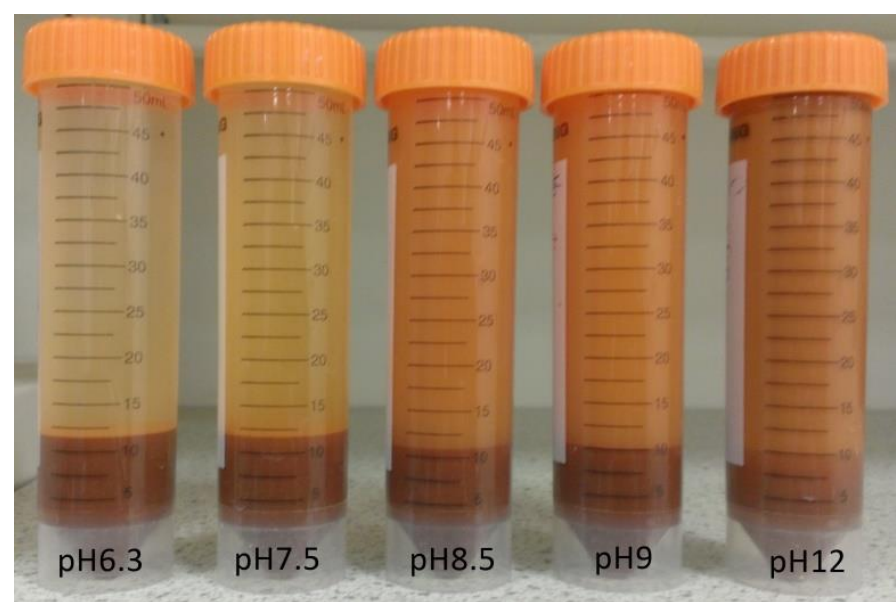

(a)

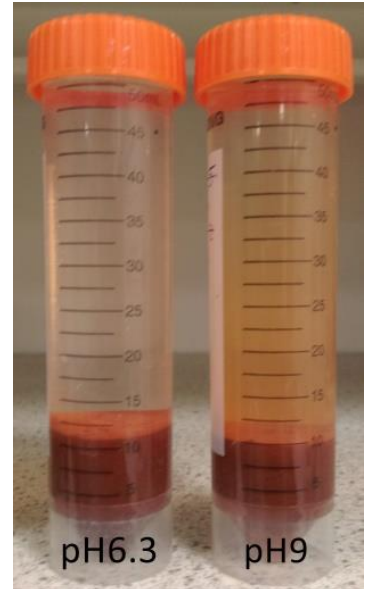

(b)

Figure 5.1 - Brasilia Soil: (a) pH6.3 (only distilled water), 7.5, 8.5, 9 and 12 and (b) detail of pH6.3 and 9 after two months

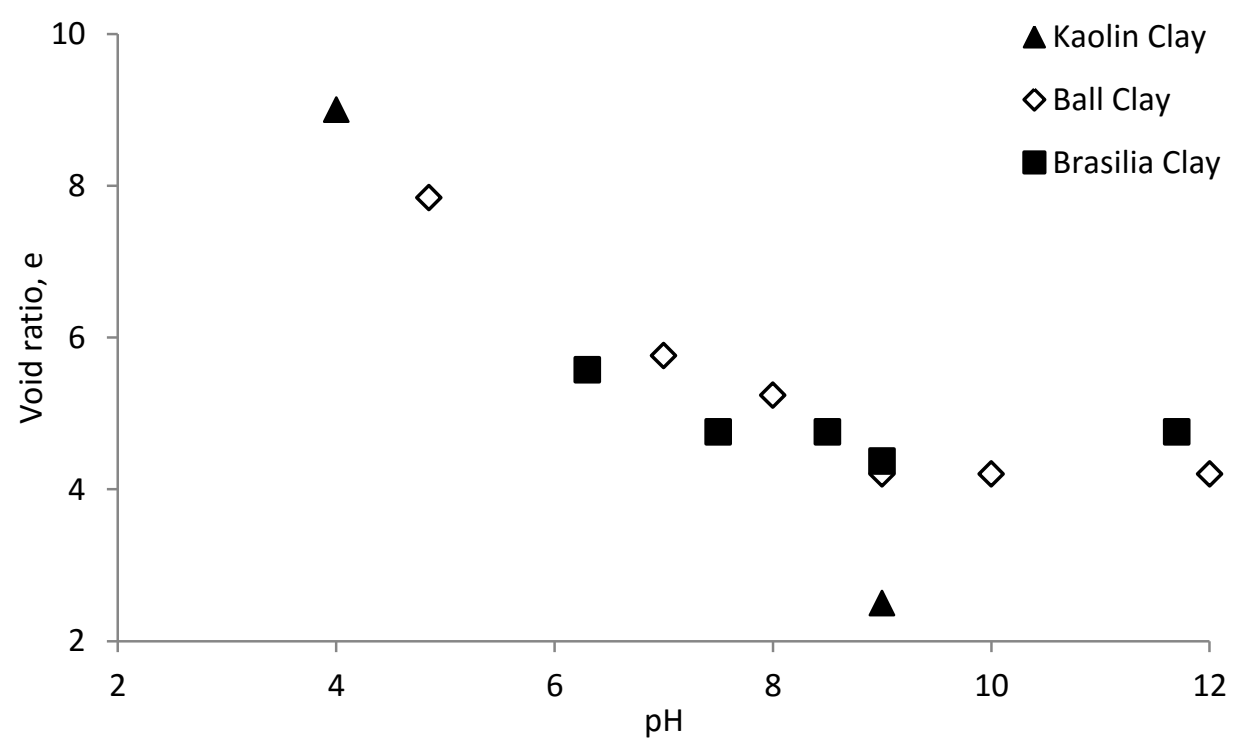

Figure 5.2 - Brasilia Soil: Final void ratio of the sediments

The results of the sedimentation tests of the Brasilia Soil with varying values of $\mathrm{pH}$ show that the electrical charge of the edges of the kaolinite is responsible for the small difference in the particles' configuration while undergoing sedimentation. The following sections investigate whether this observation is still true when the samples are subjected to a mechanical load.

\section{2 - CONSOLIDATION RESULTS}

In this section, samples at different initial states (natural, reconstituted, remoulded and pH9) were consolidated in order to investigate whether such an initial state influences the arrangement of particles when subjected to vertical effective stresses. Figure 5.3 shows the consolidation curves of Brasilia Soil specimens prepared at initial water content of $52.5 \%$, 
$42 \%$ and $31.5 \%$ and with $\mathrm{KOH}$ solution resulting in $\mathrm{pH} 9$, as well as the undisturbed specimen, called natural. These curves, as well as the consolidation curves shown in Chapter 4 , are a combination of the results from the conventional oedometer test (from $2 \mathrm{kPa}$ to $2 \mathrm{MPa}$ ) and the Constant Rate of Strain (CRS) consolidometer (from $2 \mathrm{MPa}$ to $11 \mathrm{MPa}$ ). The same observation made for the consolidation curves of the clays in Chapter 4 applies here: the higher the initial water content, the higher the initial void ratio, noting that the natural sample has the highest initial void ratio. As with the clays, it is noticeable that the samples' preparation processes at different initial water contents, moulding of the undisturbed specimen and $\mathrm{pH} 9$ affect the curve's behaviour, leading to a variation in the preconsolidation stress. In order to investigate this effect in detail, the hypothesis followed in Chapter 4 - that the samples' preparation procedure induces the appearance of suction and this suction is in turn directly related to the preconsolidation stress - was applied here as well. The line of preconsolidation stresses calculated by the relationship shown in Eq. 4.1 is drawn in Figure 5.3. For the Brasilia Soil, $\varphi=30^{\circ}$ (Borges, 2014).

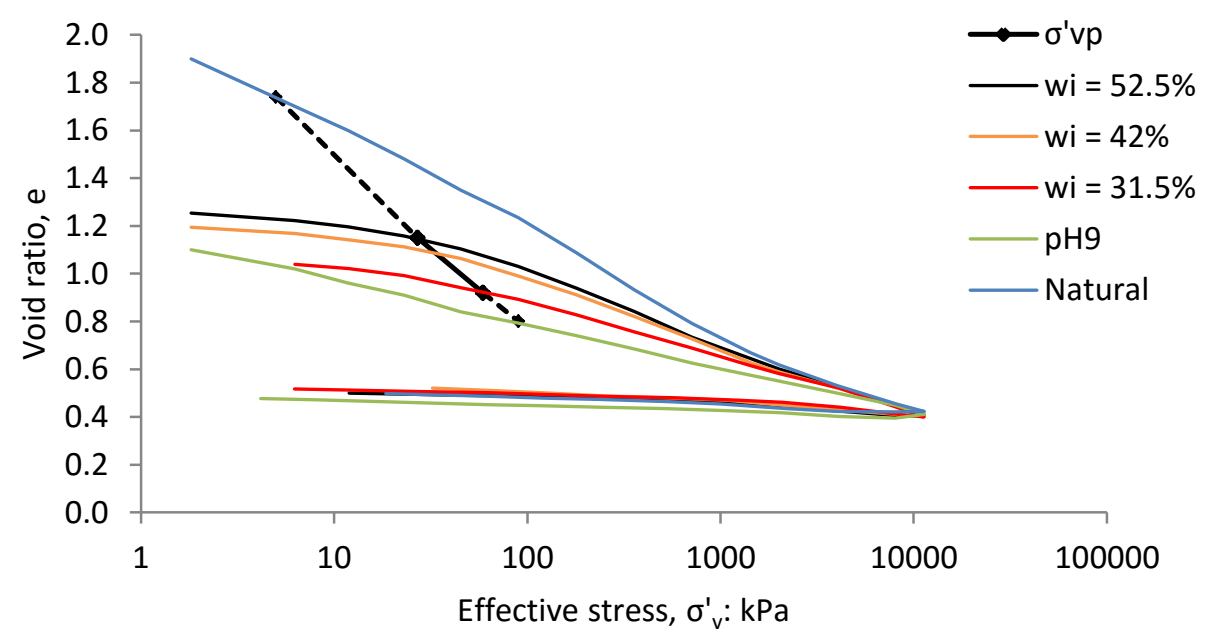

Figure 5.3 - Brasilia Soil: Consolidation curves

Table 5.1 shows the values of suction measured, preconsolidation stresses calculated by Eq. 4.1 and preconsolidation stresses obtained by Casagrande's graphical method (Casagrande, 1936) for specimens of Brasilia Soil. Suction measurements were carried out with tensiometers in two of those specimens of Brasilia Soil (52.5\% and 31.5\%). Due to the presence of $\mathrm{KOH}$ in the $\mathrm{pH} 9$ specimen, it was not possible to measure the suction with tensiometers. Therefore, the specimens with suction measurement had their preconsolidation stresses calculated with Eq. 4.1, while the intermediate curves without suction measurements 
had their values of preconsolidation stresses interpolated. The values of preconsolidation stresses determined by Eq. 4.1 are not too far from the values obtained by Casagrande's graphical method. Therefore, although the approach proposed does not influence the results obtained in current practice, it gives them physical meaning. Here, similarly to what happens with the Kaolin and Ball Clay specimens, the specimen of the Brasilia Soil at pH9 produces a rearrangement of particles in such a way that does not allow as many plastic deformations as other specimens. The same effect can also be seen, at different degrees, in the specimens prepared at different initial water contents - the lower the water content, the fewer the plastic deformations observed, hence increasing the preconsolidation stress values. The highest preconsolidation stress and the lowest plastic deformations are those associated with the $\mathrm{pH} 9$ specimen.

Table 5.1- Suction measurements and preconsolidation stresses of Brasilia Soil specimens

\begin{tabular}{cccc}
\hline $\begin{array}{c}\text { Initial water } \\
\text { content, w: } \\
\%\end{array}$ & $\begin{array}{c}\text { Initial suction } \\
\text { measured: kPa }\end{array}$ & $\begin{array}{c}\text { Calculated } \\
\text { preconsolidation stress, } \\
\sigma^{\prime}{ }_{\mathrm{vp}}: \mathrm{kPa}\end{array}$ & $\begin{array}{c}\text { Preconsolidation stress, } \sigma_{\mathrm{vp}}: \mathrm{kPa} \\
\text { determined by Casagrande's } \\
\text { graphical method }\end{array}$ \\
\hline Natural & - & 12 & 10 \\
52.5 & 18 & 27 & 30 \\
42.0 & - & 30 & 40 \\
31.5 & 40 & 59 & 50 \\
pH9 & - & 90 & - \\
\hline
\end{tabular}

The initial void ratio of the specimens of the Brasilia Soil before the consolidation test, obtained by the extrapolation of the consolidation curves up to a vertical effective stress close to zero, was plotted against their initial water content and is shown in Figure 5.4, together with the data obtained for the Kaolin and Ball Clays for comparison purposes, already shown in Figure 4.7. It is clear that, as the water content reduces, the void ratio also reduces for both clays. There is a slight increase in the void ratio for both $\mathrm{pH} 9$ samples of clays. For the Brasilia Soil, it is clear that the bonding within particles helps the natural sample to maintain the open structure. The difference between the initial void ratio of the other (reconstituted, remoulded and $\mathrm{pH} 9$ ) samples is not as noticeable for the Brasilia Soil as it is for the Kaolin and Ball Clays. There is also a slight increase in the void ratio of the $\mathrm{pH} 9$ sample for the Brasilia Soil. The results of the comparison between the pH9 specimen and the other specimens seem to suggest that the arrangement of particles is also influenced by the fluid, whether only distilled water or a solution of $\mathrm{KOH}$ in distilled water. 


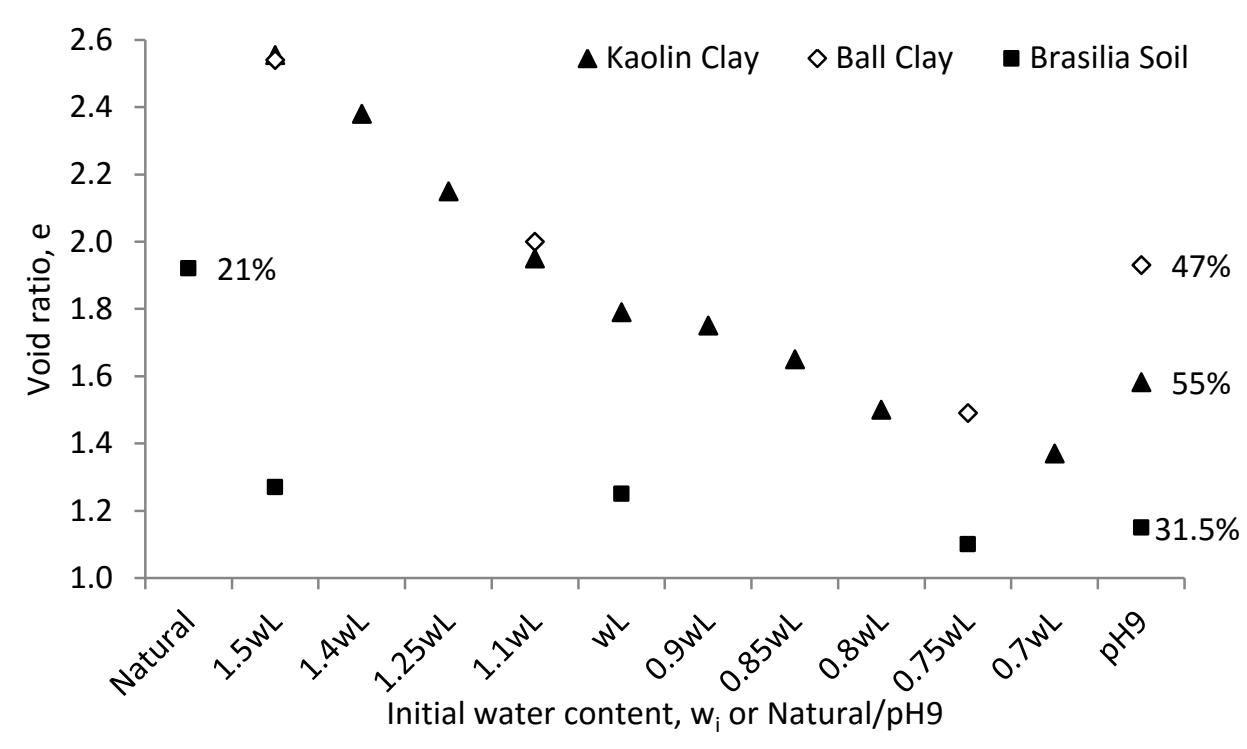

Figure 5.4 - Initial void ratio against initial water content for Kaolin and Ball Clay and Brasilia Soil specimens

Brasilia Soil is a transitional soil, as it is grading between clays and sands and neither has a unique Normal Consolidation Line (NCL), nor a unique critical state line and therefore does not have to comply with Burland's theory of reconstitution. However, the same analyses made for the clay soils were made for the Brasilia Soil for comparison purposes. It is clear in this case that convergence between reconstituted specimens (Figure 5.3) happens at later stages of loading (around 500kPa). Table 5.2 shows the Compression and Swelling indexes of the Brasilia Soil specimens. The swelling indexes are identical for all specimens and there is a variation between the compression indexes, showing the same trend as observed for the clays. The natural soil has bonding within its particles, which might be responsible for the higher compression index. The difference in the other compression indexes seems to be statistical, since Duncan (2000) reported that the coefficient of variation $(\mathrm{CoV})$ of the compression index is between $10 \%$ and $34 \%$.

Table 5.2 - Compression and Swelling indexes of Brasilia Soil specimens

\begin{tabular}{ccc}
\hline Initial water content, w: \% & Compression Index, $\lambda^{*}$ & Swelling Index, $\mathrm{K}$ \\
\hline Natural & 0.16 & 0.01 \\
$52.5 \%$ & 0.12 & 0.01 \\
$42.0 \%$ & 0.11 & 0.01 \\
$31.5 \%$ & 0.10 & 0.01 \\
pH9 & 0.08 & 0.01 \\
\hline "calculated between the vertical effective stress of 1,000 and $11,000 \mathrm{kPa}$ &
\end{tabular}

The graph of Figure 5.5 shows the initial void ratio against the void ratios at 100, 1,000 and $10,000 \mathrm{kPa}$. In order to show convergence, each one of the three series of data, between the vertical lines $\mathrm{w}_{\mathrm{L}}$ and $1.5 \mathrm{w}_{\mathrm{L}}$, should be horizontal. As observed for the clays, it is clear that at 
$100 \mathrm{kPa}$ the curves are not convergent, but as load progresses the convergence becomes more realistic $(1,000$ and $10,000 \mathrm{kPa}$ data) for all the specimens tested, even for the natural specimen, which has an initial void ratio much higher than the other specimens.

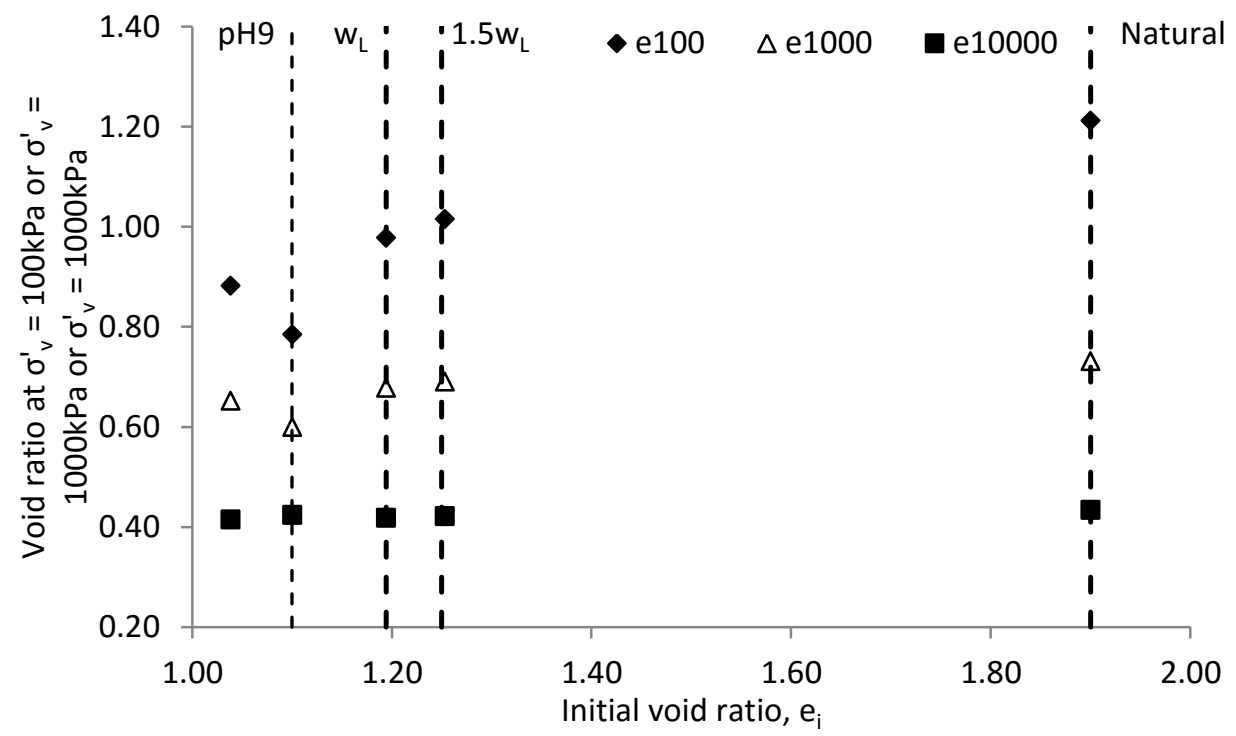

Figure 5.5 - Variation of void ratio at 100, 1,000 and 10,000 kPa with initial void ratio for Brasilia Soil

Qualitatively speaking, there is no difference in the mechanical behaviour between the clays and transitional soil studied. Therefore, the $\mathrm{pH} 9$ specimen is also used as a reference state for the Brasilia Soil as, although this soil is constituted of several minerals and its particles have a variety of sizes, it also shows a great amount of kaolinite mineral in its composition. In this way, the $\mathrm{pH} 9$ sample appears to work better as a reference, for the same reasons it does for the clays. The pH9 sample offers a dispersed arrangement for the clay fraction and not much option for a different arrangement once the 1-D consolidation starts; the plastic deformations are also smaller. For all these reasons, the $\mathrm{pH} 9$ sample is a choice of reference more convenient than the reconstituted sample, as it is more likely to describe the intrinsic behaviour of the soil.

\section{3 - MIP RESULTS}

In order to investigate the microstructure, Mercury Intrusion Porosimetry (MIP) tests were carried out for freeze-dried specimens of the Brasilia Soil previously loaded in the conventional oedometer/CRS consolidometer prepared with initial water contents of $52.5 \%$, $31.5 \%$, pH9 and undisturbed (natural). The specimens were loaded up to 2, 90, 360, 2,000, 5,000 and $11,000 \mathrm{kPa}$. 
As explained in Chapter 4, the objective of these experiments was to understand the microstructure of the specimens at various loading stages; thus the samples loaded in the conventional oedometer/CRS consolidometer for the MIP test were unloaded quickly in one step. Therefore, a difference in void ratio between the consolidation curve and these samples is expected. Again, the freeze-drying did not necessarily happen immediately after the consolidation, due to availability of the lyophilizer. Thus, a difference might be expected between the void ratios after the consolidation test and immediately before the freeze-drying. Finally, a difference between the real void ratios of the sample and the MIP one is also expected, as explained in Chapter 4. Hence, Figure 5.6 shows these three differences for the Brasilia Soil. Annex A shows the difference in results of the MIP test carried out in specimens of Brasilia Soil that had been unloaded quickly in the oedometer/CRS consolidometer and also unloaded in many steps as if the specimen was being prepared for an ordinary consolidation test. In Annex A it is also possible to check the difference in the consolidation curve depending on the unloading method chosen - whether the unloading is done in one single step (removing all the weight at once) and not allowing the swelling to stabilize, or the unloading is done in as many steps as for the loading, allowing the swelling of the specimens to stabilize at every step of the unloading process.

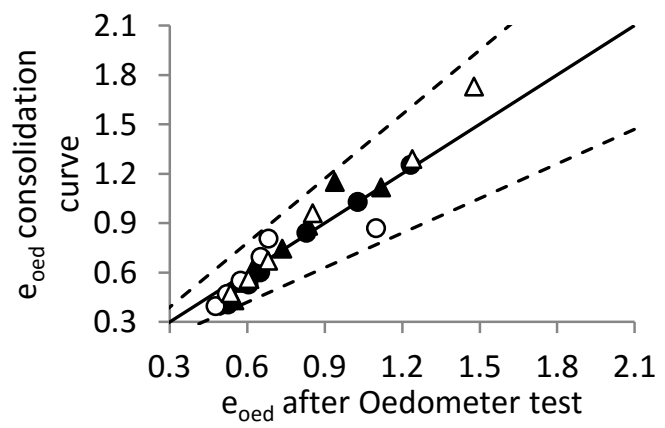

(a)

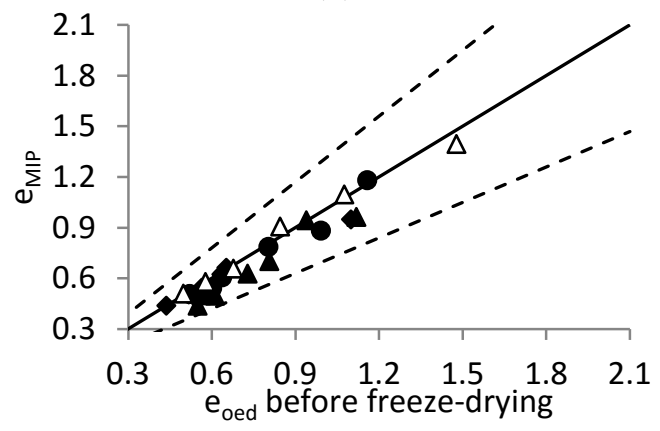

(c)

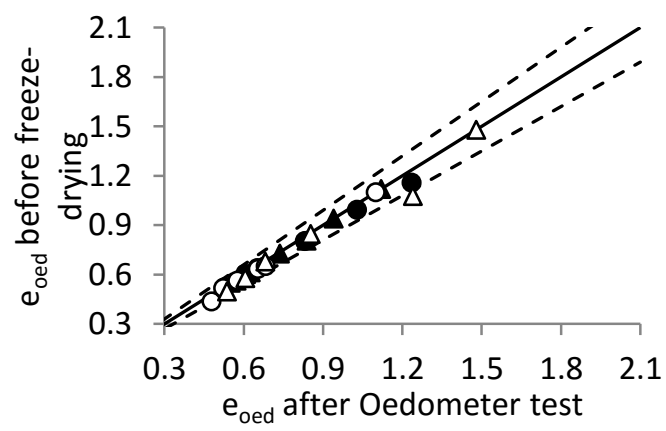

(b)

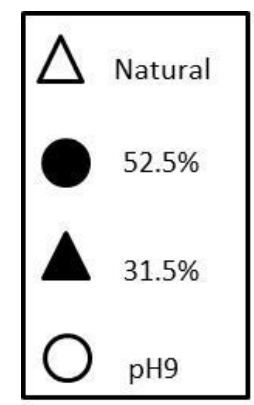

(d)

Figure 5.6 - Brasilia Soil: Relationship between (a) void ratio at the consolidation curve and void ratio after the oedometer/CRS test, (b) void ratio after the oedometer/CRS test and void ratio before freeze-drying and (c) void ratio before freeze-drying and MIP void ratio. Full lines are 1:1 and dashed lines are: (a) and (c) $30 \%$ span tolerance and (b) $10 \%$ span tolerance, (d) legend 
The graphs show that the difference between the void ratio at the consolidation curve and the oedometer/CRS test and between the void ratio before freeze-drying and MIP is within $\pm 30 \%$, while the difference between the void ratio after the oedometer/CRS test and before the freeze-drying is within $\pm 10 \%$. The four groups of data (void ratios: consolidation curve, oedometer/CRS, freeze-drying and MIP) went through the ANOVA statistical test. The ANOVA compares the averages of $\mathrm{K}$ samples and decides whether these samples were extracted from populations of the same average value. They were considered to be part of the same group within $95 \%$ of reliability (Annex B). The differences found were then considered acceptable, especially when it is taken into account that the four groups of data are a result of three different procedures. The major sources of error are also highlighted in Annex B.

Figure 5.7 shows the MIP results, in terms of the cumulative consolidation curves and Pore Size Density (PSD) curves, of the loading progress for the specimens of Brasilia Soil. The van Genuchten fitting parameters used to fit the cumulative intrusion curve for the Brasilia Clay are presented in Annex D, together with details of the van Genuchten fitting procedure. Herein, it is anticipated that the fittings were adequate, with the smallest $\mathrm{R}^{2}$ of 0.9899 for the Brasilia Soil.

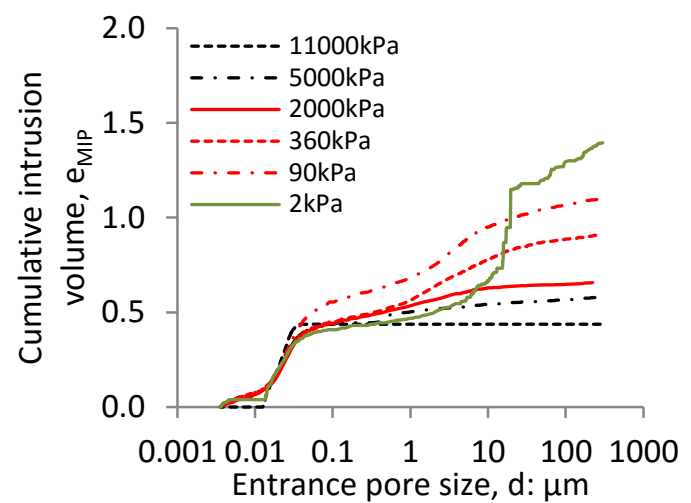

(a)

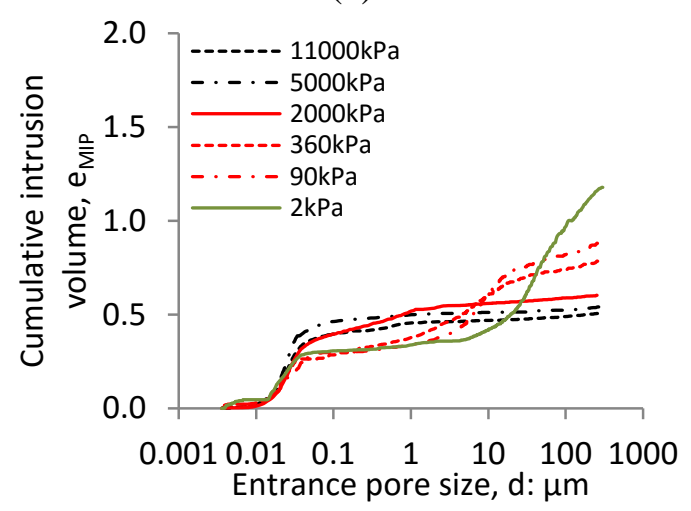

(c)

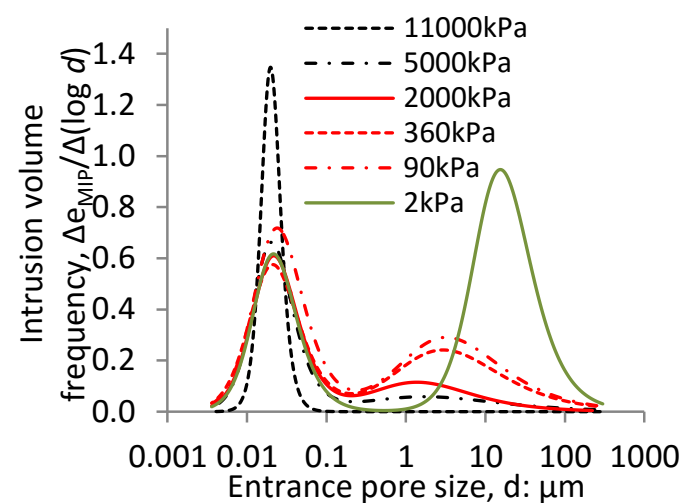

(b)

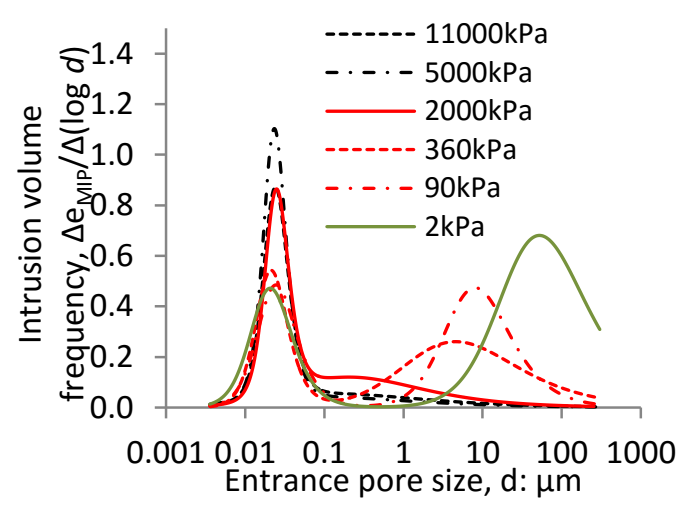

(d) 


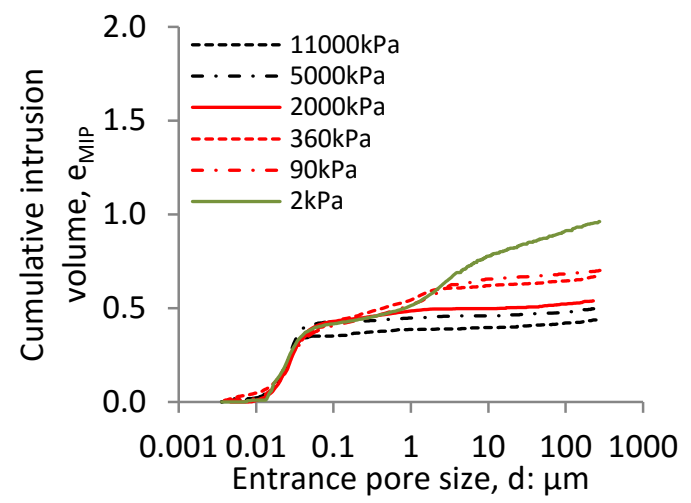

(e)

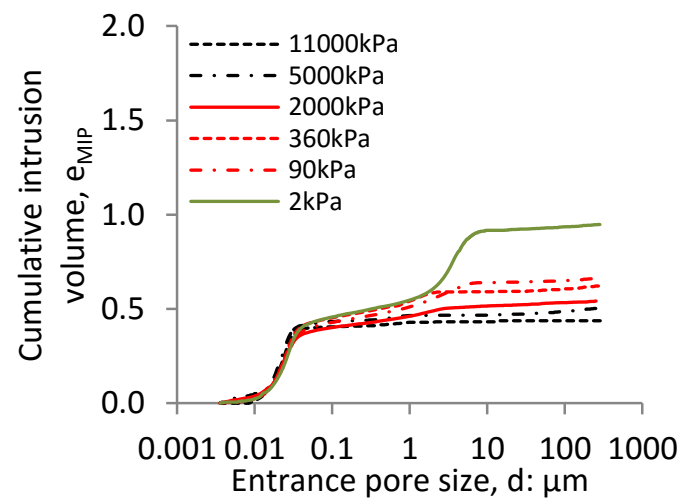

(g)

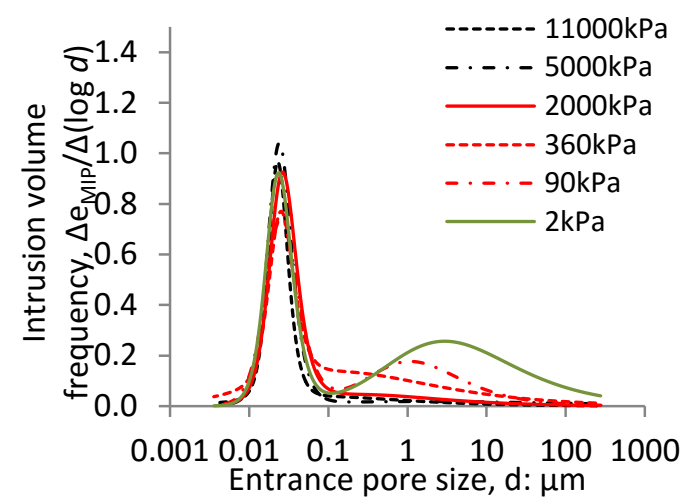

(f)

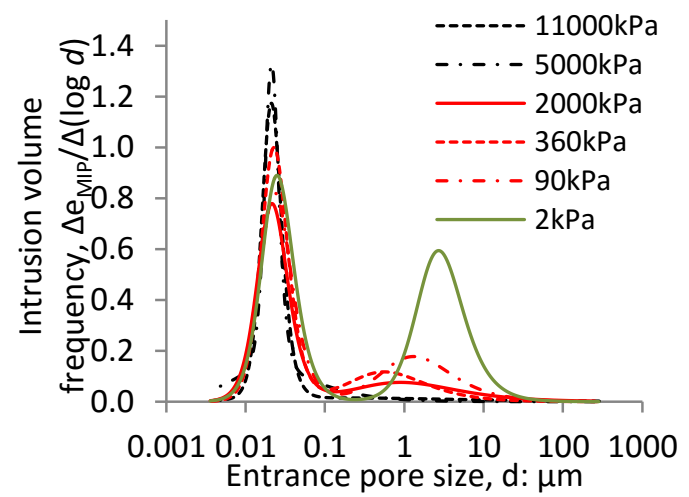

(h)

Figure 5.7 - Brasilia Soil: (a) Cumulative intrusion curve Natural, (b) Pore Size Density curve Natural, (c) Cumulative intrusion curve $\mathrm{w}_{\mathrm{i}}=52.5 \%$, (d) Pore Size Density curve $\mathrm{w}_{\mathrm{i}}=52.5 \%$, (e) Cumulative intrusion curve $\mathrm{w}_{\mathrm{i}}=31.5 \%$, (f) Pore Size Density curve $\mathrm{w}_{\mathrm{i}}=31.5 \%$, (g) Cumulative intrusion curve $\mathrm{pH} 9$ and (h) Pore Size

Density curve $\mathrm{pH} 9$

Figure 5.7a and $\mathrm{b}$ show the cumulative intrusion curve and PSD of the natural specimens. As expected, the overall void ratio reduces with the increase in the loading. The curves in almost all loading stages clearly have two distinct modes (the nature of these modes is explained in the next section). The frequency of the bigger pores reduces with loading and the dominant pore size for the bigger mode also reduces as load increases. Only at $11 \mathrm{MPa}$ is it possible to say that the curve appears to have a single mode. The frequency of the smallest pores changes with the loading but the dominant pore size of this mode does not change significantly.

Figure 5.7c and $\mathrm{d}$ present the cumulative intrusion curve and PSD of the reconstituted specimens of $52.5 \%$ initial water content. Again, for these specimens it is shown that as load progresses the overall void ratio of the specimens reduces. The curves of the specimens loaded up to $2 \mathrm{MPa}$ have clearly two distinct modes. The same observations apply to these specimens. The frequency of the bigger pores reduces with loading and the dominant pore size for the bigger mode also reduces as load increases, while the frequency of the smallest 
pores increases with loading but the dominant pore size of this mode does not change significantly.

Figure 5.7e and $\mathrm{f}$ present the cumulative intrusion curve and PSD of the remoulded specimens of $31.5 \%$ initial water content. Once again, for these specimens it is shown that as the load progresses the overall void ratio of the specimens reduces. However, the transition from two distinct modes to a single mode distribution happens faster than it does for the previous specimens (after $360 \mathrm{kPa}$ ). The frequency of the bigger pores reduces with loading and the dominant pore size for the bigger mode also reduces as load increases, while the frequency of the smallest pores increases slightly with loading but the dominant pore size of this mode does not change significantly.

Figure 5.7g and h present the cumulative intrusion curve and PSD of $\mathrm{pH} 9$ specimens. Here, as well as for the other specimens, it is shown that as load progresses the overall void ratio of the specimens reduces. The transition from two distinct modes to a single mode distribution happens around $2 \mathrm{MPa}$. The frequency of the bigger pores reduces with loading and the dominant pore size for the bigger mode also reduces as load increases, while the frequency of the smallest pores increases with loading without significant change in the dominant pore size.

To analyse the results from another perspective, the data of the four samples (natural, reconstituted, remoulded and $\mathrm{pH} 9$ ) presented in Figure 5.7 were plotted at various loading stages, as shown in Figure 5.8.

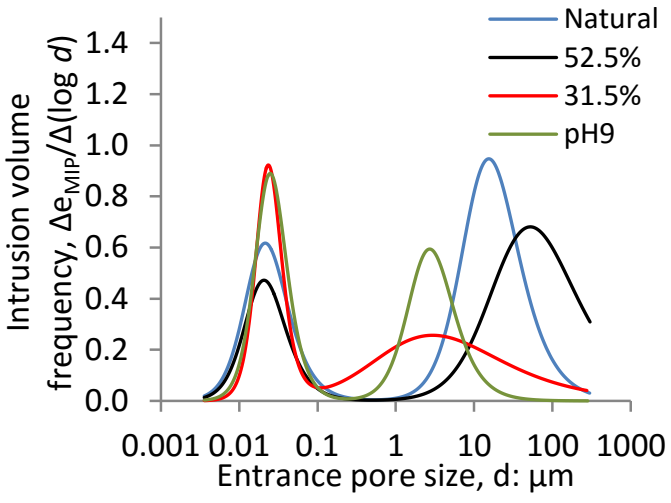

(a)

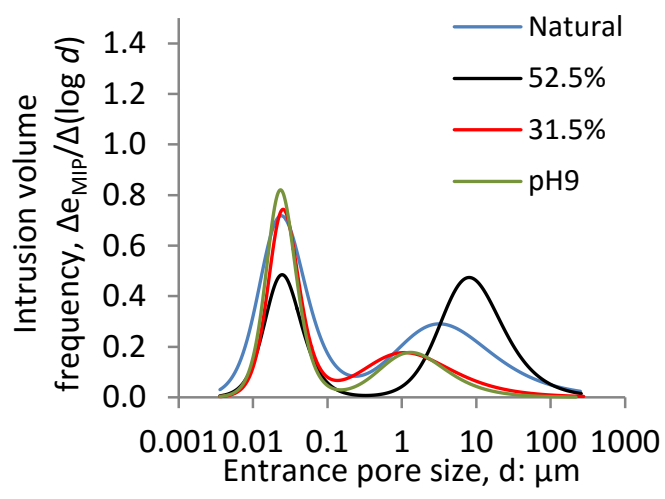

(b) 


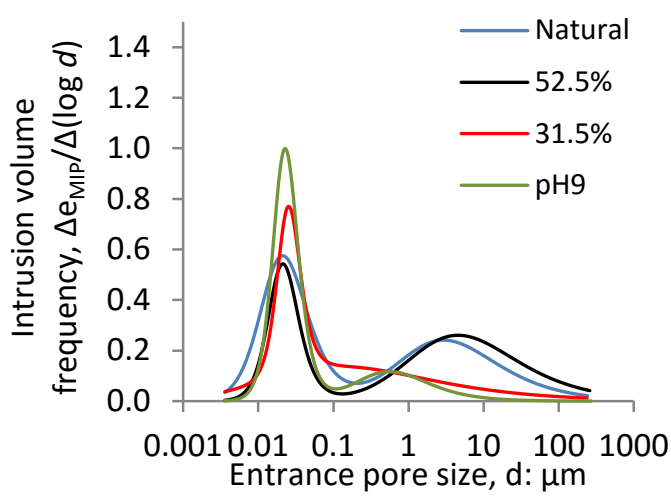

(c)

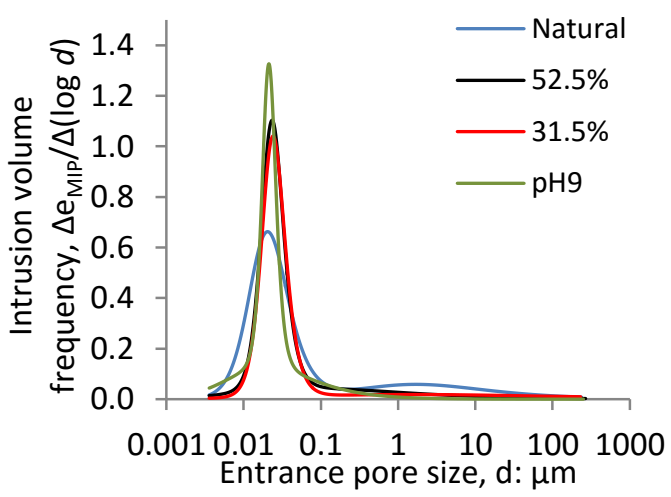

(e)

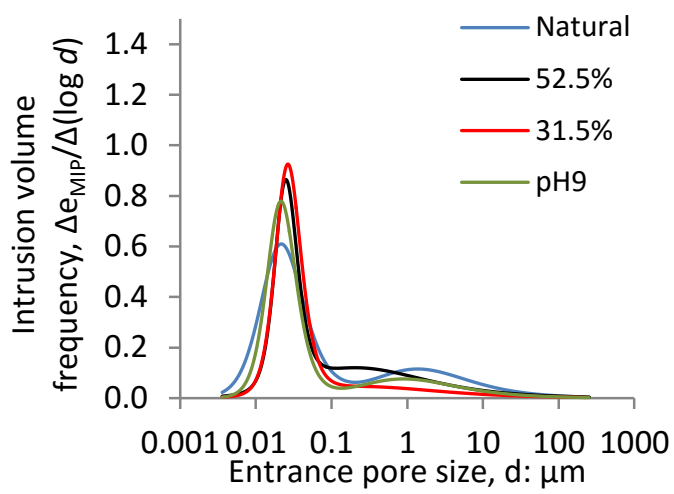

(d)

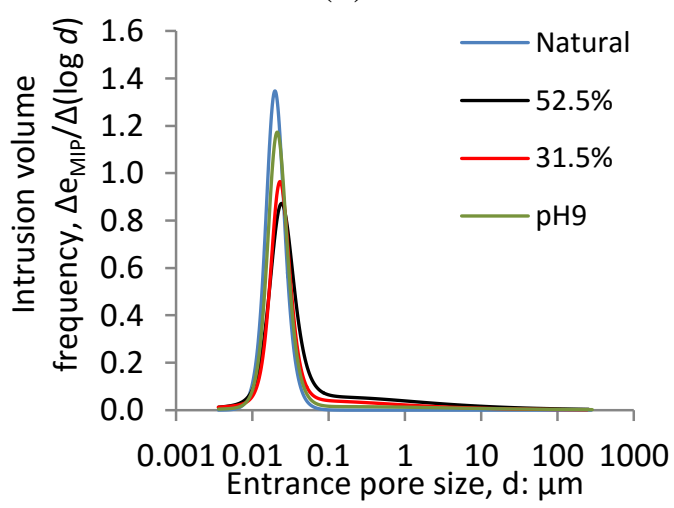

(f)

Figure 5.8 - PSD of Brasilia Soil: (a) $2 \mathrm{kPa}$, (b) $90 \mathrm{kPa}$, (c) $360 \mathrm{kPa}$, (d) $2,000 \mathrm{kPa}$, (e) $5,000 \mathrm{kPa}$ and (f) $11,000 \mathrm{kPa}$

It is clear that up to around 2MPa there are still two modes for the majority of the specimens. The dominant pore size for the smaller pores is the same for all four samples at all loading stages; however, the frequency of the pores is variable. The frequency and the dominant pore size for the bigger mode are not coincident for the four specimens subjected to the load of $2 \mathrm{kPa}$. From $90 \mathrm{kPa}$ onwards, the $31.5 \%$ and $\mathrm{pH} 9$ specimens start to have similar frequency and dominant pore size for the bigger mode, while the natural and 52.5\% specimens show the same trend at $360 \mathrm{kPa}$. From 5MPa onwards, the bigger mode is almost non-existent, while at $11 \mathrm{MPa}$ the curves are almost coincident and only the frequencies of pores are slightly different. Similar observation can be drawn from the consolidation curves.

Table 5.3 shows the difference between the overall porosity of the natural, or reconstituted $(52.5 \%)$ or remoulded $(31.5 \%)$ specimens, and the $\mathrm{pH} 9$ specimen in the consolidation curve and in the MIP test, as well as the difference in results between these two experiments. These data again show what has been previously said - that the difference in the overall porosity between the natural, reconstituted or remoulded and $\mathrm{pH} 9$ specimens reduces as the load increases, with a sporadic small increase seen in particular in the MIP test, which is not necessarily real (Annex C). 
Table 5.3 - Brasilia Soil: difference in overall porosity between natural or $52.5 \%$ or $31.5 \%$ and pH9 specimens in the consolidation curve and MIP test

\begin{tabular}{cccccccccc}
\hline & \multicolumn{2}{c}{$\Delta \mathrm{n}(\mathrm{Natural}-\mathrm{pH})$} & \multicolumn{2}{c}{$\Delta \mathrm{n}(52.5 \%-\mathrm{pH})$} & \multicolumn{2}{c}{$\Delta \mathrm{n}(31.5 \%-\mathrm{pH})$} \\
$\begin{array}{c}\text { Load } \\
(\mathrm{kPa})\end{array}$ & $\begin{array}{c}\text { Consolid } \\
\text { ation } \\
\text { Curve }\end{array}$ & MIP & $\begin{array}{c}\Delta \text { (Cons - } \\
\text { MIP) }\end{array}$ & $\begin{array}{c}\text { Consolidati } \\
\text { on Curve }\end{array}$ & MIP & $\begin{array}{c}\Delta \text { (Cons - } \\
\text { MIP) }\end{array}$ & $\begin{array}{c}\text { Consolidati } \\
\text { on Curve }\end{array}$ & $\begin{array}{c}\text { MIP } \\
\text { on (Cons - } \\
\text { MIP) }\end{array}$ \\
\hline 2 & $13.1 \%$ & $9.2 \%$ & $3.9 \%$ & $3.2 \%$ & $8.4 \%$ & $5.2 \%$ & $1.4 \%$ & $0.4 \%$ & $1.0 \%$ \\
90 & $11.0 \%$ & $12.8 \%$ & $1.8 \%$ & $6.5 \%$ & $6.3 \%$ & $0.2 \%$ & $2.9 \%$ & $1.2 \%$ & $1.7 \%$ \\
360 & $7.6 \%$ & $10.0 \%$ & $2.4 \%$ & $5.1 \%$ & $6.9 \%$ & $1.8 \%$ & $2.4 \%$ & $2.5 \%$ & $0.1 \%$ \\
2,000 & $2.7 \%$ & $4.8 \%$ & $2.1 \%$ & $2.1 \%$ & $2.2 \%$ & $0.1 \%$ & $1.3 \%$ & $0.8 \%$ & $0.5 \%$ \\
5,000 & $1.0 \%$ & $4.6 \%$ & $3.6 \%$ & $0.9 \%$ & $2.4 \%$ & $1.5 \%$ & $0.6 \%$ & $1.2 \%$ & $0.6 \%$ \\
11,000 & $0.7 \%$ & $3.4 \%$ & $2.7 \%$ & $0.2 \%$ & $2.2 \%$ & $2.0 \%$ & $0.5 \%$ & $1.7 \%$ & $1.2 \%$ \\
\hline
\end{tabular}

In the following section a conceptual model is introduced to help in the interpretation of the MIP results described in this section.

\section{4 - CONCEPTUAL MODEL}

The conceptual model proposed for the transitional soils is different from that proposed for the clays. The reason for this is due to the composition and grain sizes present in the transitional soil. Here, the transitional soil studied is the Brasilia Soil, in which the main mineral is kaolinite; however, the fraction of sand and silt cannot be disregarded. As a way to simplify the analyses, it was assumed that the soil was formed by sand, silt and clay, where the latter was only kaolin.

The assumption made is that, for the natural, reconstituted and remoulded specimens subjected to the lowest loads, the bigger pores are those within the silt and/or sand fraction as well as between the clay fraction, as long as this arrangement is edge-to-face due to the size of the pores, while the smallest pores are those within the clay fraction, or between clay and silt and clay and sand, and the arrangement of the clay fraction is face-to-face rather than edge-to-face due to the size of the smallest dominant pores. As for the specimens under the highest loads, the clay fraction seems be the dominant matrix of the overall soil behaviour and there is no arrangement in which silt and/or sand particles are in contact forming pores, only pores between the clay fraction and between clay and silt and clay and sand are visible. There is a slight difference for the $\mathrm{pH} 9$ specimens. These specimens do not allow contact between clay particles; therefore the bigger pores of the specimens subjected to lower loads are pores within the silt and/or the sand fraction. The idealized arrangement of particles proposed are those presented in Figure 5.9. 

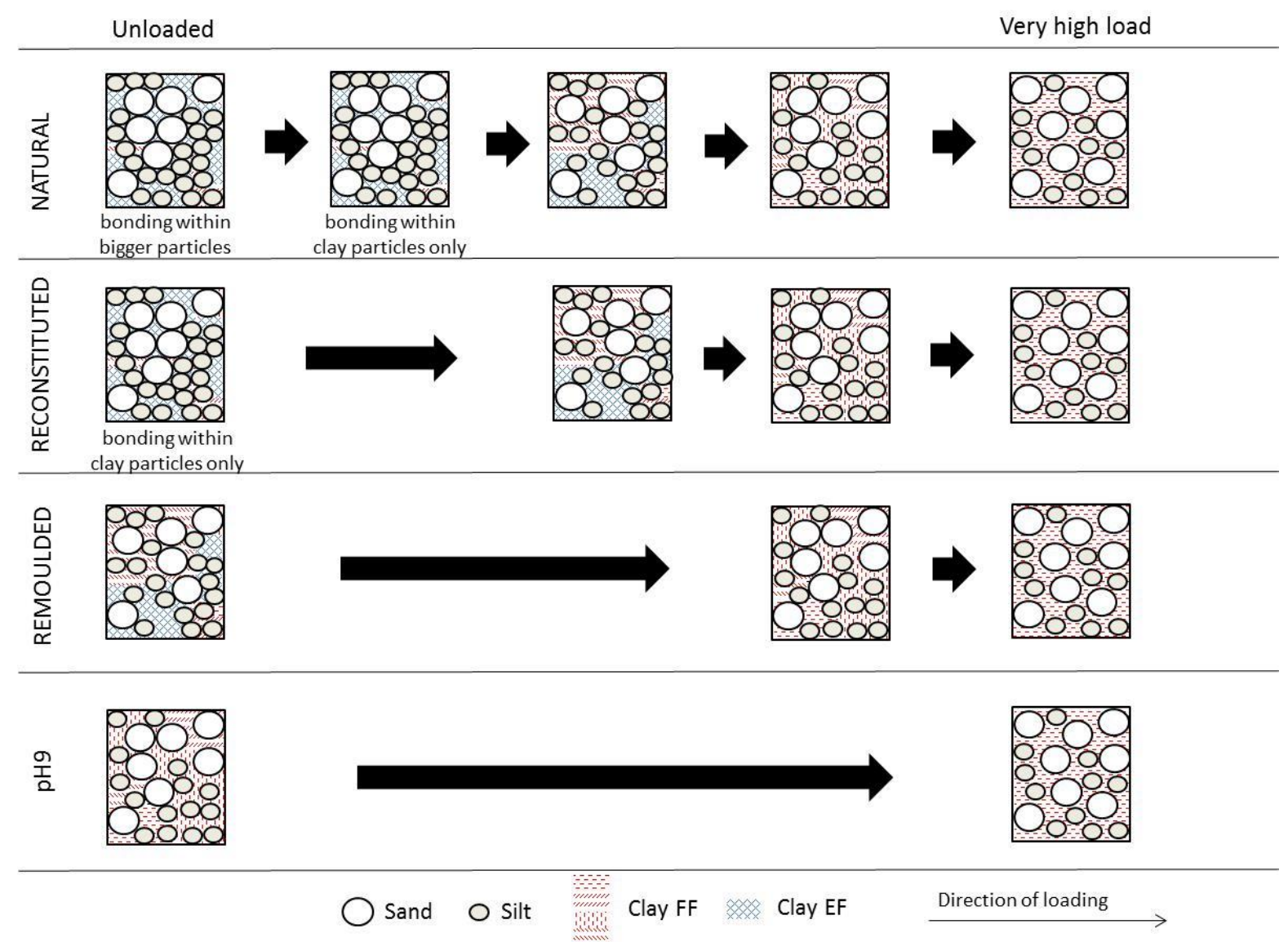

Figure 5.9 - Summary of the particles' arrangement change with loading for natural, reconstituted, remoulded and pH9 specimens (idealized clay arrangement after Barden \& Sides, 1971)

Herein, in the same way as was done for the clays, the pH9 specimen is considered the reference state for the structure study. Taking into account the MIP results of section 5.3, it is assumed that pores greater than $1 \mu \mathrm{m}$ are definitely within sand or silt particles, while pores between 0.01 and $0.1 \mu \mathrm{m}$ are within clay (FF) particles, between silt and clay, sand and clay and sand and silt particles. The pH9 specimens do not allow contacts; therefore these specimens only have FF pores and the non-contact, non-parallel arrangement also considered EF within the clay fraction. The natural specimen can have any configuration and it could be random without any load applied. As load is applied, the weak bonding between sand and silt particles is broken, the clay matrix starts to dominate the behaviour, separating sand and silt particles and the clay particles tend to align, going from cardhouse to turbostatic, before finally forming a dispersed arrangement.

The reconstituted specimen is one step ahead of the natural specimen since it does not have the bonding within sand and silt particles. As load is applied, the same change in arrangement is expected. The remoulded specimen without any load already has fewer pores within sand 
and silt particles and within clay particles the configuration is already more turbostatic, i.e., one step ahead of the reconstituted specimen. The $\mathrm{pH} 9$ specimen is the most advanced specimen. Without any load its configuration has fewer pores within sand and silt particles and within clay particles the configuration is already dispersed.

For the Brasilia Soil, for consistency, considering the many types of pores present in this soil, the smaller pores within FF clay particles, between clay and silt, clay and sand and silt and sand were called micro and the bigger pores within sand and silt particles and within EF clay particles (including the non-contact, non-parallel arrangement also considered EF) were called macro.

As already mentioned in Chapter 3, the fitting of the cumulative intrusion data from MIP tests was carried out with a bi-modal van Genuchten-type equation, even for the data that had an apparent mono-modal distribution.

Figure 5.10a and b show the micro and macro void ratios respectively obtained in the MIP test against effective stress for the natural, reconstituted, remoulded and $\mathrm{pH} 9$ specimens of the Brasilia Soil. The micro void ratio is roughly constant and around the same value for all loads and all specimens. The real difference is then due to the macro arrangement. Again, as mentioned many times in this chapter, this difference reduces as the load increases. Figure 5.10c and d show the dominant diameter of the micro and macro pores of the Brasilia Soil specimens respectively against the vertical effective stress. It is clear that the dominant micro pores do not change significantly with load for all specimens. The dominant macro pores are widely distributed at the lowest loads, but after $360 \mathrm{kPa}$ they tend towards zero for all specimens, which implies the change in arrangement proposed here. Figure 5.10e and f show the $\mathrm{n}$ fitting parameter of the micro and macro pores of the Brasilia Soil specimens respectively against the vertical effective stress. The $\mathrm{n}_{\text {micro }}$ reduces slightly with the increase in vertical effective stress and the $\mathrm{n}_{\text {macro }}$, on the other hand, shows a line trend and low values, apart from a single value of $\mathrm{n}_{\text {micro }}$ of the natural specimen loaded at $11,000 \mathrm{kPa}$. Finally, Figure $5.10 \mathrm{~g}$ and $\mathrm{h}$ show the micro and macro void ratios against the fitting parameters $\mathrm{n}_{\text {micro }}$ and $\mathrm{n}_{\text {macro }}$ of the Brasilia Soil specimens respectively. It can be seen that the values of $\mathrm{n}_{\text {micro }}$ reduce with the decrease in the $e_{\text {micro }}$. The $\mathrm{n}_{\text {macro }}$ values are kept almost constant with the reduction in the macro void ratio, with the exception of a natural specimen loaded at $11,000 \mathrm{kPa}$. 


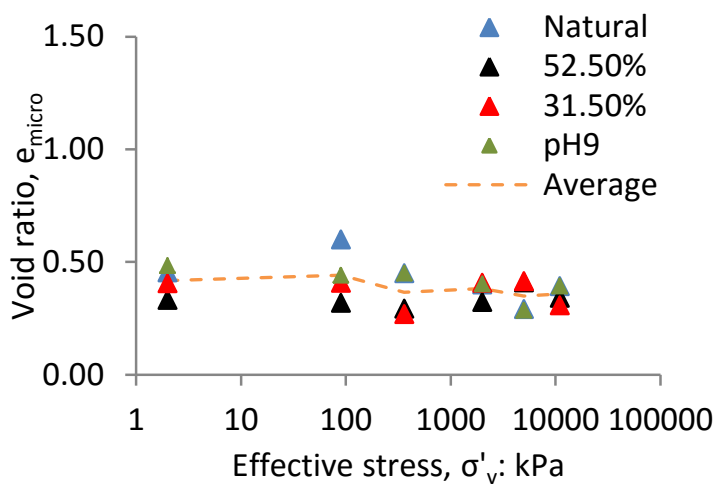

(a)

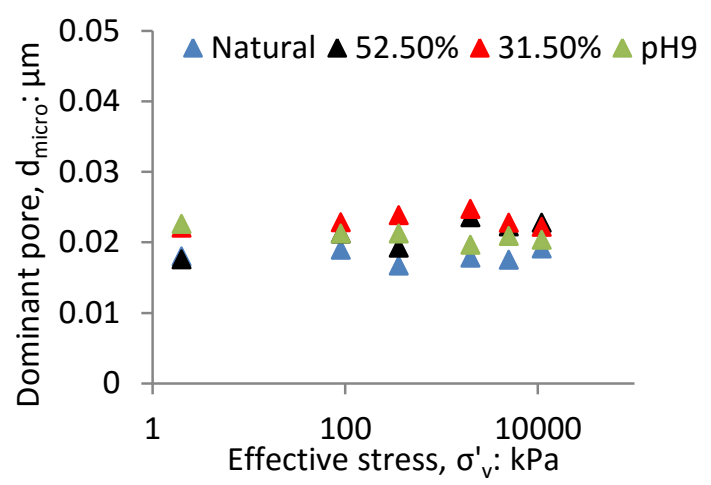

(c)

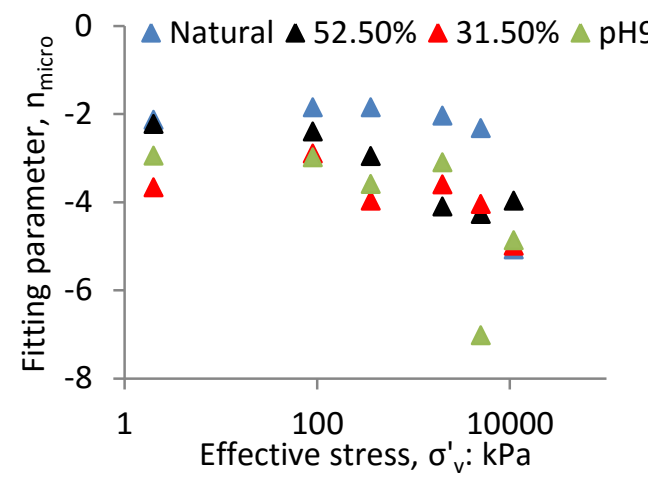

(e)

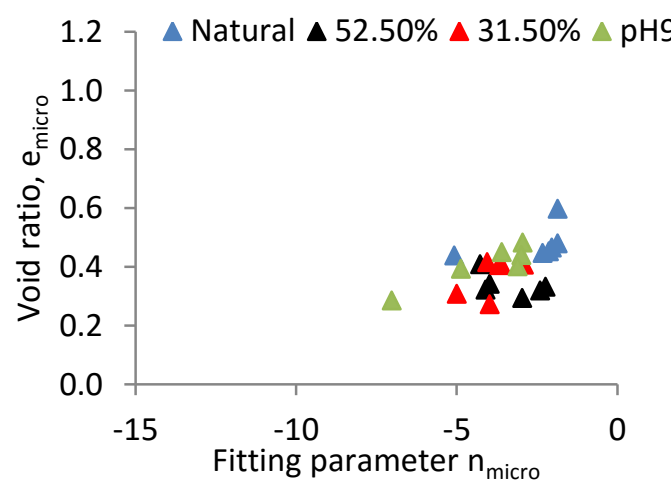

(g)

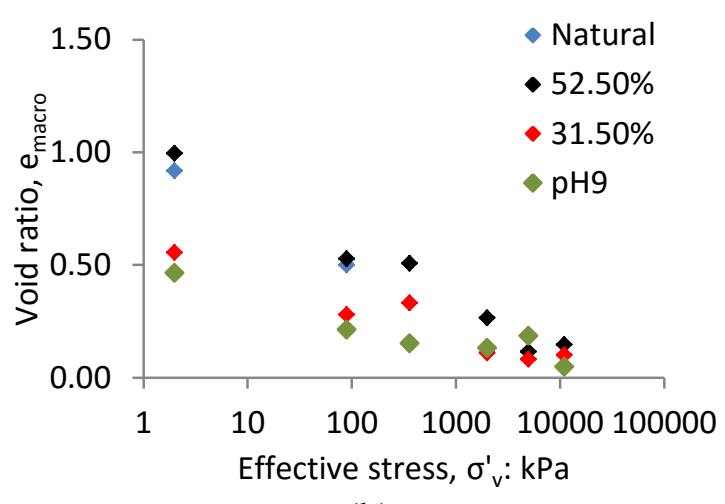

(b)

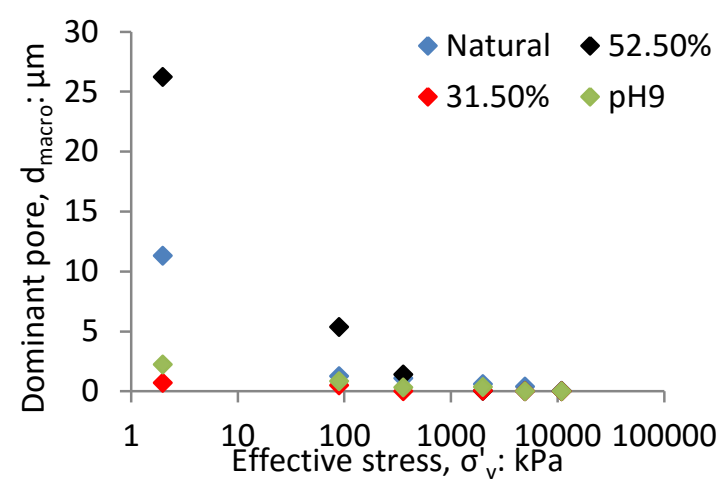

(d)

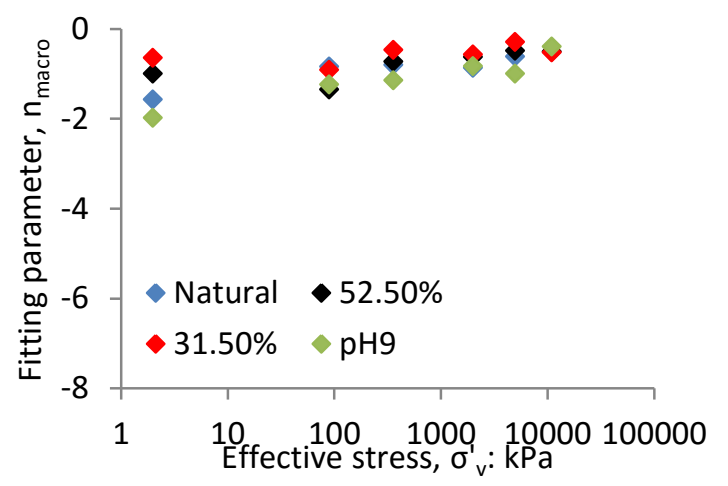

(f)

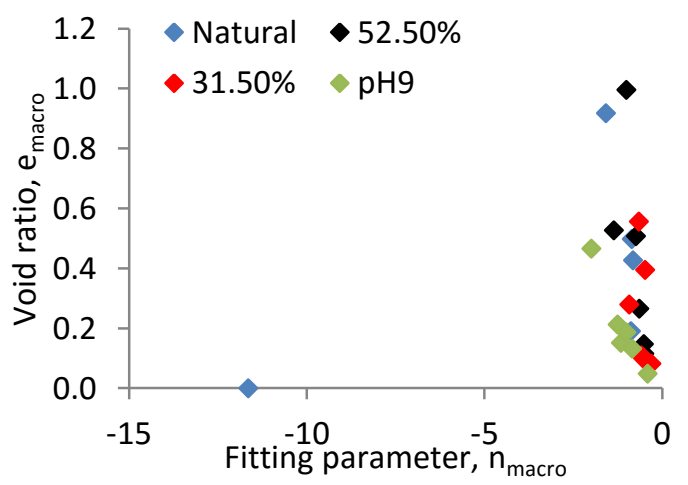

(h)

Figure 5.10 - MIP void ratio of: (a) micro pores and (b) macro pores of the four specimens 


\section{5 - CONSTITUTIVE MODEL}

The results of the consolidation test carried out for the Brasilia Soil specimens were modelled using the elastoplastic hardening model S-CLAY1S (Koskinen et al., 2002), in the same way as for the clays in Chapter 4. For these analyses the anisotropy was also turned off and the amount of structure, $x$, was used differently from that proposed in the original model, in the same manner as it was used for the Kaolin and Ball Clays. Again, the pH9 specimen is the reference; therefore the reconstituted specimens are considered to have structure as well as the remoulded specimens. For modelling purposes, the structure of $\mathrm{pH} 9$ was taken as a reference and set as zero for comparison with other types of structures: reconstituted, remoulded and natural specimens.

Table 5.4 shows the parameters used in the modelling for the Brasilia Soil specimens tested in this research (undisturbed, reconstituted, remoulded and $\mathrm{pH} 9$ ) and compacted (Normal Proctor) specimens (dry side, $\mathrm{w}_{\mathrm{i}}=20 \%$, optimum, $\mathrm{w}_{\mathrm{i}}=24 \%$ and wet side, $\mathrm{w}_{\mathrm{i}}=28 \%$ ) of Brasilia Soil tested by Otalvaro (2013). It is worth noticing that the preconsolidation stress $\left(\sigma^{\prime}{ }_{\text {vp }}\right)$ of the specimens tested in this research was taken as the calculated value based on the initial suction of the sample (Table 5.1) presented in item 5.2, using Eq. 4.1. The preconsolidation stresses of the compacted specimens were taken graphically according to Casagrande's graphical method (Casagrande, 1936). The compression index, $\lambda$, and the swelling index, $\mathrm{K}$, are all the same for all specimens and are taken as the compression and swelling indexes of the $\mathrm{pH} 9$ curve. The critical state value of the stress ratio in triaxial space, $\mathrm{M}$, is the parameter of the soil; thus it is the same for all specimens. The initial effective stress, $\sigma^{\prime}{ }_{\mathrm{o}}$, and the initial void ratio, $\mathrm{e}_{\mathrm{o}}$, are the initial pair of results from each experiment. The size of the intrinsic yield surface, $\mathrm{p}_{\mathrm{mi}}$, was obtained graphically according to Figure 4.21. The initial amount of structure, $x_{o}$, was calculated according to Eq. (2.12) and the degradation rate, $\mathrm{a}_{\mathrm{x}}$, is merely a best-fit parameter. The evolution law of the amount of structure, $\mathrm{x}$, is given by Eq. 4.2. The effect of parameter $a_{x}$ can be seen in Figure 4.22.

Table 5.4 - S-CLAY1S model parameters and state variables for Brasilia Soil specimens

\begin{tabular}{cccccccccc}
\hline Specimen & $\sigma_{\text {vp }}^{\prime}(\mathrm{kPa})$ & $\mathrm{M}$ & $\mathrm{p}_{\mathrm{mi}}$ & $\lambda$ & $\mathrm{k}$ & $\mathrm{e}_{\mathrm{o}}$ & $\mathrm{x}_{\mathrm{o}}$ & $\mathrm{a}_{\mathrm{x}}$ & $\sigma_{\mathrm{o}}(\mathrm{kPa})$ \\
\hline Natural & 12 & 1.05 & 0.003 & 0.08 & 0.01 & 1.60 & 2399 & 17 & 12 \\
$52.5 \%$ & 27 & 1.05 & 0.47 & 0.08 & 0.01 & 1.25 & 38 & 17 & 2 \\
$42.0 \%$ & 30 & 1.05 & 1 & 0.08 & 0.01 & 1.19 & 19 & 17 & 2 \\
$31.5 \%$ & 59 & 1.05 & 6 & 0.08 & 0.01 & 1.04 & 6 & 17 & 6 \\
\hline
\end{tabular}




\begin{tabular}{cccccccccc}
\hline Compacted WS $^{*}$ & 66 & 1.05 & 67 & 0.08 & 0.01 & 0.86 & 1 & 10 & 16 \\
Compacted OP $^{*}$ & 136 & 1.05 & 233 & 0.08 & 0.01 & 0.79 & 2 & 10 & 16 \\
Compacted DS $^{*}$ & 128 & 1.05 & 11 & 0.08 & 0.01 & 0.99 & 7 & 15 & 16 \\
pH9 & $\mathbf{4 5}$ & $\mathbf{1 . 0 5}$ & $\mathbf{3 0}$ & $\mathbf{0 . 0 8}$ & $\mathbf{0 . 0 1}$ & $\mathbf{0 . 9 1}$ & $\mathbf{0}$ & $\mathbf{0}$ & $\mathbf{4 5}$ \\
\hline experimental data from Otalvaro (2013) & & & & & & &
\end{tabular}

Figure 5.11a shows the results of the modelling as well as the experimental data for each specimen of the Brasilia Soil tested in this research. It is important to note that, although the fitting was appropriate, it was not possible to carry out the modelling with the first pair of points of the consolidation curve for the natural and $\mathrm{pH} 9$ specimens. Figure 5.11b shows the modelling results of the experimental data obtained by Otalvaro (2013) for compacted samples of the Brasilia Soil (wet side, optimum and dry side) and also the $\mathrm{pH} 9$ specimen for comparison purposes. The modelling also appears to be adequate, reproducing the main characteristics of the compacted curves.

In order to fit the results of the compacted sample on the wet side (WS) of optimum and the compacted specimen at the optimum (OP) water content, which start below the reference line, the following equation was applied in order to establish the value of the initial amount of structure, $\mathrm{x}_{0}$ :

$$
\mathrm{x}_{\mathrm{o}}=\left(\frac{\mathrm{pm}_{\mathrm{i}}}{\mathrm{pm}}\right)-1
$$

where: $\mathrm{x}_{\mathrm{o}}$ is the initial amount of structure, $\mathrm{pm}_{\mathrm{i}}$ is the size of the intrinsic yield surface and pm is the size of the yield surface of the specimen considered.

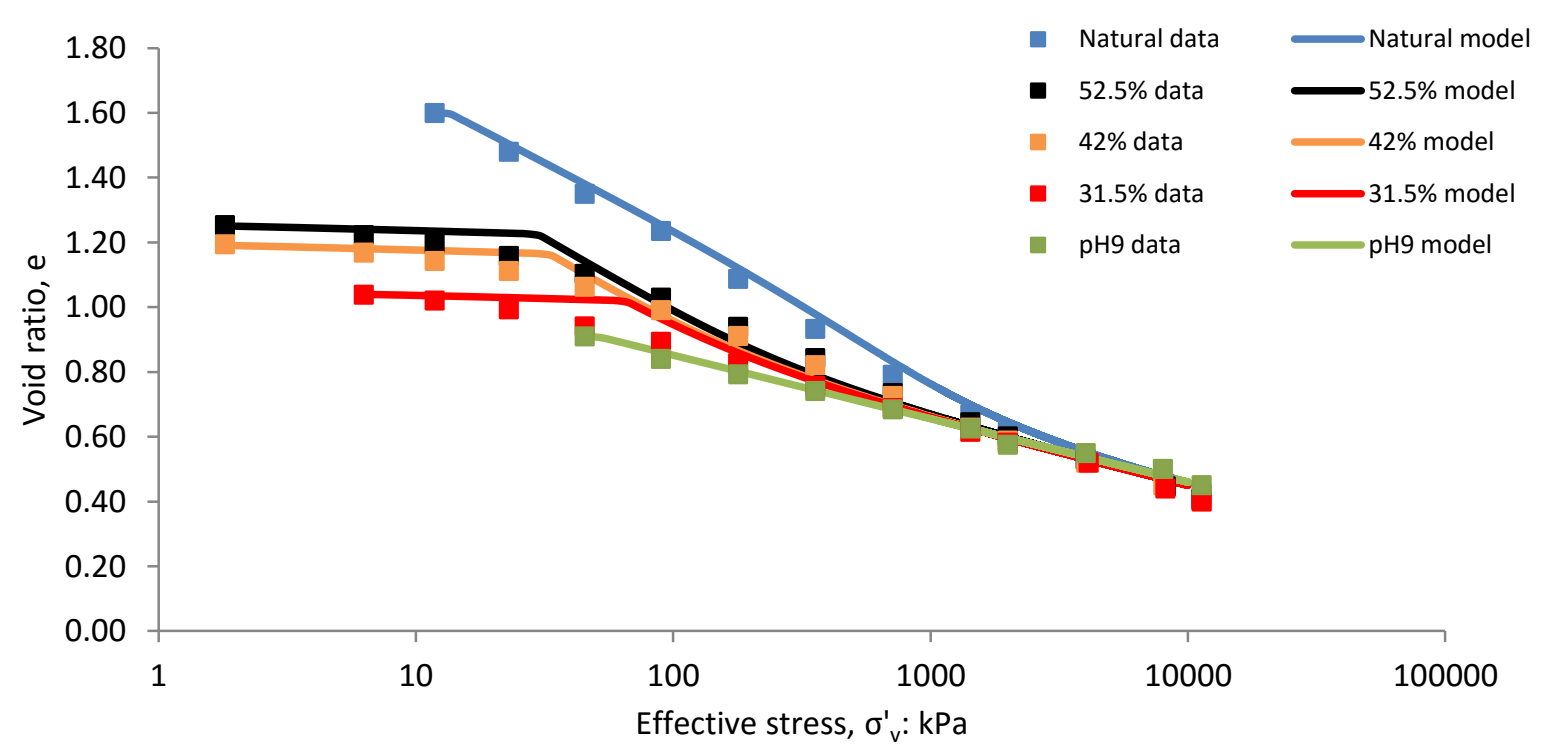

(a) 


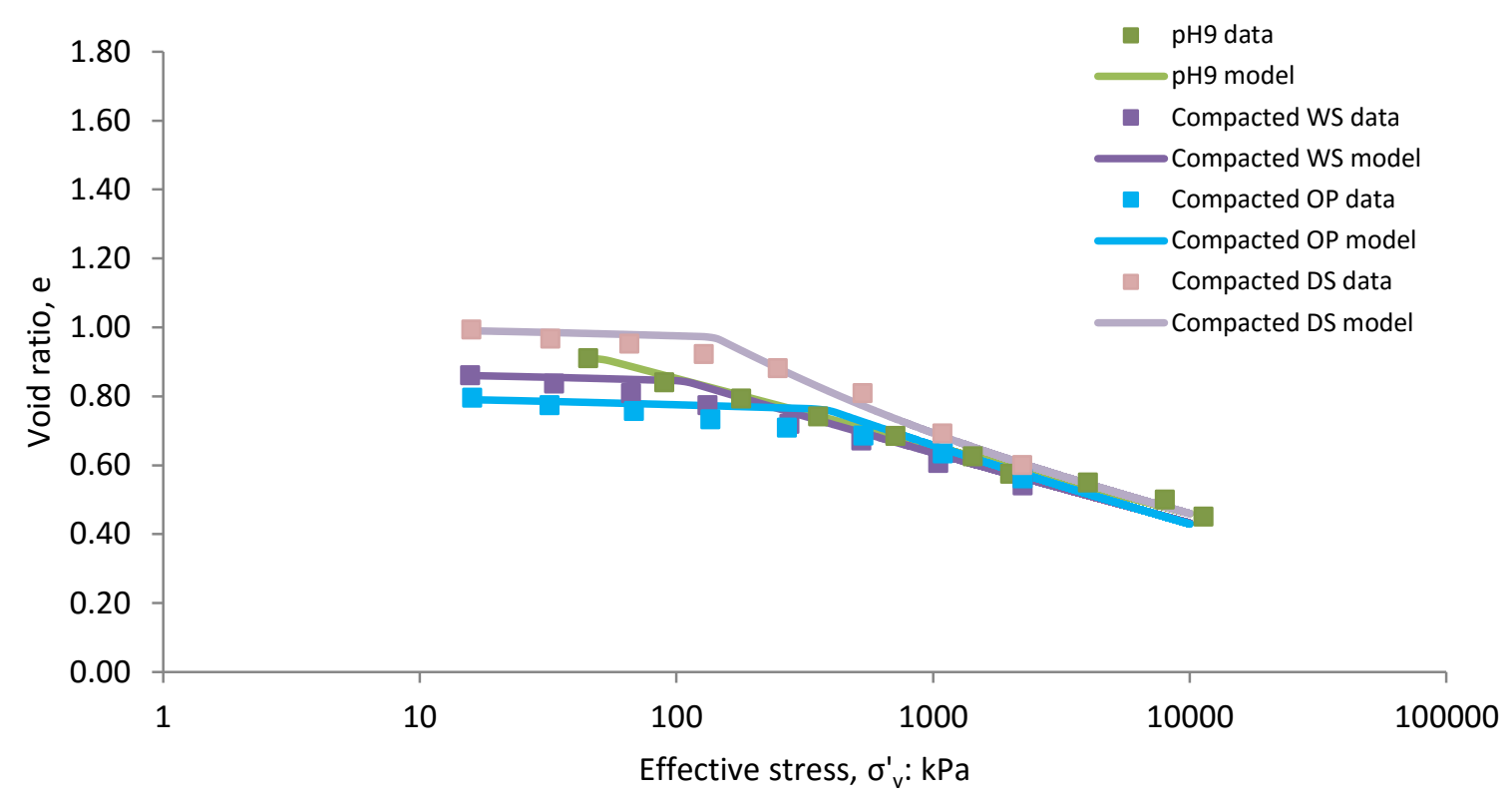

(b)

Figure 5.11 - Experimental data and S-CLAY1S modelling of Brasilia Soil specimens: (a) Natural $\left(\mathrm{w}_{\mathrm{i}}=21 \%\right)$, Reconstituted $\left(\mathrm{w}_{\mathrm{i}}=52.5 \%\right.$ and $\left.42 \%\right)$, Remoulded $\left(\mathrm{w}_{\mathrm{i}}=31.5 \%\right)$ and $\mathrm{pH} 9$ and $(\mathrm{b}) \mathrm{pH} 9$ and Compacted - wet side

(WS) $\mathrm{w}=28 \%$, optimum $(\mathrm{OP}) \mathrm{w}=24 \%$ and dry side $(\mathrm{DS}) \mathrm{w}=20 \%$ (experimental data of compacted specimens from Otalvaro, 2013)

The authors are aware of the fact that the best-fit is not the best way of deriving the values of the degradation rate; however, more detailed studies, especially concerning the microstructure, should be carried out in order to obtain an appropriate way to derive this parameter.

Although the state variable $x_{o}$ - initial amount of structure - has not been associated with the conceptual model proposed, the values obtained for the modelling are coherent with the microstructure results obtained and are shown in section 5.3, with the values decreasing as the initial water content decreases. Figure 5.12 shows the variation in the initial amount of structure with initial void ratio of Brasilia Soil specimens, including the compacted specimens' data (Otalvaro, 2013). Note that, for the natural specimens, the initial amount of structure value is much higher than that for the other specimens, which suggests that the nature of the structure of the natural specimens is different from the nature of the structure of the reconstituted and remoulded specimens, which was observed in the MIP results (section $5.3)$. 


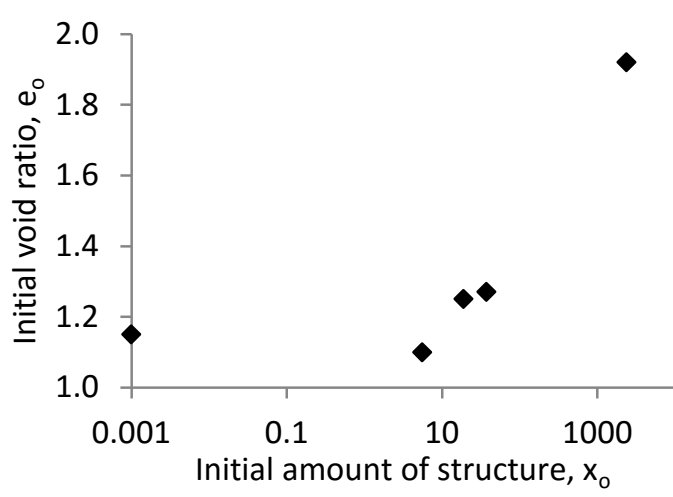

(a)

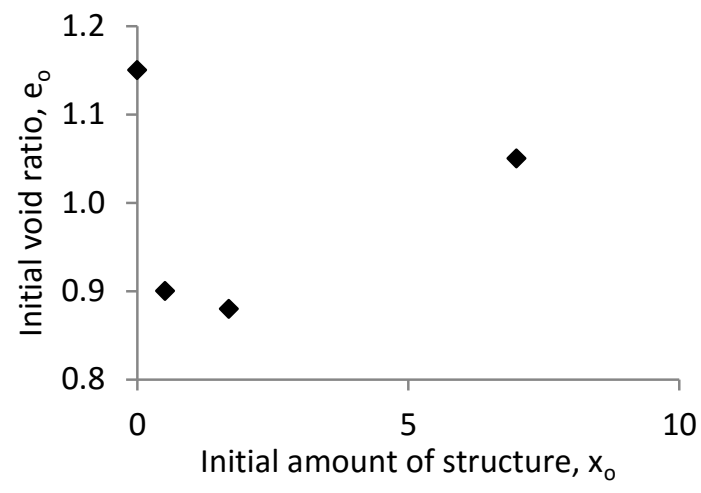

(b)

Figure 5.12 - Variation in initial amount of structure against initial void ratio: (a) in a semi-log plot for the natural, reconstituted, remoulded and $\mathrm{pH} 9$ specimens of Brasilia Soil and (b) compacted and $\mathrm{pH} 9$ specimens of the Brasilia Soil 


\section{6 - FINAL CONSIDERATIONS}

This chapter presents the conclusions obtained from the results of laboratory tests and numerical modelling carried out in reconstituted, remoulded, $\mathrm{pH} 9$ and undisturbed (only for the Brasilia Soil) specimens of three soils: Kaolin Clay, Ball Clay and Brasilia Soil. In addition, suggestions for future work are also a topic for discussion in this chapter.

\section{1 - CONCLUSIONS}

The microstructure of reconstituted, remoulded and $\mathrm{pH} 9$ specimens of Kaolin Clay, Ball Clay and Brasilia Soil, as well as an undisturbed specimen of the latter soil, were analysed with the help of Mercury Intrusion Porosimetry tests. From the analysis and discussion of results, some observations and hypotheses, valid within the limits of this research, are put forward and presented in topics, as follows:

Concerning the materials and methods proposed:

- The methodology suggested for the preparation of specimens for the microstructural study appears to be acceptable.

- The four groups of void ratios (consolidation curve, oedometer test, freeze-drying and MIP) for all three soils were put through the ANOVA statistical test and the results showed that each one was part of the same group within $95 \%$ of reliability.

- Van Genuchten fittings were adequate, with the smallest $\mathrm{R}^{2}$ of $0.9995,0.9984$ and 0.9899 for the Kaolin, Ball Clay and Brasilia Soil respectively.

Results of sedimentation tests:

- Results of the sedimentation tests of the Kaolin Clay show that the void ratio of the pH4 suspension (no dispersant) is more than three times higher than that of the $\mathrm{pH} 9$. For the Ball Clay the void ratio of the $\mathrm{pH} 4.8$ suspension (no dispersant) is almost twice as high as that of the $\mathrm{pH} 9$ and for the Brasilia Soil the void ratio of $\mathrm{pH} 6.3$ suspension (no dispersant) is only 1.2 times higher than that of the pH9. It is worth remembering that these differences are reasonable when the composition of the three soils is taken into account. In contrast to the Kaolin Clay, Ball Clay and Brasilia Soil are not composed solely of kaolinite. Therefore, the electrical charge of the edges is responsible for the difference in the particles' configuration between the suspension with no dispersant and $\mathrm{pH} 9$ while undergoing sedimentation. 
Results of consolidation tests:

- Suction of a few specimens of Kaolin Clay, Ball Clay and Brasilia Soil at the reconstituted and remoulded states were measured and efficiently linked to their preconsolidation stresses. Therefore, it seems that the preparation procedure induces the appearance of suction even in saturated samples, which affects the preconsolidation stress of the samples. However, further influence was not clearly seen beyond the preconsolidation stress that could be directly connected to such a suction generated, due to the preparation procedure.

- Consolidation results of the clay soils show that the reconstituted samples prepared at different initial water content do not converge at $100 \mathrm{kPa}$, as proposed by Burland (1990) and questioned by Shipton \& Coop (2012); however, contrary to the observation by the latter authors, convergence was more realistic as the load increased, especially if the coefficient of variance of the compression indexes (between 10\% and 34\% according to Duncan, 2000) is taken into account. Similar results were observed for the transitional soil, Brasilia Soil, where convergence within reconstituted specimens was observed at about $500 \mathrm{kPa}$, and for the clays, around $200 \mathrm{kPa}$, considering also the coefficient of variance of the compression indexes.

- The pH9 specimens of all three soils were set as the reference state, as it has been demonstrated that this state offers a dispersed arrangement for the clay fraction and not much option for a different arrangement once the 1-D consolidation starts; the plastic deformations are also smaller. In this way, $\mathrm{pH} 9$ is much more suitable to be used as a reference than the reconstituted state.

Results of MIP tests:

- It is noticeable that, as opposed to what the majority of the literature suggests, the void ratio values obtained through the MIP tests are greater than the void ratios obtained before the freeze-drying only for the Kaolin Clay specimens. Similar results were also obtained by Pedrotti (2016) for saturated specimens of Kaolin Clay. It is a challenge to draw definite conclusions regarding the reasons for such behaviour. Herein it is speculated that such difference is a combination of possible errors associated with sample preparations, regarding formation of cracks and crystals on the specimens. 
- As expected, the overall void ratio reduces with the increase in the loading for all specimens of the three soils tested. All states of specimens (undisturbed, reconstituted and remoulded) also tend towards the $\mathrm{pH} 9$ state when compared at the same stage. At the lowest loads they can be distinct, but as load progresses this difference is almost negligible.

- Modelling the results of the MIP helps in analytical understanding, rather than qualitative, of the changes in the microstructure with loading and within different states.

- The parameters of the modelling proposed using the van Genuchten-type bi-modal cumulative distribution equation showed a consistent trend, as expected.

Conceptual model proposed:

- The conceptual model proposed for the clays states that face-to-face pores have a normal distribution due to their lack of space for providing wide ranges of pore sizes, while edge-to-face pores have a log-normal distribution for the opposite reason, since in this case these pores can have a wide range of pore sizes. This has proven to be a reasonable assumption, as seen in Annex D.

- It was proposed for the clay's conceptual model that the $\mathrm{pH} 9$ has a dispersed configuration and, as load progresses, particles tend to orient even more, theoretically reaching the stack configuration. The remoulded state is allowed to have contacts, therefore presents a more open structure. The reconstituted state is a chaotic configuration with plenty of edge-to-face configurations. Both states, remoulded and reconstituted, tend to the well-oriented dispersed configuration, eventually reaching the idealized stack configuration.

- The conceptual model for the Brasilia Soil is slightly different, due to the number of other particles present in the material. However, the idea is similar to that proposed for the clays, the only difference being the number of possibilities for the particles' arrangements, which is greater. The $\mathrm{pH} 9$ is the reference with the clay fraction in a dispersed arrangement, eventually reaching the idealized stack configuration, and all other states (undisturbed, reconstituted and remoulded) tend towards the $\mathrm{pH} 9$ as load increases, where the undisturbed is the more open configuration, since the natural sample has bonding within particles. 
- As a consequence, the $\mathrm{pH} 9$ has been proven to be a better reference state than the reconstituted state, as proposed by Burland (1990).

Constitutive modelling carried out:

- The constitutive model S-CLAY1S (Koskinen et al., 2002) was adapted and used to model the experimental data of Kaolin Clay, Ball Clay and Brasilia Soil, all tested in this research, and also three experimental data of China clays presented by Hong et al. (2010), Lianyungang Clay, Baimahu Clay and Kemen Clay, as well as compacted samples of Brasilia Soil tested by Otalvaro (2013).

- The model proposed fitted the experimental data of all three soils tested (Kaolin Clay, Ball Clay and Brasilia Soil) reasonably well. The same could be observed for the experimental data presented by Hong et al. (2010) and Otalvaro (2013) for Lianyungang Clay, Baimahu Clay and Kemen Clay, as well as compacted samples of Brasilia Soil.

- Although the state variable $\mathrm{x}$ - initial amount of structure - has not been associated with the conceptual model proposed, the values obtained for the modelling are coherent with the microstructure results obtained for all soils and sample states, with the values decreasing as the initial water content decreases.

- The parameter $\mathrm{a}_{\mathrm{x}}$ is a best-fitting parameter; however, it should be somehow linked to the numbers of contacts between particles and other characteristics of the microstructure.

\section{2 - SUGGESTIONS FOR FUTURE WORK}

Based on the results obtained and the knowledge acquired through the development of this research, the following suggestions for future work are introduced:

- Extend this study to unsaturated samples of the same soils;

- Develop more detailed studies, concerning the microstructure, in order to obtain an appropriate way to derive the amount of structure, $x$, and degradation rate, $a_{x}$, parameters, improving the application of the constitutive model used in this research;

- Develop studies to understand how different types of stress, shear and stain paths affect the pores' distributions, using trivial tests as support;

- Study the changes in pore distributions of other types of soils under a variety of other hydromechanical paths; 
- Develop, improve or standardize techniques for freeze-drying that could ensure more reliable results;

- Use of the Discrete Element Methods (DEM) should be considered to support the studies of the soil behaviour. 


\section{REFERENCES}

Addis, M.A. \& Jones, M.E. (1990). Mechanical behaviour and strainrate dependence of high porosity chalk. Proceedings of the International Chalk Symposium, Brighton, 111-116.

Ahmed, S., Lovell Jr., C.W. \& Diamond, S. (1974). Pore sizes and strength of a compacted clay. Tech. Rep. J. Geotech. Engrg., 400(4): 407-425.

Alonso, E.E., Gens, A. \& Josa, A. (1990). A constitutive model for partially saturated soils. Géotechnique, 40(3): 405-430.

Alonso, E.E., Pinyol, N.M. \& Gens, A. (2013). Compacted soil behaviour: initial state, structure and constitutive modelling. Géotechnique, 63(6): 463-478.

Alonso, E.E., Romero, E. \& Hoffmann, C. (2011). Hydromechanical behaviour of compacted granular expansive mixtures: experimental and constitutive study. Géotechnique, 61(4): 329-344.

Anagnostopoulos, A., Kalteziotis, N., Tsiambaos, G.K. \& Kavvadas, M. (1991). Geotechnical properties of the corinth canal marls. Geotech.Geol. Engng, (9): 1-26.

Anandarajah, A. \& Chen, J. (1997). Van der waals attractive force between clay particles in water and contaminants. Soils Found., (37): 27-37.

Axelsson, K., Yu, Y. \& Runesson, K. (1989). Constitutive properties and modelling of silty soils. 12th ICSMFE, Rio de Janeiro, 687-690.

Barden, L. \& Sides, G. (1971). Sample disturbance in the investigation of clay structure. Géotechnique, 21(3): 211-222.

Baudet, B.A. \& Stallebrass, S.E. (2001). Modelling the destructuration of soft natural clays. Proc. 10th Int. Conf. on Computer Methods and Advances in Geomechanics, Tucson, 297-301.

Baudet, B.A. \& Stallebrass, S.E. (2004). A constitutive model for structured clays. Géotechnique, 54(4): 269-278.

Been, K. \& Jefferies, M.G. (1985). A state parameter for sands. Géotechnique, 35(2): 95112.

Borges, C. (2014). Estudo microestrutural do comportamento hidromecânico do solo de Brasília-DF. Doutorado, Universidade de Brasília, 112 p.

Braggs, B., Fornasiero, D., Ralston, J. \& Smart, R.S. (1994). The effect of surface modification by an organosilane on the electrochemical properties of kaolinite. Clays Clay Miner., (42): 123-136. 
Buenfil, C. (2007). Caracterización experimental del comportamiento hidromecánico de una arcilla compactada. $\mathrm{PhD}$ thesis, Universitat Politècnica de Catalunya.

Burland, J.B. (1990). On the compressibility and shear strength of natural clays. Géotechnique, 40(3): 329-378.

Burland, J.B., Rampello, S., Georgiannou, V.N. \& Calabresi, G. (1996). A laboratory study of the strength of four stiff clays. Géotechnique, 46(3): 491-514.

Calabresi, G. \& Scarpelli, G. (1985). Ffects of swelling caused by unloading in overconsolidated clays. Proc. 11th ICSMFE, San Francisco, 411-414.

Carrier, W.D. \& Beckman, J.F. (1985). Discussions: correlations between index tests and the properties of remoulded clays. Géotechnique, 35(2): 223-229.

Casagrande, A. (1932). The structure of clay and its importance in foundation engineering. J. Bost. Soc. Civ. Eng., : 68.

Casagrande, A. (1936). The determination of the pre-consolidation load and its practical signficance. Proceedings of the First International Conference on Soil Mechanics and Foundation Engineering, Cambridge, 60-64.

Cerrolaza, M. \& Delage, P. (1997). Microstructure and volume change behaviour of soft clays: a boundary element simulation. Int. J. Numer. Anal. Meth. Geomech., 21: 665686.

Clayton, C.R.I. \& Serratrice, J.F. (1993). The mechanical properties and behaviour of hard soils and soft rocks. Proceedings of the international symposium on hard soils-soft rocks, Athens, 1839-1877.

CoolSafe. (2006). Coolsafe freeze dryer instruction manual.

Coop, M.. \& Lee, I.K. (1993). The behaviour of granular soils at elevated stresses. Predict. Soil Mech., : 186-198.

Coop, M.R. \& Atkinson, J.H. (1993). The mechanics of cemented carbonate sands. Géotechnique, 43(1): 53-67.

Cotecchia, F. (1996). The effects of structure on the properties of an Italian pleistocene clay. $\mathrm{PhD}$. thesis, University of London.

Cotecchia, F. \& Chandler, R.J. (1997). The influence of structure on the pre-failure behaviour of a natural. Géotechnique, 47(3): 523-544.

Craig, R.F. (2004). Craig's soil mechanics. J. Chem. Inf. Model.,. 53, 447 p.

Delage, P., Audiguier, M., Cui, Y.-J. \& Howat, M.D. (1996). Microstrucure of a compacted silt. Can. Geotech. J., 33: 150-158. 
Delage, P. \& Lefebvre, G. (1984). Study of the structure of a sensitive champlain clay and of its evolution during consolidation. Can. Geotech. J., 21: 21-35.

Delage, P. \& Pellerin, F.M. (1984). Influence de la lyophilisation sur la structure d'une argile sensible du quebec. Clay Miner., 19: 151-160.

Delage, P., Tessier, D. \& Marcel-Audiguier, M. (1982). Use of the cryoscan apparatus for observation of freeze-fractured planes of a sensitive quebec clay in scanning electron microscopy. Can. Geotech. J., 19(1): 111-114.

Diamond, S. (1970). Pore size distribution in clays. Clays Clay Miner., (18): 7-23.

Duncan, J.M. (2000). Factors of safety and reliability in geotechnical engineering. J. Geotech. Geoenvironmental Eng., 126(4): 307-316.

Durner, W. (1994). Hydraulic conductivity estimation for soils with heterogeneous pore structure. Water Resourses Res., (30): 211-223.

Eliot, G.M. \& Brown, E.T. (1985). Yield of a soft, high-porosity rock. Géotechnique, 35(4): 413-423.

Fearon, R.E. \& Coop, M.R. (2000). Reconstitution: what makes an appropriate reference material? Géotechnique, 50(4): 471-477.

Ferreira, P.M. V \& Bica, a V.D. (2006). Problems in identifying the effects of structure and critical state in a soil with a transitional behaviour. Geotechnique, 56(7): 445-454.

Gens, A. \& Nova, R. (1993). Conceptual bases for a constitutive model for bonded soils and weak rocks. Proceedings of the international symposium on hard soils-soft rocks, Athens, 485-494.

Gillott, J.E. (1969). Study of the fabric of fine-grained sediments with the scanning electron microscope. J. Sediment. Petrol., 39(1): 90-105.

Goldschmidt, V.M. (1926). Undersokelser over lersedimenter. Nord. Jordbrugs forskuing, (47): 435-445.

Gorman, C.T., Hopkins, T.C. \& Drnevich, V.P. (1978). Constant of-strain and controlledgradient consolidation testing. Geotech. Test. J., 1(1): 3-15.

Griffiths, F.J. \& Joshi, R.C. (1990). Discussions: change in pore size distribution due to consolidation of clays. Géotechnique, 40(1): 303-309.

Gupta, V., Hampton, M.A., Stokes, J.R., Nguyen, A.V.\& \& Miller, J.D. (2011). Particle interactions in kaolinite suspensions and corresponding aggregate structures. J. Colloid Interface Sci.,.

Hong, Z. (2007). Void ratio-suction behavior of remolded ariake clays. Geotech. Test. J., 30(3): 234-239. 
Hong, Z. \& Tsuchida, T. (1999). On compression characteristics of ariake clays. Can. Geotech. J., 36(5): 807-814.

Hong, Z.-S., Yin, J. \& Cui, Y.-J. (2010). Compression behaviour of reconstituted soils at high initial water contents. Géotechnique, 60(9): 691-700.

Hong, Z.-S., Zeng, L.-L., Cui, Y.-J., Cai, Y.-Q. \& Lin, C. (2012). Compression behaviour of natural and reconstituted clays. Géotechnique, 62(4): 291-301.

Huertas, F.J., Chou, L. \& Wollast, R. (1998). Mechanism of kaolinite dissolution at room temperature and pressure: part 1. surface speciation. Geochim. Cosmochim. Acta, (62): $417-431$.

Imerys Minerals. (2015). Kaolin Clay and Ball Clay [WWW Document]. URL http://www.imerys-perfmins.com/kaolin/eu/kaolin.htm

Karstunen, M. \& Koskinen, M. (2004). Anisotropy and destructuration of murro clay. Advances in geotechnical engineering: The Skempton conference, 476-487.

Karstunen, M., Krenn, H., Wheeler, S., Koskinen, M. \& Zentar, R. (2005). The effect of anisotropy and destructuration on the behaviour of murro test embankment. Soil Mech. Found. Div., 5(June): 87-97.

Karstunen, M., Wiltafsky, C., Krenn, H., Scharinger, F. \& Schweiger, H.F. (2006). Modelling the behaviour of an embankment on soft clay with different constitutive models. Int. J. Numer. Anal. Methods Geomech., 30(January): 953-982.

Kavvadas, M. \& Amorosi, A. (2000). A constitutive model for structured clays. Géotechnique, 50(3): 263-273.

Kohgo, Y., Nakano, M. \& Miyazaki, T. (1993). Theoretical aspects of constitutive modelling for unsaturated soils. Soils Found., 33(4): 39-63.

Koliji, a., Vulliet, L. \& Laloui, L. (2010). Structural characterization of unsaturated aggregated soil. Can. Geotech. J., 47: 297-311.

Koskinen, M., Karstunen, M. \& Wheeler, S.J. (2002). Modelling destructuration and anisotropy of a natural soft clay. Proceedings of the 5th European Conference Numerical Methods in Geotechnical Engineering, Paris.

Kretzschmar, R., Holthoff, H. \& Sticher, H. (1998). Influence of ph and humic acid on coagulation kinetics of kaolinite: a dynamic light scattering study. J. Colloid Interface Sci., (202): 95-103.

Lambe, T.W. (1953). The structure of inorganic soil. Proc. Am. Soc. Civ. Eng., 79: 1-49.

Lambe, T.W. \& Whitman, R.V. (1969). Soil Mechanics. John Wiley and Sons, Inc, New York, $553 \mathrm{p}$. 
Larsson, R. \& Sallfors, G. (1985). Automatic continuous consolidation testing in sweden. Proceedings of the ASTM Committee D-18 Symposium on Soil and Rock, 299-328.

Lawrence, G.P. (1978). Stability of soil pores during mercury intrusion porosimetry. J. Soil Sci., (29): 299-304.

Lawrence, G.P., Payne, D. \& Greenland, D.J. (1979). Pore size distribution in critical point and freeze dried aggregates from clay subsoils. J. Soil Sci., (30): 499-516.

Lee, K. (1981). Consolidation with constant rate of deformation. Géotechnique, 31(2): 215229.

Lee, K., Choa, V., Lee, S.H. \& Quek, S.. (1993). Constant rate of strain consolidation of singapore marine clay. Géotechnique, 43(3): 471-488.

Leroueil, S. (1977). Quelques considerations sur le comportement des argiles sensibles. Universite Laval.

Leroueil, S., Tavenas, F., Samson, L. \& Morin, P. (1983). Preconsolidation pressure of champlain clays. part ii. laboratory determination. Can. Geotech. J., 20(4): 803-816.

Leroueil, S., Tavernas, F., Brucy, F., La Rochelle, P. \& Roy, M. (1979). Behavior of destructured natural clays. J. Geotech. Engrg, 105(6): 759-778.

Leroueil, S., Tavernas, F. \& Locat, J. (1985). Discussion on "correlations between index tests and the properties of remolded clays." Géotechnique, 35(2): 223-226.

Leroueil, S. \& Vaughan, P.. (1990). The general and congruent effects of structure natural soils and weak rocks. Géotechnique, 40(3): 467-488.

Liu, M.D. \& Carter, J.P. (1999). Virgin compression of structured soils. Géotechnique, 49(1): 43-57.

Liu, M.D. \& Carter, J.P. (2000). Modelling the destructuring of soils during virgin compression. Géotechnique, 50(4): 479-483.

Liu, M.D. \& Carter, J.P. (2002). A structured cam clay model. Can. Geotech. J., 39: 13131332.

Locat, J. \& Lefebvre, G. (1986). The origin of structuration of the grande-baleine marine sediments, québec, canada. Q. J. Eng. Geol., 19(4): 365-374.

Lopes, B.C.F.L., Tarantino, A. \& Cordão Neto, M.P. (2014). An approach to detect microand macro-porosity from mip data. Unsaturated soils: research \& applications: proceedings of the Sixth International Conference on Unsaturated Soils, UNSAT 2014, . CRC Press/Balkema, Sydney, 685-690.

Loret, B. \& Khalili, N. (2002). An effective stress elastic-plastic model for unsaturated porous media. Mech. Mater., (34): 97-116. 
Martins, E.S. (2000). Petrografia, mineralogia e geomorfologia de regolitos lateriticos no Distrito Federal. Universidade de Brasilia, 195 p.

Mascarenha, M.M. dos A. (2008). Influência da microestrutura no comportamento hidromecânico de uma argila siltosa não saturada incluindo pequenas deformações. Doutorado, Universidade de Brasília, 158 p.

McDowell, G.R. \& Bolton, M.. (1998). On the micro mechanics of crushable aggregates. Géotechnique, 48(5): 667-679.

Mitchell, J.K. (1976). Fundamentals of soil behaviour. John Wiley and Sons, New York.

Mitchell, J.K. \& Soga, K. (2005). Fundamentals of Soil Behavior. Third Edit. John Wiley \& Sons, INC, $558 \mathrm{p}$.

Mitchell, J.K. \& Solymar, Z. V. (1984). Time-dependent strength gain in freshly deposited or densified sand. Journal of Geotechnical Engineering division, 1559-1576.

Monroy, R., Zdravkovic, L. \& Ridley, A. (2010). Evolution of microstructure in compacted london clay during wetting and loading. Géotechnique, 60(2): 105-119.

Nash, D.F.T., Sills, G.C. \& Davison, L.R. (1992). One-dimensionalconsolidation testing of soft clay from bothkennar. Géotechnique, 42(2): 241-256.

Nocilla, A., Coop, M.R. \& Colleselli, F. (2006). The mechanics of an italian silt: an example of "transitional" behaviour. Géotechnique, 56(4): 261-271.

Nova, R., Castellanza, R. \& C., T. (2003). A constitutive model for bonded geomaterials subject to mechanical and/or chemical degradation. International Journal for Numerical and analytical Methods in Geomechanics, 705-732.

Van Olphen, H. (1977). An Introduction to Clay Colloid Chemistry. $2^{\circ}$ edition. John Wiley and Sons, Inc, $318 \mathrm{p}$.

Otalvaro, I.F.C. (2013). Comportamento Hidromecânico de um solo tropical compactado. Thesis, Universidade de Brasilia, 122 p.

Pedrotti, M. (2016). An experimental investigation on the micromechanisms of non-active clays in saturated and partially saturated states. $\mathrm{PhD}$. Thesis, University of Strathclyde.

Penumadu, D. \& Dean, J. (2000). Compressibility effect in evaluating the pore-size distribution of kaolin clay using mercury intrusion porosimetry. Can. Geotech. J., 37: 393-405.

Prashant, A. \& Penumadu, D. (2007). Effect of microfabric on mechanical behavior of kaolin clay using cubical true triaxial testing. J. Geotech. Geoenvironmental Eng., 133(4): 433444.

Quantachrome. (2009). Poremaster user guide. 
Rampello, S. (1989). Effetti del rigonamento sul comportamento meccanico di argille fortemente sovraconsolidate. University of Rome 'La Sapienza'.

Romero, E. (1999). Characterisation and thermo-hydro-mechanical behaviour of unsaturated Boom clay: an experimental study. PhD, Universitat Politècnica de Catalunya.

Romero, E. \& Simms, P.H. (2008). Microstructure investigation in unsaturated soils: a review with special attention to contribution of mercury intrusion porosimetry and environmental scanning electron microscopy. Geotech. Geol. Eng., 26(6): 705-727.

Roscoe, K.H. \& Burland, J.B. (1968). On the generalized stress-strain behaviour of wet clay. Engineering plasticity, Cambridge, 535-609.

Rouainia, M. \& Wood, D.M. (2000). A kinematic hardening constitutive model for natural clays with loss of structure. Géotechnique, 50(2): 153-164.

Schmertmann, J.H. (1991). The mechanical aging of soils. J. Geotech. Engrg, 117: 12881330.

Sheahan, T.C. \& Watters, P.J. (1997). Experimental verification ofcrs consolidation theory. J. Geotech. Geoenvironmental Eng., 123(5): 430-437.

Shipton, B. \& Coop, M.R. (2012). On the compression behaviour of reconstituted soils. Soils Found., 52(4): 668-681.

Silvestri, V., Yong, R.N., Souile, M. \& Gabriel, F. (1986). Controlled-strain, controlledgradient, and standard consolidation testing of sensitive clays. Proceedings of the ASTM Committee D-18 Symposium on Soil and Rock, 433-450.

Simms, P.H. \& Yanful, E.K. (2001). Measurement and estimation of pore shrinkage and pore distribution in a clayey till during soil-water characteristic curve tests. Can. Geotech. J., 38: 741-754.

Simms, P.H. \& Yanful, E.K. (2002). Predicting soil-water characteristic curves of compacted plastic soils from measured pore-size distributions. Géotechnique, 52(4): 269-278.

Simms, P.H. \& Yanful, E.K. (2004). A discussion of the application of mercury intrusion porosimetry for the investigation of soils, including an evaluation of its use to estimate volume change in compacted clayey soils. Géotechnique, 54(6): 421-426.

Sivakumar, R., Mackinnon, P., Sivakumar, V., Murray, E.J. \& Boyd, J. (2010). Mechanical behaviour of unsaturated kaolin (with isotropic and anisotropic stress history). part 1: wetting and compression behaviour. Géotechnique, 60(8): 581-594.

Smith, P.R., Jardine, R.J. \& Hight, D.W. (1992). The yielding of bothkennar clay. Géotechnique, 42(2): 257-274. 
Smith, R.E. \& Wahls, H.E. (1969). Consolidation under constant rates of strain. J. Soil Mech. Found. Div., 95(SM2): 519-539.

Tarantino, a. \& Mongiovì, L. (2001). Experimental procedures and cavitation mechanisms in tensiometer measurements. Geotech. Geol. Eng., 19: 2.

Tarantino, a. \& Mongiovì, L. (2003). Calibration of tensiometer for direct measurement of matric suction. Géotechnique, 53(1): 137-141.

Tarantino, A. \& De Col, E. (2008). Compaction behaviour of clay. Géotechnique, 58(3): $199-213$.

Tarantino, A. \& Mongiovi, L. (2002). Design and construction of a tensiometer for direct measurement of matric suction. Proc. 3rd Int. Conf. Unsaturated Soils, 1: 319-324.

Tavenas, F. \& Leroueil, S. (1990). Laboratory and in-situ stress-strain-time behaviour of soft clays. Int. Symp. Geotech. Engng Soft Soils, Mexico.

Terzaghi, K. (1925). Erdbaumechanik auf bodenphysikalischer grundlage: Leipzig und Wien, Franze Dutike. 399 p.

Vaid, Y.P., Robertson, P.K. \& Campanella, R.G. (1979). Strain rate behaviour of saint-jeanvianney clay. Can. Geotech. J., 16(1): 34-42.

Vaughan, P.R. (1985). Mechanical and hydraulic properties of in-situ residual soils. Proc. First Int. Conf. Geomech. Tropical Soils, Brasilia, 231-263.

Vaughan, P.R. (1988). Characterizing the mechanical properties of insitu residual soil. Proc. Second Int. Conf. Geomech. Tropical Soils, Singapore, 469-487.

Wang, Y.-H. \& Siu, W.-K. (2006). Structure characteristics and mechanical properties of kaolinite soils. i. surface charges and structural charaterizations. Can. Geotech. J., 43: 601-617.

Wesley, L.D. (1990). Influence of structure and composition on residual soils. J. Geotech. Engrg, 116: 589-603.

Wheeler, S.J. (1997). A rotational hardening elasto-plastic model for clays. In Proc. 14th Int. Conf. on Soil Mechanics and Foundation Engineering, Hamburg, 431-434.

Wheeler, S.J., Näätänen, A., Karstunen, M. \& Lojander, M. (2003). An anisotropic elastoplastic model for soft clays. Can. Geotech. J., 40: 403-418.

Wheeler, S.J. \& Sivakumar, V. (1995). An elasto-plastic critical state framework for unsaturated soils. Géotechnique, 45(1): 35-53.

Wijaya, M., Leong, E.C. \& Rahardjo, H. (2014). Crs compression tests of an unsaturated kaolin with pore-water pressure measurement. Unsaturated soils: Research \& Applications proceedings., 1639-1643. 
Wissa, A.E.Z., Christian, J.T., Davis, E.H. \& Heiberg, S. (1971). Consolidation at constant rate of strain. J. Soil Mech. Found. Div., 97(SM10): 1393-1413.

Wood, D.M. (1995). Evaluation of material properties. Proc. Int. Symp. Prefailure Deformation Characteristics Geomaterials, 1179-1199.

Wood, D.M. (2004). Geotechnical Modelling. $1^{\mathrm{o}}$ edition. Taylor and Francis group.

Znidarčić, D., Schiffman, R.L., Pane, V., Croce, P., Ko, H.Y. \& Olsen, H.W. (1986). The theory of one-dimensional consolidation ofsaturated clays. part v. constant rate of deformation testing andanalysis. Géotechnique, 36(2): 227-237. 


\section{ANNEX A}

\section{MIP RESULTS LOADED AND UNLOADED SAMPLES}

Figure A.1 shows the difference between MIP results, in terms of cumulative intrusion curve and PSD curve, of Kaolin Clay specimens of $\mathrm{w}_{\mathrm{i}}=96 \%$ loaded up to 90, 360, 2,000, 5,000 and $11,000 \mathrm{kPa}$ and unloaded quickly, without allowing the swelling of the specimens to stabilize, and unloaded in as many steps as the loading stage, allowing the specimens to stabilize at every single step. Figure A.2 shows similar results for Kaolin Clay specimens of $\mathrm{w}_{\mathrm{i}}=45 \%$, while Figure A.3 shows results of Kaolin Clay specimens of $\mathrm{pH} 9$ at $11,000 \mathrm{kPa}$.

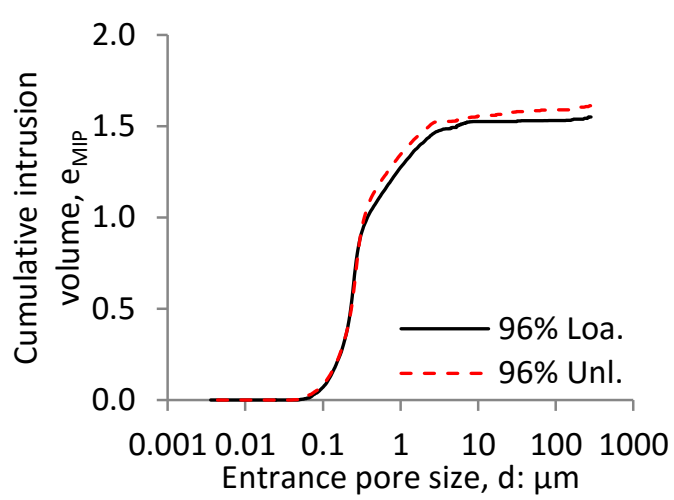

(a)

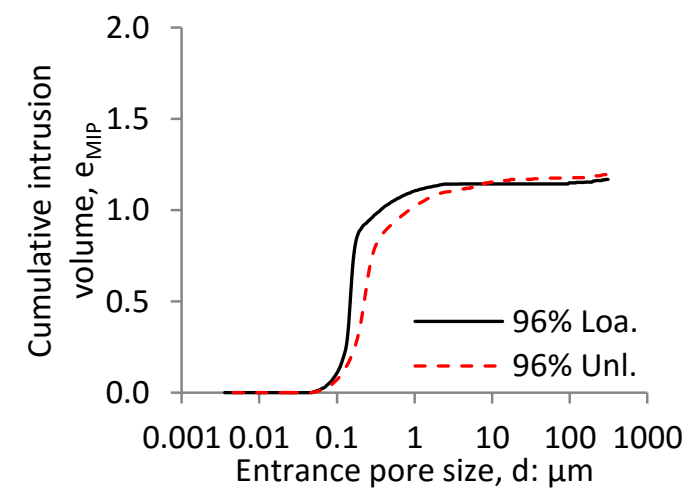

(c)

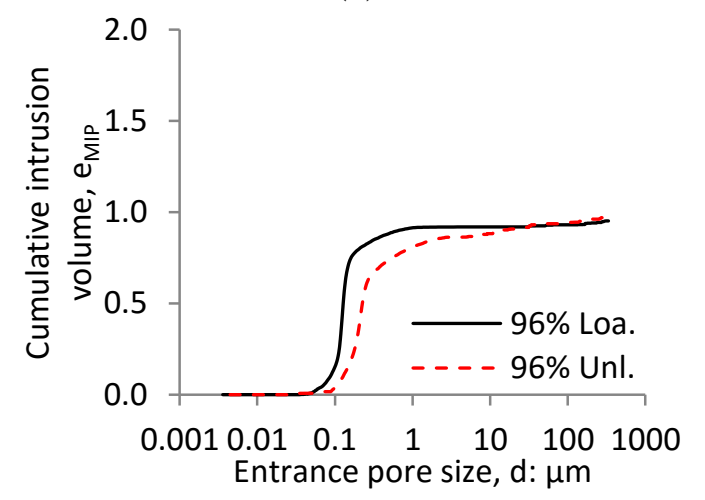

(e)

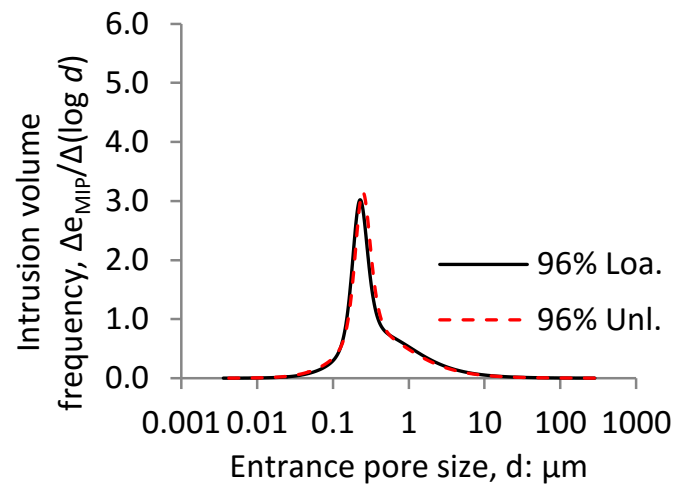

(b)

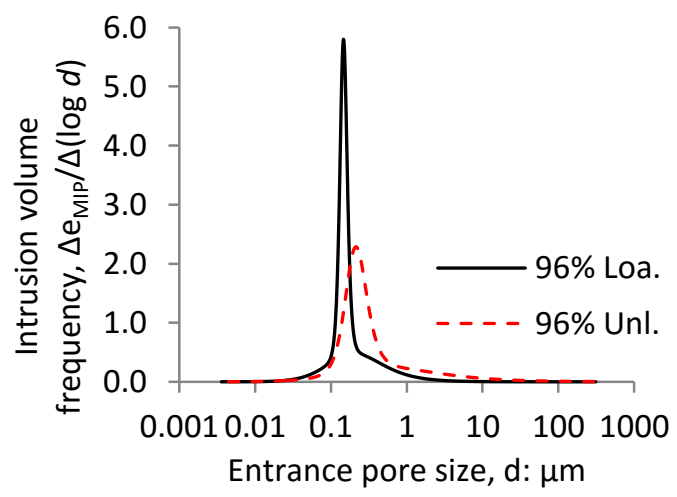

(d)

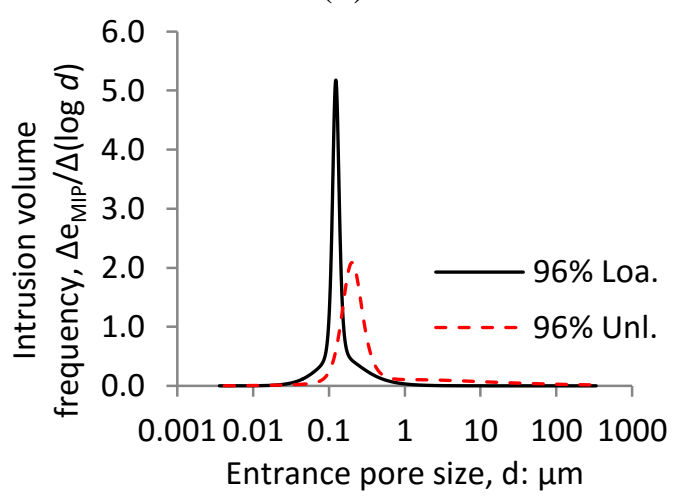

(f) 


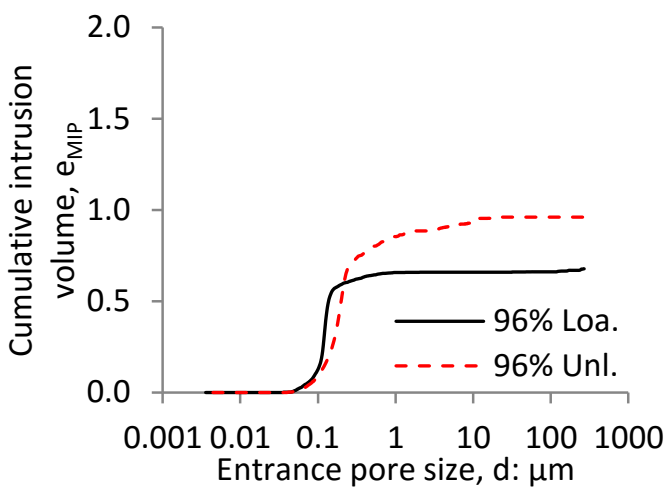

(g)

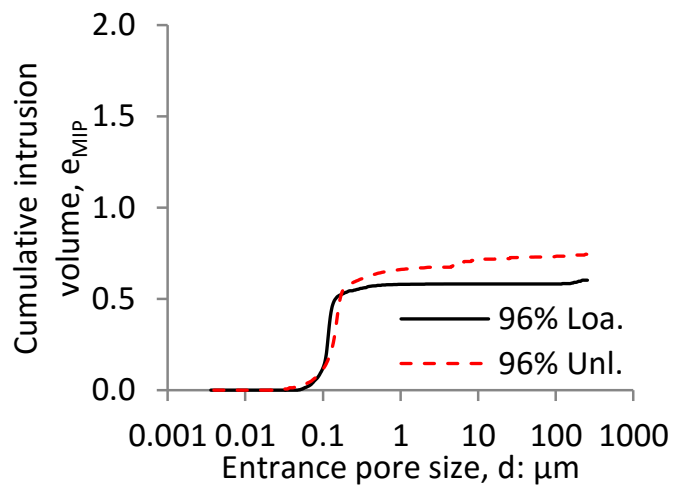

(i)

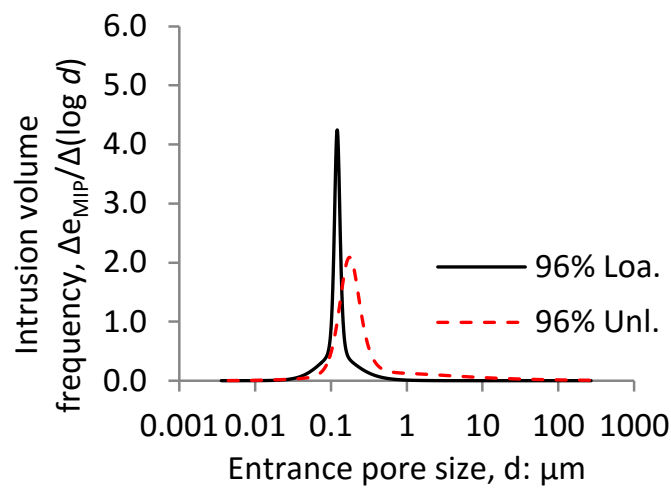

(h)

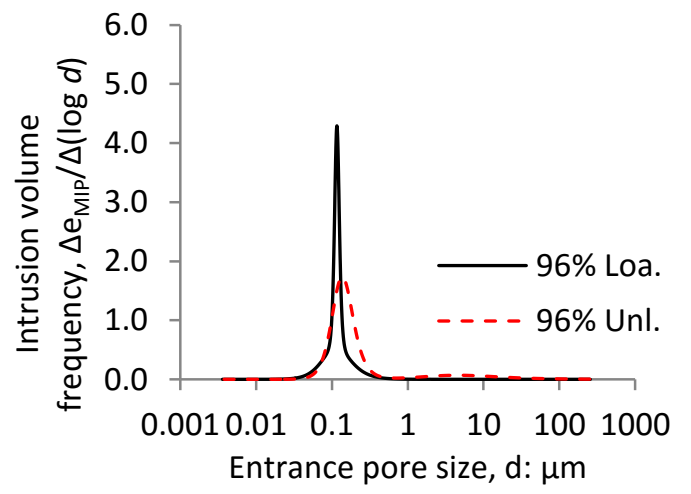

(j)

Figure A.1 - Kaolin Clay, $\mathrm{w}_{\mathrm{i}}=96 \%$, MIP data of specimen loaded in many steps and unloaded quickly in one step and loaded and unloaded in many steps: (a) 90kPa Cumulative intrusion curve, (b) 90kPa PSD curve, (c) $360 \mathrm{kPa}$ Cumulative intrusion curve, (d) $360 \mathrm{kPa}$ PSD curve, (e) 2,000kPa Cumulative intrusion curve, (f) $2,000 \mathrm{kPa}$ PSD curve, (g) 5,000kPa Cumulative intrusion curve, (h) 5,000kPa PSD curve, (i) $11,000 \mathrm{kPa}$ Cumulative intrusion curve and (j) $11,000 \mathrm{kPa}$ PSD curve

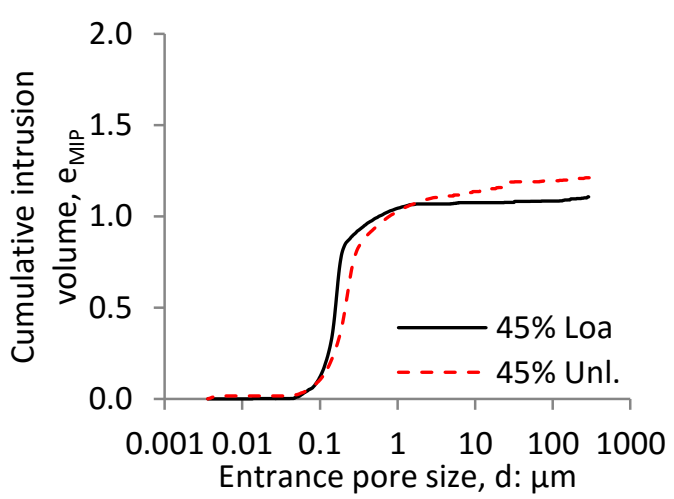

(a)

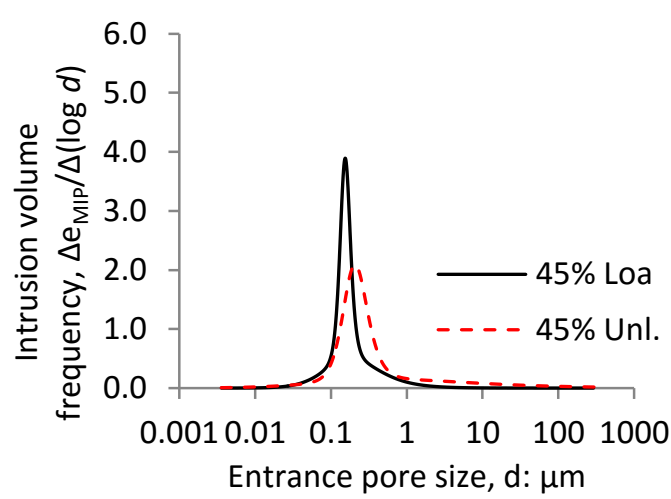

(b) 


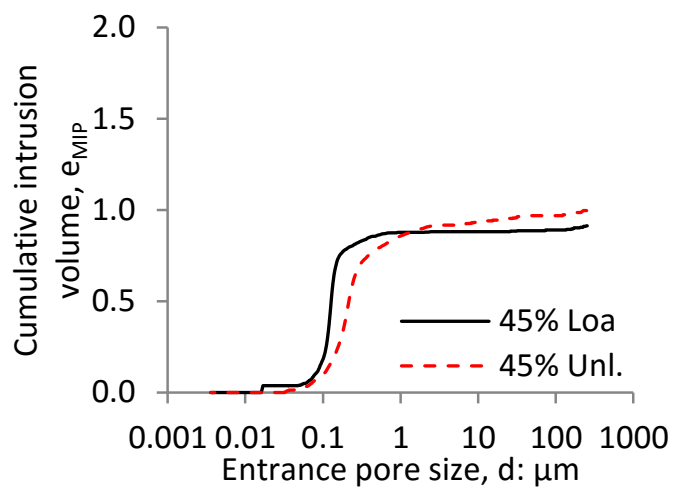

(c)

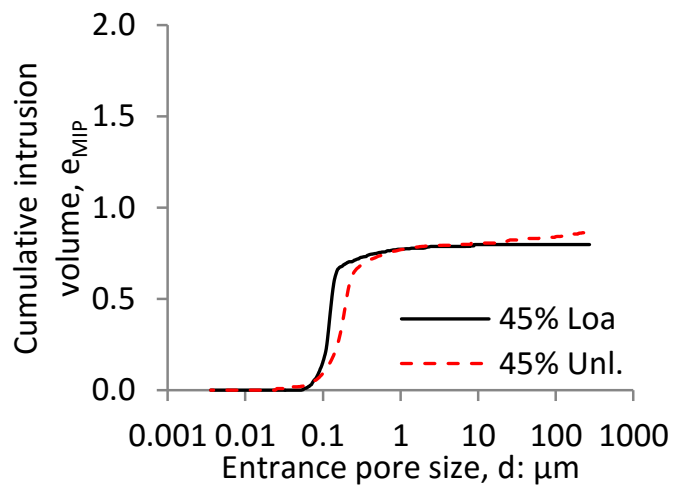

(e)

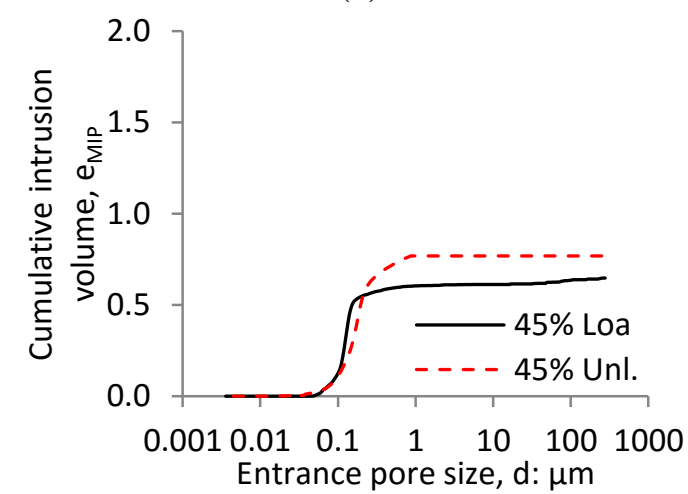

(g)

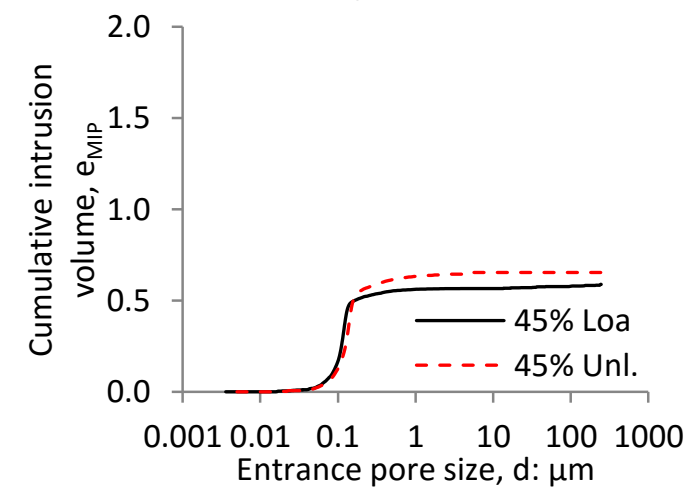

(i)

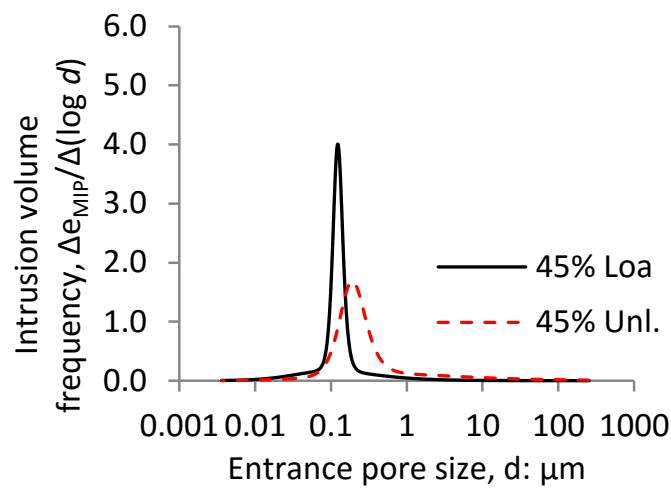

(d)

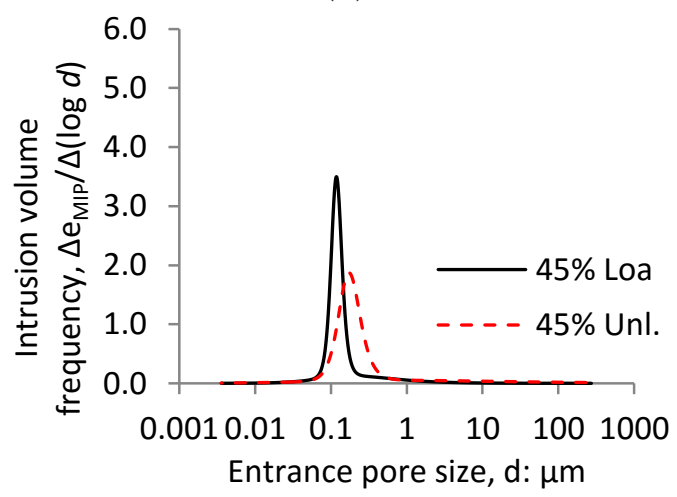

(f)

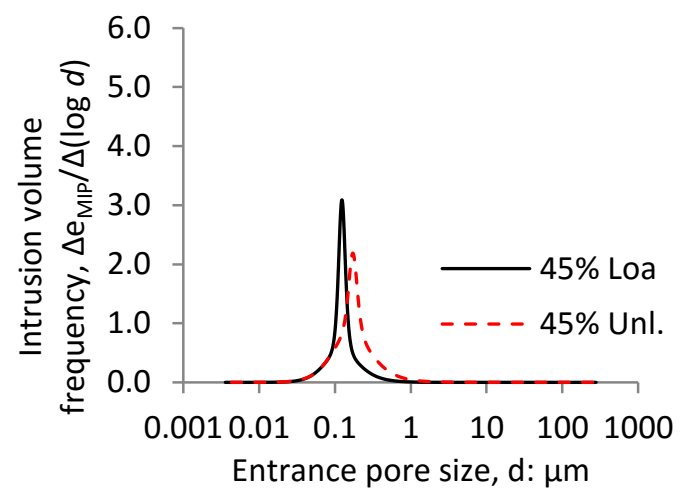

(h)

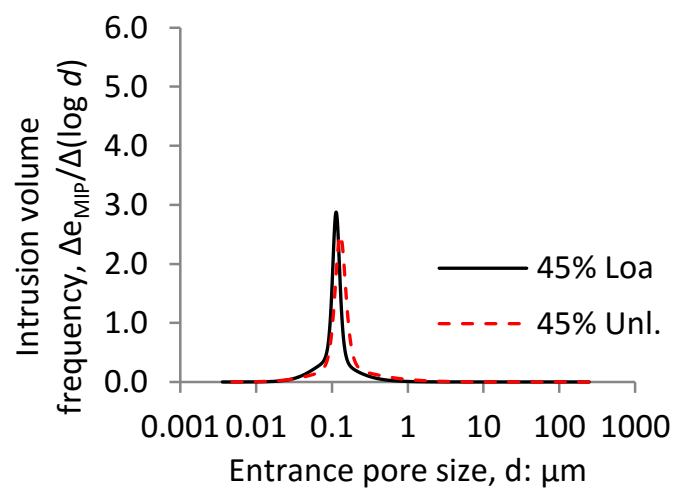

(j)

Figure A.2 - Kaolin Clay, $\mathrm{w}_{\mathrm{i}}=45 \%$, MIP data of specimen loaded in many steps and unloaded quickly in one step and loaded and unloaded in many steps: (a) 90kPa Cumulative intrusion curve, (b) 90kPa PSD curve, (c) $360 \mathrm{kPa}$ Cumulative intrusion curve, (d) $360 \mathrm{kPa}$ PSD curve, (e) 2,000kPa Cumulative intrusion curve, (f) 
2,000kPa PSD curve, (g) 5,000kPa Cumulative intrusion curve, (h) 5,000kPa PSD curve, (i) 11,000kPa

Cumulative intrusion curve and (j) $11,000 \mathrm{kPa}$ PSD curve

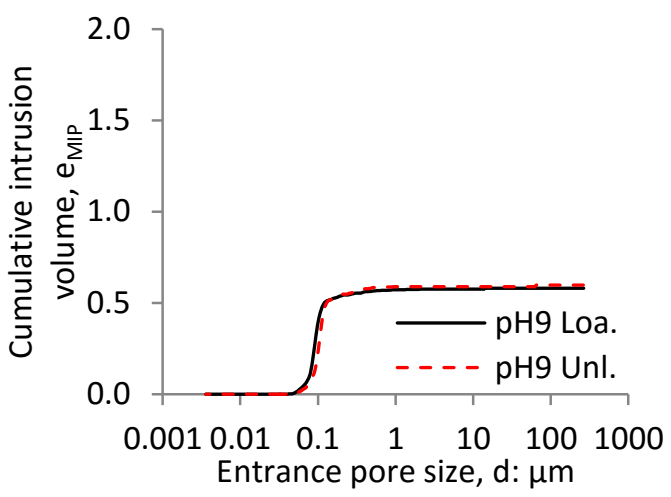

(a)

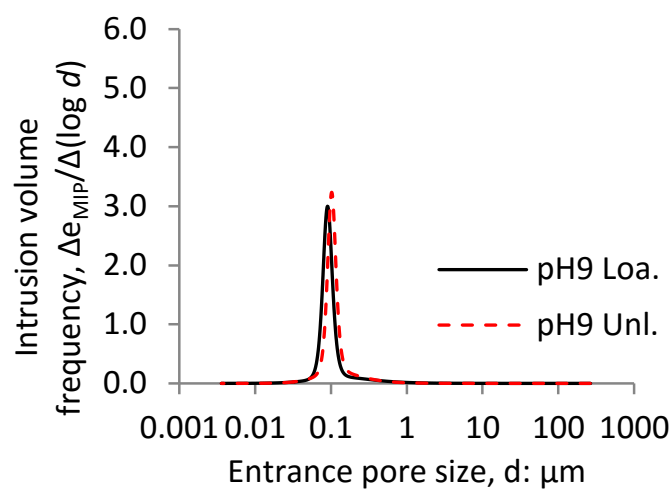

(b)

Figure A.3 - Kaolin Clay, pH9 - load 11,000kPa, MIP data of specimen loaded in many steps and unloaded quickly in one step and loaded and unloaded in many steps: (a) Cumulative intrusion curve, (b) PSD curve

Figure A. 4 shows the difference between MIP results, in terms of cumulative intrusion curve and PSD curve, of Ball Clay specimens of $\mathrm{w}_{\mathrm{i}}=94.5 \%$ and $\mathrm{w}_{\mathrm{i}}=47.25 \%$ loaded up to $2,000 \mathrm{kPa}$ and unloaded quickly, without allowing the swelling of the specimens to stabilize, and unloaded in as many steps as the loading stage, allowing the specimens to stabilize at every single step.

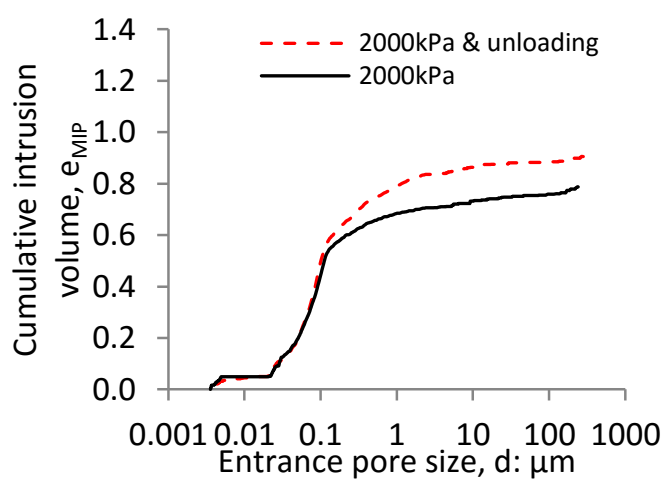

(a)

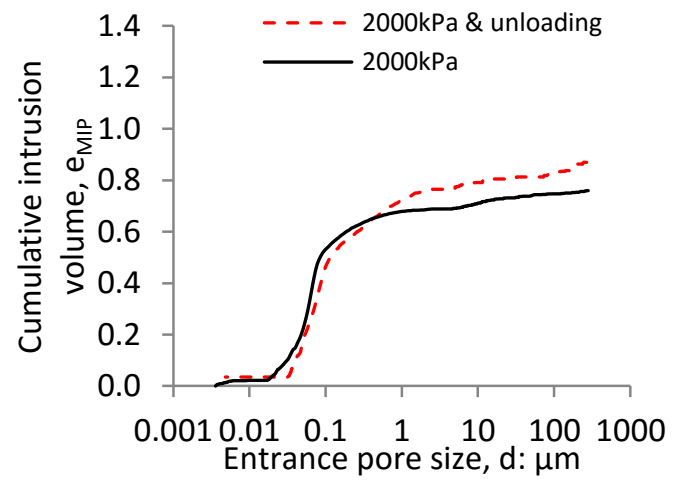

(c)

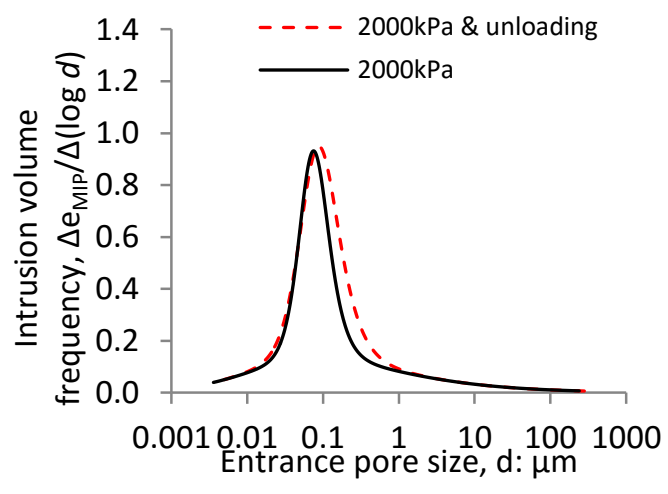

(b)

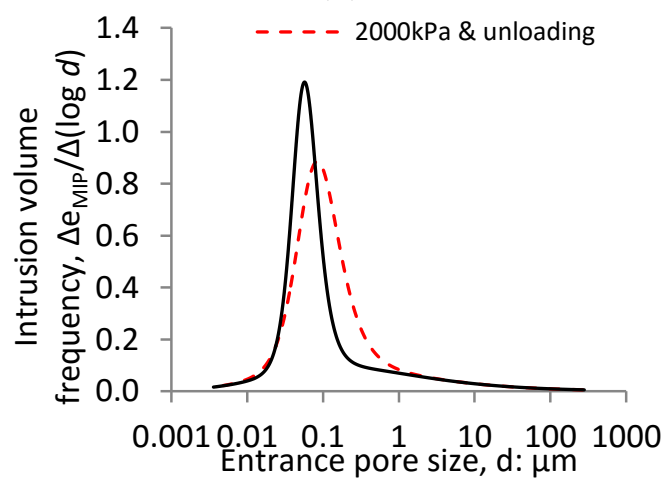

(d)

Figure A.4 - Ball Clay, 2,000kPa MIP data of specimen loaded in many steps and unloaded quickly in one step and loaded and unloaded in many steps: (a) $\mathrm{w}_{\mathrm{i}}=94.5 \%$ Cumulative intrusion curve, (b) $\mathrm{w}_{\mathrm{i}}=94.5 \%$ PSD curve, (c) $\mathrm{w}_{\mathrm{i}}=47.25 \%$ Cumulative intrusion curve and (d) $\mathrm{w}_{\mathrm{i}}=47.25 \%$ PSD curve 
Figure A.5 shows the same kind of results for Brasilia Soil specimens of $\mathrm{w}_{\mathrm{i}}=31.5 \%$ loaded at $2,000 \mathrm{kPa}$ and unloaded quickly, without allowing the swelling of the specimens to stabilize, and unloaded in as many steps as the loading stage, allowing the specimens to stabilize at every single step.

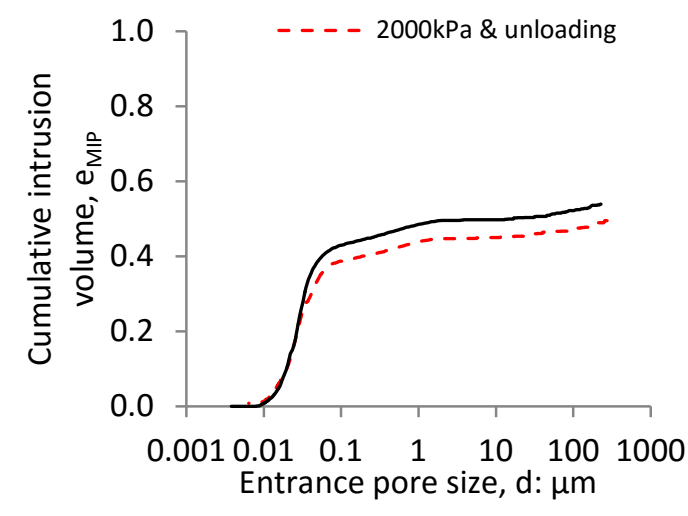

(a)

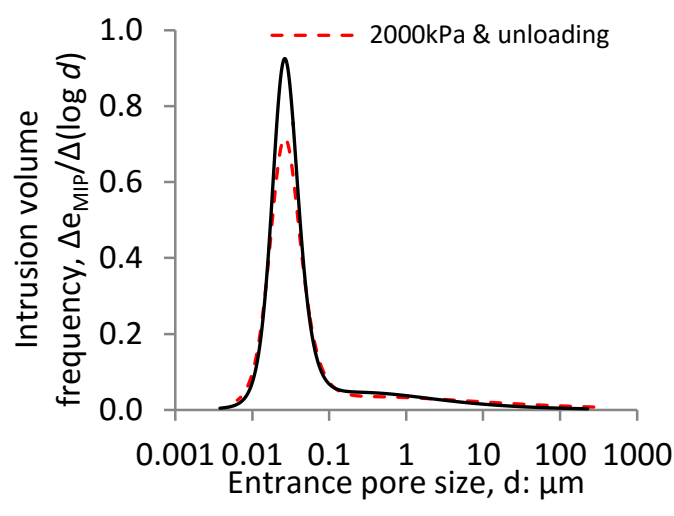

(b)

Figure A.5 - Brasilia Soil, $\mathrm{w}_{\mathrm{i}}=31.5 \%, 2,000 \mathrm{kPa}$ MIP data of specimen loaded in many steps and unloaded quickly in one step and loaded and unloaded in many steps: (a) Cumulative intrusion curve, (b) PSD curve 


\section{ANNEX B}

\section{ANOVA STATISTICAL TEST}

Analysis of variance (ANOVA) is the technique used to compare averages of two or more populations, through a hypothesis test. Analysis of variance is efficient for comparing the different factors that may result in a systematic change in the population's average.

The aim of analysis of variance is to compare the averages of $\mathrm{K}$ samples and decide whether these samples were extracted from populations of the same average value. As the samples' averages are usually different, two sources of variability can be the cause of this difference:

- Populations are different. This variability is called variability between populations. The higher the variability, the greater the evidence for the existence of differences between the populations in which the samples were extracted.

- Samples are different, but belong to the same population. This variability is called variability within the population. The higher the variability, the greater the difficulty in concluding whether the populations are different.

The following premises are valid for the analysis of variance:

- Samples are random and independent;

- Samples are extracted from normal populations;

- Normal populations have the same variance.

The hypothesis test is set up in the following way:

- Null hypothesis $H_{0}$ asserts that the $K$ populations have the same average $\left(H_{0}: \mu_{1}=\mu_{2}\right.$ $=\ldots=\mu_{\mathrm{k}}$ );

- The alternative hypothesis $\mathrm{H}_{1}$ asserts that at least one of the populations has a different average $\left(\mathrm{H}_{1}: \mu_{\mathrm{i}} \neq \mu_{\mathrm{j}}\right)$.

The null hypothesis asserts that the populations are identical. On the contrary, the alternative hypothesis asserts that there is a difference within at least two of the populations. Thus, the variance is calculated in two different and independent ways, to obtain the value F of Fisher distribution. Therefore, the hypothesis test is:

$$
\mathrm{F}=\frac{\mathrm{S}_{\mathrm{B}}^{2}}{\mathrm{~S}_{\mathrm{W}}^{2}}
$$

where: $\mathrm{F}$ is Fisher distribution, $\mathrm{S}_{\mathrm{B}}{ }^{2}$ is the variance between and $\mathrm{S}_{\mathrm{W}}{ }^{2}$ is the variance within. The variance between and within is calculated as follows: 


$$
\mathrm{S}_{\mathrm{W}}^{2}=\frac{\sum_{\mathrm{i}=1}^{\mathrm{k}} \sum_{\mathrm{j}=1}^{\mathrm{n}}\left(\mathrm{x}_{\mathrm{ij}}-\overline{\mathrm{x}}\right)^{2}}{\mathrm{k}(\mathrm{n}-1)}
$$

where: the numerator is the sum of the square errors within samples (SQW), which is the variability not explained within the samples. The degrees of freedom associated with SQW $\operatorname{are~} \mathrm{k}(\mathrm{n}-1)$.

$$
\mathrm{S}_{\mathrm{B}}^{2}=\mathrm{n}\left[\frac{\sum_{\mathrm{i}=1}^{\mathrm{k}}\left(\overline{\mathrm{X}_{\mathrm{i}}}-\overline{\overline{\mathrm{X}}}\right)^{2}}{(\mathrm{k}-1)}\right]
$$

where: the numerator is the sum of the square errors between the samples' averages (SQB). The degrees of freedom associated with SQB are k-1.

The following tables, Table B.1 to Table B.3, show the results of the statistical test ANOVA carried out in Microsoft Excel ${ }^{\circledR}$ for the void ratios of the consolidation curve, conventional oedometer/CRS consolidometer, freeze-drying and MIP for the Kaolin Clay, Ball Clay and Brasilia Soil respectively.

The blank spaces in the Kaolin Clay values are values of void ratios that were not obtained due to a variety of issues experienced in the laboratory, the majority of which have to do with the author failing to remember to take such measurements.

For all three soils analysed, the results obtained show that $\mathrm{F}<\mathrm{F}_{\text {critical, }}$, which suggests that the null hypothesis is true, in this case resulting in the conclusion that the four groups of populations are identical, within $95 \%$ reliability.

Table B.1 - ANOVA statistical test for Kaolin Clay void ratios

\begin{tabular}{cccc}
\hline \multicolumn{4}{c}{ Kaolin Clay } \\
\hline $\mathrm{e}_{\text {curve }}$ & $\mathrm{e}_{\text {OED }}$ & $\mathrm{e}_{\mathrm{F}-\mathrm{D}}$ & $\mathrm{e}_{\text {MIP }}$ \\
\hline 1.370 & 1.202 & & 1.248 \\
1.130 & 1.084 & 1.035 & 1.036 \\
0.960 & 0.989 & 0.976 & 0.892 \\
0.790 & 0.813 & 0.823 & 0.756 \\
0.670 & 0.709 & 0.704 & 0.635 \\
0.540 & 0.617 & 0.600 & 0.580 \\
2.220 & & 2.095 & 2.237
\end{tabular}




\begin{tabular}{llll}
1.400 & 1.637 & 1.557 & 1.150 \\
1.120 & 1.303 & 1.275 & 1.168 \\
0.800 & 1.073 & 0.985 & 0.952 \\
0.670 & 0.860 & & 0.678 \\
0.520 & 0.782 & & 0.602 \\
1.360 & & 1.182 & 1.372 \\
1.170 & 1.094 & 1.093 & 1.107 \\
1.000 & 0.995 & 0.984 & 0.913 \\
0.790 & 0.882 & 0.896 & 0.798 \\
0.670 & 0.751 & & 0.647 \\
0.520 & 0.650 & & 0.588 \\
\hline
\end{tabular}

ANOVA: single factor

SUMMARY

\begin{tabular}{|c|c|c|c|c|}
\hline Group & Count & Sum & Average & Variance \\
\hline$e_{\text {curve }}$ & 18 & 17.7 & 0.983333 & 0.182294 \\
\hline $\mathrm{e}_{\mathrm{OED}}$ & 16 & 15.44203 & 0.965127 & 0.071423 \\
\hline$e_{F-D}$ & 13 & 14.20285 & 1.092527 & 0.150632 \\
\hline $\mathrm{e}_{\mathrm{MIP}}$ & 18 & 17.359 & 0.964389 & 0.162273 \\
\hline
\end{tabular}

\begin{tabular}{|c|c|c|c|c|c|c|}
\hline Source of variation & $S Q$ & $g l$ & $M Q$ & $F$ & P-value & F critical \\
\hline Between groups & 0.157232 & 3 & 0.052411 & 0.365938 & 0.777823 & 2.755481 \\
\hline Within groups & 8.736572 & 61 & 0.143222 & & & \\
\hline Total & 8.893804 & 64 & & & & \\
\hline
\end{tabular}

Table B.2 - ANOVA statistical test for Ball Clay void ratios

\begin{tabular}{cccc}
\hline \multicolumn{4}{c}{ Ball Clay } \\
\hline $\mathrm{e}_{\text {curve }}$ & $\mathrm{e}_{\mathrm{OED}}$ & $\mathrm{e}_{\mathrm{F}-\mathrm{D}}$ & $\mathrm{e}_{\mathrm{MIP}}$ \\
\hline 0.540 & 0.774 & 0.709 & 0.550 \\
0.680 & 0.878 & 0.867 & 0.681 \\
0.820 & 0.957 & 0.878 & 0.788 \\
1.140 & 1.178 & 1.158 & 0.924 \\
1.420 & 1.351 & 1.328 & 1.070 \\
2.070 & 1.879 & 1.879 & 1.722 \\
0.510 & 0.735 & 0.736 & 0.570 \\
0.670 & 0.860 & 0.830 & 0.607 \\
0.830 & 0.931 & 0.912 & 0.760 \\
1.100 & 1.078 & 1.075 & 0.822
\end{tabular}




\begin{tabular}{llll}
1.280 & 1.277 & 1.183 & 0.844 \\
1.480 & 1.240 & 1.240 & 1.271 \\
0.535 & 0.523 & 0.504 & 0.433 \\
0.650 & 0.676 & 0.638 & 0.612 \\
0.750 & 0.725 & 0.664 & 0.622 \\
0.940 & 0.879 & 0.858 & 0.777 \\
1.070 & 0.956 & 0.941 & 0.879 \\
1.300 & 1.260 & 1.260 & 1.230 \\
\hline
\end{tabular}

ANOVA: Single factor

SUMMARY

\begin{tabular}{|c|c|c|c|c|}
\hline Group & Total & Sum & Average & Variance \\
\hline$e_{\text {curve }}$ & 18 & 17.78492 & 0.988051 & 0.169484 \\
\hline $\mathrm{e}_{\mathrm{OED}}$ & 18 & 18.15957 & 1.008865 & 0.101266 \\
\hline$e_{F-D}$ & 18 & 17.66009 & 0.981116 & 0.105974 \\
\hline$e_{M I P}$ & 18 & 15.162 & 0.842333 & 0.099547 \\
\hline
\end{tabular}

\begin{tabular}{|c|c|c|c|c|c|c|}
\hline Source of variation & $S Q$ & $g l$ & $M Q$ & $F$ & $P$-value & F critical \\
\hline Between groups & 0.312652 & 3 & 0.104217 & 0.875278 & 0.458336 & 2.739502 \\
\hline Within groups & 8.096609 & 68 & 0.119068 & & & \\
\hline Total & 8.409261 & 71 & & & & \\
\hline
\end{tabular}

Table B.3 - ANOVA statistical test for Brasilia Soil void ratios

\begin{tabular}{cccc}
\hline \multicolumn{4}{c}{ Brasilia Soil } \\
\hline $\mathrm{e}_{\text {curve }}$ & $\mathrm{e}_{\mathrm{OED}}$ & $\mathrm{e}_{\mathrm{F}-\mathrm{D}}$ & $\mathrm{e}_{\mathrm{MIP}}$ \\
\hline 0.406 & 0.527 & 0.522 & 0.506 \\
0.528 & 0.606 & 0.602 & 0.541 \\
0.601 & 0.652 & 0.638 & 0.603 \\
0.842 & 0.831 & 0.803 & 0.785 \\
1.030 & 1.028 & 0.993 & 0.880 \\
1.253 & 1.235 & 1.158 & 1.178 \\
0.432 & 0.551 & 0.550 & 0.437 \\
0.538 & 0.572 & 0.563 & 0.497 \\
0.562 & 0.609 & 0.604 & 0.508 \\
0.744 & 0.737 & 0.728 & 0.626 \\
0.884 & 0.838 & 0.807 & 0.701 \\
1.117 & 1.120 & 1.120 & 0.962 \\
0.395 & 0.479 & 0.437 & 0.437 \\
0.470 & 0.522 & 0.518 & 0.502
\end{tabular}




\begin{tabular}{llll}
0.550 & 0.576 & 0.564 & 0.542 \\
0.695 & 0.653 & 0.635 & 0.621 \\
0.807 & 0.683 & 0.652 & 0.660 \\
0.869 & 1.100 & 1.100 & 0.948 \\
0.475 & 0.536 & 0.498 & 0.508 \\
0.560 & 0.607 & 0.578 & 0.578 \\
0.672 & 0.682 & 0.678 & 0.656 \\
0.960 & 0.854 & 0.846 & 0.906 \\
1.290 & 1.241 & 1.076 & 1.095 \\
1.730 & 1.479 & 1.479 & 1.394 \\
\hline
\end{tabular}

ANOVA: single factor

SUMMARY

\begin{tabular}{|c|c|c|c|c|}
\hline Group & Count & Sum & Average & Variance \\
\hline $\mathrm{e}_{\text {curve }}$ & 24 & 18.40902 & 0.767042 & 0.110226 \\
\hline $\mathrm{e}_{\mathrm{OED}}$ & 24 & 18.71619 & 0.779841 & 0.076517 \\
\hline$e_{F-D}$ & 24 & 18.14998 & 0.756249 & 0.070797 \\
\hline$e_{\text {MIP }}$ & 24 & 17.0714 & 0.711308 & 0.065001 \\
\hline
\end{tabular}

ANOVA

\begin{tabular}{lcrcccc}
\hline \multicolumn{1}{c}{ Source of variation } & SQ & gl & $M Q$ & $F$ & $P$-value & F critical \\
\hline Between groups & 0.063958 & 3 & 0.021319 & $\mathbf{0 . 2 6 4 3 9 1}$ & 0.850891 & $\mathbf{2 . 7 0 3 5 9 4}$ \\
Within groups & 7.418439 & 92 & 0.080635 & & & \\
& & & & & & \\
Total & 7.482397 & 95 & & & & \\
\hline
\end{tabular}




\section{ANNEX C \\ MIP SOURCES OF ERRORS}

Although Mitchell \& Soga (2005) have suggested that the MIP major sources of errors are mainly due to sample preparation in the removal of water, evidence found while carrying out the MIP experiment at the Advanced Materials Research Laboratory of the Department of Mechanical and Aerospace Engineering at the University of Strathclyde may have suggested that the pressure generated during MIP on soil structure, the influence of pore accessibility and conversion from pore entrance to actual pore size might also be significant.

An example of a sample after the MIP test can be seen in Figure C.1a. Depending on the state of the sample, the pressure applied to the mercury may affect the structure, destroying part of it at a high (Figure C.1b) or mild (Figure C.1c) degree, consequently adding to the errors associated with the technique.

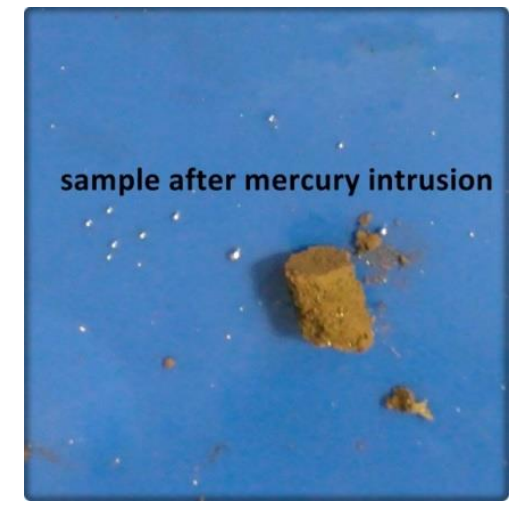

(a)

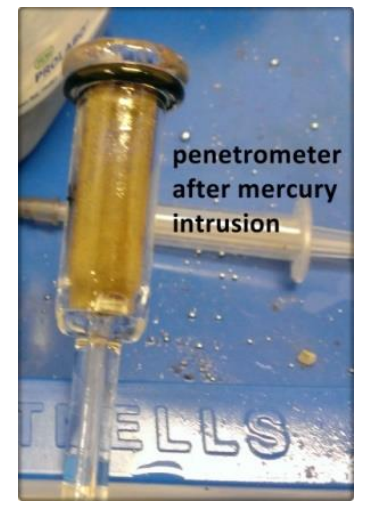

(b)

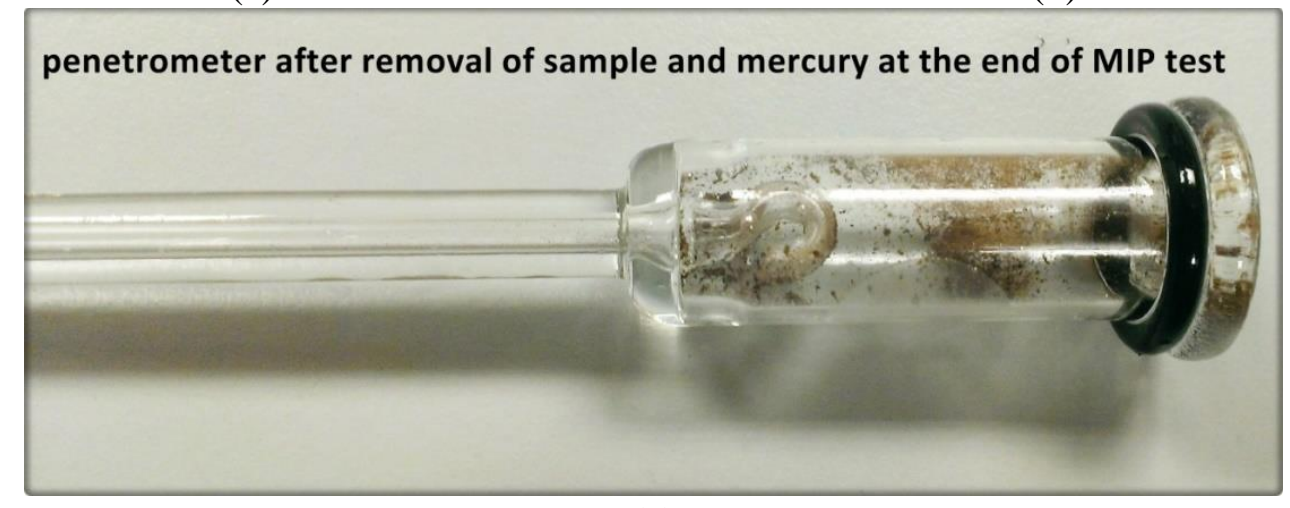

(c)

Figure C.1 - (a) Sample after the MIP test, (b) and (c) Penetrometer after MIP test and after removal of mercury and sample

Figure C.2 shows a pH9 specimen of Ball Clay at 5MPa after the MIP test. Note that mercury can be identified as partially filling cracks and diameters of mercury also fill pores of smaller 
size, suggesting that the curve of pore distribution could have been making up diameters, as already highlighted by other authors (Simms \& Yanful, 2004; Romero \& Simms, 2008).

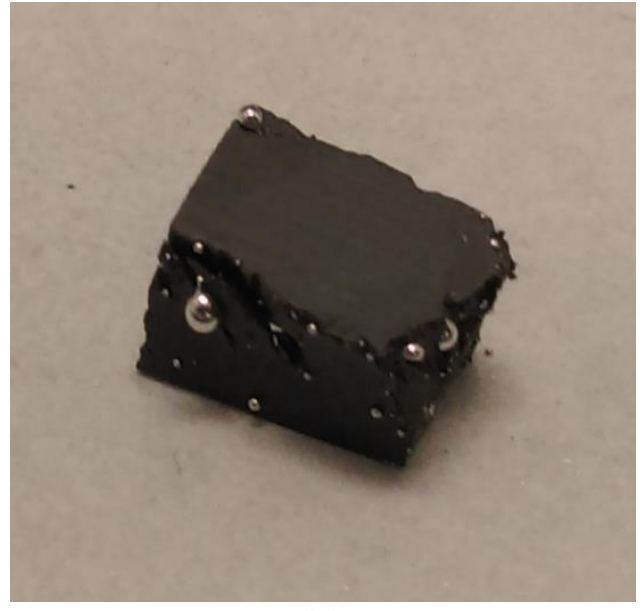

(a)

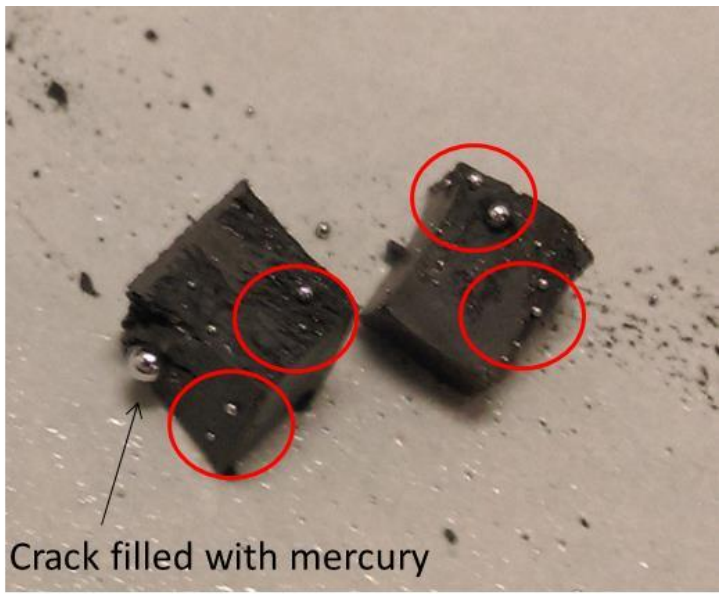

(b)

Figure C.2 - Ball Clay pH9 specimen loaded up to 5Mpa (a) right after MIP test intrusion and extrusion, (b) specimen sliced open showing an external crack filled with mercury and also small internal and external voids filled with a diameter of mercury much larger than their sizes

Figure C.3 shows the possible diameters that mercury can assume when filling a pore. Although this might not produce significant difference in the overall void ratio, it can significantly influence the pore size density curve.

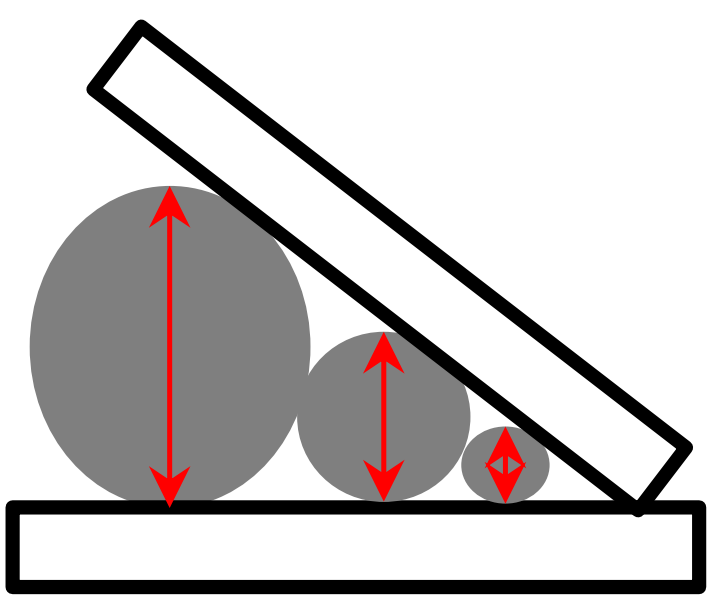

Figure C.3 - Diameters that can be assumed by mercury when filling a pore

Although these sources of errors are identified as part of the limitations of the technique, it is still a challenge to minimize their effects and, more importantly, to point out with certainty in a result what may have caused such an unexpected response. 


\section{ANNEX D \\ VAN GENUCHTEN-TYPE CUMULATIVE DISTRIBUTION FITTING}

Figure D.1 presents the sensitivity study carried out for a single mode of the van Genuchten-type equation as suggested by Lopes et al. (2014). Table D.1 shows the interpretations of the results obtained by the analyses of the graphs shown in Figure D.1. The standard parameters used for the sensitivity analysis were: $e=1.0, \alpha=50 \mu m^{-1}$ and $n=-1.5$. Figure D.1a and $\mathrm{b}$ show the cumulative intrusion and PSD of the variation in $e(1.5,1.0$ and $0.5) ; \alpha$ and $n$ were kept constant. Figure D.1c and d show the cumulative intrusion and PSD of the variation in $\alpha(100,50$ and 20); $e$ and $n$ were kept constant. Finally, Figure D.1e and $\mathrm{f}$ show the cumulative intrusion and PSD of the variation in $n(-2.0,-1.5$ and -1.0$) ; e$ and $\alpha$ were kept constant.

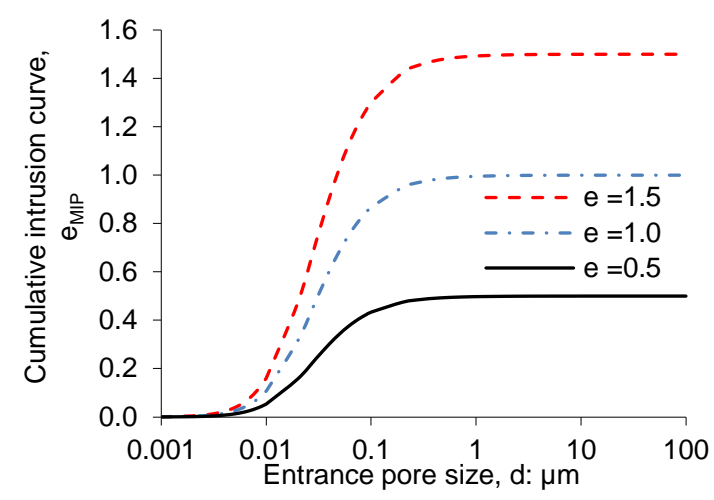

(a)

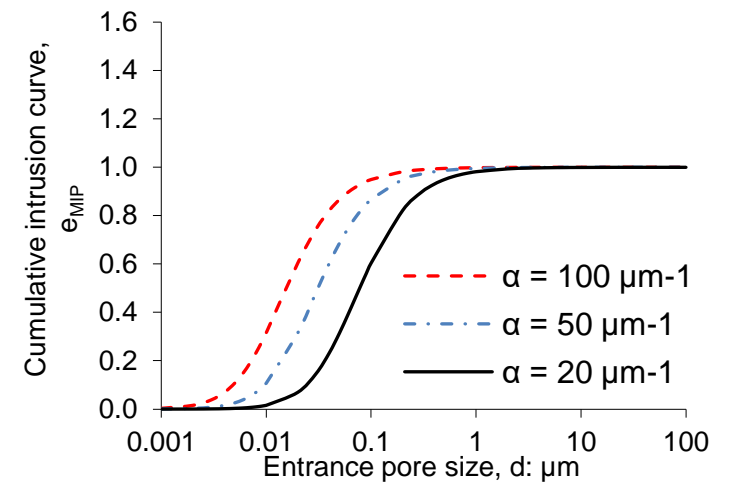

(c)

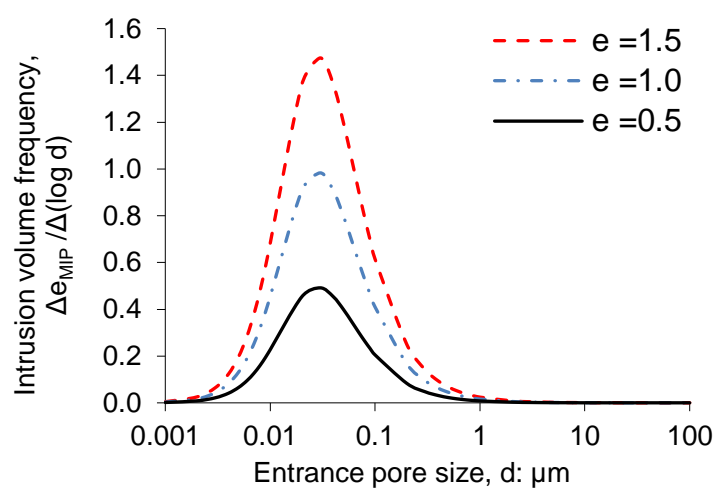

(b)

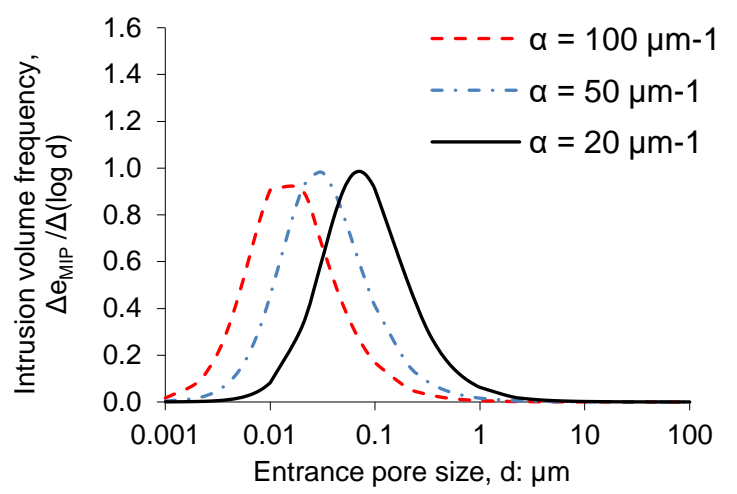

(d) 


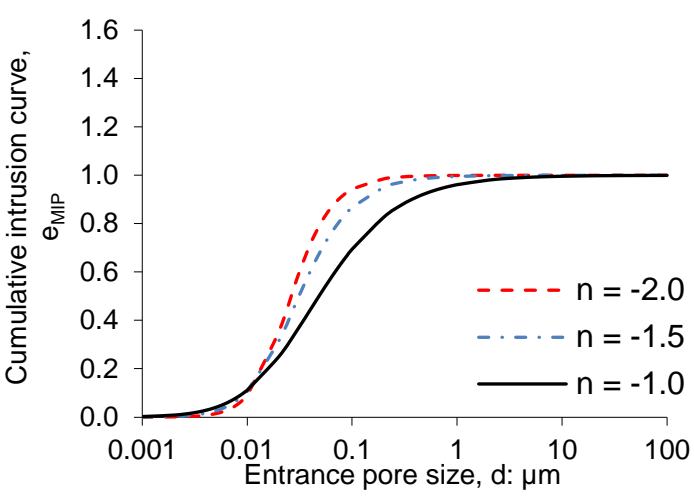

(e)

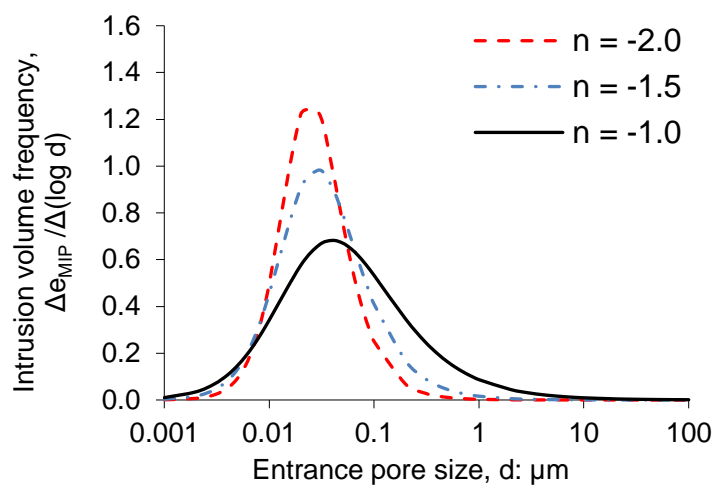

(f)

Figure D.1- Sensitivity analysis carried out for the van Genuchten-type mono-modal equation: (a) Cumulative intrusion curve, $e=1.5,1.0$ and 0.5 and $\alpha$ and $n=$ constant, (b) PSD, $e=1.5,1.0$ and 0.5 and $\alpha$ and $n=$ constant, (c) Cumulative intrusion curve, $\alpha=100,50$ and 20 and e and $n=$ constant, (d) PSD, $\alpha=100,50$ and 20 and e and $n=$ constant, (e) Cumulative intrusion curve, $n=-2.0,-1.5$ and -1.0 and $e$ and $\alpha=$ constant and (f) PSD, $n=-2.0,-1.5$ and -1.0 and $e$ and $\alpha=$ constant

Table D.1 - Results interpretation of the sensitivity analysis carried out for a van Genuchten-type mono-modal equation

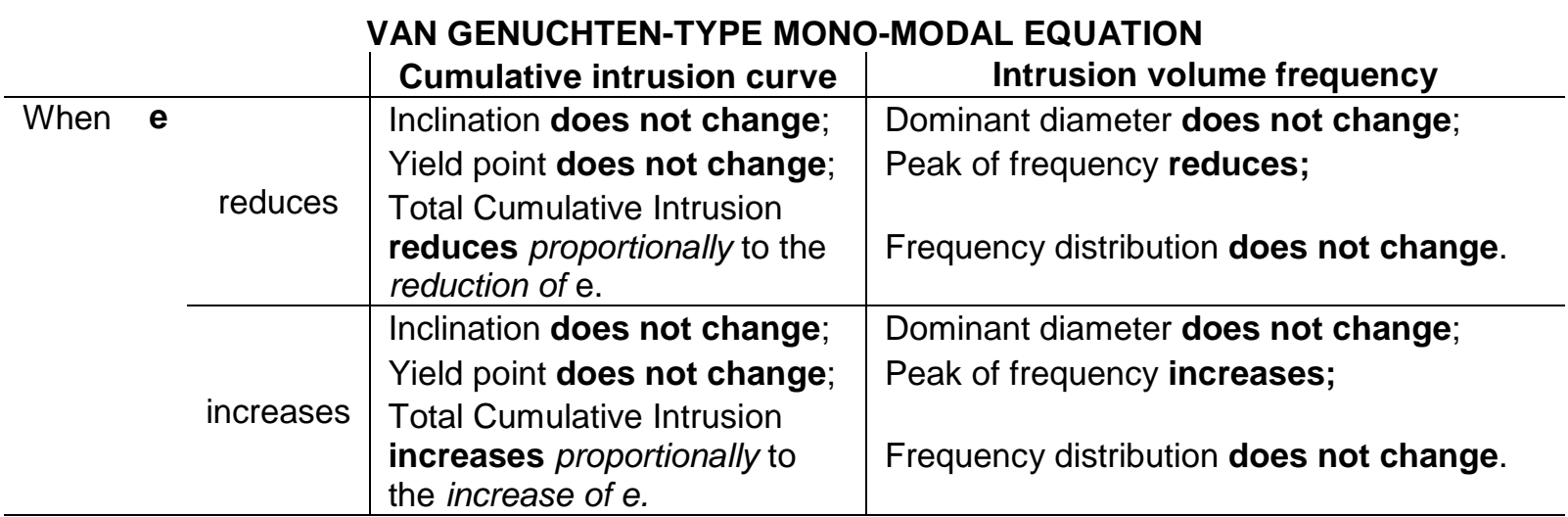

$e$ controls the frequency of the dominant pore diameter and the total cumulative intrusion $-\boldsymbol{e}$ corresponds to the Total Cumulative Intrusion of the sample, in this case the void ratio

\begin{tabular}{|c|c|c|c|}
\hline When $\boldsymbol{\alpha}$ & reduces & $\begin{array}{l}\text { Inclination does not change; } \\
\text { Yield point increases; } \\
\text { Total Cumulative Intrusion } \\
\text { does not change. }\end{array}$ & $\begin{array}{l}\text { Dominant diameter shifts towards larger } \\
\text { pore diameters; } \\
\text { Peak of frequency does not change; } \\
\text { Frequency distribution does not change. }\end{array}$ \\
\hline & increases & $\begin{array}{l}\text { Inclination does not change; } \\
\text { Yield point reduces; } \\
\text { Total Cumulative Intrusion } \\
\text { reduces slightly. }\end{array}$ & $\begin{array}{l}\text { Dominant diameter shifts towards smaller } \\
\text { pore diameters; } \\
\text { Peak of frequency does not change; } \\
\text { Frequency distribution does not change. }\end{array}$ \\
\hline
\end{tabular}

$\alpha$ controls the yield point of the cumulative curve and the value of the dominant pore diameter $-\alpha$ corresponds to inverse of the dominant pore size, $\alpha=1 / d$

\begin{tabular}{cl|l|l}
\hline \hline When $\mathbf{n}$ & Inclination steepens; & $\begin{array}{l}\text { Dominant diameter shifts slightly towards } \\
\text { smaller pore diameters; } \\
\text { Peak of frequency increases proportionally } \\
\text { reduces }\end{array}$ & $\begin{array}{l}\text { Yield point increases; } \\
\text { to reduction of } n ;\end{array}$ \\
& $\begin{array}{l}\text { Total Cumulative Intrusion } \\
\text { does not change. }\end{array}$ & $\begin{array}{l}\text { Frequency distribution narrows among } \\
\text { fewer pore diameters. }\end{array}$ \\
\cline { 2 - 3 } & Increases & Inclination flattens; & $\begin{array}{l}\text { Dominant diameter shifts slightly towards } \\
\text { larger pore diameters; }\end{array}$ \\
\cline { 2 - 3 } & &
\end{tabular}


The fitting approach used in this study is a nonlinear regression approach, which strongly depends on the set of initial value of parameters to be fitted. Additionally, if no restrictions are imposed, fitting parameters can assume values with no physical meaning.

The criteria to set initial values of parameters and parameter constraints were set as follows:

1. Parameter $\mathrm{e}_{\text {micro }}$ or $\mathrm{e}_{F F}$ is selected according to Figure D.2. For an apparent monomodal distribution (Figure D.2a), $\mathrm{e}_{\text {micro }}$ or $\mathrm{e}_{F F}$ can be taken around the inflection point. For a bi-modal distribution (Figure D.2b), the parameter $\mathrm{e}_{\text {micro }}$ or $\mathrm{e}_{F F}$ can be taken at the intersection between the tangents at the two inflection points. Parameter $e_{\text {macro }}$ or $\mathrm{e}_{E F}$ is obtained by considering that $e_{\text {micro }}+e_{\text {Macro }}=e_{M I P}$ or $e_{F F}+e_{E F}=e_{M I P}$.

2. Parameters $n_{\text {micro }}$ or $n_{F F}$ and $n_{\text {macro }}$ or $n_{E F}$ for an apparent mono-modal distribution can be taken both equal to the slope of the tangent at the single inflection point. Parameters $n_{\text {micro }}$ or $n_{F F}$ and $n_{\text {macro }}$ or $n_{E F}$ for the bi-modal distribution can be taken equal to the slope of the tangents at the two inflection points.

3. The same initial value is selected for both $d_{\text {micro }}$ or $d_{F F}$ and $d_{\text {macro }}$ or $d_{E F}$. For an apparent mono-modal distribution, $\left(d_{\text {micro }} \text { or } d_{F F}\right)_{\text {initial }}=\left(d_{\text {macro }} \text { or } d_{E F}\right)_{\text {initial }}$ is taken around the inflection point. For a bi-modal distribution, $\left(d_{\text {micro }} \text { or } d_{F F}\right)_{\text {initial }}=\left(d_{\text {macro }}\right.$ or $\left.d_{E F}\right)_{\text {initial }}$ is taken at the intersection between the tangents at the two inflection points.

4. Values of parameters $d_{\text {micro }}$ or $d_{F F}$ and $d_{\text {macro }}$ or $d_{E F}$ must be constrained, such that $d_{\text {micro }} \leq\left(d_{\text {micro }}\right)_{\text {initial }}$ or $d_{F F} \leq\left(d_{F F}\right)_{\text {initial }}$ and $d_{\text {macro }} \geq\left(d_{\text {macro }}\right)_{\text {intital }}$ or $d_{E F} \geq\left(d_{E F}\right)_{\text {initial }}$. 


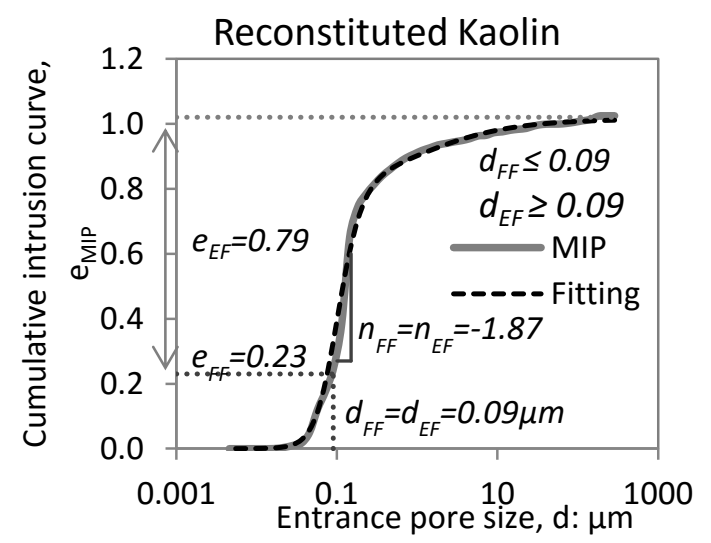

(a)

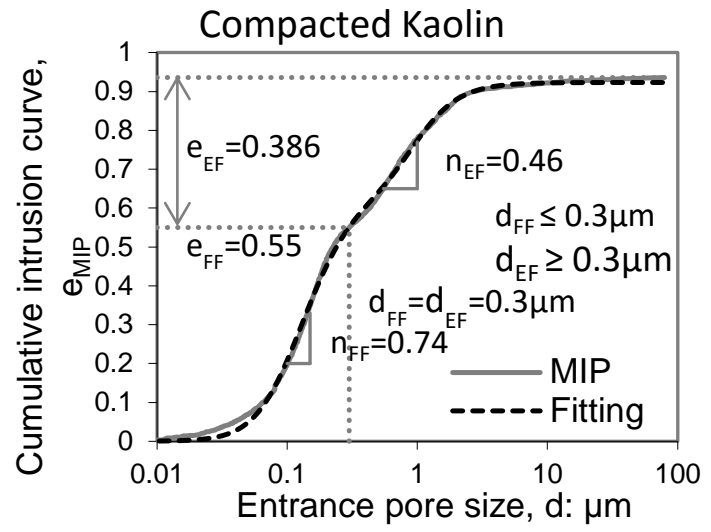

(b)

Figure D.2 - Kaolin Clay: (a) Reconstituted Sample. Cumulative intrusion curve of an apparent mono-modal distribution fitted with a bi-modal van Genuchten-type equation (data from Pedrotti, 2016) and (b) Compacted

Sample. Cumulative intrusion curve of a bi-modal distribution (data from Tarantino \& De Col, 2008)

The fitting parameters of the MIP results performed in specimens of Kaolin Clay, Ball Clay and Brasilia Soil are presented in Table D.2, Table D.3 and Table D.4 respectively.

Figure D.3 shows the pore size density in a normal distribution for FF pores and in a lognormal distribution for EF pores of Kaolin Clay specimens. Note that the normal distribution of FF pores is an adequate assumption for most of the specimens, except at $2 \mathrm{kPa}$ of specimens remoulded and $\mathrm{pH}$. This may have to do with the randomness of the $2 \mathrm{kPa}$ sample and is not considered enough evidence to rule out the assumption.

Table D.2 - Kaolin Clay: van Genuchten fitting parameters

\begin{tabular}{ccccccccccc}
\hline $\mathrm{W}_{\mathrm{i}}: \%$ & Load: $\mathrm{kPa}$ & $\mathrm{e}_{\mathrm{EF}}$ & $\begin{array}{c}1 / \mathrm{d}_{\mathrm{EF}}: \\
\mu \mathrm{m}^{-1}\end{array}$ & $\mathrm{n}_{\mathrm{EF}}$ & $\mathrm{e}_{\mathrm{FF}}$ & $\begin{array}{c}1 / \mathrm{d}_{\mathrm{F}}: \\
\mu \mathrm{m}^{-1}\end{array}$ & $\mathrm{n}_{\mathrm{FF}}$ & $\mathrm{R}^{2}$ & $\begin{array}{c}\mathrm{d}_{\mathrm{EF}} \\
(\mu \mathrm{m})\end{array}$ & $\begin{array}{c}\mathrm{d}_{\mathrm{FF}} \\
(\mu \mathrm{m})\end{array}$ \\
\hline \multirow{6}{*}{96} & 2 & 1.648 & 2.480 & -1.097 & 0.603 & 4.111 & -14.148 & 0.9998 & 0.40 & 0.24 \\
& 90 & 0.895 & 3.930 & -1.204 & 0.644 & 4.509 & -6.251 & 0.9998 & 0.25 & 0.22 \\
& 260 & 0.462 & 6.785 & -1.581 & 0.683 & 6.861 & -13.346 & 0.9998 & 0.15 & 0.15 \\
& 2,000 & 0.383 & 8.850 & -2.008 & 0.539 & 8.151 & -14.835 & 0.9998 & 0.11 & 0.12 \\
& 5,000 & 0.288 & 9.724 & -2.388 & 0.371 & 8.293 & -17.577 & 0.9998 & 0.10 & 0.12 \\
& 11,000 & 0.265 & 9.655 & -3.137 & 0.315 & 8.616 & -20.505 & 0.9998 & 0.10 & 0.12 \\
& 2 & 0.592 & 9.055 & -0.781 & 0.768 & 4.944 & -4.437 & 0.9996 & 0.11 & 0.20 \\
& 90 & 0.468 & 7.414 & -1.612 & 0.609 & 6.556 & -9.437 & 0.9997 & 0.13 & 0.15 \\
& 360 & 0.233 & 18.004 & -1.061 & 0.654 & 8.198 & -9.913 & 0.9996 & 0.06 & 0.12 \\
& 2,000 & 0.160 & 8.639 & -1.114 & 0.636 & 8.566 & -8.987 & 0.9996 & 0.12 & 0.12 \\
& 5,000 & 0.312 & 9.365 & -2.660 & 0.300 & 8.117 & -14.591 & 0.9995 & 0.11 & 0.12 \\
& 11,000 & 0.249 & 11.693 & -2.182 & 0.317 & 8.844 & -13.595 & 0.9996 & 0.09 & 0.11 \\
& 2 & 0.073 & 0.696 & -5.765 & 1.176 & 5.433 & -2.281 & 0.9999 & 1.44 & 0.18 \\
$\mathrm{pH} 9$ & 90 & 0.383 & 29.210 & -0.571 & 0.645 & 7.162 & -5.144 & 0.9997 & 0.03 & 0.14 \\
& 360 & 0.314 & 6.916 & -1.098 & 0.562 & 8.388 & -7.357 & 0.9996 & 0.14 & 0.12 \\
& 2,000 & 0.232 & 9.470 & -1.551 & 0.520 & 9.954 & -10.296 & 0.9998 & 0.11 & 0.10 \\
\hline
\end{tabular}


$\begin{array}{llllllllll}5,000 & 0.196 & 10.224 & -1.786 & 0.417 & 10.590 & -11.862 & 0.9997 & 0.10 & 0.09\end{array}$

$\begin{array}{llllllllll}11,000 & 0.104 & 10.356 & -1.526 & 0.473 & 11.181 & -10.380 & 0.9999 & 0.10 & 0.09\end{array}$

Table D.3 - Ball Clay: van Genuchten fitting parameters

\begin{tabular}{ccccccccccc}
\hline $\mathrm{W}_{\mathrm{i}:} \%$ & Load: $\mathrm{kPa}$ & $\mathrm{e}_{\mathrm{EF}}$ & $\begin{array}{c}1 / \mathrm{d}_{\mathrm{EF}}: \\
\mu \mathrm{m}^{-1}\end{array}$ & $\mathrm{n}_{\mathrm{EF}}$ & $\mathrm{e}_{\mathrm{FF}}$ & $\begin{array}{c}1 / \mathrm{d}_{\mathrm{FF}}: \\
\mu \mathrm{m}^{-1}\end{array}$ & $\mathrm{n}_{\mathrm{FF}}$ & $\mathrm{R}^{2}$ & $\begin{array}{c}\mathrm{d}_{\mathrm{EF}} \\
(\mu \mathrm{m})\end{array}$ & $\begin{array}{c}\mathrm{d}_{\mathrm{FF}} \\
(\mu \mathrm{m})\end{array}$ \\
\hline \multirow{4}{*}{94.5} & 2 & 0.49 & 0.326 & -1.496 & 1.21 & 7.869 & -1.307 & 0.9994 & 3.07 & 0.13 \\
& 90 & 0.69 & 22.134 & -0.733 & 0.36 & 11.793 & -4.704 & 0.9995 & 0.05 & 0.08 \\
& 260 & 0.63 & 25.525 & -0.852 & 0.29 & 12.275 & -6.603 & 0.9996 & 0.04 & 0.08 \\
& 5,000 & 0.35 & 100.000 & -0.503 & 0.42 & 14.599 & -3.104 & 0.9988 & 0.01 & 0.07 \\
& 11,000 & 0.27 & 104.248 & -0.560 & 0.40 & 17.199 & -3.684 & 0.9995 & 0.01 & 0.06 \\
& 2 & 0.19 & 100.000 & -0.582 & 0.33 & 16.908 & -4.958 & 0.9991 & 0.01 & 0.06 \\
& 90 & 0.50 & 4.849 & -0.777 & 0.66 & 14.175 & -2.593 & 0.9998 & 0.21 & 0.07 \\
& 360 & 0.31 & 15.972 & -0.513 & 0.51 & 16.280 & -3.136 & 0.9993 & 0.06 & 0.06 \\
& 2,000 & 0.25 & 50.000 & -0.519 & 0.50 & 18.786 & -3.624 & 0.9989 & 0.02 & 0.05 \\
& 5,000 & 0.15 & 43.722 & -0.507 & 0.44 & 19.210 & -4.221 & 0.9993 & 0.02 & 0.05 \\
& 11,000 & 0.11 & 45.962 & -0.511 & 0.45 & 22.192 & -4.297 & 0.9986 & 0.02 & 0.05 \\
& 2 & 0.43 & 1.260 & -2.521 & 0.80 & 17.185 & -1.352 & 0.9999 & 0.79 & 0.06 \\
& 90 & 0.48 & 50.257 & -0.498 & 0.42 & 23.978 & -3.881 & 0.9997 & 0.02 & 0.04 \\
$\mathrm{pH} 9$ & 360 & 0.31 & 18.070 & -0.761 & 0.47 & 22.661 & -3.835 & 0.9997 & 0.06 & 0.04 \\
& 2,000 & 0.32 & 80.745 & -0.706 & 0.27 & 24.993 & -6.209 & 0.9986 & 0.01 & 0.04 \\
& 5,000 & 0.32 & 37.762 & -1.289 & 0.29 & 24.906 & -6.895 & 0.9998 & 0.03 & 0.04 \\
& 11,000 & 0.26 & 34.684 & -2.279 & 0.17 & 30.903 & -13.436 & 0.9993 & 0.03 & 0.03 \\
\hline
\end{tabular}

Table D.4 - Brasilia Soil: van Genuchten fitting parameters

\begin{tabular}{ccccccccccc}
\hline $\mathrm{W}_{\mathrm{i}}: \%$ & Load: $\mathrm{kPa}$ & $\mathrm{e}_{\text {MACRO }}$ & $\begin{array}{c}1 / \mathrm{d}_{\text {MACRO }} \\
\mu \mathrm{m}^{-1}\end{array}$ & $\mathrm{n}_{\text {MACRO }}$ & $\mathrm{e}_{\text {MICRO }}$ & $\begin{array}{c}1 / \mathrm{d}_{\text {MICRO }} \\
\mu \mathrm{m}^{-1}\end{array}$ & $\mathrm{n}_{\text {MICRO }}$ & $\mathrm{R}^{2}$ & $\begin{array}{c}\mathrm{d}_{\text {MACRO }} \\
(\mu \mathrm{m})\end{array}$ & $\begin{array}{c}\mathrm{d}_{\text {MICRO }} \\
(\mu \mathrm{m})\end{array}$ \\
\hline \multirow{5}{*}{ Natural } & 2 & 0.92 & 0.089 & -1.577 & 0.45 & 55.659 & -2.132 & 0.990 & 11.29 & 0.02 \\
& 90 & 0.50 & 0.791 & -0.841 & 0.60 & 52.775 & -1.856 & 0.999 & 1.26 & 0.02 \\
& 2,000 & 0.43 & 0.917 & -0.811 & 0.48 & 59.897 & -1.855 & 0.998 & 1.09 & 0.02 \\
& 5,000 & 0.19 & 1.733 & -0.868 & 0.47 & 56.148 & -2.038 & 0.998 & 0.58 & 0.02 \\
& 11,000 & 0.00 & 2.685 & -0.625 & 0.45 & 57.166 & -2.326 & 0.997 & 0.37 & 0.02 \\
& 2 & 1.00 & 0.038 & -11.633 & 0.44 & 52.420 & -5.072 & 0.999 & 0.05 & 0.02 \\
& 90 & 0.53 & 0.187 & -1.354 & 0.32 & 47.071 & -2.401 & 0.998 & 5.34 & 0.02 \\
& 360 & 0.51 & 0.714 & -0.730 & 0.29 & 52.012 & -2.958 & 0.998 & 1.40 & 0.02 \\
& 2,000 & 0.27 & 20.471 & -0.634 & 0.32 & 42.509 & -4.105 & 1.000 & 0.05 & 0.02 \\
& 5,000 & 0.12 & 108.764 & -0.491 & 0.41 & 44.928 & -4.276 & 1.000 & 0.01 & 0.02 \\
& 11,000 & 0.15 & 65.547 & -0.506 & 0.34 & 43.945 & -3.971 & 0.999 & 0.02 & 0.02 \\
& 2 & 0.56 & 1.422 & -0.649 & 0.41 & 45.359 & -3.668 & 0.999 & 0.70 & 0.02 \\
31.5 & 90 & 0.28 & 2.053 & -0.920 & 0.41 & 43.793 & -2.905 & 1.000 & 0.49 & 0.02 \\
& 360 & 0.40 & 88.807 & -0.469 & 0.27 & 41.966 & -3.969 & 0.999 & 0.01 & 0.02 \\
& 2,000 & 0.11 & 22.077 & -0.577 & 0.41 & 40.471 & -3.603 & 0.999 & 0.05 & 0.02
\end{tabular}




\begin{tabular}{ccccccccccc} 
& 5,000 & 0.08 & 100.000 & -0.296 & 0.42 & 43.926 & -4.050 & 0.999 & 0.01 & 0.02 \\
& 11,000 & 0.10 & 100.000 & -0.531 & 0.31 & 45.103 & -4.991 & 0.998 & 0.01 & 0.02 \\
& 2 & 0.47 & 0.453 & -1.987 & 0.48 & 44.300 & -2.953 & 0.999 & 2.21 & 0.02 \\
& 90 & 0.21 & 1.226 & -1.245 & 0.44 & 47.123 & -2.989 & 0.999 & 0.82 & 0.02 \\
\multirow{4}{*}{$\mathrm{pH} 9 \quad$} & 360 & 0.15 & 3.090 & -1.148 & 0.45 & 47.054 & -3.595 & 0.999 & 0.32 & 0.02 \\
& 2,000 & 0.13 & 2.879 & -0.831 & 0.40 & 50.986 & -3.100 & 0.999 & 0.35 & 0.02 \\
& 5,000 & 0.19 & 100.000 & -0.999 & 0.29 & 47.957 & -7.023 & 0.998 & 0.01 & 0.02 \\
& 11,000 & 0.05 & 116.456 & -0.403 & 0.39 & 49.150 & -4.872 & 0.999 & 0.01 & 0.02 \\
\hline
\end{tabular}

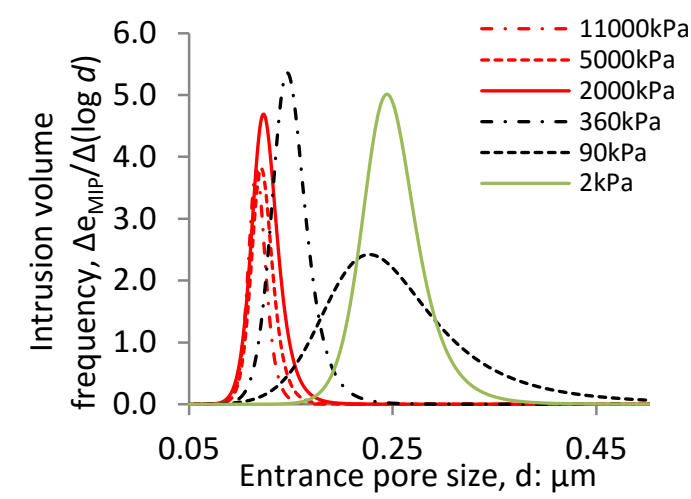

(a)

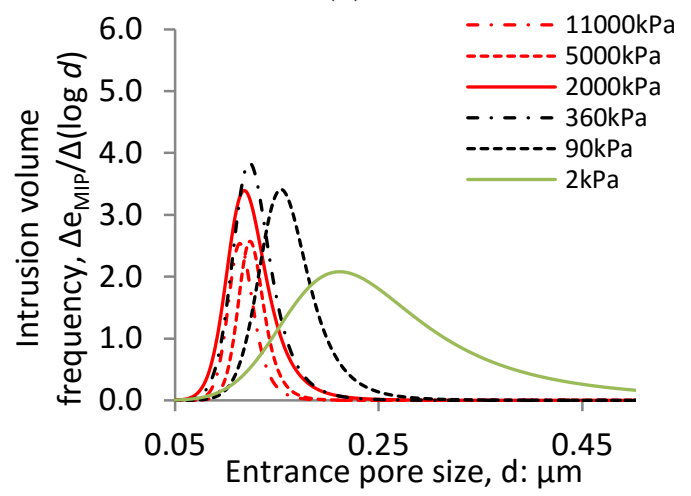

(c)

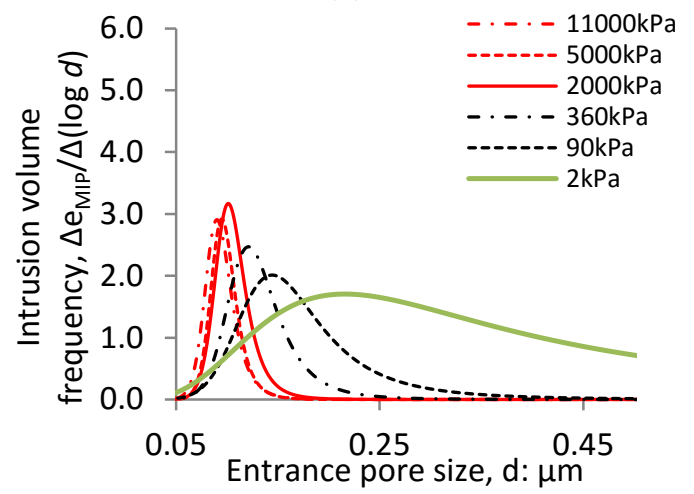

(e)

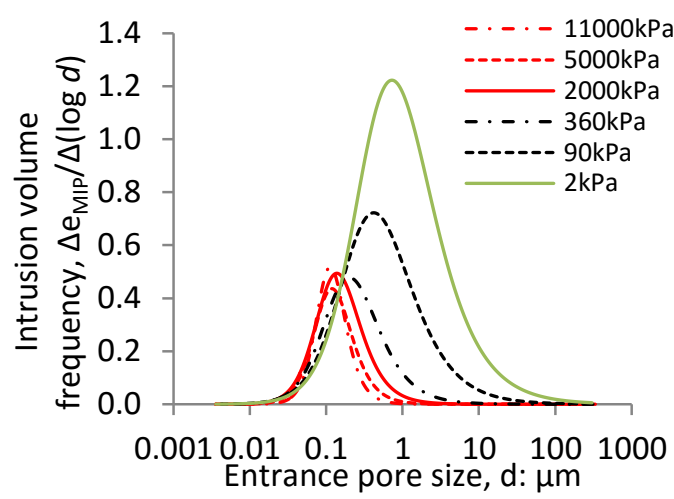

(b)

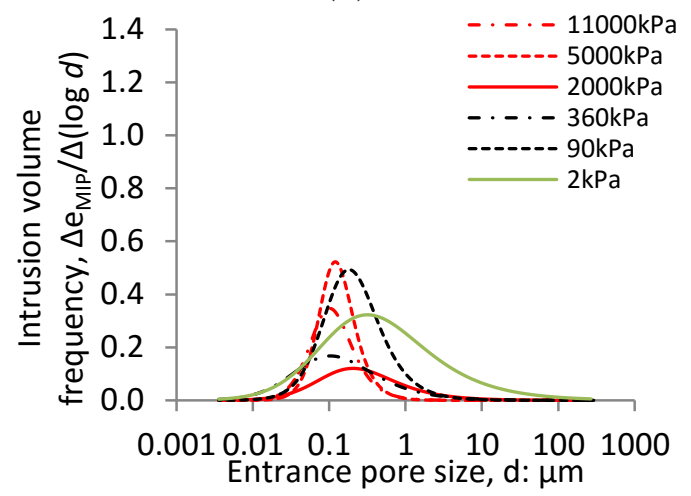

(d)

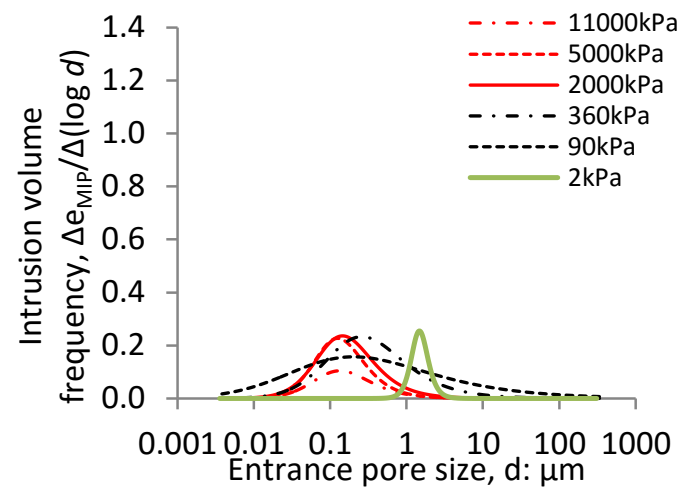

(f)

Figure D. 3 - PSD curves of $\mathrm{w}_{\mathrm{i}}=96 \%$ (a) normal distribution of FF pores, (b) log-normal distribution of EF pores; $\mathrm{w}_{\mathrm{i}}=45 \%$, (c) normal distribution of FF pores, (d) log-normal distribution of EF pores; and pH9 (e) normal distribution of FF pores, (f) log-normal distribution of EF pores 